\author{
Universidade de São Paulo \\ Instituto de Física
}

\title{
Determinação experimental da distribuição de dose absorvida em diferentes qualidades de feixes mamográficos
}

\author{
Josilene Cerqueira Santos
}

Orientador: Prof. Dr. Paulo Roberto Costa

Tese de doutorado apresentada ao Instituto de Física como requisito parcial para a obtenção do título de Doutor em Ciências.

Banca Examinadora:

Prof. Dr. Paulo Roberto Costa - orientador (IFUSP)

Prof. Dr. Vito Roberto Vanin (IFUSP)

Prof. Dr. Manfredo Harri Tabacniks (IFUSP)

Prof. Dr. Teógenes Augusto da Silva (CDTN/CNEN)

Prof. Dr. João Emílio Peixoto (IRD/CNEN) 

À minha mãe, minha fonte de força e coragem. Ao meu amor, Luiz. Fernando. 



\section{AGRADECIMENTOS}

Ao Professor Paulo Costa, por me aceitar no grupo, por acreditar em mim, por me incentivar sempre. Obrigada por me orientar com paciência e otimismo, por valorizar o meu trabalho. Evoluí bastante nesse processo e reconheço a importância do seu papel nisso. Serei eternamente grata.

À Professora Alessandra Tomal, por sua valiosa colaboração e orientação, pelas dicas e opiniões inestimáveis.

Às professoras Elisabeth Yoshimura e Emiko Okuno por seus ensinamentos e por me tirar dúvidas algumas vezes.

Ao Professor Ricardo Terini pelas inúmeras discussões e apoio com experimentos.

Aos professores José Maria e Kwan Ng pelo incentivo e preciosa colaboração na estruturação e correção do meu paper da Medical Physics.

Aos meus irmãos de pesquisa e de coração, Juliana, Louise, Alejandro, Carlos Eduardo e Lorena. Obrigada por compartilharem comigo momentos inesquecíveis com muitas risadas e por fazerem me sentir em família. Juliana e Louise, obrigada por serem as melhores companheiras de viagens para congressos do mundo!

Aos colegas Leandro Mariano, Victor Santoro, Daniel Cruz e Daniel Vieira pela amizade e discussões enriquecedoras.

À Denise, Camila, Eric e Tânia pela imensa colaboração com minhas medições em nos equipamentos clínicos.

Ao Francisco por todo apoio técnico e a Nancy por sempre me ajudar com o uso da leitora Riso.

À Agnes por me receber tão bem no CPqCTR, por me ajudar com as medições no equipamento Selenia e por colaborar com o meu paper. Obrigada Agnes e Anderson pela boa companhia, risadas e cafés.

À Joana Rojas e Gisel, pelo apoio e companhia nas minhas medições no mamógrafo do CPqCTR.

À Maria do Socorro Nogueira pela importante colaboração com o meu projeto, por permitir que grande parte dos meus experimentos fossem realizados no LARAM, por ter me ajudado em tudo que precisei enquanto estive lá, por colaborar com o meu paper.

À Carolina Vilória, Katiane Costa e Danielle Soares, pela imensa colaboração com minhas medições no LARAM. À Madelon pelo cuidado e boas conversas. 
À minha família do 507, Rose, André e Magna pela agradável companhia e cuidado. À Graciela Fonseca, pela amizade.

À Alana Azevedo, minha flor, pela agradável companhia para tudo. Pela amizade, carinho, por me contagiar sempre com sua alegria.

Aos amigos Mateus e Geisa, porque são as pessoas que mais me entendem nesse mundo! Pelas conversas agradáveis, pelos abraços reconfortantes, pelas incontáveis demonstrações de amor.

Ao Fernando, meu companheiro, pelo incentivo e apoio incondicional, pelo cuidado que sempre teve comigo, pelo amor, amizade e cumplicidade. Obrigada pelos abraços que me fazem recarregar as energias quando me sinto esgotada.

À Mainha, por todo amor. Por ser exemplo de força e determinação, pela confiança ao me apoiar em tudo que decido fazer mesmo sem saber bem o que faço. Ao meu pai que nunca mediu esforços para criar a mim e meus irmãos, por ser exemplo de homem trabalhador.

Aos meus irmãos, meus amores, por todo carinho, pelos mimos e pelo cuidado que tem com os nossos pais. Agradecimento especial ao meu irmão Carlos, que sempre acreditou em mim, me incentivou e me fez dar os primeiros passos para superar os meus medos. Carlos, sem você e Fernando eu não teria vindo para a USP!

Aos meus sobrinhos, pelo imenso carinho, pela diversão que sempre me proporcionam, por me fazerem relembrar a maravilhosa sensação de ser criança.

Ao pessoal da Oficina Central, que sempre atenderam as minhas solicitações com presteza.

Ao Vitor Vivolo por me auxiliar na irradiação dos dosímetros TLDs para calibração.

Ao ICESP e InRaD por aceitarem colaborar com o meu projeto permitido acesso aos mamógrafos.

À FAPESP por financiar esta pesquisa (projeto 2013/07117-0). 
Ninguém pode construir em teu lugar

as pontes que precisarás passar, para atravessar o rio da vida -ninguém, exceto tu, só tu.

(F. Nietzsche) 



\section{RESUMO}

A dose glandular média é a grandeza utilizada para dosimetria em mamografia. Esta grandeza apresenta grande dependência com propriedades específicas referentes ao tipo de mama a ser avaliada, tais como sua glandularidade e espessura comprimida. Depende também das propriedades do espectro de raios $X$, tais como a combinação anodo/filtro e a tensão aplicada ao tubo, que modificam a camada semirredutora do feixe. A caracterização do feixe de raios X através da medição direta do seu espectro é um procedimento de alta complexidade e de difícil execução em sistemas de mamografia, devido à arquitetura dos equipamentos e da alta taxa de fluência de fótons característica dos feixes. Estes espectros representam a fonte de informações quantitativas e qualitativas mais completa do feixe. $\mathrm{O}$ objetivo geral desse trabalho é estimar distribuições de dose glandular em diferentes profundidades de materiais simuladores de tecido mamário por meio de espectros de raios $\mathrm{X}$ medidos em mamógrafos. Para isso, foram utilizadas técnicas radiográficas comumente empregadas na mamografia para o rastreamento do câncer de mama. Foi avaliado o comportamento da dose glandular média normalizada pelo kerma no ar incidente $\left(\mathrm{DgN}_{\mathrm{p}}\right)$ com parâmetros relacionados à mama (glandularidade e espessura) e aos espectros (camada semirredutora, tensão, combinação alvo/filtro). Primeiramente, foi desenvolvida uma metodologia experimental para medição dos espectros de raios $\mathrm{X}$ nos mamógrafos. Em seguida, foram propostos os seguintes métodos de cálculo da $\mathrm{DgN}_{\mathrm{p}}$ utilizando esses espectros: Método I, que calcula a $\mathrm{DgN}_{\mathrm{p}}$ com espectros incidentes; Método II, que utiliza espectros incidentes e transmitidos para este cálculo e Método III, que usa espectros incidentes e transmitidos para estimar a distribuição de dose em profundidade. Por fim, para efeito de comparação, a distribuição da $\operatorname{DgN}_{p}$ também foi estimada utilizando dosímetros termoluminescentes (TLDs). A metodologia desenvolvida para medição de espectros mostrou-se eficaz para posicionamento e alinhamento adequados do detector no feixe e consequentemente a medição dos espectros diretos. Os espectros incidentes experimentais mostraram boa concordância com espectros simulados. Os resultados mostraram uma distribuição bem-comportada desses coeficientes $\left(\mathrm{DgN}_{\mathrm{p}}\right)$, com tendência linear ou exponencial, com relação aos parâmetros analisados. Para um dado espectro, os valores de $\operatorname{DgN}_{\mathrm{p}}$ apresentaram decrescimento exponencial com a espessura do material simulador ao tecido mamário e dependencia linear com a glandularidade. Além disso, esses coeficientes crescem linearmente com o aumento da camada semirredutora e, consequentemente, com a energia efetiva. A partir das distribuições de $\mathrm{DgN}_{\mathrm{p}}$ (obtidas pelo Método III) foi possível estimar a dose no volume completo da mama com diferença máxima de $5,2 \%$ dos valores obtidos com o Método II. A variação da $\mathrm{DgN}_{\mathrm{p}}$ com a profundidade obtidas com TLDs mostrou-se bastante coerente com os resultados observados com a utilização do Método III. Conclui-se que é possível avaliar a dose glandular em mamografia utilizando espectros de raios $\mathrm{X}$ e que a metodologia proposta tem potencial para ser aplicada como procedimentos alternativos para dosimetria em mamografia.

Palavras-chave: Mamografia, Dose glandular normalizada, Espectrometria de raios X, Dosimetria 


\section{ABSTRACT}

The mean glandular dose is the quantity used for dosimetry in mammography. This quantity has a strong dependence with some properties of the evaluated breast, such as its glandularity and compressed thickness. It also depends on the X-ray spectrum used for the mammographic image production, such as the target/filter combination and the tube voltage, which are related to the half value layer $(\mathrm{HVL})$ of the beam. The X-ray beam characterization by means of the direct measurement of its spectrum is a complex procedure, and it is difficult to be implemented in clinical systems due to the architecture of the mammography equipment and the high photon fluence rates. These spectra provide a complete qualitative and quantitative information of the X-ray beam. The general objective of this work is to estimate mean glandular dose distributions in different depths of breast tissue-equivalent materials (bTEM) considering the X-ray spectra measured in clinical mammography devices. Radiographic techniques commonly applied for breast cancer screening were used. The behavior of the mean glandular dose normalized to the incident air kerma $\left(\mathrm{DgN}_{\mathrm{p}}\right)$, with parameters related to the breast (glandularity and compressed thickness) and to the mammographic spectra (HVL, tube voltage, target/filter combination), was evaluated. First, an experimental methodology was developed to measure $\mathrm{X}$-ray spectra in clinical mammography devices. Then, the following methods for calculating the $\mathrm{DgN}_{\mathrm{p}}$ using these spectra were considered: Method I, which calculates the $\mathrm{DgN}_{\mathrm{p}}$ using the incident spectra; Method II, which uses incident and transmitted spectra by the bTEMs, and Method III, which uses incident and transmitted spectra to estimate the dose distributions in depth of the breast equivalent materials. Finally, thermoluminescent dosimeters (TLDs) were used as a comparative method to evaluate $\mathrm{DgN}_{\mathrm{p}}$ distributions. The methodology developed for measuring spectra proved to be efficient for the proper positioning and alignment of the detector and, consequently, for the measurement of direct X-ray spectra. The experimental incident spectra showed good agreement with spectra simulated in similar conditions. The results showed well-defined trends (either linear or exponential) of the distributions of these coefficients $\left(\mathrm{DgN}_{\mathrm{p}}\right)$ regarding the analyzed parameters. The $\operatorname{DgN}_{\mathrm{p}}$ values presented an exponential decay with the bTEM thickness and linear decrease with the glandularity. In addition, these coefficients increase linearly with the increase of the HVL and, consequently, with the increase of the effective energy. From the distributions of $\operatorname{DgN}_{\mathrm{p}}$ (obtained by Method III) it was possible to estimate the $\mathrm{DgN}_{\mathrm{p}}$ in the whole breast with a maximum difference of $5.2 \%$ from the values obtained using the Method II. The variation of the $\mathrm{DgN}_{\mathrm{p}}$ with the depth, obtained with TLDs, showed to be consistent with the results observed using the Method III. In conclusion, it is possible to evaluate the glandular dose in mammography examinations using X-ray spectra and the suggested methodology, with some adaptations, can be applied as an alternative procedure for dosimetry in mammography.

Keywords: Mammography, Normalized glandular dose coefficients, X-ray spectrometry, Dosimetry 


\section{Lista de Figuras}

Figura 1: Coeficientes de atenuação linear médios $\left(\mathrm{cm}^{-1}\right)$ para os tecidos normais glandular e adiposo e para as neoplasias dos tipos carcinoma (neoplasia maligna) e fibroadenoma (neoplasia benigna). Dados extraídos de Tomal $(2011)^{23}$.

Figura 2: Esquema de um equipamento convencional de mamografia. Adaptado de Bushberg e colaboradores ${ }^{18}$

Figura 3: Modelo geométrico de mama utilizado por Dance ${ }^{38 ;}{ }^{40}$, à esquerda, e $\mathrm{Wu}^{14 ; 41}$, à direita.

Figura 4: Sistema de posicionamento do espectrômetro portátil (à esquerda) para medições de espectros de raios $\mathrm{X}$ aparelhos de mamografia. O sistema foi montando a partir de posicionadores mecânicos (Optron, ltda, Campinas, Brasil.). Dispositivo de alinhamento do espectrômetro feito em PMMA (à direita).

Figura 5: Esquema da geometria do espectrômetro (baseado em Amptek inc.) e do dispositivo de alinhamento. As dimensões não estão em escala.

Figura 6: (a) Dispositivo de alinhamento produzido em PMMA com as esferas de tungstênio destacadas com um círculo vermelho; (b) dispositivo de alinhamento e, (c), espectrômetro com detector de CdTe, posicionados sobre o sistema de posicionamento.

Figura 7: Imagem radiográficas do dispositivo de alinhamento. Imagem completa do dispositivo num campo de $15 \mathrm{~cm}$ x $15 \mathrm{~cm}$ (a), zoom da região onde foram observadas as esferas desalinhadas (b) e alinhadas (c).

Figura 8: Posição do espectrômetro alinhado á $4,3^{\circ}$ de acordo com o sistema de referência adotado (eixo $\mathrm{z}$ na figura).

Figura 9: Imagens radiográficas do dispositivo de alinhamento obtidas para cada posição do espectrômetro avaliada (de $2,9^{\circ}$ a $\left.5,4^{\circ}\right)$.

Figura 10: Blindagem de chumbo (parte superior esquerda) confeccionada para cobrir o suporte de colimador e evitar o espalhamento de fótons que podem ser detectados e deformar o espectro medido.

Figura 11: Espectros brutos de W/Rh medidos usando: o colimador de W (linha preta) e absorvedor de $\mathrm{W}$ cobrindo o detector, espectro de espalhamento, (linha vermelha). Espectro corrigido pela subtração do espectro de espalhamento pelo espectro medido usando o colimador (linha azul).

Figura 12: Espectro de $\mathrm{W} / \mathrm{Rh}, 27 \mathrm{kV}$ não corrigido (linha preta) comparado com um espectro gerado pelo modelo TASMICS (linha vermelha).

Figura 13: Espectro de W/Rh, $27 \mathrm{kV}$ corrigido pela subtração de fótons espalhados (linha preta) comparado com um espectro gerado pelo modelo TASMICS (linha vermelha). 
Figura 14: Espectro de $\mathrm{Mo} / \mathrm{Rh}$ medidos: utilizando somente um colimador de $\mathrm{W}$ sobre o detector (linha preta); utilizando um disco absorvedor de W no lugar do colimador, espectro de espalhamento (linha vermelha); utilizando colimador mais a blindagem de $\mathrm{Pb}$ (linha preta); Espectro medido com o colimador com a subtração do espectro de espalhamento.

Figura 15: Espectro de Mo/Mo medidos: utilizando somente um colimador de W sobre o detector (linha preta); utilizando um disco absorvedor de W no lugar do colimador, espectro de espalhamento (linha vermelha); utilizando colimador mais a blindagem de $\mathrm{Pb}$ (linha preta); Espectro medido com o colimador com a subtração do espectro de espalhamento. 50

Figura 16: Posicionamento do espectrômetro para medições de espectros primários nos equipamentos de mamografia: (a), Mammomat 3000 Nova; (b), Selenia Dimensions, (c) Selenia (equipamento dedicado à pesquisa); (d) Selenia (equipamento de uso clínico ).........53

Figura 17: Posicionamento do espectrômetro de raios $\mathrm{X}$ e phantom de material tecidoequivalente à mama para medições de espectros de raios $\mathrm{X}$ transmitidos (a) e, posicionamento da câmara de ionização para medições de kerma no ar (b) para cada espectro transmitido medido.

Figura 18: Representação dos espectros incidente e transmitido através de um material radiologicamente equivalente ao tecido mamário.

Figura 19: Representação de um material simulador de tecido mamário em um campo de radiação típico de mamografia, com destaque no volume no qual o feixe de radiação atravessa antes de chegar ao espectrômetro. A figura não está em escala.

Figura 20: Esquema dos espectros incidentes e transmitidos ao atravessar um material simulador de tecido mamário (a), das diversas camadas consideradas no material simulador (b) e dos espectros incidentes e transmitidos em cada camada deste material....................... 72

Figura 21: Leitora TL/OSL Ris $\phi$, modelo DA-20. Fonte: nutech.dtu.dk 74

Figura 22: Posicionamento dos TLDs para irradiação no processo de seleção. Matiz de dosimetros posicionada frente à fonte de $\mathrm{Co}^{60}$ (à direita) e porta-dosimetros de PMMA com compacidade de posicionamento de 900 TLDs (à esquerda).

Figura 23: Intensidade do sinal de termoluminescência nos dosímetros TL. A intensidade do sinal representa a integral da curva inteira subtraída do sinal de fundo (background) 76

Figura 24: Grupo de dosímetros termoluminescentes irradiados com diferentes valores de dose para calibração.

Figura 25: Esquema de posicionamento dos dosímetros TL para irradiação em feixes de raios $\mathrm{X}$ produzidos pelo mamógrafo (a). Neste esquema, o eixo y representa sentido catodo-anodo, como apresentado no corte vertical que representa o plano xz (b)...... 78

Figura 26: Setup de irradiação dos dosímetros sobre a superfície do phantom 50/50 no equipamento Mammomat 3000 Nova. O posicionamento dos dosímetro foi guiado pelas marcações opacas da bandeja de compressão. 
Figura 27: Imagem radiográfica de um conjunto de dosímetros sobre um phantom de tecido equivalente irradiados no mamógrafo. $\mathrm{O}$ eixo y representa o sentido cátodo-anodo.

Figura 28: Plot 3D da Figura 7 apresentando a posição no plano xy em função do valor do pixel. O eixo y representa o sentido cátodo-anodo.

Figura 29: Curva de calibração em energia utilizando dados de fontes de ${ }^{241} \mathrm{Am},{ }^{133} \mathrm{Be}$ raios $\mathrm{X}$ de fluorescência do molibdênio. A incerteza nos pontos experimentais é inferior a $1,1 \%$..... 83

Figura 30: Espectros de raios $\mathrm{X}$ experimentais de Mo/Mo médios no equipamento Selenia (linha preta) e espectros gerados pelo modelo de Boone e colaboradores (1997) (linha vermelha) para valores típicos de tensão utilizados em mamografia.

Figura 31: Espectros de raios $\mathrm{X}$ experimentais de $\mathrm{Mo} / \mathrm{Rh}$ medidos no equipamento Selenia (linha preta) e espectros gerados pelo modelo de Boone e colaboradores (1997) (linha vermelha) para valores típicos de tensão no utilizados em mamografia.

Figura 32: Espectros de raios $\mathrm{X}$ experimentais de $\mathrm{Mo} / \mathrm{Mo}$ médios no equipamento Mammomat 3000 Nova (linha preta) e espectros gerados pelo modelo de Boone e colaboradores (1997) (linha vermelha) para valores típicos de tensão utilizados em mamografia.

Figura 33 : Espectros de raios $\mathrm{X}$ experimentais de $\mathrm{Mo} / \mathrm{Rh}$ médios no equipamento Mammomat 3000 Nova (linha preta) e espectros gerados pelo modelo de Boone e colaboradores (1997) (linha vermelha) para valores típicos de tensão utilizados em mamografia.

Figura 34: Espectros de raios $\mathrm{X}$ experimentais de W/Rh médios no equipamento Mammomat 3000 Nova (linha preta) e espectros gerados pelo modelo de Hernandez and Boone (2014) (linha vermelha) para valores típicos de tensão utilizados em mamografia.

Figura 35: Diferença percentual entre a fluência de fótons dos espectros experimentais e espectros calculados, para cada intervalo de energia $(0,056 \mathrm{keV})$. (a) apresenta os resultados para os espectros de Mo/Mo de 25 a $28 \mathrm{kV}$ correspondentes ao equipamento Selenia. (b) apresenta os resultados para os espectros de $\mathrm{Mo} / \mathrm{Rh}$ deste mesmo equipamento. A diferença média e desvio padrão estimados a partir dos histogramas foram -3,53 \% e 9,6\%, respectivamente, para os espectros de $\mathrm{Mo} / \mathrm{Mo}$. Para os espectros de $\mathrm{Mo} / \mathrm{Rh}$, a média e o desvio padrão obtidos foram $2,2 \%$ e $18,8 \%$. Estes valores foram estimados a partir do ajuste de uma gaussiana (curva em preto) com $\mathrm{R}^{2}$ iguais a 0,96 e 0,92 para os dados correspondentes a $\mathrm{Mo} / \mathrm{Mo}$ e $\mathrm{Mo} / \mathrm{Rh}$, respectivamente.

Figura 36: Diferença percentual entre a fluência de fótons dos espectros experimentais e espectros calculados, para cada intervalo de energia (0,055 keV) para: (a) $\mathrm{Mo} / \mathrm{Mo}$, (b) $\mathrm{Mo} / \mathrm{Rh}$ e (c) W/Rh correspondentes ao equipamento Mammomat 3000 Nova. A diferença média e desvio padrão estimados a partir dos histogramas foram $-2,92 \% \pm 10,5 \%$ para $\mathrm{Mo} / \mathrm{Mo},-1,26 \%$ $\pm 13,0 \%$ para $\mathrm{Mo} / \mathrm{Rh}$ e $-5,37 \% \pm 18,2 \%$ para $\mathrm{W} / \mathrm{Rh}$. Estes valores foram estimados a partir do ajuste de uma função gaussiana (curva em preto) com $\mathrm{R}^{2}$ iguais a 0,96, 0,95 e 0,93 para os dados correspondente a $\mathrm{Mo} / \mathrm{Mo}, \mathrm{Mo} / \mathrm{Rh}$ e $\mathrm{W} / \mathrm{Rh}$, respectivamente. 
Figura 37: Comparação dos espectros de fluência gerados usando 28 kV e combinação ando/filtro de W/Rh. Espectros medidos com espectrômetro posicionado em diferentes inclinações, para ângulos maiores (Figura 37 (a)) e menores que 4,3 (Figura 37 (b) ).

Figura 38: Valores de camada semirredutora derivados a partir dos espectros medidos como função do ângulo de posicionamento do espectrômetro.

Figura 39: Espectros de fluência de fótons de feixes de raios $\mathrm{X}$ transmitidos por várias espessuras dos phantoms de tecido equivalente 30/70 (a) e 50/50 (b). Os feixes de radiação foram gerados com $28 \mathrm{kV}$ utilizando a combinação Mo/Mo. Todos os espectros foram normalizados pela carga total (mAs).

Figura 40: Espectros de fluência de fótons de feixes de raios $\mathrm{X}$ transmitidos por várias espessuras dos phantoms de tecido equivalente 30/70 (a) e 50/50 (b). Os feixes de radiação foram gerados com $28 \mathrm{kV}$ utilizando a combinação $\mathrm{Mo} / \mathrm{Rh}$. Todos os espectros foram normalizados pela carga total (mAs).

Figura 41: Espectros de fluência de fótons de feixes de raios $\mathrm{X}$ transmitidos por várias espessuras dos phantoms de tecido equivalente 30/70 (a) e 50/50 (b). Os feixes de radiação foram gerados com $28 \mathrm{kV}$ utilizando a combinação W/Rh. Todos os espectros foram normalizados pela carga total (mAs).

Figura 42: Curvas de transmissão de feixes utilizados em mamografia por phantoms de composições 30/70 e 50/50. Os feixes foram produzidos utilizando as combinações anodo/filtro $\mathrm{Mo} / \mathrm{Mo}, \mathrm{Mo} / \mathrm{Rh}$ e W/Rh com valores de tensão aplicada ao tubo iguais a: $26 \mathrm{kV}$ (a), $28 \mathrm{kV}$ (b) e $30 \mathrm{kV}$ (c)

Figura 43: Valores de $\mathrm{DgN}_{\mathrm{p}}$ como função da camada semirredutora (CSR) obtidos utilizando espectros experimentais (símbolos cheios) e espectros simulados (símbolos vazios) para espectros de Mo/Mo e mama com composição de tecido glandular equivalente a $50 \%$. As linhas cheias e pontilhadas representam um ajuste linear aos dados.

Figura 44: Valores de $\mathrm{DgN}_{\mathrm{p}}$ como função da camada semirredutora (CSR) obtidos utilizando espectros experimentais (símbolos cheios) e espectros simulados (símbolos vazios) para espectros de $\mathrm{Mo} / \mathrm{Rh}$ e mama com composição de tecido glandular equivalente a $50 \%$. As linhas cheias e pontilhadas representam um ajuste linear aos dados. 96

Figura 45: Valores da função DGN(E) para glandularidade de $30 \%$ e espessuras de mama entre 2 e $8 \mathrm{~cm}$. Valores obtidos por meio de interpolação linear da relação DGN(E) x glandularidade $\left(0,50\right.$ e $100 \%$.) fornecida na literatura ${ }^{79}$

Figura 46: Valores da função DGN(E) para glandularidade de $70 \%$ e espessuras de mama entre 2 e $8 \mathrm{~cm}$. Valores obtidos por meio de interpolação linear da relação DGN(E) x glandularidade $\left(0,50\right.$ e $100 \%$.) fornecida na literatura ${ }^{79}$.

Figura 47: Variação da $\mathrm{DgN}_{\mathrm{p}}$ com a espessura de mamas com valores de glandularidade entre de $0 \%$ e $100 \%$ para o espectro de Mo/Mo, $28 \mathrm{kV}$.

Figura 48: Variação da $\mathrm{DgN}_{\mathrm{p}}$ com a espessura de mamas com valores de glandularidade entre de $0 \%$ e $100 \%$ para o espectro de $\mathrm{Mo} / \mathrm{Rh}, 28 \mathrm{kV}$. 
Figura 49: $\mathrm{DgN}_{\mathrm{p}}$ em função da glandularidade para quatro diferentes espessuras (entre 2 e 8 $\mathrm{cm}$ ) e espectro de $28 \mathrm{kV}$ gerado com alvo de Mo e filtros de Mo (símbolos cheios) e Rh (símbolos vazios). As linhas cheias representam ajuste linear aos resultantes provenientes do uso do espectro de $\mathrm{Mo} / \mathrm{Mo}$ e as linhas vazias representam o mesmo ajuste aos resultados obtidos com o espectro de $\mathrm{Mo} / \mathrm{Rh}$.

Figura 50: Espectros de fluência normalizados pela carga total (mAs) gerados com $28 \mathrm{kV}$ e com combinações alvo/filtro de: Mo/Mo (linha preta), Mo/Rh (linha vermelha), W/Rh (linha azul) e W/Ag (linha magenta). O subplot à direita destaca os espectros de bremsstrahlung de cada feixe. 100

Figura 51: $\operatorname{DgN}_{\mathrm{p}}$ como função da espessura da mama comprimida para 4 diferentes combinações alvo/filtro. Estes resultados consideram uma mama 50/50 e um feixe gerado com $28 \mathrm{kV}$.

Figura 52: $\operatorname{DgN}_{\mathrm{p}}$ como função da espessura da mama comprimida para 4 diferentes combinações alvo/filtro. Estes resultados consideram uma mama 30/70 e um feixe gerado com $28 \mathrm{kV}$. 100

Figura 53: $\mathrm{DgN}_{\mathrm{p}}$ em função da espessura de mama comprimida para valores de tensão entre 25 e $31 \mathrm{kV}$. Estes resultados consideram um espectro de Mo/Mo e composição mamária de 50/50. As linhas representam um ajuste exponencial aos dados. 101

Figura 54: $\mathrm{DgN}_{\mathrm{p}}$ em função da espessura de mama comprimida para valores de tensão entre 25 e $31 \mathrm{kV}$. Estes resultados consideram um espectro de $\mathrm{Mo} / \mathrm{Rh}$ e composição mamária de 50/50. As linhas representam um ajuste exponencial aos dados. 101

Figura 55 : Dados de DGNp obtidos neste trabalho para mamas 50/50 (em preto) em comparação com dados de dose glandular normalizada obtidos por meio de imagens de pacientes, utilizando dados extraídos do cabeçalho DICOM (em vermelho) e estimativa de dose feita pelo software Volpara (em azul).

Figura 56: Comparação dos valores de $\mathrm{DgN}_{\mathrm{p}}$ obtidos por meio dos Métodos I (símbolos vazios) e Método II (símbolos cheios) para materiais que representam mama com composição 30/70 (em preto) e 50/50 (em azul). Estes resultados consideram um espectro de Mo/Mo gerado com $28 \mathrm{kV}$.

Figura 57: Comparação dos valores de $\mathrm{DgN}_{\mathrm{p}}$ obtidos por meio dos Métodos I (símbolos vazios) e Método II (símbolos cheios) para materiais que representam mama com composição 30/70 (em preto) e 50/50 (em azul). Estes resultados consideram um espectro de $\mathrm{Mo} / \mathrm{Rh}$ gerado com $28 \mathrm{kV}$.

Figura 58: $\operatorname{DgN}_{\mathrm{p}}$ em função da espessura para os espectros gerados com as combinações alvo/filtro Mo/Mo (em preto), Mo/Rh (em vermelho) e W/Rh (em azul) e tensão de $28 \mathrm{kV}$. Os símbolos vazios representam os resultados para a composição 30/70 enquanto que os símbolos cheios representam resultados para a composição 50/50. As linhas representam um ajuste exponencial aos dados. 108

Figura 59: Distribuição de dose glandular normalizada com a espessura do material simulador de tecido mamário. $\mathrm{O}$ diagrama de cores (a) ilustra a os valores de $\mathrm{DgN}_{\mathrm{p}}$ para 
várias camadas de um phantom de $4 \mathrm{~cm}$ de espessura. Os resultados apresentados em (b) correspondem aos resultados apresentados em (a). Os pontos em (b) foram dispostos para os valores máximos de profundidade de cada camada analisada. Assim, por exemplo, o valor de $\mathrm{DgN}_{\mathrm{p}}$ correspondente a $0,5 \mathrm{~cm}$ de profundidade refere-se a $\mathrm{DgN}_{\mathrm{p}}$ calculada entre 0 e $0,5 \mathrm{~cm} .111$

Figura 60: Resposta dos dosimetros TL em função da dose absorvida no ar nas quais foram irradiados nas qualidades RQR-M2 (preto) e RQR-M4 (azul). As retas indicam ajuste linear aplicado para cada conjunto de dados. 113

Figura 61: Coeficientes mássicos para absorção de energia, $(\mu / \rho)_{\text {Abs, }}$ dos phantoms CIRS30/70, CIRS50/50 e CIRS70/30. Valores calculados a partir da composição química estimada por Poletti e colaboradores ${ }^{84}$ Coeficientes mássicos para a absorção de energia dos elementos químicos fornecidas pelo NIST. 114

Figura 62: Fatores f calculados para as combinações de tipo de phantom (CIRS30/70 ou CIRS50/50) e tipo de espectro (Mo/Mo, Mo/Rh e W/Rh) em função da energia efetiva dos espectros transmitidos. 118

Figura 63: Distribuição de dose absorvida sobre o eixo catodo-anodo em diferentes profundidades dos Phantoms Cirs30/70 (a), Cirs50/50 (b) e Cirs70/30 (c). O feixe utilizado para irradiação foi produzido com $28 \mathrm{kV}, 100 \mathrm{mAs}$ e a combinação de anodo/filtro Mo/Mo. A máxima incerteza no valor de dose absorvida, considerando as incertezas propagadas do fator de calibração e fator $\mathrm{f}$, foi de $2,3 \%$ do valor da dose.

Figura 64: Distribuição de dose absorvida sobre o eixo catodo-anodo em diferentes profundidades dos Phantoms Cirs30/70 (a), Cirs50/50 (b) e Cirs70/30 (c). O feixe utilizado para irradiação foi produzido com $28 \mathrm{kV}, 100 \mathrm{mAs}$ e a combinação de anodo/filtro $\mathrm{Mo} / \mathrm{Rh}$. A máxima incerteza no valor de dose absorvida, considerando as incertezas propagadas do fator de calibração e fator $\mathrm{f}$, foi de $2,3 \%$ do valor da dose. 120

Figura 65: Distribuição de dose absorvida sobre o eixo catodo-anodo em diferentes profundidades dos Phantoms Cirs50/50 (a) e Cirs70/30 (b). O feixe utilizado para irradiação foi produzido com $28 \mathrm{kV}, 100 \mathrm{mAs}$ e a combinação de anodo/filtro W/Rh. A máxima incerteza no valor de dose absorvida, considerando as incertezas propagadas do fator de calibração e fator $\mathrm{f}$, foi de $2,3 \%$ do valor da dose.

Figura 66: Variação de dose absorvida em diferentes profundidades dos phantoms CIRS30/70, CIRS50/50 e CIRS70/30 para feixes incidentes produzidos com a combinação $\mathrm{Mo} / \mathrm{Mo}$ (a), Mo/Rh (b) e W/Rh (c). Os valores de dose apresentados para cada espessura representam a média dos valores de dose absorvida obtidos com dosimetros alocados em sete diferentes posições do eixo catodo anodo, conforme apresentado nas Figuras 63-65. 121 


\section{Lista de Tabelas}

Tabela 1: Principais características dos modelos de Boone e colaboradores (1997) e Hernandez e Boone (2014) para a gerações de espectros de mamografia

Tabela 2: Algumas especificações dos equipamentos de mamografia utilizados neste trabalho.51

Tabela 3: Parâmetros usados para as medições de espectros de raios $\mathrm{X}$ produzidos por um aparelho de mamografia digital Selenia e os respectivos valores de kerma no ar. A incerteza nos valores de kerma no ar foi estimada em 7,6\% $(\mathrm{k}=2)$

Tabela 4: Espectros de raios X produzidos pelo equipamento Mammomat 3000 Nova e valores correspondentes de kerma no ar para cada espectro com incerteza estimada de 7,1\% considerando $\mathrm{k}=2$.

Tabela 5: Espectros de raios $\mathrm{X}$ medidos nos equipamentos Selenia e Selenia Dimensions e valores correspondentes de kerma no ar para uma exposição.

Tabela 6: Configurações para medições de espectros de 26, 28 e $30 \mathrm{kV}$ de feixes de Mo/Mo transmitidos por diferentes espessuras dos phantoms de tecido equivalente 30/70 e 50/50. N, é o número de irradiações feitas para a aquisição do espectro, Col $(\mu \mathrm{m})$ é o diâmetro do colimador utilizado no detector e L é a leitura da câmara de ionização em (mGy).

Tabela 7: Configurações para medições de espectros de 26, 28 e $30 \mathrm{kV}$ de feixes de $\mathrm{Mo} / \mathrm{Rh}$ transmitidos por diferentes espessuras dos phantoms de tecido equivalente $30 / 70$ e 50/50. N, é o número de irradiações feitas para a aquisição do espectro, Col $(\mu \mathrm{m})$ é o diâmetro do colimador utilizado no detector e L é a leitura da câmara de ionização em (mGy)

Tabela 8: Configurações para medições de espectros de 26, 28 e $30 \mathrm{kV}$ de feixes de W/Rh transmitidos por diferentes espessuras dos phantoms de tecido equivalente 30/70 e 50/50. N, é o número de irradiações feitas para a aquisição do espectro, Col $(\mu \mathrm{m})$ é o diâmetro do colimador utilizado no detector e L é a leitura da câmara de ionização em (mGy)

Tabela 9: Características das qualidades padrão de feixes de radiação de mamografia utilizadas para a calibração dos dosimetros TLDs num sistema Pantak/Seifert.

Tabela 10: Valores de doses (mGy) esperados com a irradiação dos dosímetros para calibração nas qualidades RQR-2M e RQR-4M. Valores de correntes (mA) utilizados, tempo estimado de irradiação (s) e tempo medido (s). A incerteza no tempo medido foi estimada como $0,23 \mathrm{~s}$

Tabela 11: Combinações de tipo de phantom e anodo/filtro utilizados para irradiações dos TLDs. Todas as irradiações foram realizadas utilizando feixes produzidos com $28 \mathrm{kV}$ e 100 mAs no equipamento Mammomat 3000 Nova.

Tabela 12: Posição média de cada dosímetro, (x, y), no plano de irradiação conforme apresentado na Figura 28

Tabela 13: Valores de CSR calculados a partir dos espectros experimentais (Selenia) e espectros calculados pelo modelo de Boone e colaboradores (1997). As incertezas nos valores 
de CSR obtidas para os espectros experimentais foram menores que $0,3 \%$ e para os espectros calculados foram menores que $0,6 \%$.

Tabela 14: Valores de CSR calculados a partir dos espectros experimentais de (Mammomat 3000 Nova) espectros calculados por modelos computacionais. As incertezas nos valores de CSR obtidas para os espectros experimentais foram menores que $1 \%$ e para os espectros calculados foram menores que $0,7 \%$.

Tabela 15: Dados extraídos do cabeçalho DICOM de imagens de mamografia de pacientes do ICESP* tensão 28, 100 mAs- met 1 50/50 - inc 4,4 \% met i.

Tabela 16: Valores de $\mathrm{DgN}_{\mathrm{p}}$ obtidos usando espectros incidentes e transmitidos por diversas espessuras de materiais simuladores de tecido mamário com composições de 30/70 e 50/50. Estes valores foram obtidos por meio da equação (27) para espectros de $\mathrm{Mo} / \mathrm{Mo}, / \mathrm{Mo} / \mathrm{Rh}$ e $\mathrm{W} / \mathrm{Rh}$ gerados com tensões aplicadas ao tubo de $26 \mathrm{kV}$ e $28 \mathrm{kV}$. As incertezas representam, em média, $1,3 \%$ dos valores de $\mathrm{DgN}_{\mathrm{p}}$.

Tabela 17: Diferença percentual entre valores de $\operatorname{DgN}_{\mathrm{p}}$ obtidos por meio dos Métodos I e II, relativa aos valores obtidos com o Método I [100x(DgNp(II) - $\operatorname{DgNp}(\mathrm{I})) / \mathrm{DgNp}(\mathrm{I})]$.

Tabela 18: $\mathrm{DgN}_{\mathrm{p}}$ para camadas em diferentes profundidades do material simulador de tecido mamário de composições 30/70 e 50/50. Valores obtidos para espectros de $\mathrm{Mo} / \mathrm{Mo}, \mathrm{Mo} / \mathrm{Rh}$ e $\mathrm{W} / \mathrm{Rh}$ gerados com tensões de 26 e $28 \mathrm{kV}$. As incertezas representam em média $1,8 \%$ dos valores de $\operatorname{DgN} N_{p}$

Tabela 19: Comparação entre valores dos $\mathrm{DgNp}$ obtidos pelo Método II para espessuras de 2, 3 e $4 \mathrm{~cm}$ e valores obtidos utilizando a equação (41) e Método III.

Tabela 20: Valores de doses absorvidas devido à exposição dos dosímetros aos feixes de raios $\mathrm{X}$ equivalentes aos feixes padrões para mamografia de qualidades RQR-M2 e RQR-M4 ${ }^{32} .113$

Tabela 21: Fator de calibração dos TLDs (coeficientes angulares do ajuste linear) e coeficientes de correlação, $\mathrm{R}^{2}$, para as duas retas ajustadas na Figura 60. Os valores de incerteza na resposta (considerados 6,5\% do valor da leitura) foram transferidos para o eixo das ordenadas e os ajustes interceptaram a origem $(0,0)$.

Tabela 22: Camada semirredutora (CSR) e energia efetiva (Eef) para os espectros de raios $\mathrm{X}$ medidos com $28 \mathrm{kV}$ e utilizando diferentes combinações alvo/filtro. Esses espectros foram usados para irradiar os dosímetros TLs em diferentes profundidades dos phantoms Cirs30/70, Cirs50/50. Coeficientes mássicos para a absorção de energia para o ar, $\left(\mu_{a b} / \rho\right)_{\text {ar }}$, e para os phantoms CIRS30/70, $\left(\mu_{a b} / \rho\right)_{30 / 70}$ e CIRS50/50, $\left(\mu_{a b} / \rho\right)_{50 / 50}$. 116

Tabela 23: Parâmetros de ajuste da equação (47) e valores dos correspondentes coeficientes de determinação $\left(\mathrm{R}^{2}\right)$

Tabela 24: Valores de energia efetiva dos feixes transmitidos por espessuras de 15 e $25 \mathrm{~mm}$ dos phantoms CIRS30/70 e CIRS50/50 e correspondentes valores de coeficientes mássicos de absorção de energia para o ar e para os phantoms. 


\section{Lista de Siglas}

CC - Crânio Caudal;

CDTN - Centro de Desenvolvimento de Tecnologia Nuclear;

CSR - Camada semirredutora;

DGM - Dose Glandular Média;

DgN - Dose Glandular normalizada;

$\mathrm{DgN}_{\mathrm{p}}$ - Dose glandular normalizada para espectros polienergéticos;

DICOM - Digital Imaging and Communications in Medicine;

DR - Digital Radiology;

IAEA - International Atomic Energy Agency;

ICESP - Instituto do Câncer do Estado de São Paulo;

ICRP - International Comission on Radiation Protection;

INCA - Instituto Nacional do Câncer;

InRaD - Instituto de Radiologia do Hospital das Clínicas da Faculdade de Medicina da USP;

MASMIP - Molybdenum anode spectral model using interpolating polynomials;

MCA - Multi channel Analizer

MLO - Médio lateral oblíquo;

NIST - National Institute of Standards and Technology

RASMIP - Rhodium anode spectral model using interpolating polynomials;

RQR - Standard Radiation Quality for Radiodiagnostic;

RQR-M - Standard Radiation Quality for Mammography;

SID - Source to image distance;

SSDL - Secondary Standard Dosimetry Laboratory;

TASMICS - Tungsten anode spectral model using interpolating cubic splines;

TL - Termoluminescência/termoluminescente;

TLDs - Dosímetros termoluminescentes;

UESC - Universidade Estadual de Santa Cruz; 



\section{SUMÁRIO}

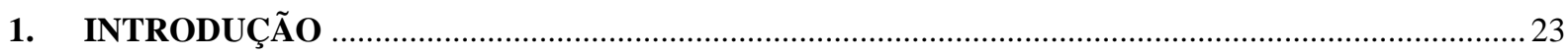

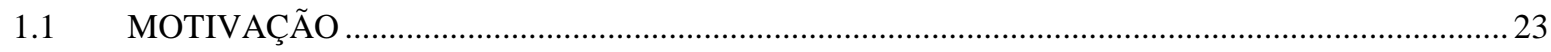

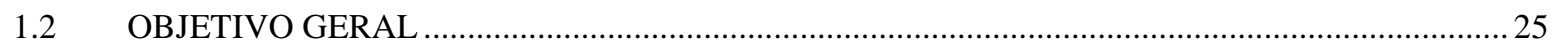

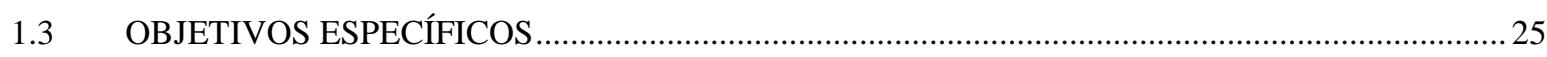

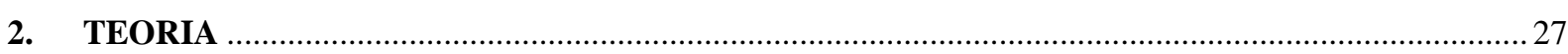

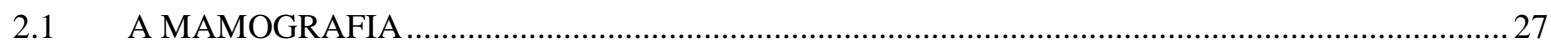

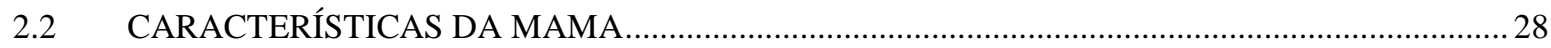

2.3 CARACTERÍSTICAS DE UM SISTEMA CONVENCIONAL PARA MAMOGRAFIA ...................29

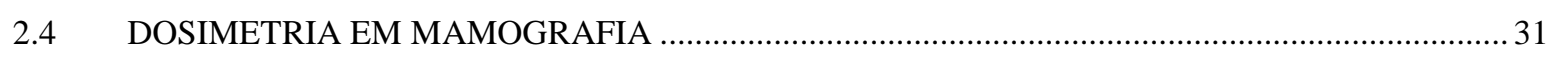

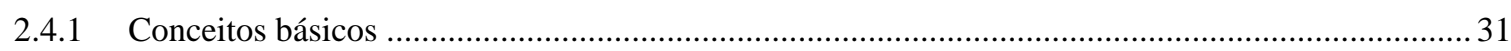

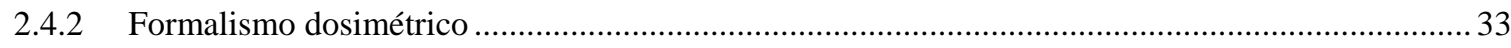

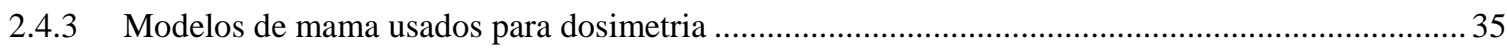

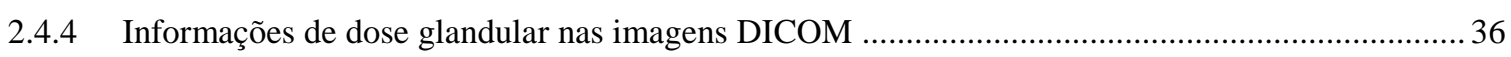

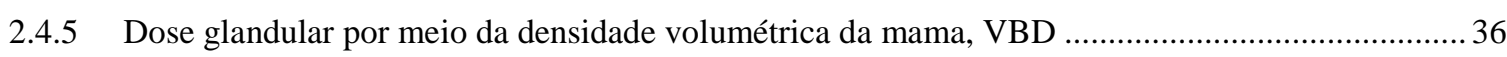

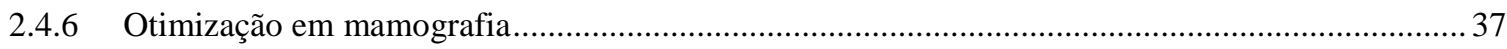

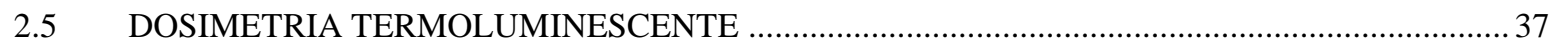

2.5.1 Algumas aplicações de dosímetros TL em Mamografia....................................................................... 38

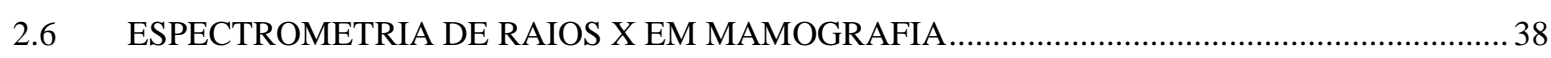

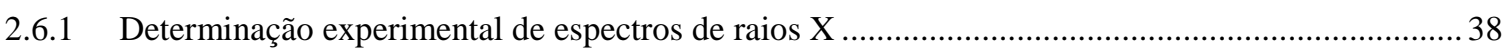

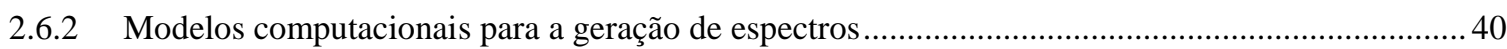

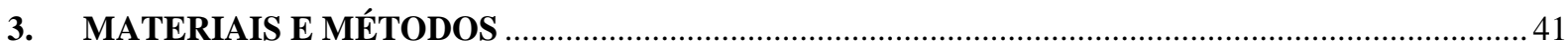

3.1 METODOLOGIA EXPERIMENTAL PARA MEDIÇÕES DE ESPECTROS DE RAIOS X EM

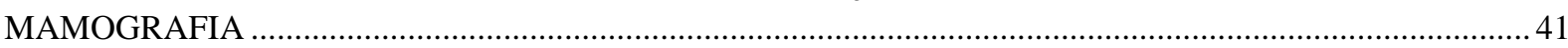

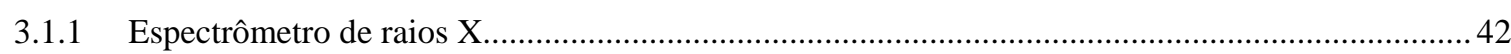

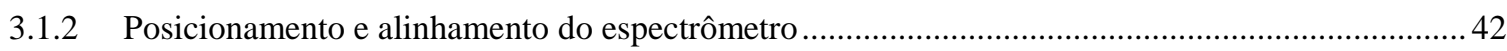

3.1.3 Análise do efeito do desalinhamento do espectrômetro nos espectros medidos ................................ 46

3.1.4 Analise da influência de contribuição de espalhamento nos espectros medidos ............................... 47

3.2 MEDIÇÕES DE ESPECTROS DE RAIOS X EM EQUIPAMENTOS DE MAMOGRAFIA ............51

3.2.1 Medições de espectros de raios X primários.................................................................................... 52

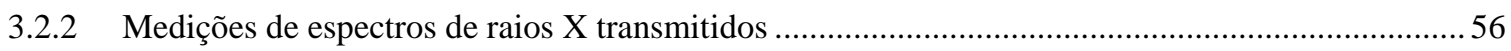

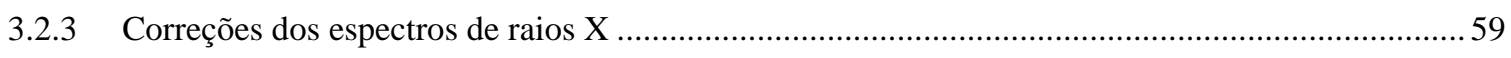

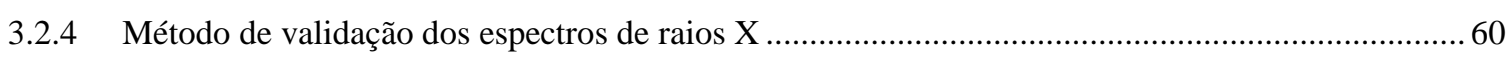

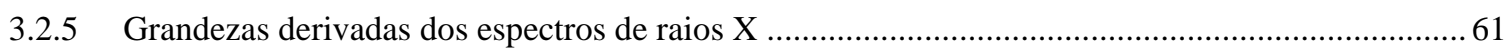

3.3 AVALIAÇÃO DA DOSE GLANDULAR NORMALIZADA UTILIZANDO ESPECTROS DE RAIOS

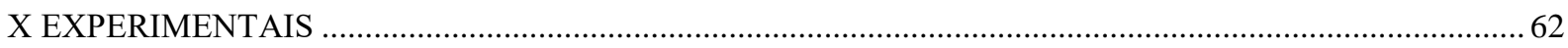

3.3.1 Método I: Cálculo de dose glandular normalizada usando espectros primários ...............................62 62

3.3.2 Método II: Cálculo de dose glandular normalizada usando espectros transmitidos .......................... 65

3.3.3 Método III: Cálculo da distribuição de dose glandular normalizada com a profundidade ............... 71 


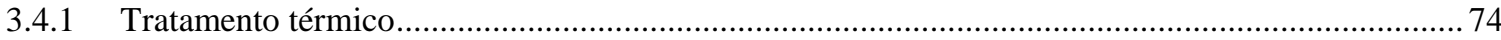

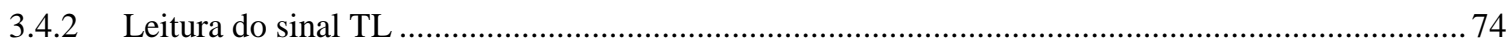

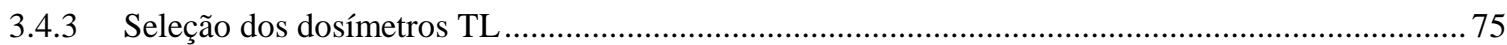

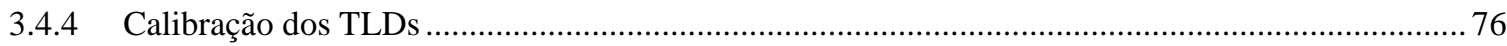

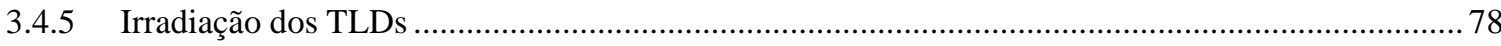

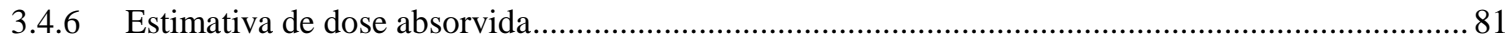

3.4.7 Estimativa de dose glandular normalizada utilizando os TLDs .................................................. 82

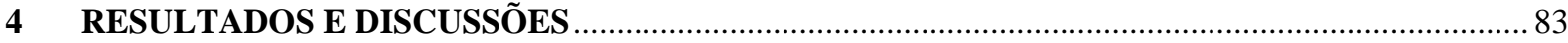

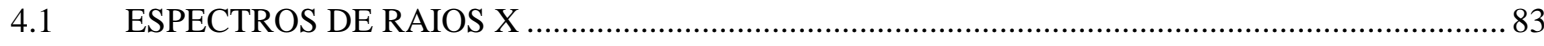

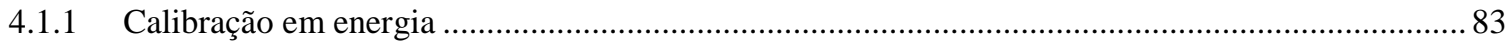

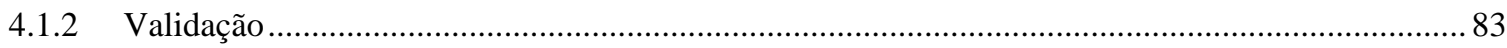

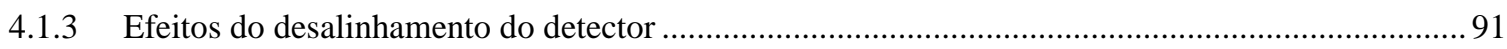

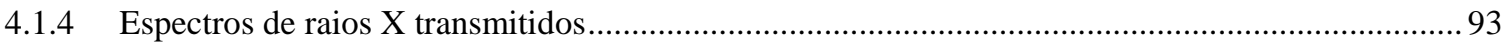

4.2 AVALIAÇÃO DA DOSE GLANDULAR NORMALIZADA UTILIZANDO ESPECTROS

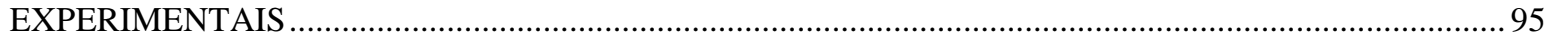

4.2.1 Método I: Dose glandular normalizada $\left(\mathrm{DgN}_{\mathrm{p}}\right)$ usando espectros primários...............................95

4.2.2 Método II: Dose glandular normalizada $\left(\mathrm{DgN}_{\mathrm{p}}\right)$ usando espectros transmitidos ......................... 105

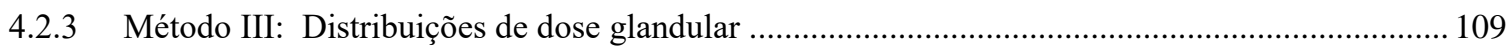

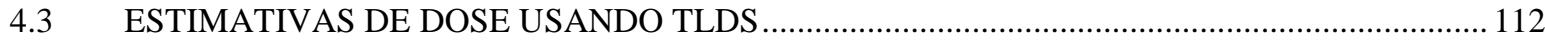

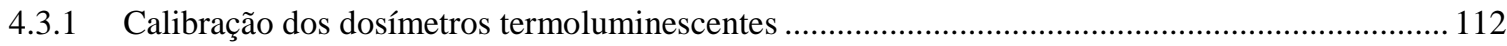

4.3.2 Coeficientes mássicos de absorção de energia dos phantoms................................................. 114

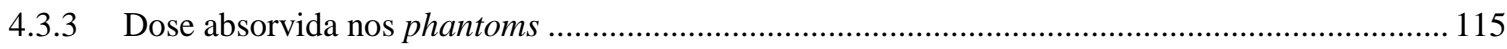

4.3.4 Distribuições da dose glandular normalizada ................................................................ 122

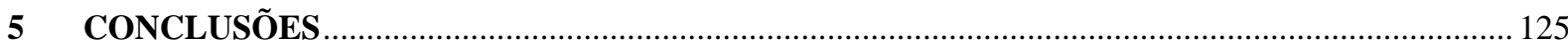

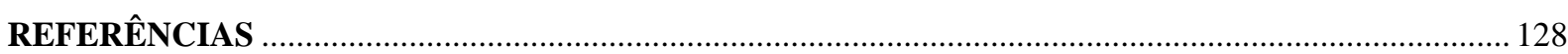

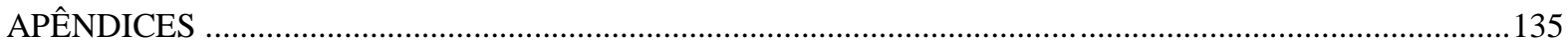

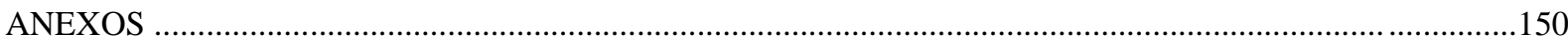




\section{INTRODUÇÃO}

\subsection{MOTIVAÇÃO}

Desde sua introdução como modalidade diagnóstica usual para prospecção de patologias mamárias, a mamografia utilizando equipamentos radiológicos dedicados é considerada a técnica mais adequada para a identificação, rastreamento e estadiamento de doenças da mama, em especial o câncer. O câncer de mama é alvo de atenção especial por parte da comunidade médica por ser um dos tipos de câncer que mais afetam mulheres em todo o mundo. Excluindo o câncer de pele não melanoma, o câncer de mama foi o câncer mais comum em mulheres em todo o mundo, contribuindo com mais de $25 \%$ do número total de casos diagnosticados em 2012 ${ }^{1}$. No Brasil, em 2013, foram registrados 14.206 óbitos causados por câncer de mama e para 2016 foram estimados cerca de 57.960 novos casos esperados, com um risco estimado pelo $\mathrm{INCA}^{2}$ de 56,20 casos a cada 100 mil mulheres.

O diagnóstico precoce e o acesso ao tratamento adequado têm mostrado impacto na redução da mortalidade por câncer de mama em outros países e por isso é fundamental que as ações destinadas a aumentar a taxa de detecção precoce sejam implementadas no Brasil ${ }^{3 ;} 4$. Em vista disso, o Colégio Brasileiro de Radiologia e Diagnóstico por Imagens tem publicado recomendações para realização de exames de rastreamento do câncer mamário em função da idade, grau de risco e de outras características da mulher a ser diagnosticada. A preocupação com o câncer de mama também levou à criação do movimento popular Outubro Rosa, na década de 1990, para estimular a participação da população no controle do câncer de mama por meio da divulgação da importância do diagnóstico precoce desse tipo de câncer 5 .

Devido às características anatômicas e teciduais da mama feminina, equipamentos e tecnologias especiais tiveram que ser desenvolvidas para garantir os parâmetros de qualidade das imagens, que maximizem seu potencial na identificação das lesões típicas que caracterizam o câncer de mama, e minimizem doses correspondentes a estes exames. Isto é importante, uma vez que existe um risco de indução de câncer associado à dose recebida por pacientes submetidos à mamografia ${ }^{6-7 ; 8}$. Diante da necessidade de uma grandeza dosimétrica que pudesse caracterizar adequadamente as doses mamárias e sua correlação com o risco de indução de câncer, foi definida a grandeza dose glandular média ${ }^{6}$. Esta grandeza é a mais aceita pela comunidade científica e é adotada pela regulamentação sanitária de diversos países $^{9 ; 10 ; 11}$ como item obrigatório em programas de avaliação e acreditação de instalações que oferecem serviços de mamografia. Apesar disso, no Brasil não há a exigência do uso da 
grandeza dose glandular média no controle de qualidade de equipamentos em mamografia. Recomenda-se, apenas, a medição de dose na entrada da pele ${ }^{12}$. A dose glandular média não pode ser determinada de forma direta, mas pode ser correlacionada com grandezas de fácil medição, como o kerma no ar.

$\mathrm{Na}$ prática, as estimativas de dose glandular média são realizadas a partir de uma medição externa à mama ou a um objeto simulador que represente uma mama típica de forma aproximada. Essa estimativa é feita a partir de resultados obtidos pela aplicação do método Monte Carlo, que considera arquiteturas de medição específicas e que devem ser reproduzidas pelo processo de medição em questão. Além disso, pesquisadores como Dance ${ }^{13}$ e $\mathrm{Wu}^{14}$ estabeleceram correlações entre propriedades específicas do tipo de mama a ser avaliada, tais como sua glandularidade e espessura comprimida. Estes autores também estudaram propriedades do espectro de raios $\mathrm{X}$ utilizado para a produção da imagem, como a combinação anodo/filtro e a tensão aplicada ao tubo, que modifica a camada semirredutora do feixe de raios $X$.

Resultados de investigações realizadas por Dance ${ }^{15}$, Sobol e $\mathrm{Wu}^{16}$ e $\mathrm{Wu}$ e colaboradores $^{14}$ nas últimas décadas tem servido como referências principais para o estabelecimento de correlações entre estas grandezas mensuráveis em programas de dosimetria ou controle de qualidade em mamografia. A dose glandular depende do espectro de raios X utilizado para irradiar a mama. Esses espectros são caracterizados, entre outros fatores, pelos tipos de combinações de materiais do anodo/filtro utilizados e tensão aplicada ao tubo. $\mathrm{O}$ uso de diferentes combinações anodo/filtro incorporadas aos equipamentos de mamografia permite que estes sistemas possam realizar imagens com qualidades adequadas e doses aceitáveis mesmo com a vasta variabilidade de anatomias mamárias distribuídas na população feminina. Atualmente, estas combinações são escolhidas em função da espessura da mama comprimida e de sua composição estimada através da proporção entre tecido glandular e adiposo, que varia com a idade da paciente. Além disso, depende também do tipo de detector utilizado para a detecção da imagem (digital ou analógico). A escolha adequada pode, ainda, variar em função da existência de próteses mamárias ou de solicitações de investigações especiais pelo clínico ou mastologista, como no caso de estadiamento de câncer pós-terapia.

Adicionalmente a esta complexa rede de correlações que caracteriza a avaliação dosimétrica da mamografia, está o difícil estabelecimento de padrões confiáveis de identificação da glandularidade ${ }^{17}$ das mamas típicas, que são dependentes da idade da paciente e também de outras características inerentes de seu biótipo. Além disso, a 
caracterização do feixe de raios X através da medição direta de seu espectro é um procedimento complexo e de difícil execução em sistemas clínicos, devido à arquitetura dos equipamentos e da impossibilidade de controles adequados da fluência de fótons produzida por estes dispositivos. Devido à dependência da dose glandular com a qualidade do feixe de radiação espera-se que exista uma correlação entre a forma do espectro medido e a dose glandular. Além disso, ainda não foram bem estabelecidas as variações na forma dos espectros incidentes na superfície da mama em diferentes profundidades e como essas variações afetam a distribuição da dose glandular na mama.

\subsection{OBJETIVO GERAL}

O objetivo geral desta pesquisa foi estimar distribuições de dose glandular produzidas por equipamentos de mamografia em diferentes profundidades de materiais simuladores de tecido mamário utilizando espectrometria de raios $\mathrm{X}$ e dosimetria por termoluminescência (TL). Foi avaliada a correlação entre as distribuições de dose glandular e os espectros de raios $\mathrm{X}$ medidos em diferentes profundidades, considerando mamas com glandularidades distintas e técnicas radiográficas comumente usadas nos exames para o rastreamento de câncer de mama

Espera-se que as informações produzidas possam contribuir para o melhor entendimento do comportamento das distribuições de dose nas mamas ao serem realizados procedimentos diagnósticos típicos e superar, ao menos parcialmente, as limitações atualmente encontradas para uma abordagem experimental da determinação dos espectros de radiação produzidos pelos equipamentos de mamografia.

\subsection{OBJETIVOS ESPECÍFICOS}

- Desenvolvimento de um arranjo experimental para medição de espectros de raios $\mathrm{X}$ em sistemas mamográficos;

- Medição de espectros de raios X e análise da correlação entre os espectros medidos e as distribuições de dose glandular correspondentes em diferentes profundidades de simuladores de tecidos mamários com distintas glandularidades.

- Medição de distribuições de dose glandular em diferentes profundidades da mama utilizando dosímetros termoluminescentes; 
- Avaliar como a variação do espectro em diferentes profundidades dos materiais simuladores de tecido mamário pode influenciar na estimativa de dose glandular média.

- Propor modelos alternativos e/ou complementares aos atualmente adotados para o cálculo da dose glandular normalizada. 


\section{TEORIA}

\subsection{A MAMOGRAFIA}

Mamografia é o exame realizado por meio de imagens radiográficas da mama para a identificação de patologias ${ }^{18}$. É o método mais eficiente para a detecção precoce de sinais indicadores do câncer de mama $^{3}$ e tem sido largamente utilizado em todo o mundo, principalmente para o rastreamento de neoplasias mamárias em mulheres assintomáticas.

O exame compreende na irradiação da mama, mecanicamente comprimida, para a aquisição da imagem radiográfica para o diagnóstico clínico. As técnicas de irradiação devem produzir imagens com qualidade suficiente para identificar assimetrias na mama, diferenciar tecido glandular e tecido neoplásico e identificar microcalcificações, depósitos de fosfato de cálcio ou oxalato de cálcio da ordem de micrômetros (de 50 a $300 \mu \mathrm{m}$ ), resultantes de secreção da lesão maligna ${ }^{19}$.

O exame inicial geralmente é realizado com irradiações nas projeções craniocaudal (CC) e médiolateral oblíqua (MLO). No entanto, alguns achados radiográficos como microcalcificações ou densidades assimétricas de tecido fibroglandular podem não ser completamente identificados no exame inicial e uma avaliação adicional pode ser necessária. A localização de anormalidades como microcalcificações pode ser realizada utilizando a projeção lateral (LAT), e a ampliação dessas estruturas na imagem pode ser realizada com técnicas de magnificação ${ }^{19}$.

A ampliação geométrica (magnificação) consiste na aquisição da imagem com a mama posicionada sobre um suporte (torre de magnificação) a uma distância fixa do detector, de aproximadamente $30 \mathrm{~cm}$ (depende do fator de ampliação desejado). Essa técnica produz uma imagem ampliada de $1,5 \mathrm{x}$ a $2 \mathrm{x}$ de uma região específica da mama com melhor resolução espacial, com menos ruído e menor influência da radiação espalhada na mama e que atinge o detector $^{18}$.

O rastreamento do câncer de mama por meio da mamografia tem mostrado impacto na queda da taxa de mortalidade, devido a este tipo de câncer, em diversos países ${ }^{20}$. No Brasil o Ministério da Saúde (MS) recomenda este exame para mulheres numa faixa etária de 50 a 69 anos com intervalo máximo de dois anos entre os exames ${ }^{21}$. No entanto, na prática, o rastreamento esse exame é realizado conforme a recomendação do Colégio Brasileiro de Radiologia e Diagnóstico por Imagens, para mulheres que compõem o grupo de risco médio, com idades entre 40 e 74 anos com periodicidade anual ${ }^{20}$. 


\subsection{CARACTERÍSTICAS DA MAMA}

Macroscopicamente, e para fins de dosimetria, a mama pode ser considerada como sendo constituída por duas partes principais: tecido glandular e tecido adiposo. Estas duas componentes formam uma mistura heterogênea e é coberta por pele de espessura média geral de aproximadamente $1,45 \mathrm{~mm}^{22}$. Além disso, um estudo populacional ${ }^{23}$ mostrou que a espessura de mama comprimida de pacientes de 13 países analisados varia entre $0,5 \mathrm{~cm}$ e $11,7 \mathrm{~cm}$. Neste trabalho o termo glandularidade é utilizado para representar a fração de massa de tecido glandular presente na mama. A Figura 1 ilustra as principais estruturas presentes na mama (figura a esquerda) e destaca essas estruturas numa imagem radiográfica da mama (figura a direita).

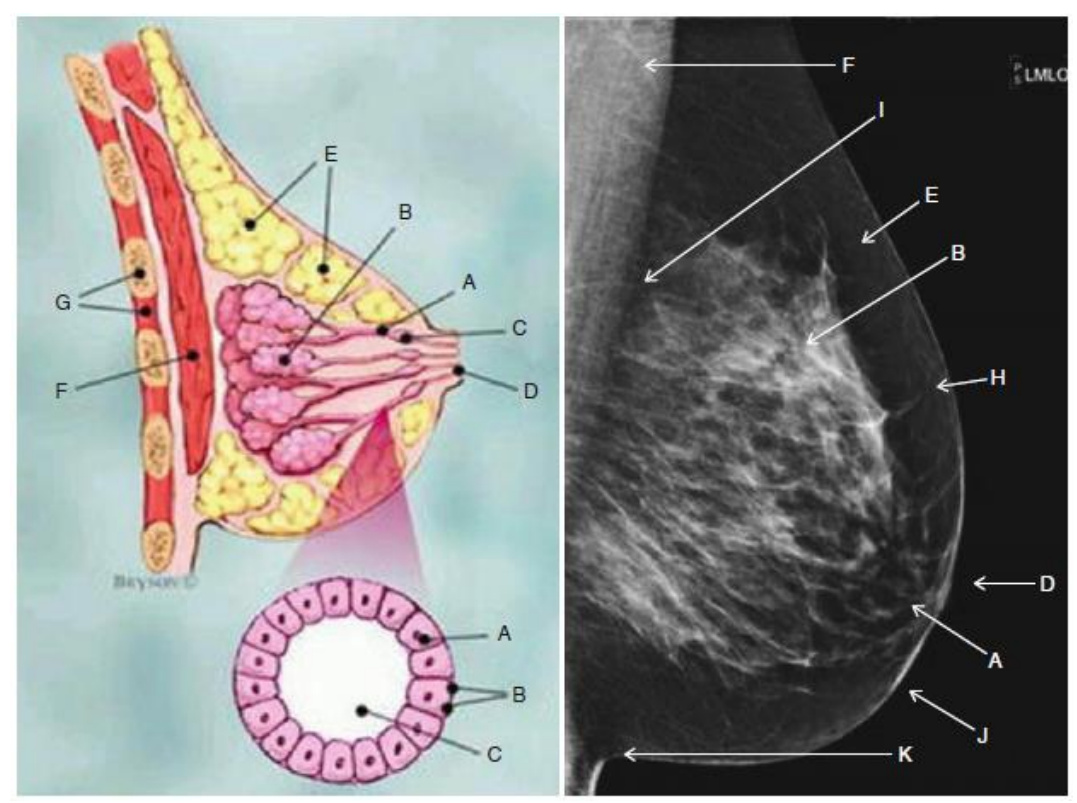

Figura 1: Principais estruturas presentes na mama (figura a esquerda) e imagem radiográfica da mama com destaque dessas estruturas (figura a direita). A: ductos lactíferos; B: lóbulos; C: seção transversal dos ductos lactíferos; D: mamilo; E: tecido adiposo; F: músculo peitoral; G: parede torácica; H: ligamentos de Cooper; I: espaço retromamário; J: pele; K: dobra inframamária. Imagem extraída de Darlington (2015) ${ }^{24}$

O tecido glandular é mais denso que o adiposo, e, portanto, a densidade geral da mama está diretamente relacionada à proporção de tecido glandular que ela possui. Com relação às propriedades de atenuação da radiação, os tecidos glandular e adiposo possuem coeficientes de atenuação linear com diferença significativa na faixa de energia usada em mamografia. Desse modo, esses dois tipos de tecidos são facilmente distinguíveis numa imagem de mamografia. No entanto, são pequenas as diferenças de atenuação dos raios $\mathrm{X}$ entre os tecidos glandular e cancerosos, e esse fato explica a necessidade do uso de equipamentos de raios $\mathrm{X}$ especificamente projetados para otimizar detecção do câncer de mama ${ }^{18}$. A Figura 2 apresenta os coeficientes de atenuação linear médios dos tecidos glandular, adiposo, 
carcinoma (neoplasia maligna) e fibroadenoma (neoplasia benigna) obtidos por Tomal $(2011)^{25}$.

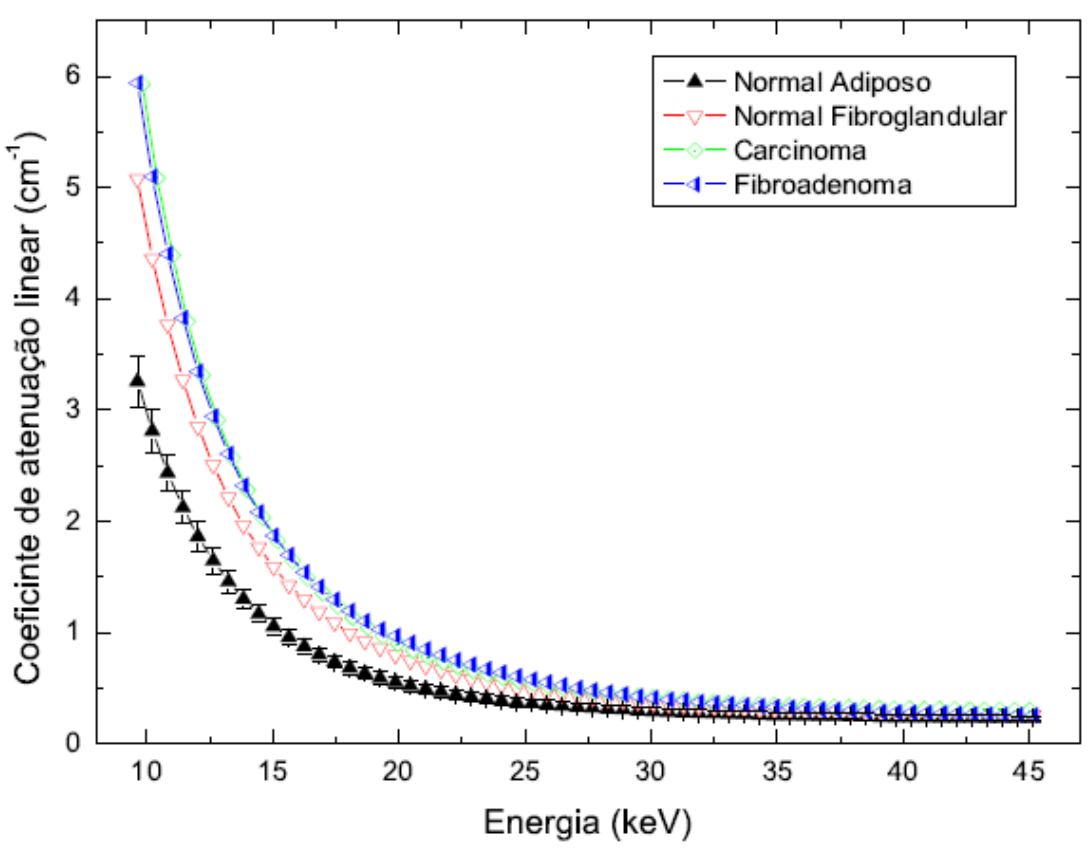

Figura 2: Coeficientes de atenuação linear médios $\left(\mathrm{cm}^{-1}\right)$ para os tecidos normais glandular e adiposo e para as neoplasias dos tipos carcinoma (neoplasia maligna) e fibroadenoma (neoplasia benigna). Dados extraídos de Tomal $(2011)^{25}$.

Apesar dos tecidos glandular e adiposo formarem uma composição heterogênea da mama, os modelos de mama mais comuns ${ }^{14 ; 15 ; 26}$ utilizados para estimativas de dose glandular consideram a mama como uma mistura homogênea. Além disso, a maioria dos modelos físicos de mama comprimida (materiais radiologicamente equivalentes a tecido mamário ou phantoms de mama $^{27}$ ) também consideram essa mistura homogênea. A consideração da composição percentual de tecidos glandular/adiposo igual 50/50 (glandularidade de 50\%) é muito comum na estimativa de dose. No entanto, uma investigação com imagens obtidas por meio de tomografias de mamas mostrou que a mama com 50\% de tecido glandular é incomum, e que a glandularidade média é bem menor variando entre $13,7 \%$ e $25,6 \%{ }^{28}$.

\subsection{CARACTERÍSTICAS DE UM SISTEMA CONVENCIONAL PARA MAMOGRAFIA}

A Figura 3 apresenta um esquema básico de um equipamento de mamografia. O tubo de raios $\mathrm{X}$ está localizado na parte superior do equipamento e é composto por anodos, que operam em rotação, cujos materiais mais comuns utilizados são Molibdênio (Mo), Tungstênio (W), ou Ródio (Rh). 


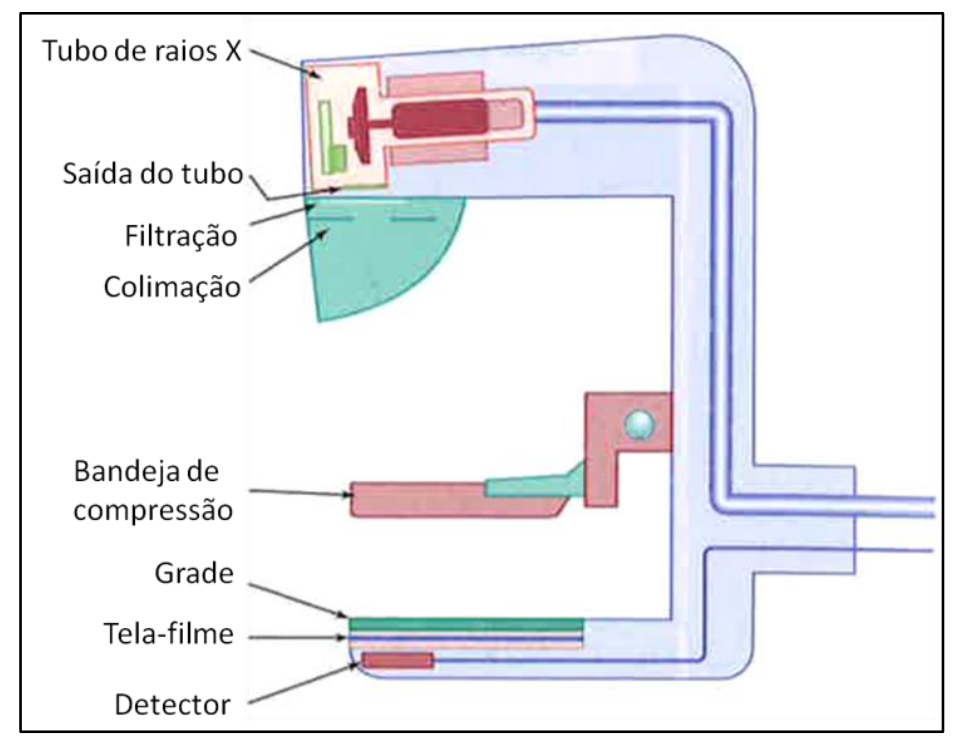

Figura 3: Esquema de um equipamento convencional de mamografia. Adaptado de Bushberg e colaboradores $^{18}$.

Para anodos de Molibdênio, há emissão de radiação característica de fótons, resultantes das transições de elétrons para a camada K, com energias de 17,5 e 19,6 keV e para Ródio, essa radiação característica tem energia de 20,2 e 22,7 keV. As linhas características do $\mathrm{W}$ possuem valores de energia superior à faixa de energia usada em mamografia. Os tamanhos de ponto focal do feixe de elétrons no ânodo geralmente variam de 0,1 a $0,15 \mathrm{~mm}$ (ponto focal pequeno), utilizado principalmente em técnicas de magnificação, e 0,3 a $0,4 \mathrm{~mm}$ (ponto focal grande) para técnicas sem amplificação ${ }^{18}$.

$\mathrm{Na}$ prática, os tubos de raios $\mathrm{X}$ usados em equipamentos de mamografia são, geralmente, operados com valores de tensão no intervalo de 25-35 kV. Os espectros produzidos são compostos por uma região contínua (bremsstrahlung) mais um conjunto de linhas de emissão característica do material do anodo. No entanto, o melhor contraste para distinção entre o tecido normal e tecido cancerígeno ocorre quando a imagem é produzida por fótons de energias próximas a $20 \mathrm{keV}$. Energias acima desse valor reduzem o contraste e energias menores contribuem significativamente para dose na mama ${ }^{18}$. Desse modo, para minimizar a dose e otimizar o contraste da imagem, é necessário o uso de filtros que reduzam, do espectro de bremsstrahlung, parte dos fótons de baixas e altas energias, respectivamente. Os filtros de um equipamento de mamografia estão localizados após a saída do tubo (Figura 3), sendo os mais usuais constituídos por Mo ou Rh. Esses materiais têm bordas de absorção em 20 e 23,2 $\mathrm{keV}^{29}$, respectivamente, cujo efeito sobre o espectro é a criação de uma "janela" de transmissão para uma determinada faixa de energia ${ }^{18}$. Por exemplo, quando se utiliza a combinação anodo/filtro $\mathrm{Mo} / \mathrm{Rh}$, o espectro final é composto na sua maior parte por fótons entre 20 e $23 \mathrm{keV}$. 
Os equipamentos de mamografia também possuem um sistema de colimação que permite variar o tamanho do campo. A bandeja de compressão é constituída de material plástico de alta resistência e pressiona a mama contra um suporte com uma força da ordem de dezenas de Newtons. Os exames geralmente são realizados numa faixa de tensão entre 25 e $35 \mathrm{kV}$, com correntes anódicas entre 28 e $180 \mathrm{~mA}$ e tempos de exposição da ordem de milissegundos. Este tempo é considerado suficientemente baixo para reduzir o desconforto da paciente causado pela compressão da mama, além de diminuir o aparecimento de artefatos na imagem devidos ao movimento da paciente durante a exposição. Os sistemas de detecção mais modernos utilizados atualmente podem ser computadorizados (Computerized Radiology - CR) ou digitais (Digital Radiology - DR), apesar de ainda haverem sistemas com base em combinações tela-filme em uso.

As técnicas aplicadas para a realização dos exames dependem da densidade e espessura de mama comprimida. Como exemplo, para uma mama com composição de $50 \%$ de tecido glandular e 50\% de tecido adiposo, e a utilização de um detector de selênio de um sistema digital de mamografia. A combinação alvo/filtro Mo/30 $\mu \mathrm{m}$ Mo é geralmente usada para espessuras de mama comprimida até $7 \mathrm{~cm}$ e, para espessuras maiores que $7 \mathrm{~cm}$ usa-se $\mathrm{Mo} / 25 \mu \mathrm{m} \mathrm{Rh}$. Quanto menor a espessura de mama comprimida, menores os valores de tensão e carga aplicadas. Por exemplo, para espessuras menores que $3 \mathrm{~cm}$ usa-se tensão e carga aproximadamente iguais a $24 \mathrm{kV}$ e $35 \mathrm{mAs}$, respectivamente. Para espessuras maiores que $7 \mathrm{~cm}$ utiliza-se $33 \mathrm{kV}$ e $150 \mathrm{mAs}^{18}$.

\subsection{DOSIMETRIA EM MAMOGRAFIA}

\subsubsection{Conceitos básicos}

\section{A - Fluência}

A fluência, $\phi$, é a razão de $d N$ por $d a$, onde $d N$ é o número de partículas incidentes sobre uma esfera de área transversal $d a$, então ${ }^{30}$ :

$$
\phi=\frac{d N}{d a} \quad\left[\mathrm{~m}^{-2}\right]
$$

A unidade de fluência no SI é expressa em $\mathrm{m}^{-2}$. 
B - Fluência de energia, $\psi$

A fluência de energia, $\psi$, é a razão de $d R$ por $d a$, onde $d R$ é a energia radiante incidente sobre uma esfera de área transversal $d a$, então ${ }^{30}$ :

$$
\psi=\frac{d R}{d a} \quad\left[\mathrm{~J} \mathrm{~m}^{-2}\right]
$$

$R$ é a energia (excluindo a energia de repouso) de partículas que são emitidas, transferidas ou recebidas $^{30}$. Para partículas de energia $E$, a energia radiante, $R$, é igual a NE.

Para um feixe de fótons polienergético deve-se considerar o espectro de energias nas estimativas de fluência.

$\mathrm{C}-$ Kerma, $\mathrm{K}$

O kerma, $K$, para partículas ionizantes não carregadas, é a razão de $d E_{t r}$ por $d m$, onde $d E_{t r}$ é a soma da média das energias cinética inicial de todas as partículas carregadas liberadas em uma massa $d m$ de um material por partículas não carregadas incidentes em $d m$, então ${ }^{30}$ :

$$
K=\frac{d E_{t r}}{d m} \quad\left[\mathrm{~J} \mathrm{~kg}^{-1}\right]
$$

A unidade no SI do kerma é $\mathrm{J} \mathrm{kg}^{-1}$ que também recebe o nome especial Gray (Gy). O meio mais comum de se avaliar o kerma é o ar. Na prática o kerma no ar é estimado por meio de instrumentos chamados câmara de ionização. Nesse instrumento o kerma no ar é relacionado com a quantidade de ionizações produzidas pelo feixe ao atravessar um volume de ar.

Considerando um feixe de raios $\mathrm{X}$, o kerma no ar também pode ser calculado por meio da fluência de fótons do feixe $\mathrm{e}^{31}$ :

$$
K_{a r}=\sum_{E_{\min }}^{E_{\max }} \phi(E) E\left(\frac{\mu_{t r}(E)}{\rho}\right)_{a r} \Delta E
$$

Onde $\left(\frac{\mu_{t r}(E)}{\rho}\right)_{a r}$ são os coeficientes mássicos de transferência de energia para o ar geralmente apresentados em unidades de $\mathrm{cm}^{-1}$. 


\subsubsection{Formalismo dosimétrico}

Com a introdução da mamografia como método de detecção de neoplasias mamárias, fez-se necessário a definição de uma grandeza dosimétrica para estimar as doses recebidas na mama. Dance e colaboradores ${ }^{6}$ listam algumas grandezas propostas por alguns pesquisadores para dosimetria em mamografia, tais como dose na entrada da pele, dose no centro da mama, energia total absorvida pela mama, etc. A dose no centro da mama, dose recebida no plano localizado na metade da mama comprimida, foi a grandeza utilizada até a década de $70^{18}$. No entanto, essa grandeza não leva em consideração a variação da dose no interior da mama nem a composição do tecido mamário. Sendo assim, a dose glandular média (DGM), sugerida por Karlson e colaboradores ${ }^{32}$, passou a ser a grandeza recomendada pelo ICRP ${ }^{33}$ para dosimetria em mamografia, por estar diretamente associada ao risco de indução de câncer pela radiação. Desde então, essa grandeza passou a fazer parte da regulamentação sanitária de vários países ${ }^{34-10 ; 11}$ e é utilizada até os dias atuais.

A dose glandular média é a grandeza utilizada para dosimetria em mamografia por sua correlação com o risco de indução de câncer no tecido mamário devido aos procedimentos mamográficos, uma vez que o tecido glandular é o mais susceptível a este tipo de risco. A dose glandular média, $\bar{D}_{g}$ é definida ${ }^{35}$ como a razão entre a energia média absorvida no tecido glandular, $\left(\bar{E}_{a b s}\right)_{g}$, e a massa do tecido glandular da mama, $m_{g}$ ou seja,

$$
\bar{D}_{g}=\frac{\left(\bar{E}_{a b s}\right)_{g}}{m_{g}}
$$

A dose glandular média recebida pela mama não pode ser medida diretamente e é comum o uso de fatores de conversão que relacionam kerma no ar com essa dose ${ }^{15}$. De forma mais prática, a $\bar{D}_{g}$ pode ser determinada por meio do produto entre o kerma no ar $\left(K_{a r}\right)$ na entrada da pele e fatores de conversão que compõem dose glandular normalizada ${ }^{26 ; 36}$ $(D g N)$, ou seja:

$$
\bar{D}_{g}=K_{a r} \times D g N
$$

A dose glandular média normalizada pelo kerma no ar incidente $\left(\bar{D}_{g} / K_{a r}\right)$ é, contudo, uma grandeza de interesse prático. Essa normalização facilita a intercomparação de resultados obtidos considerando mesmas técnicas de exposição e mesma anatomia mamária. A dose glandular depende de parâmetros relacionados tanto ao espectro do feixe incidente quanto às características da mama. Com relação ao feixe incidente, os parâmetros de maior influência na dose glandular são as combinações alvo/filtro e tensão aplicada ao tubo, que são 
determinantes para a camada semirredutora do feixe. Com relação às características da mama, a consideração da composição da mama, em termos de proporções dos tecidos glandular/adiposo, e da espessura da mama comprimida também é de grande relevância.

Na prática dosimétrica, as definições de dose glandular média (equação (5)) e de dose glandular média normalizada são de difícil aplicação e, até hoje, não foram desenvolvidos métodos simples o suficiente para a medição direta dos parâmetros utilizados em seu cálculo. Por esta razão, historicamente, recorreu-se à aplicação do Método Monte Carlo para a estimativa da dose glandular média a partir de um valor mensurável, como o kerma no ar na entrada de um objeto que simule a mama. Os trabalhos de David Dance e colaboradores durante as últimas duas décadas serviram de base para esta metodologia, que vem sendo estabelecida como padrão de avaliação dosimétrica no Reino Unido ${ }^{37}$ e na União Europeia ${ }^{38}$. Além disso, esse método é também sugerido pela Agência Internacional de Energia Atômica $^{39}$. O assim chamado Método de Dance ${ }^{15}$ apresentou, em sua primeira abordagem, uma relação simples para o cálculo da dose glandular média, através do produto do kerma no ar na superfície de entrada da mama por um fator de conversão, $g$, calculado pelo Método Monte Carlo para uma mama com $50 \%$ de tecido glandular e $50 \%$ de tecido adiposo ${ }^{15}$, (50/50). Este fator também está associado a diferentes combinações anodo/filtro utilizados, na época da publicação do trabalho, pelos mamógrafos comerciais. Posteriormente, a metodologia de Dance foi revisada e outros parâmetros de correção foram introduzidos viabilizando o cálculo da dose glandular média para mamas com diferentes glandularidades e diferentes espectros de raios X. Assim, atualmente, o cálculo da dose glandular média a partir de valores de kerma no ar é modelado como ${ }^{13 ; 40}$

$$
\bar{D}_{g}=K_{a r} g c s
$$

Onde $K_{a r}$ é o valor do kerma no ar incidente na superfície de entrada da mama, medido na ausência do material equivalente à mama, $g$ é o fator de conversão entre o valor do kerma no ar e a dose glandular média para uma mama 50/50, $c$ é um fator que promove a correção para outras composições da mama ( $c$ é igual a 1 para mamas 50/50) e $s$ é o fator que compensa as diferenças no comportamento da dose em função dos diferentes espectros de raios $\mathrm{X}$ incidentes. Recentemente, Dance e colaboradores ${ }^{41}$ introduziram um fator adicional, $t$, para adequar o modelo aos sistemas que utilizam a tomossíntese. O produto dos fatores $g, c$ e $s$ representa a dose glandular normalizada, $\mathrm{DgN}$. 


\subsubsection{Modelos de mama usados para dosimetria}

Quase todas as metodologias utilizadas para estimar a dose glandular média, $\bar{D}_{g}$, empregam o método Monte Carlo para calcular os fatores de conversão que relacionam uma quantidade mensurável, geralmente o kerma no ar incidente, com a dose glandular ${ }^{22}$. Essas metodologias são baseadas em diferentes modelos geométricos simples da mama, e seus resultados são amplamente utilizados nos protocolos de dosimetria internacionais para mamografia ${ }^{10 ; 11 ; 37}$.

A Figura 4 apresenta o modelo geométrico de mama simples proposto por Dance ${ }^{40 ; 42,}$ à esquerda, cujos resultados são utilizados pelos protocolos de dosimetria em mamografia pela União Europeia (EC 2013) ${ }^{10}$, Reino Unido (IPEM 2005) ${ }^{37}$ e também no código de prática internacional de dosimetria em radiologia diagnóstica da IAEA (TRS 457) ${ }^{39}$. A Figura 4, à direita, apresenta o modelo de $\mathrm{Wu}^{14 ; 43}$, que é utilizado nos protocolos de dosimetria em mamografia dos Estados Unidos (ACR, 1999) ${ }^{11}$.

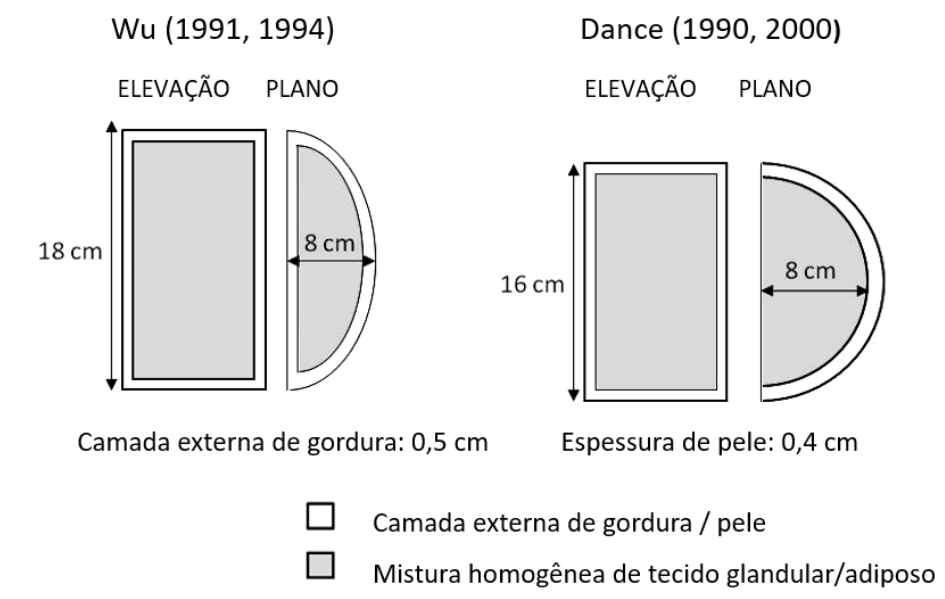

Figura 4: Modelo geométrico de mama utilizado por Dance ${ }^{40 ; 42}$, à esquerda, e $\mathrm{Wu}^{14 ; 43}$, à direita.

Os modelos geométricos apresentados na Figura 4 consideram a mama comprimida como um bloco semielíptico onde os tecidos glandular e adiposo estão misturados homogeneamente, e esta mistura está envolta por uma camada de pele, no modelo do $\mathrm{Wu}$, de 0,4 cm de espessura, ou uma camada externa de gordura, no modelo do Dance, de 0,5 cm de espessura. Os fatores de conversão calculados a partir desses modelos são tabelados para diferentes combinações alvo/filtro, camada semirredutora, espessuras de mama comprimida e glandularidade.

As simplificações e consideração inadequada dos parâmetros do modelo de cálculo têm grande impacto nas estimativas de dose glandular ${ }^{44}$. As principais limitações desses 
modelos estão relacionadas à superestimação da camada de pele, que possui espessura média $^{22}$ de aproximadamente $1,45 \mathrm{~mm}$, e à consideração do tecido glandular e adiposo como mistura homogênea. Além disso, as estimativas de glandularidade necessárias para escolher os fatores de conversão tabelados são também superestimadas ${ }^{28 ;}{ }^{45}$. Como consequência disso, estimativas de dose utilizando modelos mais complexos têm mostrado que a dose glandular é superestimada em cerca de $30 \%$ quando modelos simples são utilizados ${ }^{46}$. Esses resultados apontam para a necessidade de atualização dos métodos de cálculo de dose glandular e dos protocolos de dosimetria em mamografia.

\subsubsection{Informações de dose glandular nas imagens DICOM}

A maioria dos fabricantes de equipamentos de mamografia digitais fornecem, no cabeçalho DICOM das imagens da mama, informações de dose glandular média para cada exposição. Estes valores de dose glandular média, no entanto, são estimativas de dose para phantoms padrões específicos e não consideram características individuais do paciente ${ }^{47}$.

Existem muitos algoritmos diferentes utilizados para estimar dose glandular média nesses equipamentos. Sabe-se que esses algoritmos utilizam, na maioria dos casos, os modelos de Dance e Wu citados anteriormente ${ }^{48}$. No entanto, os fabricantes não fornecem detalhes específicos, nem deixam claro qual algoritmo é utilizado nem como a glandularidade da mama é estimada ${ }^{49}$. Desse modo, valores diferentes de dose glandular média, para uma mesma configuração de exposição, são encontrados para equipamentos produzidos por diferentes fabricantes ${ }^{49}$.

\subsubsection{Dose glandular por meio da densidade volumétrica da mama, VBD}

Uma opção para a estimativa de dose glandular individual é a utilização do software

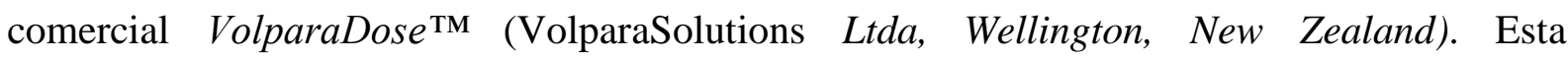
ferramenta é baseada no modelo de Dance ${ }^{40 ;} 42$ uma vez que este é amplamente utilizado e cobre a maioria dos equipamentos de mamografia ${ }^{48}$. No entanto, diferentemente do modelo de Dance, o cálculo de dose do VolparaDose considera a densidade volumétrica da mama, VBD (do inglês Volumetric Breast Density), estimada por meio da imagem radiográfica da mama, em vez da fração de massa de tecido glandular. O VDB é a porcentagem do volume de tecido glandular dentro da mama inteira e geralmente varia entre 0 e $35 \%$, enquanto a glandularidade definida por Dance é a fração de massa de tecido glandular somente na região central da 
mama e varia entre 3 e $100 \%^{22}$. Dance estabeleceu uma relação entre a glandularidade e espessura da mama comprimida para mulheres de faixa etárias entre 40-49 anos e 50-64 $\operatorname{anos}^{15}$. Assim, por exemplo, segundo o modelo de Dance, duas mulheres de mesma idade e com mesma espessura de mama comprimida supostamente teriam mamas de mesma glandularidade e, portanto, sendo irradiadas com a mesma técnica, deveriam receber a mesma dose glandular média. No entanto, isso não é necessariamente verdade e a dose glandular pode ser sub ou superestimada utilizando esta relação ${ }^{48}$..

\subsubsection{Otimização em mamografia}

A exposição da mama a feixes de radiação ionizante na mamografia oferece risco de indução de câncer, uma vez que o tecido glandular é radiossensível ${ }^{7}$. Por outro lado, o rastreamento por meio da mamografia está associado à significativa redução de mortalidade por câncer de mama, devido à sua capacidade de detectar lesões malignas precocemente ${ }^{20}$. O conceito de otimização nesse contexto, busca a melhor relação risco-benefício e requer, portanto, a minimização da dose sem comprometer a qualidade da imagem necessária para a detecção do câncer. Desse modo, o processo de otimização exige a avaliação combinada da dose e da qualidade da imagem.

\subsection{DOSIMETRIA TERMOLUMINESCENTE}

Os dosímetros termoluminescentes, TLDs, são caracterizados pela emissão de uma certa quantidade de luz, depois de expostos à radiação ionizante, causada pelo aquecimento ${ }^{50}$. Os materiais termoluminescentes são cristais com elétrons fortemente ligados à banda de valência à temperatura ambiente. Esses cristais geralmente possuem defeitos intrínsecos e extrínsecos (impurezas) que, em termos gerais, acredita-se dar origem a níveis de energia dentro da banda proibida, entre as bandas de valência e condução, e que são essenciais para o processo de termoluminescência ${ }^{51}$. Quando são expostos à radiação ionizante, os elétrons ganham energia suficiente para deixar a banda de valência, criando pares elétron-buraco. No entanto, esses elétrons podem ser armadilhados nos níveis de energia criados pelas impurezas e lá permanecerem até que uma fonte de energia externa estimule a recombinação. A estimulação desse material com calor resulta na recombinação dos elétrons e buracos aprisionados e a consequente emissão de luz ${ }^{51}$. A quantidade de luz emitida nesse processo, para determinadas faixas de energias, apresenta relação linear com a dose na qual os cristais 
foram irradiados. Conhecendo bem esta relação, a dosimetria de radiação com materiais TL pode então ser realizada.

\subsubsection{Algumas aplicações de dosímetros TL em Mamografia}

O uso de materiais termoluminescentes para dosimetria das radiações já é bem estabelecido. Em mamografia, diversos protocolos de controle e garantia de qualidade utilizam dosímetros TLs em testes recomendados para a dosimetria ${ }^{52}$. Para esse tipo de aplicação, a dose na entrada da pele é estimada com uso desses dosimetros posicionados na superfície de phantoms e a dose glandular média (DGM) é calculada a partir desse valor por aplicações de fatores de conversão ${ }^{14 ; 15 ; 16}$. O código de prática da IAEA para dosimetria em radiologia, TRS $457^{39}$, descreve detalhadamente o processo da estimação de DGM utilizando dosímetros TL.

Os dosimetros TL também são utilizados para o estudo de doses relativas e doses em profundidade de phantoms de tecido equivalente à mama ${ }^{16 ; 53 ; 54}$. Para essa aplicação, deve-se considerar a variação da sensibilidade do material dosimétrico com a qualidade do feixe. Os valores de camada semirredutora aumentam com a espessura do phantom devido à grande atenuação dos fótons de baixa energia e, portanto, os dados devem ser corrigidos para este efeito $^{54}$.

\subsection{ESPECTROMETRIA DE RAIOS X EM MAMOGRAFIA}

\subsubsection{Determinação experimental de espectros de raios X}

Espectros de raios X são distribuições de quantidade de fótons em função da energia e representam a mais completa informação sobre um feixe de radiação $\mathrm{X}^{55}$. Eles determinam a quantidade de energia dos fótons detectados por um sistema de detecção que geralmente utiliza-se de um detector de estado sólido, permitindo assim, a estimativa de grandezas derivadas geralmente utilizadas em controle de qualidade e na avaliação de dose no paciente, tais como tensão aplicada ao tubo, camada semirredutora $(\mathrm{CSR})^{56}$, kerma no ar, energia média, entre outras. Apesar disso, a espectrometria de raios $\mathrm{X}$ em mamografia não é uma prática usual devido à complexidade instrumental envolvida neste experimento.

A medição de espectros de raios $X$ em equipamentos clínicos de mamografia é um experimento complexo devido à alta intensidade dos feixes produzidos pelos tubos de raios $\mathrm{X}$ desses equipamentos ${ }^{57-58 ; 59 ; 60}$. A geometria do mamógrafo é também uma limitação, uma vez 
que a distância entre o ponto focal do tubo e o suporte da mama é relativamente pequena e fixa (da ordem de $65 \mathrm{~cm}$ ) impossibilitando o posicionamento do detector afastado da fonte para evitar as altas taxas de fluência de fótons. Portanto, a maneira mais comum de obter espectros de raios $\mathrm{X}$ de mamografia é pelo uso de modelos matemáticos ${ }^{61-62 ; 63}$. Também são encontrados, na literatura, pesquisadores que utilizam métodos indiretos para obter representações destes espectros, como por exemplo, a reconstrução do espectro primário por meio de espectros espalhados medidos ${ }^{64-65 ; 66 ; 67}$ e medições de espectros de raios X gerados por tubo não clínico com anodo de tungstênio ${ }^{68}$. No entanto, o método mais realístico para a obtenção dos espectros usados na mamografia é a medição direta em um equipamento clínico.

Devido à curta distância entre o ponto focal do tubo e o detector de imagens, espectrômetros portáteis que operam à temperatura ambiente são os mais apropriados para medições de espectros em mamografia. Alguns pesquisadores já usaram esse tipo de equipamento com detectores de CdZnTe ${ }^{58 ; 59 ; 69}$ e CdTe $^{70 ; 71}$ para medições de espectros em mamografia.

Matsumoto e colaboradores ${ }^{58}$ usaram um detector de CdZnTe com um colimador de $\mathrm{W}$ de $35 \mu \mathrm{m}$ de diâmetro para medir espectros de raios $\mathrm{X}$ de um mamógrafo gerados com 25$32 \mathrm{kV}$ usando as combinações de anodo filtro $\mathrm{Mo} / \mathrm{Mo}$ e $\mathrm{Mo} / \mathrm{Rh}$. Miyajima e colaboradores ${ }^{59}$ usaram este mesmo tipo de detector para medir espectros em unidades de mamografia e radiodiagnostico. No entanto, este trabalho concentrou-se no método de alinhamento e poucos espectros em termos de contagens relativas foram apresentados. Abbene e colaboradores ${ }^{70}$ usaram um detector de CdTe com um colimador de $\mathrm{W}$ de $100 \mu \mathrm{m}$ de diâmetro para medir espectros diretos em um equipamento de mamografia com anodo de Mo. O propósito deste trabalho foi a caracterização do sistema de detecção para alta taxa de fluência de fótons. Zhang e colaboradores ${ }^{71}$ também usaram CdTe para medições de espectros em mamografia, mas eles modificaram as configurações originais do tubo e reduziram a corrente anódica (mA). Apesar destas aplicações de detectores portáteis em mamografia, ainda não havia na literatura um método prático que permitisse o alinhamento do detector com o eixo central do feixe e medições de espectros de mamografia mantendo as configurações originais do equipamento clínico. A primeira proposta de um método prático para as medições desses espectros foi, no entanto, apresentada por Santos et. al $(2017)^{72}$. 
2.6.2 Modelos computacionais para a geração de espectros

Diante da complexidade de um estudo experimental de espectros de raios $\mathrm{X}$ de mamografia, a simulação utilizando recursos computacionais é um instrumento usualmente utilizado por pesquisadores para estudo dos espectros e os fenômenos relacionados à interação da radiação com o meio. Um modelo para geração de espectros de mamografia bem conhecido por pesquisadores da área foi proposto por Boone e colaboradores em $1997^{61}$. Estes pesquisadores propuseram um modelo polinomial que gera espectros para os anodos de Mo, Rh e W. Estes modelos são denominados pelos autores como MASMIP (para alvo de Mo), RASMIP (para alvo de Rh) e TASMIP (para alvo de W) e permitem ao usuário o uso de uma grande variedade de filtração nos espectros. Recentemente Hernandez e Boone ${ }^{73}$ propuseram um novo modelo para geração de espectros de W (denominado TASMICS) baseado na interpolação por spline cúbica de dados de espectros gerados pelo método Monte Carlo. Estes modelos serviram como referência para a comparação dos espectros experimentais medidos no presente trabalho*. A Tabela 1 apresenta as principais características desses modelos.

Tabela 1: Principais características dos modelos de Boone e colaboradores (1997) e Hernandez e Boone (2014) para a gerações de espectros de mamografia.

\begin{tabular}{|c|c|c|}
\hline & Boone e colaboradores (1997) & Hernandez e Boone (2014) \\
\hline Modelo & $\begin{array}{l}\text { Baseado em interpolação linear de } \\
\text { espectros medidos. }\end{array}$ & $\begin{array}{l}\text { Baseado em interpolação por spline } \\
\text { cubica em espectros gerados por } \\
\text { modelo de Monte Carlo }\end{array}$ \\
\hline Anodo & W, Rh, Mo & $\mathrm{W}$ \\
\hline Janela de Be & $0,5 \mathrm{~mm}$ & $0,8 \mathrm{~mm}$ \\
\hline Tensão & $18-40 \mathrm{kV}$ & $20-640 \mathrm{kV}$ \\
\hline Kerma no ar & Dado de entrada pelo usuário & Dado de entrada pelo usuário \\
\hline Filtração & $\begin{array}{l}\text { Possibilita o uso de filtrações } \\
\text { comumente usadas em mamografia }\end{array}$ & $\begin{array}{l}\text { Possibilita o uso de filtrações } \\
\text { comumente usadas em mamografia }\end{array}$ \\
\hline Referência & Boone e colaboradores (1997) ${ }^{61}$ & Hernandez e Boone (2014) ${ }^{73}$ \\
\hline
\end{tabular}

*Programa cedido pelo pesquisador John M. Boone - UCDAVIS Biomedical Engineering 


\section{MATERIAIS E MÉTODOS}

Este capítulo descreve os materiais e métodos utilizados para a realização deste trabalho. O uso de equipamentos de mamografia foi fundamental para a execução dos métodos propostos e, para isso, este trabalho contou com importantes colaborações de laboratórios e hospitais que permitiram o uso de seus equipamentos de mamografia para o desenvolvimento de parte desta pesquisa. Este projeto foi realizado em parceria com o Instituto do Câncer do Estado de São Paulo (ICESP) e com o Instituto de Radiologia do Hospital das Clínicas da Faculdade de Medicina da USP (InRaD), com devida aprovação em seu Comitê de Ética em pesquisa (Anexo A). Essa parceria possibilitou a realização de experimentos em equipamentos de mamografia de uso em rotinas clínicas, a saber: um equipamento Selenia (Hologic Inc., Marlborough, USA), no ICESP, e um equipamento Selenia Dimensions (Hologic Inc., Marlborough, USA), no InRaD. O projeto possui, nessas instituições, o protocolo de pesquisa $n^{\circ}$ 389/14 intitulado: "DETERMINAÇÃO EXPERIMENTAL DA DISTRIBUIÇÃO DA DOSE GLANDULAR MÉDIA EM DIFERENTES QUALIDADES DE FEIXES MAMOGRÁFICOS” fornecido pelo Departamento de RADIOLOGIA E ONCOLOGIA.

Este projeto também contou com a colaboração do Laboratório de Radioproteção Aplicado à Mamografia (LARAM) do Centro de Desenvolvimento da Tecnologia Nuclear (CDTN/CNEN) situado na Universidade Federal de Minas Gerais, UFMG, Belo Horizonte, MG. Neste laboratório foram realizadas a maior parte das medições dos espectros de raios X primários e transmitidos por materiais equivalentes a tecido mamário utilizados nesse trabalho. Os feixes de raios $\mathrm{X}$ utilizados foram gerados por um equipamento Mammomat 3000 Nova (Siemens, AG., Munich, DEU) com sistema de detecção CR. Outra colaboração importante foi realizada com o Centro de Pesquisa em Ciências e Tecnologias das Radiações (CPqCTR) da Universidade Estadual de Santa Cruz, UESC, Ilhéus BA, onde foram medidos espectros de raios $\mathrm{X}$ primários gerados por um equipamento de Mamografia digital Selenia.

\subsection{METODOLOGIA EXPERIMENTAL PARA MEDIÇÕES DE ESPECTROS DE RAIOS X EM MAMOGRAFIA}

A realização de medições de espectros de raios $\mathrm{X}$ produzidos por mamógrafos clínicos é uma tarefa complexa devido à alta fluência de fótons e limitações geométricas tais como a curta distância entre o ponto focal do tubo e o detector utilizado para medir os espectros. Tais medições requerem o uso de detectores portáteis equipados com colimadores com aberturas 
pequenas o suficiente para evitar efeitos de empilhamento de pulsos e saturação no detector. Por outro lado, o uso de colimadores com aberturas muito pequenas requer um posicionamento preciso do detector garantindo que este esteja alinhado com o eixo central do feixe.

Para atender às propostas deste trabalho, um espectrômetro portátil com detector de CdTe foi utilizado para as medições dos espectros de raios X. Um sistema de posicionamento do detector foi desenvolvido por meio de adaptação de posicionadores mecânicos. Esse sistema permite o movimento bem controlado do espectrômetro sobre o suporte de mama. Adicionalmente um dispositivo de alinhamento foi projetado para trabalhar juntamente com o posicionador. Este dispositivo, construído em acrílico, tem geometria simples permite o alinhamento rápido e preciso do detector no feixe. As seções subsequentes descrevem os materiais e métodos utilizados para posicionamento e alinhamento do espectrômetro e as medições de espectros de raios $\mathrm{X}$ em equipamentos de mamografia.

\subsubsection{Espectrômetro de raios $\mathrm{X}$}

Para a realização das medições de espectros de raios $\mathrm{X}$ em equipamentos clínicos de mamografia foi utilizado um espectrômetro portátil modelo XR-100T (Amptek, Inc., Bedford, MA, USA). Este dispositivo possui um detector de telureto de cádmio (CdTe) de $9 \mathrm{~mm}^{2}$ de área, com espessura nominal de $1 \mathrm{~mm}$ localizado atrás de uma janela de berílio de $100 \mu \mathrm{m}$. Os dados coletados no detector foram tratados por um processador digital de pulso modelo PX4, do mesmo fabricante. As configurações gerais de aquisição de dados, a visualização dos dados coletados e análises preliminares foram realizadas através do software ADMCA (Amptek Inc., Bedford, MA, USA).

Colimadores compostos por uma liga metálica $(90 \% \mathrm{~W}, 6 \% \mathrm{Ni}, 4 \% \mathrm{Cu})$ foram utilizados para limitar a taxa de fluência de fótons incidentes no detector e evitar os efeitos de bordas do detector. Esses colimadores são fabricados pela Amptek (EXVC colimator kit), possuem forma de disco com aproximadamente $1,6 \mathrm{~cm}$ de diâmetro, espessuras de $1 \mathrm{~mm}$ e orifícios centrais de 25 a $100 \mu \mathrm{m}$.

\subsubsection{Posicionamento e alinhamento do espectrômetro}

O sistema de posicionamento foi montado por adaptação mecânica de três posicionadores mecânicos (Optron, Campinas, Brasil): Um minigoniômetro e dois 
transladores verticais. O sistema foi montado sobre uma base retangular a fim de garantir espaço para os conectores dos cabos usados no espectrômetro entre a base desse dispositivo e o suporte de mama. Os dois transladores verticais foram montados sobre a base com os sentidos de movimento perpendiculares entre si. Isso garante movimento no plano $x-y$ com ajuste fino de $1 \mathrm{~mm}$. O minigoniômetro foi montado verticalmente sobre os transladores verticais. Isso permite variação angular em relação ao eixo vertical com deslocamento mínimo de $0,1^{\circ}$. Finalmente, o espectrômetro é fixado na base do minigoniômetro.

Um dispositivo de alinhamento (DA) do detector foi desenvolvido para trabalhar em conjunto com o sistema de posicionamento. Esse dispositivo foi construído com PMMA e possui as mesmas dimensões básicas do espectrômetro. Isso permite que este dispositivo seja facilmente substituído pelo espectrômetro no sistema de posicionamento. A Figura 5 apresenta o sistema de posicionamento do espectrômetro, à esquerda, e o dispositivo de alinhamento, à direita, utilizados para medições de feixes clínicos de mamografia.

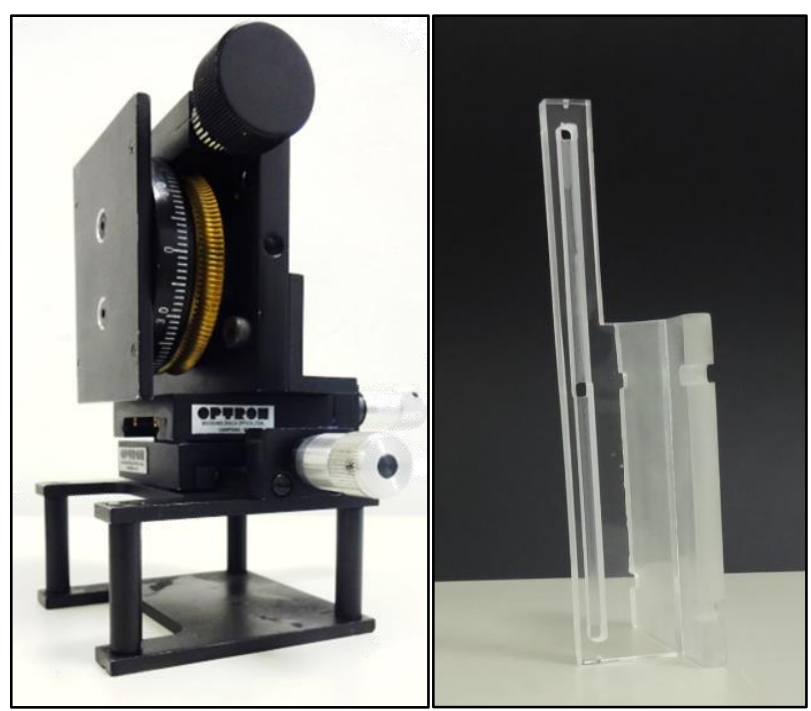

Figura 5: Sistema de posicionamento do espectrômetro portátil (à esquerda) para medições de espectros de raios $\mathrm{X}$ aparelhos de mamografia. $\mathrm{O}$ sistema foi montando a partir de posicionadores mecânicos (Optron, ltda, Campinas, Brasil.). Dispositivo de alinhamento do espectrômetro feito em PMMA (à direita).

O dispositivo de alinhamento possui duas esferas de tungstênio de $1 \mathrm{~mm}$ de diâmetro em suas extremidades. Esse dispositivo foi projetado e construído de forma que as esferas de tungstênio fiquem alinhadas com o detector, ou seja, as esferas foram geometricamente posicionadas sobre a linha imaginária que cruza o centro do detector de $\mathrm{CdTe}$, quando ambos dispositivos são montados sobre uma mesma base. A Figura 6 apresenta o esquema da geometria do dispositivo de alinhamento em comparação com o espectrômetro. 


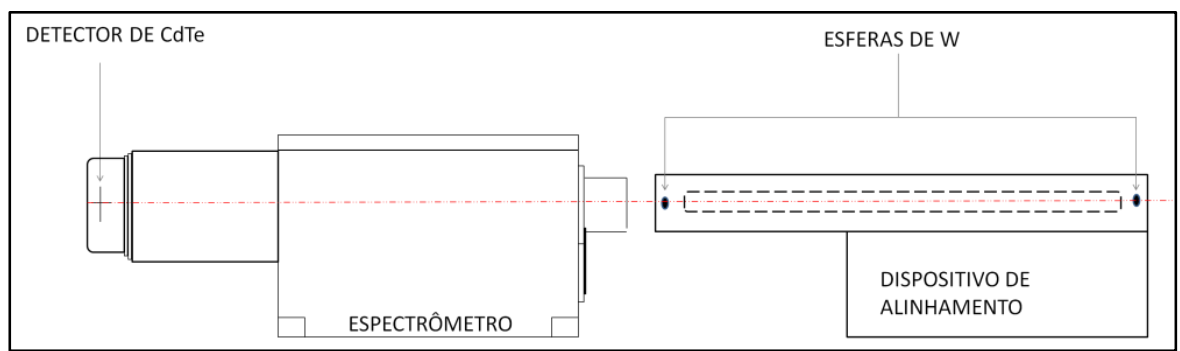

Figura 6: Esquema da geometria do espectrômetro (baseado em Amptek inc.) e do dispositivo de alinhamento. As dimensões não estão em escala.

O procedimento de alinhamento consiste em fazer imagens radiográficas do dispositivo apresentado na Figura 6, montado sobre o sistema de posicionamento. O conjunto é disposto sobre o suporte de mama numa posição aproximada àquela na qual se deseja posicionar o espectrômetro. A imagem radiográfica é adquirida utilizando o sistema de aquisição de imagens do próprio mamógrafo. Se as esferas aparecem sobrepostas nesta imagem, significa que elas estão alinhadas com o feixe, caso contrário, o dispositivo está desalinhado e ajustes de posição devem ser realizados utilizando os graus de liberdade mecânicos permitidos pelo sistema de posicionamento. Sucessivos ajustes de posição e aquisições de imagens devem ser realizados quantas vezes forem necessárias até que as esferas apareçam sobrepostas na imagem. Estando este dispositivo alinhado com o feixe, a base do dispositivo de posicionamento deve ser fixada ao suporte de mama utilizando fita adesiva e o dispositivo de alinhamento deve ser cuidadosamente substituído pelo espectrômetro. Assim, as medições de espectros de raios $\mathrm{X}$ podem então ser realizadas.

A Figura 7 apresenta o dispositivo de alinhamento, à esquerda, e o espectrômetro com detector de $\mathrm{CdTe}$, à direita, colocados sobre o sistema de posicionamento.

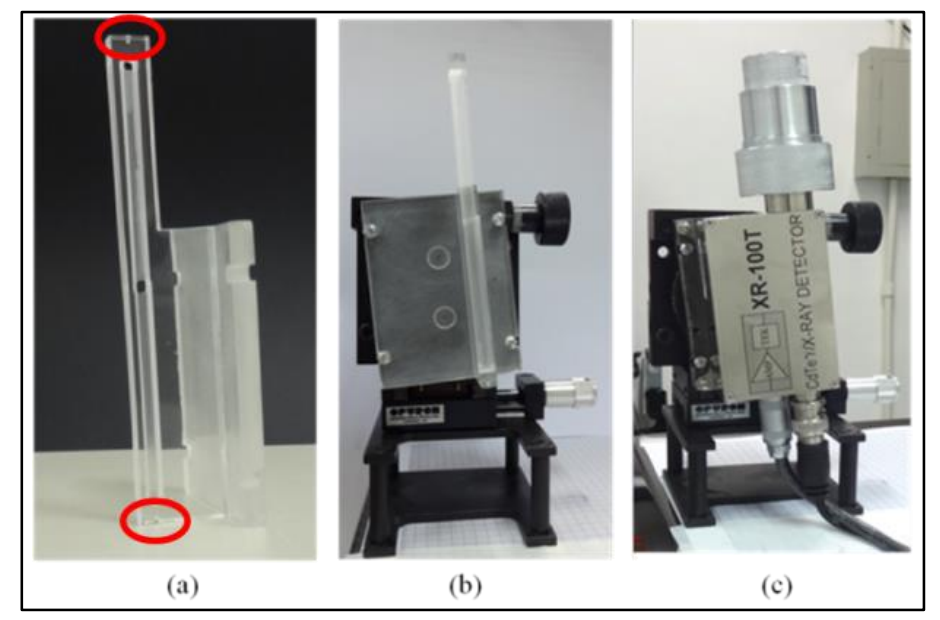

Figura 7: (a) Dispositivo de alinhamento com as esferas de tungstênio destacadas com um círculo vermelho; (b) dispositivo de alinhamento e, (c), espectrômetro com detector de CdTe, posicionados sobre o sistema de posicionamento. 
Os dispositivos apresentados na Figura 7 estão alinhados com o campo a $5 \mathrm{~cm}$ da extremidade do suporte de mama de um equipamento de mamografia. A inclinação nesses dispositivos depois de alinhados ocorre devido à inclinação do tubo de raios $\mathrm{X}$ e a divergência do feixe. A Figura 8-a apresenta uma imagem radiográfica do dispositivo de alinhamento num campo de $15 \mathrm{~cm}$ x $15 \mathrm{~cm}$. A Figura 8-b apresenta a ampliação de uma imagem na qual foram observadas as esferas desalinhadas e a Figura 8-c apresenta a ampliação de uma imagem na qual foram observadas as esferas alinhadas.

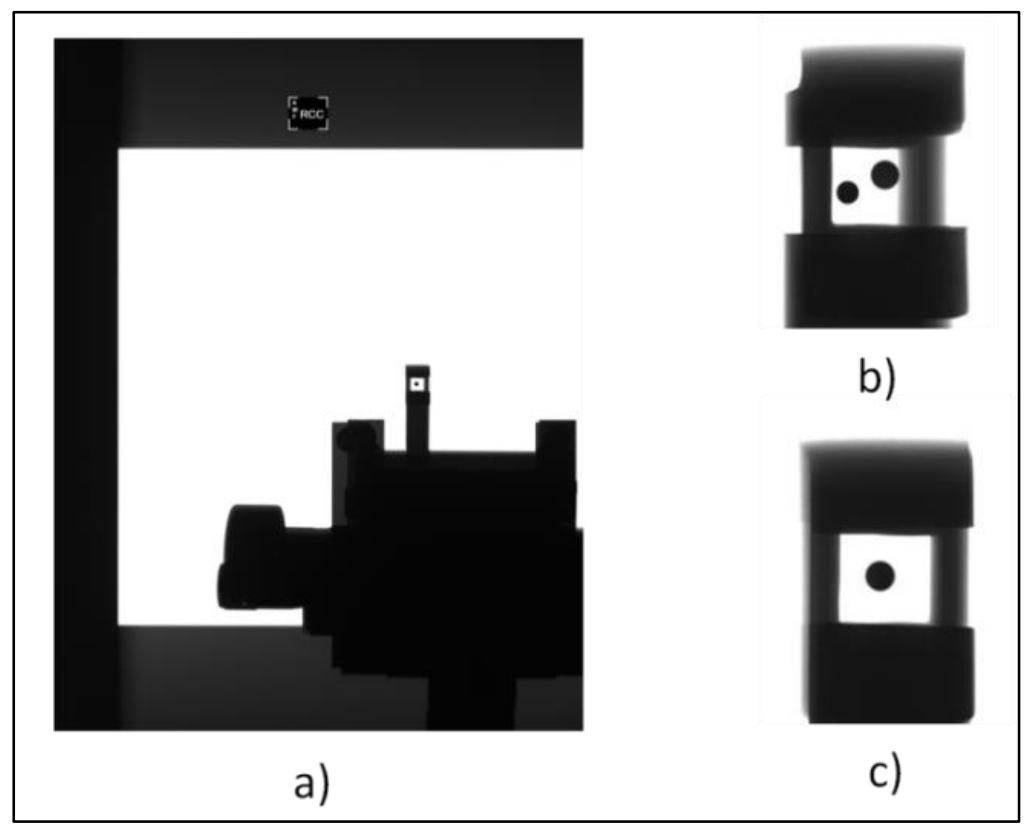

Figura 8: Imagens radiográficas do dispositivo de alinhamento. Imagem completa do dispositivo num campo de $15 \mathrm{~cm}$ x $15 \mathrm{~cm}$ (a), zoom da região de uma imagem onde foram observadas as esferas desalinhadas (b) e alinhadas (c).

O sistema desenvolvido para posicionamento e alinhamento mostrou-se eficiente, prático e de fácil utilização. $\mathrm{O}$ uso desses dispositivos permitiu rápido alinhamento do detector e medições de uma quantidade significativa de espectros de raios $\mathrm{X}$ em equipamentos de mamografia. Para se ter noção do tempo gasto com esse procedimento, para medir espectros primários em um equipamento de rotina clínica, foram necessários, aproximadamente, 15 minutos para montar o experimento, 20 minutos para o alinhamento, 30 minutos para medir 12 espectros primários utilizando duas combinações alvo/filtro, além de 15 min para desmontar o aparato, totalizando 1 hora e 20 minutos. O tempo necessário para a realização de um experimento em um mamógrafo de uso clínico deve ser otimizado por conta da limitação de tempo para esse tipo de atividade, geralmente encontrada nos serviços de mamografia, devido à alta demanda de pacientes. 
3.1.3 Análise do efeito do desalinhamento do espectrômetro nos espectros medidos

Um experimento foi realizado para estudar a influência do posicionamento do espectrômetro nos espectros de raios $\mathrm{X}$ medidos em um equipamento de mamografia. Uma avaliação quantitativa da intensidade e forma dos espectros foi realizada por meio da análise da fluência total de fótons medidos e valores de camada semirredutora, respectivamente. $\mathrm{O}$ método de alinhamento apresentado na seção anterior foi utilizado para medir espectros produzidos por um equipamento de mamografia modelo Selenia Dimensions (Hologic, Marlborough, MA, USA). O diagrama apresentado na Figura 9 apresenta o espectrômetro depois de alinhado no feixe de radiação. O sistema foi considerado alinhado quando a inclinação do espectrômetro com relação a um eixo $z$ de referência (vertical) era de $4,3^{\circ}$.

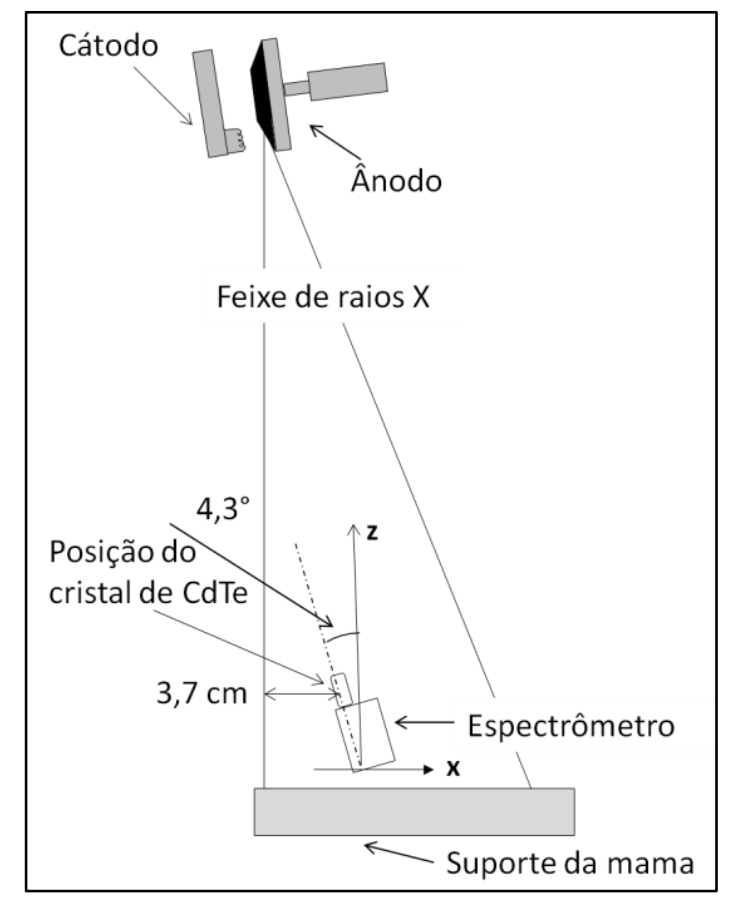

Figura 9: Posição do espectrômetro alinhado á $4,3^{\circ}$ de acordo com o sistema de referência adotado (eixo z na figura).

Depois de alinhado, o espectrômetro passou por um processo de desalinhamento controlado e espectros de raios $\mathrm{X}$ foram medidos para cada posição de desalinhamento. Um conjunto de 8 espectros foi medido com o espectrômetro em posições escolhidas com inclinação entre $2,9^{\circ}$ e $5,4^{\circ}$, com relação ao eixo vertical $z$ mostrado na Figura 9. A Figura 10 apresenta recortes das imagens radiográficas (imagens tal como a Figura 8-a) do dispositivo de alinhamento com destaque nas regiões das esferas de tungstênio. Essas imagens foram obtidas para cada uma das posições do espectrômetro avaliadas nesse estudo. O recorte com destaque em amarelo mostra a posição de melhor alinhamento $\left(\mathrm{a} 4,3^{\circ}\right)$. 


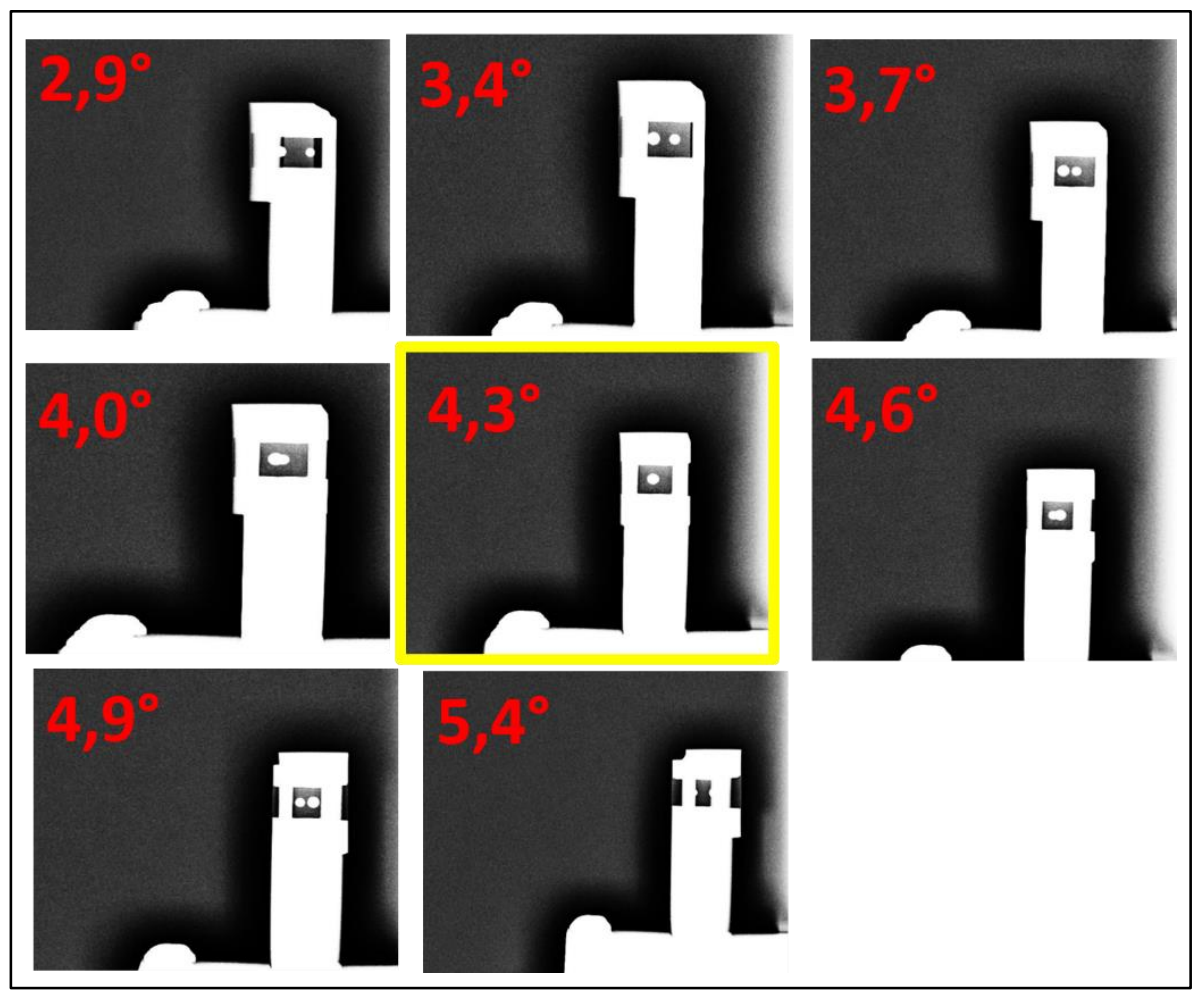

Figura 10: Imagens radiográficas do dispositivo de alinhamento obtidas para cada posição do espectrômetro avaliada (de $2,9^{\circ}$ a $\left.5,4^{\circ}\right)$.

Todos estes os feixes foram gerados com mesma técnica de exposição (usando a combinação W/Rh, $28 \mathrm{kV}$ e $120 \mathrm{mAs}$ ) e medidos com a acumulação de contagens de 3 irradiações sequenciais. Utilizou-se o ponto focal pequeno $(0,1 \mathrm{~mm})$, um campo de tamanho $7 \times 8,5 \mathrm{~cm}^{2}$ e bandeja de compressão acoplada ao equipamento. A colimação do detector de CdTe foi feita utilizando um colimador com $50 \mu \mathrm{m}$ de abertura e espessura de $1 \mathrm{~mm}$. A camada semirredutora e a intensidade do feixe foi avaliada para cada espectro medido com o espectrômetro nas posições indicadas na Figura 10.

\subsubsection{Analise da influência de contribuição de espalhamento nos espectros medidos}

Um conjunto de espectros de raios $\mathrm{X}$ tipicamente utilizados em mamografia foi medido para avaliar a influência de contribuições de espalhamento, devido ao arranjo experimental, nos espectros medidos, tanto para espectros primários quanto para espectros transmitidos. Para isto utilizou-se o sistema de espectrometria e procedimento de alinhamento descritos previamente na seção 3.1.2 e por Santos et al $(2017)^{72}$. Foram medidos espectros de raios $\mathrm{X}$ de um equipamento de mamografia (Selenia Dimensions, Hologic). Primeiro, os espectros primários foram medidos usando um colimador com $1 \mathrm{~mm}$ de espessura e $50 \mu \mathrm{m}$ de abertura cobrindo o detector de CdTe. Depois disso, outro espectro foi medido, usando a 
mesma técnica radiográfica e as mesmas configurações experimentais, com um disco de $\mathrm{W}$ de $1 \mathrm{~mm}$ de espessura substituindo o colimador. Como não há transmissão de fótons na faixa de energia de mamografia por essa espessura deste material, o espectro medido, neste caso, deve ser composto somente por fótons cuja origem é espalhamento no suporte de colimadores do espectrômetro. Para confirmar esta hipótese, um espectro foi medido usando o disco absorvedor de $\mathrm{W}$ cobrindo o detector mais uma blindagem de chumbo cobrindo toda a extensão do suporte de colimador (Figura 11) mas com abertura sobre a face do absorvedor de W. Nenhuma contagem foi registrada nesse caso.

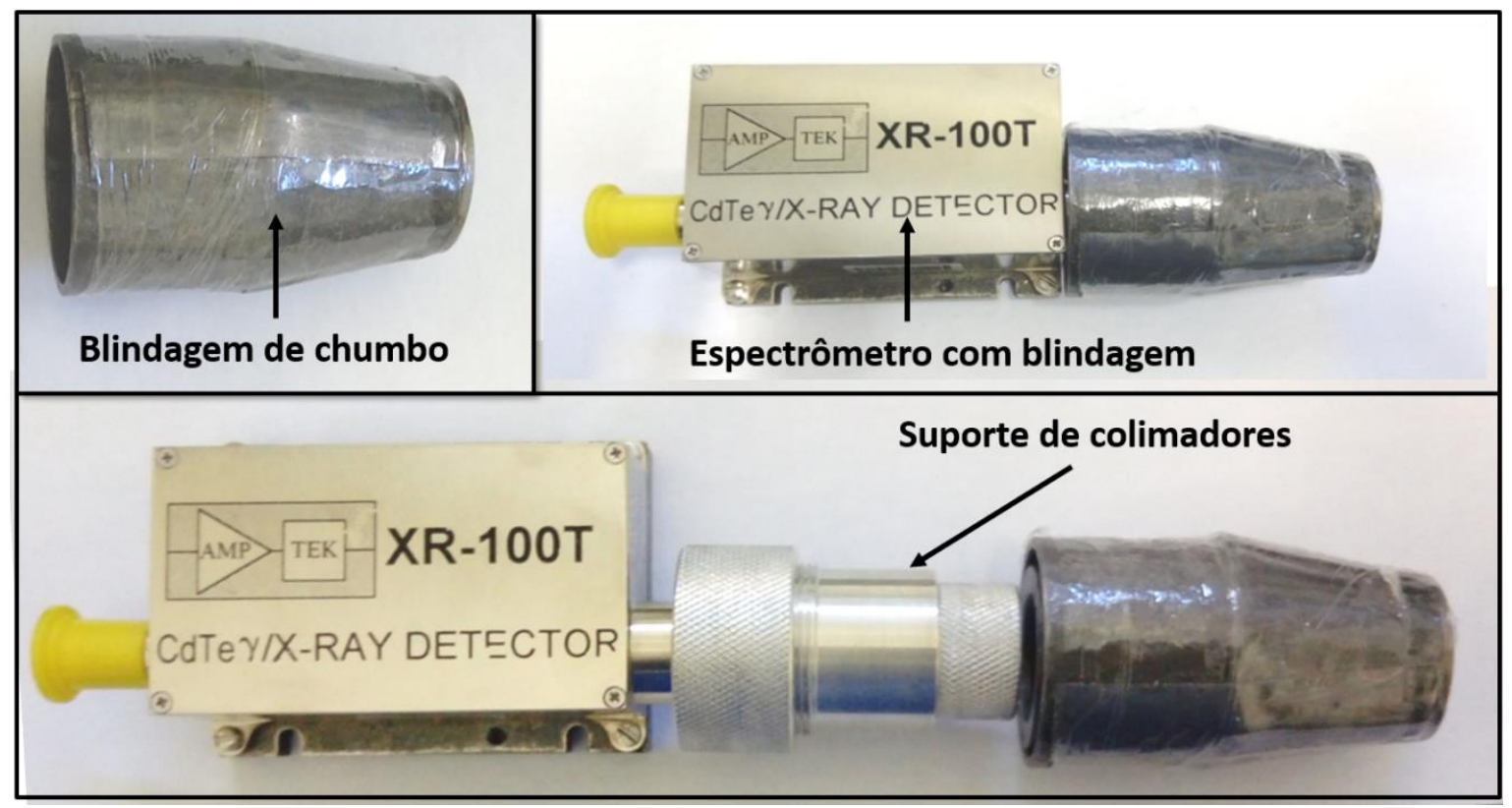

Figura 11: Blindagem de chumbo (parte superior esquerda) confeccionada para cobrir o suporte de colimador e evitar o espalhamento de fótons que podem ser detectados e deformar o espectro medido.

A Figura 12 apresenta os espectros brutos (não corrigidos) medidos para a combinação alvo/filtro W/Rh. Na figura são exibidos um espectro medido usando o colimador de W (linha preta) e um espectro medido com o absorvedor de $\mathrm{W}$ cobrindo o detector (linha vermelha), que representa o espectro de fótons espalhados que são detectados. O espectro em azul é o espectro corrigido, ou seja, é o resultado da subtração do espectro de fótons espalhados (linha vermelha) do espectro medido usando o colimador. 


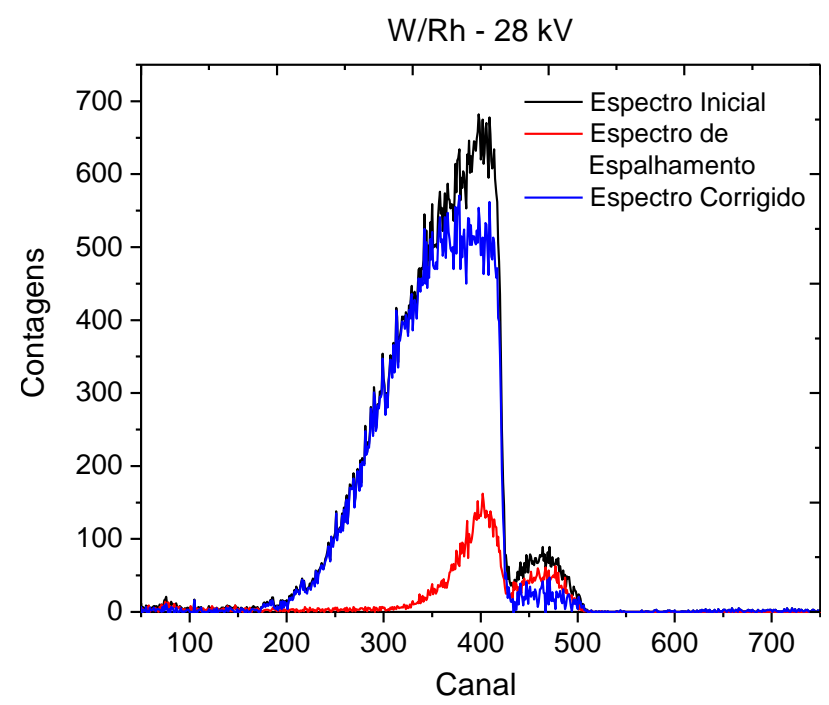

Figura 12: Espectros brutos de $\mathrm{W} / \mathrm{Rh}$ medidos usando: o colimador de $\mathrm{W}$ (linha preta) e absorvedor de $\mathrm{W}$ cobrindo o detector, espectro de espalhamento, (linha vermelha). Espectro corrigido pela subtração do espectro de espalhamento pelo espectro medido usando o colimador (linha azul).

Um espectro corrigido pelo procedimento de subtração supracitado e um espectro não corrigido foram comparados com um espectro gerado computacionalmente pelo modelo TASMICS $^{64}$. A Figura 13 apresenta um espectro experimental de W/Rh gerado no equipamento Mammomat 3000 Nova com 27 kV em unidades de fluência (linha preta), comparado com um espectro gerado pelo modelo TASMICS (linha pontilhada) com os parâmetros de simulação similares aos parâmetros experimentais. A Figura 14 apresenta uma comparação similar, mas neste caso, o espectro de fótons espalhados foi subtraído do espectro experimental.

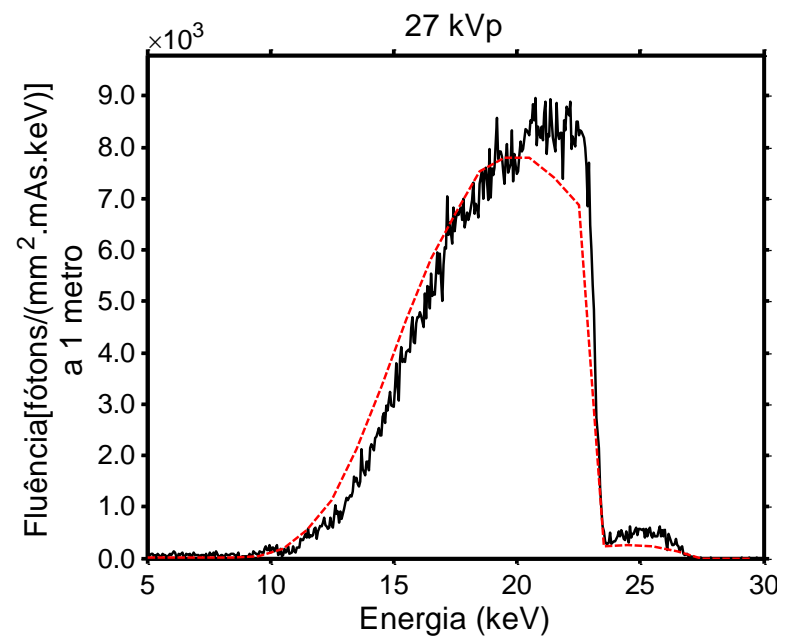

Figura 13: Espectro de $\mathrm{W} / \mathrm{Rh}, 27 \mathrm{kV}$ não corrigido (linha preta) comparado com um espectro gerado pelo modelo TASMICS (linha vermelha).

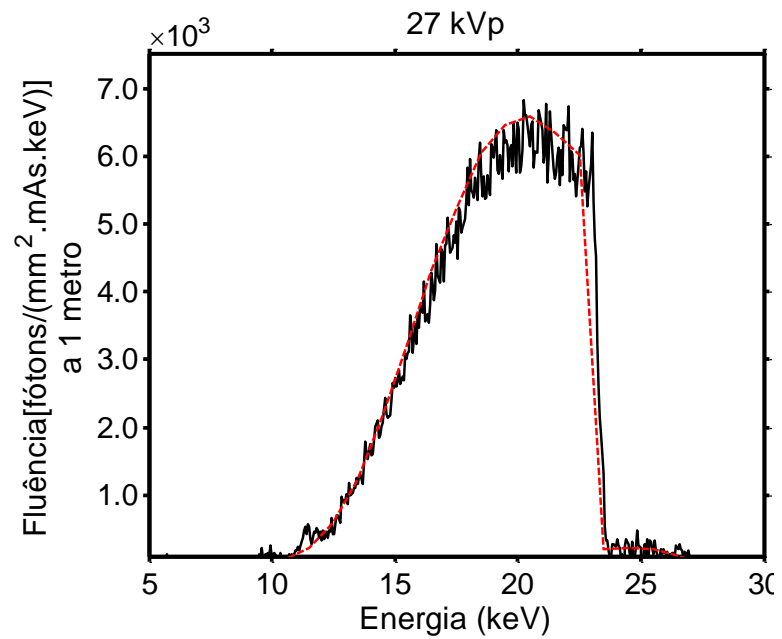

Figura 14: Espectro de $\mathrm{W} / \mathrm{Rh}, 27 \mathrm{kV}$ corrigido pela subtração de fótons espalhados (linha preta) comparado com um espectro gerado pelo modelo TASMICS (linha vermelha). 
É possível notar que no espectro experimental não corrigido (Figura 13) há uma quantidade de fótons excedentes para os valores de energias mais altos dessa distribuição. Esse excesso de fótons é causado pela detecção de fótons espalhados no suporte de colimador e outras estruturas do arranjo experimental. O espectro corrigido (Figura 14), por outro lado, apresenta melhor concordância com espectro gerado pelo modelo TASMICS, e é uma representação mais precisa do espectro de fótons gerados pelo equipamento. Essa correção é muito importante para evitar erros na estimação de grandezas derivadas dos espectros de raios $\mathrm{X}$ tais como camada semirredutora e dose absorvida.

Para avaliar a eficiência do método de correção por subtração do espectro de fótons espalhados, foram comparados espectros corrigidos por subtração com espectros medidos com a blindagem de chumbo cobrindo toda a extensão do suporte de colimador (Figura 11). A Figura 15 e a Figura 16 apresentam alguns espectros medidos no equipamento Selenia (Hologic Inc) utilizando as combinações alvo/filtro Mo/Rh e Mo/Mo, respectivamente. Em ambas figuras, o espectro em linha preta foi medido usando somente o colimador de $\mathrm{W}$, o espectro em vermelho foi medido com o disco absorvedor de W no lugar do colimador, o espectro em azul foi medido com o colimador de $\mathrm{W}$ e a blindagem de $\mathrm{Pb}$ cobrindo o suporte de colimador e, finalmente, o espectro em magenta representa a subtração do espectro de fótons espalhados (linha vermelha) do espectro medido somente com o colimador (linha preta).

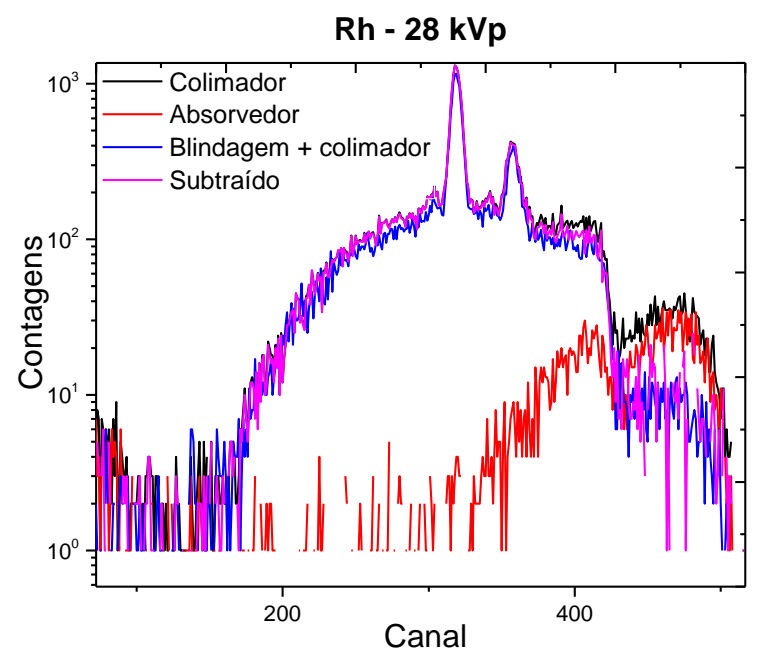

Figura 15: Espectro de Mo/Rh medidos: utilizando somente um colimador de $\mathrm{W}$ sobre o detector (linha preta); utilizando um disco absorvedor de $\mathrm{W}$ no lugar do colimador, espectro de espalhamento (linha vermelha); utilizando colimador mais a blindagem de $\mathrm{Pb}$ (linha preta); Espectro medido com o colimador com a subtração do espectro de espalhamento.

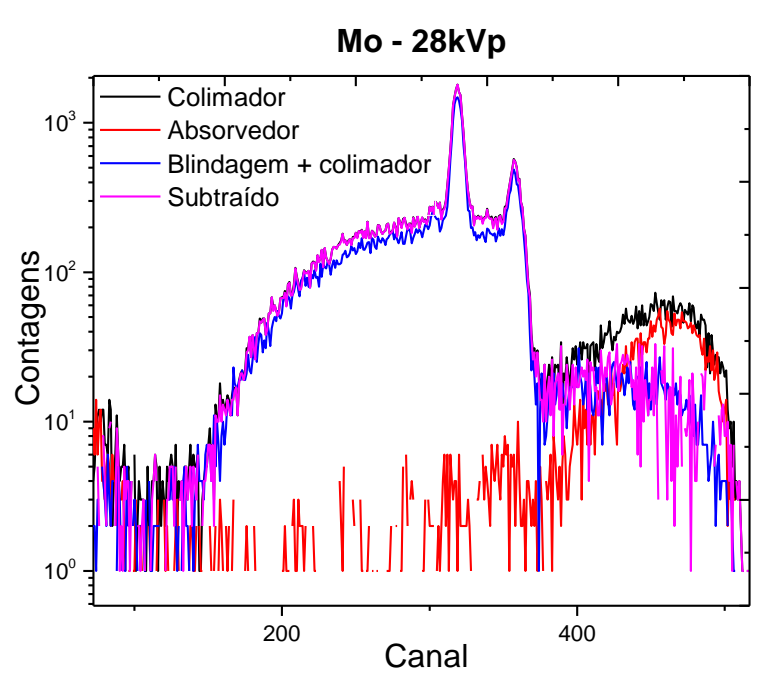

Figura 16: Espectro de Mo/Mo medidos: utilizando somente um colimador de $\mathrm{W}$ sobre o detector (linha preta); utilizando um disco absorvedor de $\mathrm{W}$ no lugar do colimador, espectro de espalhamento (linha vermelha); utilizando colimador mais a blindagem de $\mathrm{Pb}$ (linha preta); Espectro medido com o colimador com a subtração do espectro de espalhamento. 
Os resultados mostrados na Figura 15 e na Figura 16 revelam que a eliminação dos fótons resultantes de espalhamento no espectro experimental pode ser realizada de maneira prática utilizando uma blindagem sobre o meio espalhador, nesse caso, o suporte de colimador, ou pelo processo de subtração descrito.

\subsection{MEDIÇÕES DE ESPECTROS DE RAIOS $X$ EM EQUIPAMENTOS DE MAMOGRAFIA}

Espectros de raios $\mathrm{X}$ primários e transmitidos foram medidos em alguns equipamentos de mamografia. A maior parte dos espectros utilizados para avaliação de dose glandular foram medidos em equipamentos de mamografia de uso exclusivo para pesquisa: Um equipamento Selenia DR System (Hologic/Lorad Inc., Marlborough, MA, USA) e um equipamento Mammomat 3000 Nova (Siemens AG., München, DEU). Além disso, medições complementares de espectros primários e testes adicionais foram realizados em dois equipamentos de uso clínico: um equipamento Selenia DR 2D System e um Selenia Dimensions DR 3D System (Hologic/Lorad Inc., Marlborough, MA, USA). A Tabela 2 apresenta algumas especificações importantes dos equipamentos utilizados.

Tabela 2: Algumas especificações dos equipamentos de mamografia utilizados neste trabalho.

\begin{tabular}{|c|c|c|c|}
\hline & $\begin{array}{c}\text { SELENIA DIMENSIONS } \\
\text { (HOLOGIC) }\end{array}$ & SELENIA (HOLOGIC) & $\begin{array}{c}\text { MAMOMMAT } 3000 \text { NOVA } \\
\text { (SIEMENS) }\end{array}$ \\
\hline Ânodo & $\begin{array}{l}\text { Tungstênio }(\mathrm{W}) \text { - } \\
\text { biangular }\end{array}$ & Molibdênio (Mo) & $\begin{array}{l}\text { Molibdênio (Mo) } \\
\text { Tungstênio (W) }\end{array}$ \\
\hline Janela do tubo & $0,63 \mathrm{~mm}$ de $\mathrm{Be}$ & $0,8 \mathrm{~mm}$ de $\mathrm{Be}$ & $1 \mathrm{~mm}$ de $\mathrm{Be}$ \\
\hline $\begin{array}{l}\text { Espessuras de } \\
\text { filtros }\end{array}$ & 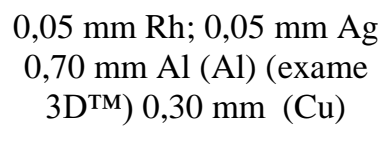 & $\begin{array}{c}0,0275 \mathrm{~mm} \mathrm{Mo} \\
0,025 \mathrm{~mm} \mathrm{Rh}\end{array}$ & $\begin{array}{c}0,03 \mathrm{~mm} \mathrm{Mo} \\
0,025 \mathrm{~mm} \mathrm{Rh}(\text { para Mo/Rh) } \\
0,05 \mathrm{~mm} \mathrm{Rh}(\text { para W/Rh) }\end{array}$ \\
\hline $\begin{array}{l}\text { Distância foco } \\
\text { - detector }\end{array}$ & $70 \mathrm{~cm}$ & $66 \mathrm{~cm}$ & $65 \mathrm{~cm}$ \\
\hline $\begin{array}{l}\text { Bandeja de } \\
\text { compressão }\end{array}$ & $3 \mathrm{~mm}$ & $\begin{array}{l}2,35 \mathrm{~mm} \text { (torre de } \\
\text { magnificação) }\end{array}$ & $1,4 \mathrm{~mm}$ \\
\hline Tensão & $\begin{array}{l}\text { 2D: } 20-39 \mathrm{kV} \\
\text { 3D: } 20-49 \mathrm{kV}\end{array}$ & $\begin{array}{l}20-35 \mathrm{kV} \text { (para } \mathrm{Mo} / \mathrm{Mo}) \\
20-39 \mathrm{kV}(\text { para } \mathrm{Mo} / \mathrm{Rh})\end{array}$ & $23-35 \mathrm{kV}$ \\
\hline Carga (mAs) & $4-500 \mathrm{mAs}$ & $\begin{array}{cl}4 \text { - } 320 \mathrm{mAs} & (\mathrm{Mo} / \mathrm{Mo}) \\
4 \text { - } 250 \mathrm{mAs} & (\mathrm{Mo} / \mathrm{Rh})\end{array}$ & $\begin{array}{l}2 \text { - } 710 \text { mAs (modo mAs) } \\
\text { Até } 752 \text { mAs (modo AEC) }\end{array}$ \\
\hline $\begin{array}{l}\text { Corrente } \\
\text { mínima }\end{array}$ & $\begin{array}{l}200 \mathrm{~mA} \text { - ponto focal } \mathrm{G} \\
50 \mathrm{~mA} \text { - Ponto focal P }\end{array}$ & $\begin{array}{l}100 \mathrm{~mA} \text { - ponto focal } \mathrm{G} \\
30 \mathrm{~mA} \text { - Ponto focal } \mathrm{P}\end{array}$ & $\begin{array}{l}\text { Mo : } 150 \mathrm{~mA} \text { ponto focal } \mathrm{G} \text {; } \\
28 \mathrm{~mA} \text { ponto focal } \mathrm{P} \\
\text { W: } 188 \mathrm{~mA}(\mathrm{G}) ; 34 \mathrm{~mA}(\mathrm{P})\end{array}$ \\
\hline Ponto focal & $0,3 \mathrm{~mm}-\mathrm{G} ; 0,1 \mathrm{~mm}-\mathrm{P}$ & $0,3 \mathrm{~mm}-\mathrm{G} ; 0,1 \mathrm{~mm}-\mathrm{P}$ & $0,3 \mathrm{~mm}-\mathrm{G} ; 0,1 \mathrm{~mm}-\mathrm{P}$ \\
\hline $\begin{array}{c}\text { Instituição de } \\
\text { origem }\end{array}$ & InRad, São Paulo & $\begin{array}{l}\text { ICESP, São Paulo } \\
\text { UESC, Ilhéus }\end{array}$ & $\begin{array}{c}\text { CDTN/CNEN, Belo } \\
\text { Horizonte }\end{array}$ \\
\hline
\end{tabular}


No equipamento Selenia, foram medidos espectros de raios $\mathrm{X}$ primários com as combinações de anodo/filtro Mo/Mo e Mo/Rh. No Mammomat 3000 Nova foram medidos espectros primários e transmitidos com as combinações Mo/Mo, Mo/Rh e W/Rh. Para cada espectro adquirido, medições de kerma no ar também foram realizadas considerando as mesmas técnicas de irradiação e posição do detector. Para isso foram utilizadas câmaras de ionização dedicada à mamografia modelo 10×5-6M (Radcal Corp., Monrovia, CA, USA) devidamente calibradas em feixes de radiação de qualidade RQR-M em um laboratório de padrão secundário (SSDL) ${ }^{39}$. A incerteza padrão combinada do kerma no ar foi estimada a partir da incerteza do fator de calibração, a incerteza da leitura do monitor e dependência energética da câmara.

Todos os espectros de raios $\mathrm{X}$ adquiridos neste trabalho foram medidos utilizando 1024 canais do MCA (Multi Chanel Analyzer), com uma dispersão em energia de aproximadamente 0,056 keV/canal e com o circuito RTD (Rise Time Descrimination) desligado. O tempo morto máximo obtido para os espectros medidos foi da ordem de $8 \%$. As seções a seguir descrevem, com mais detalhes, as medições de espectros primários e transmitidos nos equipamentos de mamografia.

\subsubsection{Medições de espectros de raios X primários}

Espectros de raios $\mathrm{X}$ primários foram medidos em 4 equipamentos de mamografia diferentes. A Figura 17 apresenta o posicionamento do espectrômetro nos equipamentos usados para as medições de espectros primários. A Figura 17 (a) apresenta o espectrômetro posicionado no equipamento Mammomat 3000 Nova. A bandeja de compressão e torre de magnificação não foram utilizadas nessas medições devido à curta distância entre o suporte de mama e o encaixe desses acessórios no mamógrafo. A Figura 17 (b) apresenta o mesmo detector no equipamento Selenia Dimensions. Nesse equipamento os espectros primários foram medidos com a bandeja de compressão acoplada. A Figura 17 (c) apresenta o mamógrafo Selenia (equipamento de pesquisa - UESC) para medições de espectros sob a torre de magnificação. Por fim, a Figura 17 (d) apresenta o mamógrafo Selenia (equipamento clínico - ICESP). Os itens que seguem apresentam descrições detalhadas das medições de espectros primários em cada equipamento citado. A bandeja de compressão foi considerada no cálculo de dose com os espectros de todos os equipamentos utilizados. Nos casos onde foi impossível incluí-la no arranjo experimental, a atenuação devido a esse dispositivo foi estimada analiticamente. 

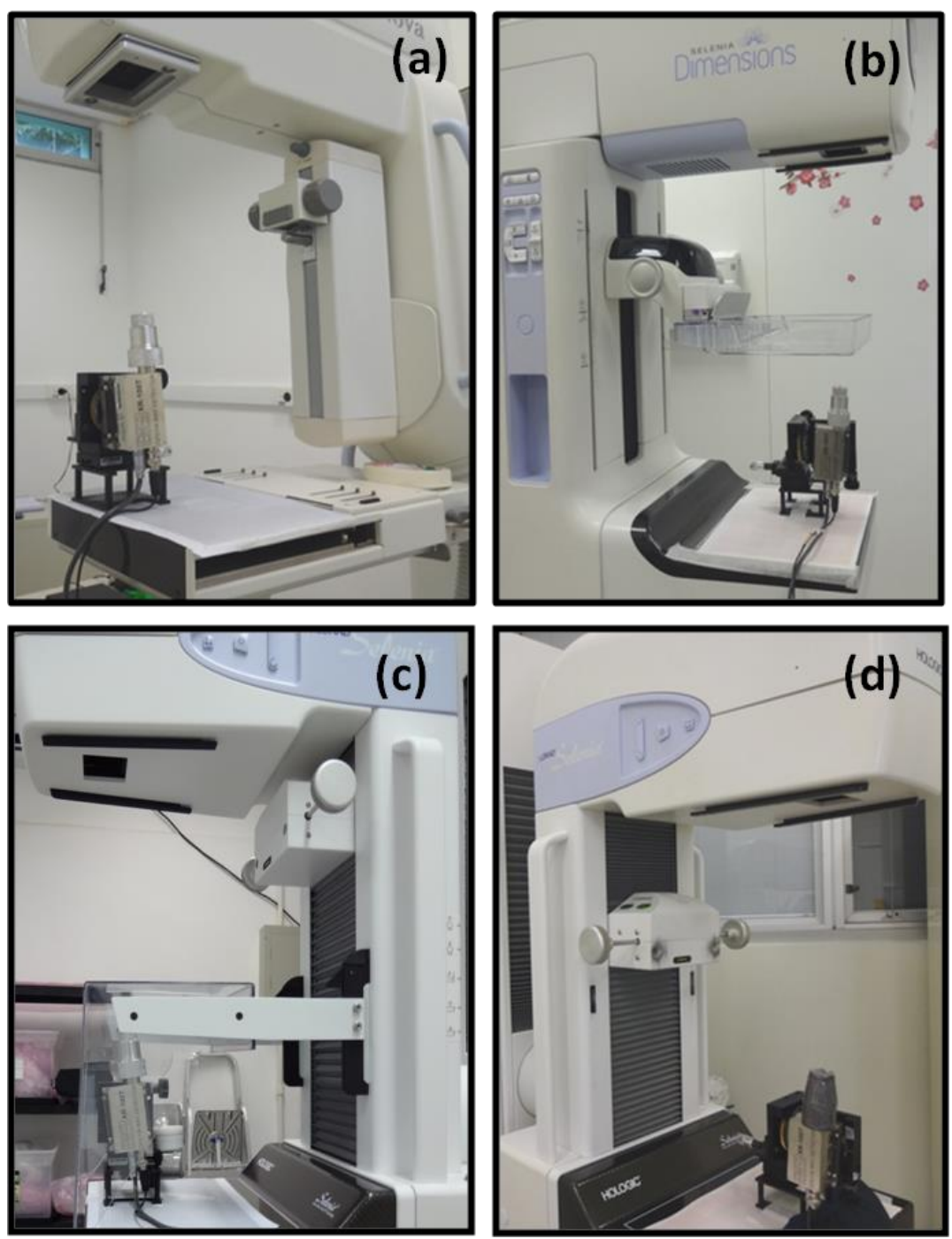

Figura 17: Posicionamento do espectrômetro para medições de espectros primários nos equipamentos de mamografia: (a), Mammomat 3000 Nova; (b), Selenia Dimensions, (c) Selenia (equipamento dedicado à pesquisa); (d) Selenia (equipamento de uso clínico ).

A. Medições realizadas no equipamento digital Selenia (Hologic) - UESC.

Medições de espectros de raios $\mathrm{X}$ primários foram realizadas no Centro de Pesquisa em Ciências e Tecnologias das Radiações (CPqCTR) da Universidade Estadual de Santa Cruz, UESC, Ilhéus BA. Foram medidos espectros de raios X primários gerados por um equipamento de Mamografia Selenia (Hologic, inc.).

Os espectros foram medidos para configurações que incluem diferentes tensões do tubo $(\mathrm{kV})$ e diferentes combinações de anodo/filtro. Foi utilizado um colimador de $\mathrm{W}$ de $50 \mu \mathrm{m}$ de diâmetro acima do detector para reduzir a taxa de contagens e tempo morto. A Tabela 3 apresenta as configurações utilizadas para as medições de espectros de raios $\mathrm{X}$ 
primários produzidos pelo equipamento de mamografia Selenia e os respectivos valores de kerma no ar medidos com a câmara de ionização.

Tabela 3: Parâmetros usados para as medições de espectros de raios $\mathrm{X}$ produzidos por um aparelho de mamografia digital Selenia e os respectivos valores de kerma no ar. A incerteza expandida nos valores de kerma no ar foi estimada em $7,6 \%(\mathrm{k}=2)$

\begin{tabular}{|c|cccc|}
\hline Equipamento & $\begin{array}{c}\text { Combinação } \\
\text { anodo/filtro }\end{array}$ & Tensão (kV) & $\begin{array}{c}\text { N. de } \\
\text { irradiações }\end{array}$ & $\begin{array}{c}\text { Kerma no ar } \\
(\mathbf{m G y}) \text { - 1 metro }\end{array}$ \\
\hline \multirow{3}{*}{ SELENIA } & \multirow{3}{*}{ Mo/Mo } & 25 & 2 & 5,3 \\
(UESC) & & 26 & 2 & 6,2 \\
& & 28 & 2 & 7,0 \\
& \multirow{3}{*}{ Mo/Rh } & 25 & 1 & 4,0 \\
& & 26 & 2 & 3,5 \\
& & 27 & 2 & 4,1 \\
& & 28 & 1 & 4,7 \\
\hline
\end{tabular}

Todos os espectros foram medidos com carga de 100 mAs e com o detector posicionado a aproximadamente $20,5 \mathrm{~cm}$ acima do suporte de mama. Para evitar ruído estatístico devido ao baixo número de contagens, alguns espectros foram medidos com mais de uma exposição. A carga total (mAs) utilizada foi calculada levando em consideração a quantidade de exposições do detector ao feixe.

Os espectros foram medidos utilizando foco fino. O espectrômetro foi posicionado abaixo da torre de magnificação. Nesse caso, mesmo no modo manual, o equipamento seleciona automaticamente as correntes de $30 \mathrm{~mA}(25-32 \mathrm{kV})$ e $28 \mathrm{~mA}(33-34 \mathrm{kV})$. Esses são os valores mínimos de corrente que se pode obter nesse intervalo de valores de tensão no tubo. Como o fluxo de fótons que chega ao detector é proporcional à corrente usada, correntes baixas são desejadas para evitar altas taxas de contagens. Com a torre de magnificação conectada ao mamógrafo esses valores de correntes são selecionados automaticamente neste equipamento.

\section{B. Medições realizadas no equipamento Mammomat 3000 Nova-CDTN/CNEN}

Medições de espectros de raios $\mathrm{X}$ primários e transmitidos foram realizadas no Laboratório de Radioproteção Aplicado à Mamografia (LARAM) do Centro de Desenvolvimento da Tecnologia Nuclear (CDTN/CNEN) situado na Universidade Federal de Minas Gerais, UFMG, Belo Horizonte, MG. Nesta subseção serão descritos os procedimentos somente para as medições dos espectros de raios $\mathrm{X}$ primários gerados pelo equipamento digital CR Mammomat 3000 Nova. 
Os espectros primários foram medidos utilizando o colimador de $25 \mu \mathrm{m}$ acoplado ao espectrômetro. O número total de irradiações do detector para a medição de cada espectro é apresentado na Tabela 4. Cada irradiação foi realizada utilizando carga de 100 mAs.

Tabela 4: Espectros de raios X produzidos pelo equipamento Mammomat 3000 Nova e valores correspondentes de kerma no ar para cada espectro com incerteza expandida estimada de 7,1\% considerando $\mathrm{k}=2$.

\begin{tabular}{|c|c|c|c|c|}
\hline Equipamento & $\begin{array}{l}\text { Combinação } \\
\text { anodo/filtro }\end{array}$ & Tensão (kV) & $\begin{array}{c}\text { N. de } \\
\text { irradiações }\end{array}$ & $\begin{array}{c}\text { Kerma no ar } \\
(\mathrm{mGy})-1 \text { metro }\end{array}$ \\
\hline \multirow{12}{*}{$\begin{array}{l}\text { MAMMOMAT } \\
3000 \text { NOVA }\end{array}$} & \multirow{4}{*}{ Mo/Mo } & 25 & 5 & 16,5 \\
\hline & & 26 & 6 & 22,5 \\
\hline & & 27 & 5 & 21,1 \\
\hline & & 28 & 5 & 23,6 \\
\hline & \multirow{4}{*}{ Mo/Rh } & 25 & 5 & 14,0 \\
\hline & & 26 & 7 & 22,4 \\
\hline & & 27 & 7 & 25,6 \\
\hline & & 28 & 5 & 20,5 \\
\hline & \multirow{4}{*}{ W/Rh } & 25 & 7 & 7,6 \\
\hline & & 26 & 10 & 12,2 \\
\hline & & 27 & 15 & 20,4 \\
\hline & & 28 & 12 & 19,5 \\
\hline
\end{tabular}

\section{Medições complementares - Equipamentos clínicos}

Medições complementares de espectros primários foram realizadas em equipamentos de uso clínico em hospitais São Paulo. Os espectros foram medidos em um equipamento Selenia (Hologic) do Instituto do Cancêr do Estado de São Paulo (ICESP) e um equipamento Selenia Dimensions (Hologic) do Instituto de Radiologia do Hospital das Clínicas da Faculdade de Medicina da Universidade de São Paulo - InRad - HCFMUSP.

Todos os espectros foram medidos com colimador de $25 \mu \mathrm{m}$ de diâmetro delimitando a área sensível do detector e tamanho de campo de utilizado foi de $7 \mathrm{~cm} \times 8,5 \mathrm{~cm}$. A Tabela 5 apresenta as técnicas utilizadas para a medição dos espectros de raios $\mathrm{X}$ nos equipamentos Selenia (sem bandeja de compressão) e Selenia Dimensions (com bandeja de compressão) e os respectivos valores de kerma no ar produzido por estes feixes, para uma única irradiação, na posição do detector de $\operatorname{CdTe}$ (a $0,445 \mathrm{~m}$ do ponto focal). 
Tabela 5: Espectros de raios $X$ medidos nos equipamentos Selenia e Selenia Dimensions e valores correspondentes de kerma no ar para uma exposição. Foi considerado a incerteza de $2 \%$ do fator de calibração da câmara usada.

\begin{tabular}{|c|c|c|c|c|c|}
\hline Equipamento & $\begin{array}{c}\text { Combinação } \\
\text { anodo/filtro }\end{array}$ & Tensão (kV) & Carga (mAs) & $\begin{array}{c}\text { N. de } \\
\text { irradiações }\end{array}$ & $\begin{array}{c}\text { Kerma no ar } \\
(\mathrm{mGy})-0,445 \mathrm{~m}\end{array}$ \\
\hline \multirow{16}{*}{$\begin{array}{l}\text { SELENIA } \\
\text { (ICESP) }\end{array}$} & \multirow{8}{*}{ Mo/Mo } & 25 & 180 & 3 & 33,60 \\
\hline & & 26 & 150 & 3 & 31,97 \\
\hline & & 27 & 150 & 3 & 35,92 \\
\hline & & 28 & 150 & 3 & 40,11 \\
\hline & & 29 & 150 & 3 & 44,57 \\
\hline & & 30 & 150 & 3 & 49,04 \\
\hline & & $31^{\mathrm{FF}}$ & 120 & 2 & 39,69 \\
\hline & & $32^{\mathrm{FF}}$ & 120 & 2 & 43,24 \\
\hline & \multirow{8}{*}{ Mo/Rh } & 25 & 180 & 3 & 22,02 \\
\hline & & 26 & 150 & 3 & 21,26 \\
\hline & & 27 & 150 & 3 & 24,36 \\
\hline & & 28 & 150 & 3 & 27,53 \\
\hline & & 29 & 150 & 3 & 30,78 \\
\hline & & 30 & 150 & 3 & 34,22 \\
\hline & & $31^{\mathrm{FF}}$ & 120 & 2 & 27,97 \\
\hline & & $32^{\mathrm{FF}}$ & 120 & 2 & 29,77 \\
\hline \multirow{6}{*}{$\begin{array}{c}\text { SELENIA } \\
\text { DIMENSIONS }\end{array}$} & \multirow{4}{*}{ W/Rh } & 25 & 120 & 3 & 5,663 \\
\hline & & 26 & 120 & 3 & 5,127 \\
\hline & & 27 & 120 & 4 & 4,571 \\
\hline & & 28 & 120 & 4 & 4,024 \\
\hline & \multirow{2}{*}{ W/Ag } & 25 & 120 & 3 & 5,713 \\
\hline & & 28 & 120 & 5 & 3,769 \\
\hline
\end{tabular}

$\mathrm{FF}=$ foco fino

\subsubsection{Medições de espectros de raios X transmitidos}

Espectros de raios $\mathrm{X}$ transmitidos por diferentes espessuras de phantoms confeccionados de materiais tecido-equivalentes modelo 012A (CIRS inc., Norfolk, USA) foram medidos para feixes produzidos pelo equipamento Mammomat 3000 Nova utilizando as três combinações anodo/filtro possíveis (Mo/Mo, Mo/Rh, W/Rh). Os phantoms utilizados possuem composições de material equivalente a tecidos glandular/adiposo iguais 50/50 (50\% de tecido glandular e 50\% de tecido adiposo) e 30/70 (30\% de tecido glandular e $70 \%$ de tecido adiposo). Para a medição desses espectros foram utilizados três valores de tensão (26, 28 e $30 \mathrm{kV}$ ). Foram medidos um total de 90 espectros transmitidos e, para cada configuração de espectro de raios X medido, uma medição de kerma no ar também foi realizada. A Figura 18 apresenta o posicionamento do espectrômetro e phantom de tecido equivalente para medições de espectros transmitidos (a) e o posicionamento da câmara de ionização, a 15,5 cm do suporte de mama para medições de kerma no ar (b). 


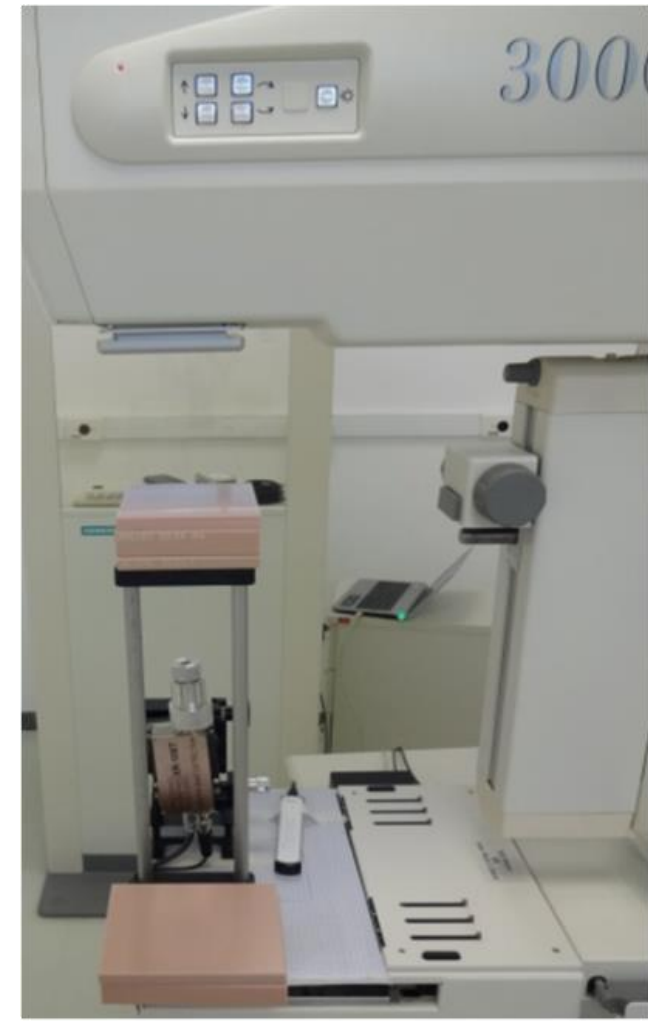

(a)

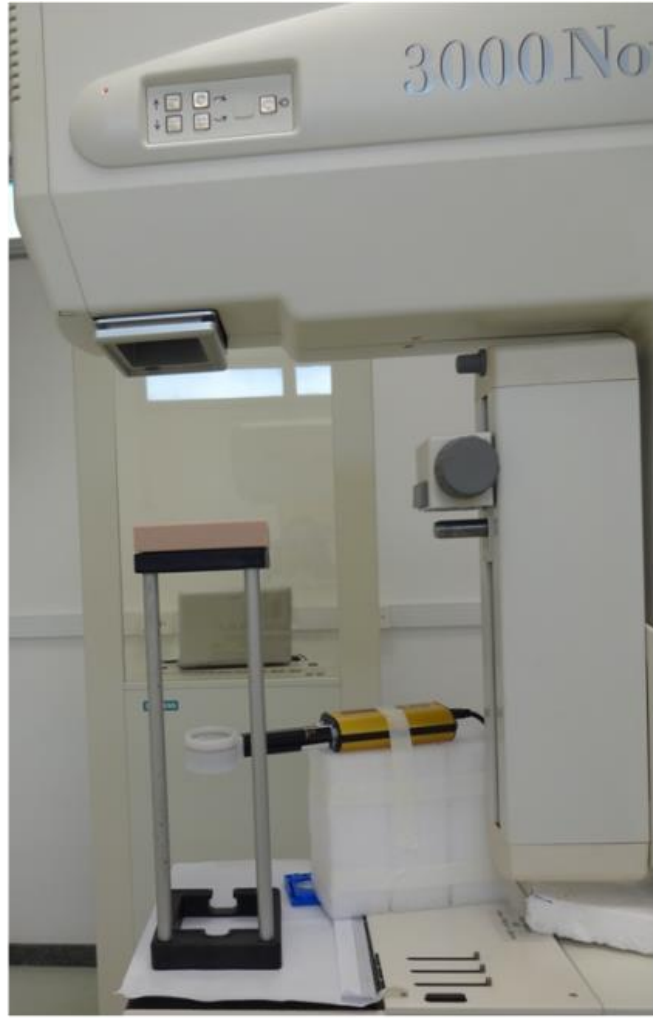

(b)

Figura 18: Posicionamento do espectrômetro de raios $\mathrm{X}$ e phantom de material tecido-equivalente à mama para medições de espectros de raios $\mathrm{X}$ transmitidos (a) e, posicionamento da câmara de ionização para medições de kerma no ar (b) para cada espectro transmitido medido.

A Tabela 6 apresenta as configurações utilizadas para irradiação do espectrômetro para as medições de espectros transmitidos por diferentes espessuras dos phantoms de tecido equivalente 30/70 e 50/50 para a combinação de anodo/filtro Mo/Mo. Para cada espectro medido são apresentados os valores de tensão aplicada ao tubo (T) em unidades de $\mathrm{kV}$, a espessura $(x)$ do phantom em $\mathrm{mm}$, a carga produzida pelo tubo (mAs), o número de irradiações $(\mathrm{N})$ para a aquisição do espectro, o diâmetro do colimador utilizado no detector $(\mu \mathrm{m})$ e a leitura da câmara de ionização (L) em unidades de mGy a 15,5 cm do suporte de mama (ou a 49,5 cm do detector) para uma única irradiação. 
Tabela 6: Configurações para medições de espectros de 26,28 e $30 \mathrm{kV}$ de feixes de Mo/Mo transmitidos por diferentes espessuras dos phantoms de tecido equivalente 30/70 e 50/50. N, é o número de irradiações feitas para a aquisição do espectro, Col $(\mu \mathrm{m})$ é o diâmetro do colimador utilizado no detector e L é a leitura da câmara de ionização em unidades de kerma no ar (mGy), com incerteza da leitura de $5 \%$, indicado pelo fabricante.

\begin{tabular}{|cc|cccc|cccc|}
\cline { 3 - 9 } \multicolumn{1}{c|}{} & \multicolumn{4}{c|}{ Mo/Mo - 30/70 } & \multicolumn{4}{c|}{ Mo/Mo- 50/50 } \\
\hline $\begin{array}{c}\mathbf{T} \\
(\mathbf{k V} \mathbf{p})\end{array}$ & $\begin{array}{c}\boldsymbol{x} \\
(\mathbf{m m})\end{array}$ & $\begin{array}{c}\text { Carga } \\
(\mathbf{m A s})\end{array}$ & $\mathbf{N}$ & $\begin{array}{c}\text { Col. } \\
(\boldsymbol{\mu} \mathbf{m})\end{array}$ & $\begin{array}{c}\mathbf{L} \\
(\mathbf{m G y})\end{array}$ & $\begin{array}{c}\text { Carga } \\
(\mathbf{m A s})\end{array}$ & $\mathbf{N}$ & $\begin{array}{c}\text { Col. } \\
(\boldsymbol{\mu m})\end{array}$ & $\begin{array}{c}\mathbf{L} \\
(\mathbf{m G y})\end{array}$ \\
\hline & $\mathbf{5}$ & 200 & 3 & 25 & 8,52 & 320 & 4 & 25 & 26,61 \\
& $\mathbf{1 0}$ & 200 & 3 & 25 & 10,65 & 320 & 6 & 25 & 15,23 \\
$\mathbf{2 6}$ & $\mathbf{2 0}$ & 100 & 2 & 50 & 2,29 & 320 & 7 & 25 & 6,10 \\
& $\mathbf{3 0}$ & 100 & 4 & 50 & 1,06 & 320 & 10 & 25 & 2,57 \\
& $\mathbf{4 0}$ & 100 & 3 & 100 & 0,52 & 320 & 12 & 25 & 1,18 \\
\hline & $\mathbf{5}$ & 100 & 2 & 25 & 11,09 & 200 & 3 & 50 & 21,19 \\
& $\mathbf{1 0}$ & 100 & 3 & 25 & 7,09 & 200 & 4 & 50 & 12,88 \\
$\mathbf{2 8}$ & $\mathbf{2 0}$ & 100 & 4 & 25 & 3,15 & 200 & 5 & 50 & 5,30 \\
& $\mathbf{3 0}$ & 100 & 2 & 50 & 1,49 & 200 & 5 & 50 & 2,35 \\
& $\mathbf{4 0}$ & 100 & 4 & 50 & 0,74 & 200 & 10 & 50 & 1,05 \\
& $\mathbf{4 5}$ & 100 & 4 & 50 & 0,52 & 100 & 6 & 50 & 0,37 \\
\hline & $\mathbf{1 0}$ & 100 & 4 & 25 & 9,05 & 100 & 2 & 25 & 8,22 \\
& $\mathbf{2 0}$ & 100 & 6 & 25 & 4,08 & 100 & 4 & 25 & 3,47 \\
$\mathbf{3 0}$ & $\mathbf{3 0}$ & 100 & 9 & 25 & 1,97 & 100 & 6 & 25 & 1,57 \\
& $\mathbf{4 0}$ & 100 & 3 & 50 & 1,00 & 100 & 5 & 50 & 0,75 \\
& $\mathbf{5 0}$ & 100 & 2 & 100 & 0,52 & 100 & 3 & 100 & 0,37 \\
\hline
\end{tabular}

A Tabela 7 e a Tabela 8 apresentam dados similares para os espectros medidos com as combinações $\mathrm{Mo} / \mathrm{Rh}$ e $\mathrm{W} / \mathrm{Rh}$, respectivamente.

Tabela 7: Configurações para medições de espectros de 26, 28 e $30 \mathrm{kVp}$ de feixes de $\mathrm{Mo} / \mathrm{Rh}$ transmitidos por diferentes espessuras dos phantoms de tecido equivalente 30/70 e 50/50. N, é o número de irradiações feitas para a aquisição do espectro, Col $(\mu \mathrm{m})$ é o diâmetro do colimador utilizado no detector e L é a leitura da câmara de ionização em unidades de kerma no ar (mGy), com incerteza da leitura de $5 \%$, indicado pelo fabricante.

\begin{tabular}{|c|c|c|c|c|c|c|c|c|c|}
\hline \multirow[b]{2}{*}{$\begin{array}{c}\mathbf{T} \\
(\mathbf{k V})\end{array}$} & \multirow[b]{2}{*}{$\begin{array}{c}x \\
(\mathbf{m m})\end{array}$} & \multicolumn{4}{|c|}{ Mo/Rh - 30/70 } & \multicolumn{4}{|c|}{ Mo/Rh - 50/50 } \\
\hline & & $\begin{array}{l}\text { Carga } \\
(\mathbf{m A s})\end{array}$ & $\mathbf{N}$ & $\begin{array}{l}\text { Col. } \\
(\mu \mathrm{m})\end{array}$ & $\begin{array}{c}\mathbf{L} \\
(\mathbf{m G y})\end{array}$ & $\begin{array}{l}\text { Carga } \\
(\mathbf{m A s})\end{array}$ & $\mathbf{N}$ & $\begin{array}{l}\text { Col. } \\
(\mu \mathrm{m})\end{array}$ & $\begin{array}{c}\mathbf{L} \\
(\mathbf{m G y})\end{array}$ \\
\hline \multirow{5}{*}{26} & 5 & 100 & 5 & 25 & 7,76 & 100 & 6 & 25 & 7,33 \\
\hline & 10 & 100 & 7 & 25 & 5,04 & 100 & 1 & 50 & 4,54 \\
\hline & 20 & 100 & 2 & 50 & 2,32 & 100 & 2 & 50 & 1,95 \\
\hline & 30 & 100 & 4 & 50 & 1,14 & 100 & 2 & 50 & 0,88 \\
\hline & 40 & 100 & 3 & 100 & 0,60 & 100 & 6 & 50 & 0,43 \\
\hline \multirow{6}{*}{28} & 5 & 100 & 2 & 25 & 10,23 & 200 & 4 & 50 & 19,63 \\
\hline & 10 & 100 & 3 & 25 & 6,79 & 200 & 5 & 50 & 12,44 \\
\hline & 20 & 100 & 5 & 25 & 3,19 & 200 & 6 & 50 & 5,45 \\
\hline & 30 & 100 & 3 & 50 & 1,59 & 200 & 10 & 50 & 2,56 \\
\hline & 40 & 100 & 4 & 50 & 0,83 & 320 & 8 & 50 & 1,94 \\
\hline & 45 & 100 & 5 & 50 & 0,60 & 100 & 6 & 50 & 0,45 \\
\hline \multirow{5}{*}{30} & 10 & 100 & 4 & 25 & 8,66 & 100 & 3 & 25 & 7,94 \\
\hline & 20 & 100 & 8 & 25 & 4,13 & 100 & 6 & 25 & 3,55 \\
\hline & 30 & 100 & 2 & 50 & 2,08 & 100 & 7 & 25 & 1,69 \\
\hline & 40 & 100 & 4 & 50 & 1,11 & 100 & 5 & 50 & 0,85 \\
\hline & 50 & 100 & 2 & 100 & 0,60 & 100 & 4 & 100 & 0,44 \\
\hline
\end{tabular}


Tabela 8: Configurações para medições de espectros de 26, 28 e $30 \mathrm{kV}$ de feixes de W/Rh transmitidos por diferentes espessuras dos phantoms de tecido equivalente 30/70 e 50/50. N, é o número de irradiações feitas para a aquisição do espectro, $\mathrm{Col}(\mu \mathrm{m})$ é o diâmetro do colimador utilizado no detector e L é a leitura da câmara de ionização em unidades de kerma no ar (mGy), com incerteza da leitura de $5 \%$, indicado pelo fabricante.

\begin{tabular}{|c|c|c|c|c|c|c|c|c|c|}
\hline \multirow[b]{2}{*}{$\begin{array}{c}T \\
(\mathbf{k V})\end{array}$} & \multirow[b]{2}{*}{$\begin{array}{c}x \\
(\mathbf{m m})\end{array}$} & \multicolumn{4}{|c|}{ W/Rh - 30/70 } & \multicolumn{4}{|c|}{ W/Rh - 50/50 } \\
\hline & & $\begin{array}{l}\text { Carga } \\
(\mathbf{m A s})\end{array}$ & $\mathbf{N}$ & $\begin{array}{l}\text { Col. } \\
(\mu \mathrm{m})\end{array}$ & $\begin{array}{c}\mathbf{L} \\
(\mathbf{m G y})\end{array}$ & $\begin{array}{l}\text { Carga } \\
(\mathbf{m A s})\end{array}$ & $\mathbf{N}$ & $\begin{array}{l}\text { Col. } \\
(\mu \mathrm{m})\end{array}$ & $\begin{array}{c}\mathbf{L} \\
(\mathbf{m G y})\end{array}$ \\
\hline \multirow{5}{*}{26} & 5 & 100 & 8 & 25 & 3,35 & 200 & 6 & 25 & 6,40 \\
\hline & 10 & 200 & 6 & 25 & 4,74 & 100 & 3 & 50 & 2,16 \\
\hline & 20 & 100 & 5 & 50 & 1,22 & 100 & 6 & 50 & 1,05 \\
\hline & 30 & 100 & 7 & 50 & 0,66 & 100 & 3 & 100 & 0,52 \\
\hline & 40 & 100 & 4 & 100 & 0,37 & 100 & 4 & 100 & 0,28 \\
\hline \multirow{6}{*}{28} & 5 & 100 & 8 & 25 & 4,15 & 200 & 6 & 100 & 8,06 \\
\hline & 10 & 100 & 10 & 25 & 2,96 & 320 & 4 & 100 & 8,86 \\
\hline & 20 & 100 & 4 & 50 & 1,56 & 320 & 5 & 100 & 4,38 \\
\hline & 30 & 100 & 5 & 50 & 0,85 & 320 & 5 & 100 & 2,28 \\
\hline & 40 & 100 & 4 & 100 & 0,48 & 320 & 8 & 100 & 1,18 \\
\hline & 45 & 100 & 7 & 50 & 0,36 & 100 & 6 & 100 & 0,28 \\
\hline \multirow{5}{*}{30} & 10 & 100 & 8 & 25 & 3,54 & 100 & 8 & 25 & 3,30 \\
\hline & 20 & 100 & 4 & 50 & 1,88 & 100 & 5 & 50 & 1,66 \\
\hline & 30 & 100 & 4 & 50 & 1,04 & 100 & 7 & 50 & 0,87 \\
\hline & 40 & 100 & 6 & 50 & 0,60 & 100 & 3 & 100 & 0,48 \\
\hline & 50 & 100 & 4 & 100 & 0,35 & 100 & 5 & 100 & 0,27 \\
\hline
\end{tabular}

\subsubsection{Correções dos espectros de raios $\mathrm{X}$}

O sistema de espectrometria usado para as medições dos espectros de raios $\mathrm{X}$ fornece os resultados em um arquivo de extensão .mca sob a forma de histograma do número de contagens em cada canal do MCA. Todos as medições de espectros de raios $\mathrm{X}$ foram realizadas utilizando 1024 canais. A calibração do espectrômetro em energia foi realizada conforme a equação (8).

$$
E[k e V]=a * \text { Canal }+b
$$

Utilizaram-se valores de energias dos picos de emissão ${ }^{74}$ de radiação X e gama obtidos por meio de espectros das fontes radioativas padrão de ${ }^{241} \mathrm{Am} \mathrm{e}{ }^{133} \mathrm{Ba}$ medidos nas mesmas configurações em que foram medidos os espectros de raios $\mathrm{X}$ no mamógrafo. Além disso, utilizou-se os valores de energia das linhas características dos espectros de raios $\mathrm{X}$ produzidos pelo alvo de molibdênio como pontos de calibração. A posição de cada pico foi determinada como o centróide de uma gaussiana ajustada aos picos com o programa Origin (OriginLab Corp., Northampton, USA.) versão 8.

Os espectros de raios $\mathrm{X}$ medidos foram corrigidos pela eficiência do detector de CdTe, espalhamento Compton e escape de fluorescência, por meio do processo de Stripping ${ }^{75}$; 
76, utilizando um programa computacional escrito em Matlab (The MathWorks Inc.). A eficiência do detector e frações de escape foram obtidos por simulação utilizando o Método de Monte Carlo por meio do código PENELOPE ${ }^{77 ;}$ 78. A determinação da eficiência Compton é descrita por Terini e colaboradores ${ }^{79}$. A descrição mais completa do programa de correção de espectros é apresentada por Santos ${ }^{80}$.

$\mathrm{A}$ área sob os espectros de raios $\mathrm{X}$ foi normalizada para representar um valor equivalente ao valor de kerma no ar medido simultaneamente às medições dos espectros. Desse modo, quando o kerma no ar é calculado por meio do espectro de fluência de fótons [número de fótons $/ \mathrm{mm}^{2} . \mathrm{mAs} . \mathrm{keV}$ ] a 1 metro, o resultado encontrado deve ser igual ao valor obtido por meio de medições com câmara de ionização.

\subsubsection{Método de validação dos espectros de raios X}

Os espectros de raios $\mathrm{X}$ medidos utilizando a metodologia desenvolvida neste trabalho foram comparados com espectros simulados usando o modelo proposto por Boone e colaboradores $^{61}$. Este modelo propõe o cálculo de espectros na faixa de energia de mamografia por meio de uma função polinomial e permite o uso de filtrações de materiais comumente presentes em um tubo clínico. Os espectros de raios $\mathrm{X}$ foram calculados considerando as mesmas configurações utilizadas para medições de espectros primários nos equipamentos Selenia e Mammomat: material do anodo, tensão, filtração da janela de berílio do tubo, filtração de Mo e Rh, valor de kerma no ar.

Para obter espectros de raios $\mathrm{X}$ simulados equivalentes ao medidos no tubo Selenia, foram considerados as filtrações de 27,5 $\mu \mathrm{m}$ de Mo e $25 \mu \mathrm{m}$ para as combinações Mo/Mo e $\mathrm{Mo} / \mathrm{Rh}$ respectivamente. Foram utilizadas também, filtrações adicionais de 0,3 $\mathrm{mm}$ (uma vez que o programa já considera uma filtração de $0,5 \mathrm{~mm}$ de Be) e 2,33 mm de PMMA, referente à filtração dos espectros experimentais pela torre de magnificação.

Os espectros simulados equivalentes ao medido no equipamento Mammomat, foram gerados com filtrações de $30 \mu \mathrm{m}, 25 \mu \mathrm{m}$ e $50 \mu \mathrm{m}$ para as combinações $\mathrm{Mo} / \mathrm{Mo}, \mathrm{Mo} / \mathrm{Rh}$ e $\mathrm{W} / \mathrm{Rh}$, respectivamente. Uma filtração adicional de $0,5 \mathrm{~mm}$ de Be também foi utilizada para representar a janela de Be do tubo de raios $\mathrm{X}$. 


\subsubsection{Grandezas derivadas dos espectros de raios $\mathrm{X}$}

\section{A. Camada semirredutora}

Um parâmetro comumente utilizado para a comparação dos espectros de raios X é a camada semirredutora (CSR). A camada semirredutora do feixe é o valor da espessura, $x$, de filtração de alumínio, necessária para reduzir a intensidade do kerma no ar produzido pelo feixe incidente, $K_{a r}(0)$, à sua metade, conforme a relação apresentada na equação (9).

$$
\frac{K_{a r}(x=C S R)}{K_{a r}(0)}=0,5
$$

Os valores CSR foram estimados a partir dos espectros experimentais. Para isso, primeiro foram calculadas as distribuições de kerma no ar a partir dos espectros de fluência, $N(E)$, conforme a equação (10).

$$
N_{k}(E)=N(E) \times\left(\frac{\mu_{a b s}(E)}{\rho}\right)_{a r} \times E
$$

onde $N(E)$ é o espectro de fluência em função da energia, $E$, e $\left(\frac{\mu_{a b s}(E)}{\rho}\right)$ ar são os coeficientes mássicos de absorção de energia pelo ar, que equivalem aos coeficientes mássicos de transferência de energia para o ar no intervalo de energias usadas em radiodiagnóstico. Em seguida, foram calculadas as distribuições de kerma no ar transmitidas por vários valores de espessuras, $x$, de alumínio. O somatório destas distribuições é equivalente ao valor de kerma no ar, $K_{a r}(x)$, de um feixe de raios $\mathrm{X}$ transmitidos por diferentes espessuras de alumínio conforme a equação (11).

$$
K_{a r}(x)=\sum N_{k}(E) e^{-\left(\frac{\mu(E)}{\rho}\right)_{A l} \rho x} \cdot \Delta E
$$

onde $\left(\frac{\mu(E)}{\rho}\right)_{A l}$ são os coeficientes mássicos de atenuação linear do alumínio. Por fim, valores da razão $\frac{K_{a r}(x)}{K_{a r}(0)}$ foram calculados para cada valor de $x$ utilizado e, por meio de interpolação por spline cúbica (função de interpolação do Matlab (MathWhorks Inc.), obteve-se o valor de $x$ para o qual esta razão apresentou valor igual a 0,5 . 


\section{B. Energia efetiva}

Uma vez conhecida a CSR do feixe em alumínio, é possível determinar a energia efetiva, $E_{e f}$, do feixe pela seguinte relação:

$$
\left(\frac{\mu\left(E_{e f}\right)}{\rho}\right)_{A l}=\frac{\log (2)}{\rho_{A l} \cdot C S R}
$$

O valor de energia efetiva pode ser determinado por meio de interpolação por spline

cúbica do valor de $\left(\frac{\mu\left(E_{e f}\right)}{\rho}\right)_{A l}$, obtido com a equação (12), no conjunto de dados de $\left(\frac{\mu(E)}{\rho}\right)_{A l}$ em função da energia ${ }^{81}$.

\subsection{AVALIAÇÃO DA DOSE GLANDULAR NORMALIZADA UTILIZANDO ESPECTROS DE RAIOS X EXPERIMENTAIS}

A dose glandular depende de vários parâmetros que estão relacionados, principalmente, às características da mama (espessura da mama comprimida e fração de massa/volume de tecido glandular) e ao espectro do feixe de raios $\mathrm{X}$ utilizado (CSR, tensão $(\mathrm{kV})$, carga (mAs), combinação alvo/filtro etc). Diante disso, a dose glandular normalizada pelo kerma no ar incidente, $D g N_{p}$, foi avaliada para cada um dos parâmetros supracitados.

Os valores de $D g N_{p}$ foram obtidos por meio dos espectros experimentais incidentes e transmitidos por materiais tecido-equivalentes à mama, pela aplicação de 3 diferentes métodos, a seguir identificados como Métodos I, II e III. No Método I, os espectros experimentais incidentes foram aplicados ao modelo de Boone ${ }^{82 ; 83}$ para a o cálculo da $D g N_{p}$. Com o Método II, valores de $D g N_{p}$ foram obtidos por meio dos espectros incidentes e transmitidos utilizando uma metodologia de cálculo introduzida no presente trabalho. Finalmente, o Método III é uma aplicação diferenciada do Método II assumindo-se várias camadas dos materiais simuladores de tecido mamário para o cálculo da distribuição da dose glandular normalizada com a profundidade desses materiais. Uma descrição mais detalhada de cada um dos métodos utilizados é apresentada nas subseções seguintes.

\subsubsection{Método I: Cálculo de dose glandular normalizada usando espectros primários}

A dose glandular normalizada $\left(D g N_{p}\right)$ pode ser obtida a partir de espectros de raios $\mathrm{X}$ polienergéticos medidos diretamente em um equipamento de mamografia. Com isso, a dose 
glandular média $(\bar{D} g)$ na mama pode ser estimada a partir desses valores de $D g N_{p}$ e do valor de kerma no ar incidente, $K_{0}$ :

$$
\bar{D} g=K_{0} \times D g N_{p}
$$

Valores de $\operatorname{DgN}_{\mathrm{p}}$ foram calculados para cada espectro medido no presente trabalho, baseado no modelo apresentado por Boone ${ }^{82 ; 83}$. Desse modo, para dado espectro de raios X e considerando glandularidade e espessura mama comprimida específicas, pode-se utilizar a equação (14) para estimar os valores de $\operatorname{DgN}_{\mathrm{p}}$ :

$$
D g N_{p}=\frac{\sum_{E_{\min }}^{E_{\max }} \phi(E) \vartheta(E) D g N(E) \Delta E}{\sum_{E_{\min }}^{E_{\max }} \phi(E) \vartheta(E) \Delta E}
$$

$\mathrm{Na}$ equação (14), segundo a abordagem adotada no presente trabalho, $\phi(E)$ é o espectro experimental em fluência, $\vartheta(E)$ representa uma função que faz a conversão de fluência para kerma no ar e $\operatorname{DgN}(E)$ são valores de dose glandular normalizada calculada para feixes monoenergéticos fornecidos na literatura ${ }^{82}$ (em unidades de $\mathrm{mGy} / \mathrm{R}$ ). Considerando $K(E)=\phi(E) \vartheta(E)$, a distribuição de kerma no ar $(\mathrm{mGy} / \mathrm{mAs}$ a $60 \mathrm{~cm})$, produzida pelos fótons de energia $E$, pode-se reescrever a equação (14) como segue:

$$
D g N_{p}=\frac{\sum_{E_{\min }}^{E_{\max }} K(E) D g N(E) \Delta E}{\sum_{E_{\min }}^{E_{\max }} K(E) \Delta E} \quad\left[\frac{\mathrm{mGy}}{\mathrm{R}}\right]
$$

Neste trabalho, os valores de $D g N_{p}$ foram obtidos em unidades de $\mathrm{mGy} / \mathrm{mGy}$ (unidade de dose absorvida por unidade de kerma no ar), pela aplicação do fator de conversão de unidades de exposição, em Roentgen, para dose, $f=(1 / 8,76) \mathrm{R} / \mathrm{mGy}^{31}$.

A função $D g N(E)$ é fornecida na literatura ${ }^{82}$ somente para valores de glandularidade de $0 \%, 50 \%$ e $100 \%$. No entanto, para um mesmo espectro, a relação $D g N(E) x$ glandularidade, tem comportamento aproximadamente linear tal como observado e assumido por Dance $(2000)^{40}$. Portanto, para obter a função para $\operatorname{DgN}(E)$ para glandularidades adicionais $(30 \%$ e $70 \%)$ foi realizada uma interpolação linear da relação $D g N(E) x$ glandularidade.

Com a montagem e método experimental para as medições dos espectros descrita por Santos et al $(2017)^{72}$, todos os espectros foram medidos a $20,5 \mathrm{~cm}$ do detector e no processo de correção, eles foram calculados a $1 \mathrm{~m}$ do ponto focal. Para todos os espectros avaliados, os 
valores de $D g N_{p}$ foram calculados a $60 \mathrm{~cm}$ do ponto focal, com a inclusão do fator de correção de distância que considera a lei do inverso do quadrado da distância:

$$
f_{d}=\left(\frac{100 \mathrm{~cm}}{60 \mathrm{~cm}}\right)^{2}
$$

Para os espectros medidos sem a bandeja de compressão, devido à curta distância entre a bandeja e o suporte de mama, limitação encontrada por exemplo com o equipamento Mammomat 3000 Nova, foi aplicada uma correção analítica que considera a atenuação do espectro por esse dispositivo. Para isso, considerou-se que a bandeja de compressão é composta de PMMA, com coeficientes de atenuação linear (incluindo o espalhamento elástico) $\mu_{P M M A}(E)(\mathrm{XCOM} / \mathrm{NIST})^{81}$ e com espessura, $x$, medida em alguns casos ou obtida na literatura ${ }^{84}$. Desse modo, o fator de correção para a atenuação desse objeto, $f_{a}$, foi estimado conforme à equação (17).

$$
f_{a}=e^{-\mu_{P M M A}(E) x}
$$

Avaliação das Incertezas associadas ao cálculo de $\operatorname{Dg} N_{p}$ pelo Método I

As incertezas dos valores de $D g N_{p}$ foram propagadas a partir das incertezas estatística dos espectros, provenientes do número de contagem em cada canal. Esse número de contagens segue a distribuição de probabilidade de Poisson e, portanto, a incerteza do número de contagens $N_{i}$ registradas em cada canal, $C_{i}$, é igual a $\sqrt{N_{i}}$. Para o desenvolvimento do cálculo, os termos da equação (15) foram renomeados como segue:

$$
\begin{gathered}
D g N_{p}=\frac{X}{Y} \\
X=\sum_{E_{\min }}^{E_{\max }} K(E) D g N(E) \Delta E \quad ; \quad Y=\sum_{E_{\min }}^{E_{\max }} K(E) \Delta E
\end{gathered}
$$

Com a propagação de incerteza de uma razão temos que:

$$
\sigma_{D g N_{p}}=D g N_{p} \times \sqrt{\left(\sigma_{X} / X\right)^{2}+\left(\sigma_{Y} / Y\right)^{2}}
$$

Uma vez considerando somente as incertezas provenientes do espectro, torna-se conveniente renomear os termos de $X$ de modo a agrupar os termos que não irão contribuir com a incerteza: 


$$
\begin{gathered}
X=\sum_{E_{\min }}^{E_{\max }} K(E) D g N(E) \Delta E=\sum_{E_{\min }}^{E_{\max }} K(E) C(E) \\
X=K_{1} C_{1}+K_{2} C_{2}+\cdots+K_{m} C_{m}
\end{gathered}
$$

Com $K_{1} C_{1}=K\left(E_{\text {min }}\right) C\left(E_{\text {min }}\right)$ e $K_{m} C_{m}=K\left(E_{\text {máx }}\right) C\left(E_{\text {máx }}\right)$. Como incertezas dos termos $C(E)$ não foram contabilizadas, a variância em $X$ pode ser obtida tal como segue:

$$
\sigma_{\mathrm{X}}{ }^{2}=C_{1}{ }^{2}{\sigma_{K 1}}^{2}+C_{2}{ }^{2}{\sigma_{K 2}}^{2}+\cdots+C_{m}{ }^{2} \sigma_{\mathrm{Km}}{ }^{2}
$$

O análogo para o termo $Y$ é:

$$
{\sigma_{Y}}^{2}=\Delta E^{2} \times\left({\sigma_{K 1}}^{2}+{\sigma_{K 2}}^{2}+\cdots+{\sigma_{K m}}^{2}\right)
$$

Por outro lado, a distribuição de kerma no ar $K(E)$ é obtida a partir da aplicação de diversos fatores de correção e conversões, $f(E)$, no espectro medido, $N(E)$, que é a fonte principal de incertezas consideradas nesse estudo:

$$
K(E)=f(E) N(E)
$$

Portanto, para um dado valor de energia $E$, a incerteza em $K(E)$ é:

$$
\sigma_{K(E)}^{2}=f(E)^{2} \sigma_{N(E)}^{2}
$$

Considerando $\sigma_{N(E)}=\sqrt{N(E)}$, as incertezas foram estimadas conforme a equação (19).

\subsubsection{Método II: Cálculo de dose glandular normalizada usando espectros transmitidos}

A dose glandular normalizada também pode ser estimada por meio de espectros incidentes e transmitidos em materiais radiologicamente equivalentes ao tecido mamário. Seja um dado material homogêneo simulador de tecido mamário com massa, $m$, fração de volume da componente glandular, $f_{g}$, e densidade, $\rho$, conhecidos. O espectro incidente, $\phi_{0}(E)$, e transmitido, $\phi_{t}(E)$, por este material estão representados na Figura 19. 


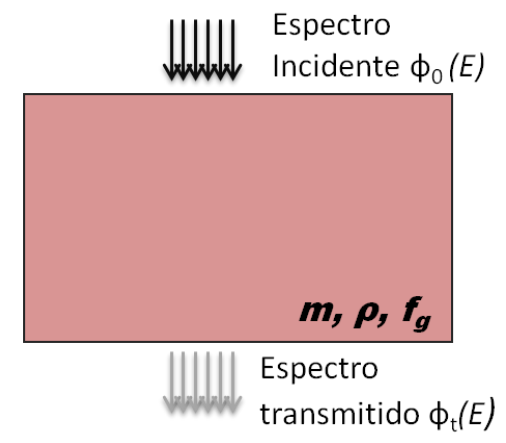

Figura 19: Representação dos espectros incidente e transmitido através de um material radiologicamente equivalente ao tecido mamário.

A diferença entre o espectro incidente e transmitido representa a distribuição energética de fótons que interagiram no material.

$$
\phi_{\text {int }}(E)=\phi_{0}(E)-\phi_{t}(E) \quad\left[\text { fótons } / \mathrm{mm}^{2} \mathrm{keV}\right]
$$

Considere que o feixe de raios $\mathrm{X}$ transmitido detectado seja resultante da transmissão dos fótons do feixe incidente através de um volume cilíndrico com área da base igual a área exposta do detector e com altura, $L$, como mostrado na Figura 20.

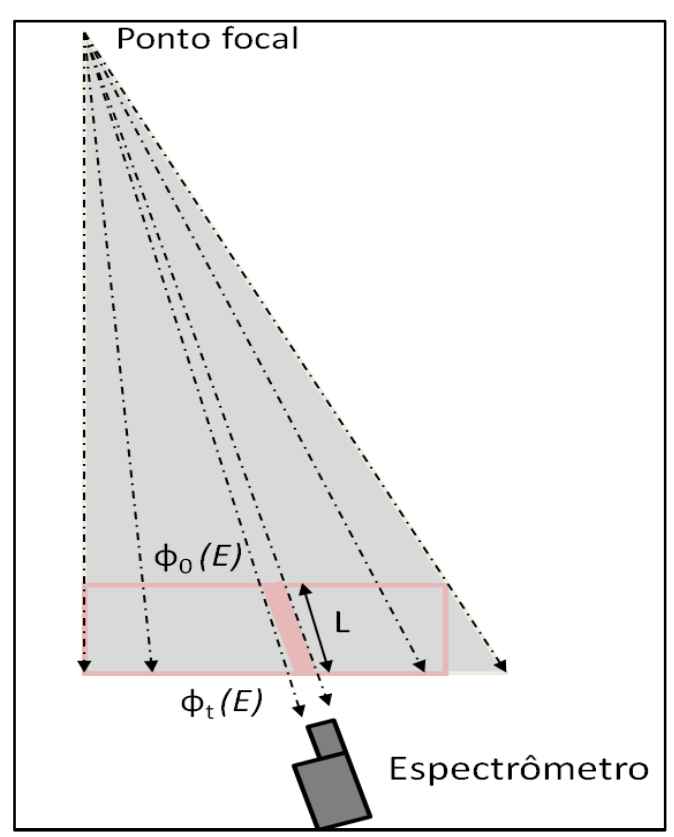

Figura 20: Representação de um material simulador de tecido mamário em um campo de radiação típico de mamografia, com destaque no volume no qual o feixe de radiação atravessa antes de chegar ao espectrômetro. A figura não está em escala.

A dose absorvida no volume em destaque na Figura 20 pode ser calculada por meio da equação (26): 


$$
D_{a b s}=\frac{\sum_{E=E_{\min }}^{E_{\max }} \phi_{\text {int }}(E) E\left(\frac{\mu_{a b s}(E)}{\mu(E)}\right)}{\rho L} \quad\left[\frac{\mathrm{keV}}{\mathrm{kg}}\right]
$$

Onde $\phi_{\text {int }}(E)$ é o espectro de fótons que foi retirado do feixe incidente por conta de interações no volume em destaque, em função da energia, $E$. O fator $\frac{\mu_{a b s}(E)}{\mu(E)}$ é a razão dos coeficientes de absorção pelos coeficientes de atenuação total. Este fator representa a probabilidade da energia $E$ de um fóton que interagiu no meio ser absorvido por este meio. Considerando o fator de conversão $c=1,6021 \times 10^{-16} \frac{\mathrm{J}}{\mathrm{keV}}$, a dose absorvida em unidades do SI (Gray (Gy)), pode ser calculada por meio da equação (27):

$$
D_{a b s}=\frac{c}{\rho L} \sum_{E=E_{\min }}^{E_{\max }} \phi_{\text {int }}(E) E\left(\frac{\mu_{a b s}(E)}{\mu(E)}\right) \Delta E \quad[\mathrm{~Gy}]
$$

A dose glandular media, $\bar{D}_{g}$, é definida como a razão da energia média absorvida no tecido glandular pela massa de tecido glandular, $m_{g}{ }^{85}$ :

$$
\bar{D}_{g}=\frac{\left(E_{a b s}\right)_{g}}{m_{g}}
$$

26 propôs a introdução de uma função, $G(E)$, para estimar a fração da dose total absorvida pela mama que é especificamente absorvida pelo componente glandular usando princípios básicos e trabalhos prévios ${ }^{42 ; 43}$. Essa função tem sido usada em outros estudos ${ }^{84 ; 85}$ para o cálculo analítico da dose glandular média:

$$
G(E)=\frac{f_{g}\left(\frac{\mu_{a b s}(E)}{\rho}\right)_{g}}{f_{g}\left(\frac{\mu_{a b s}(E)}{\rho}\right)_{g}+\left(1-f_{g}\right)\left(\frac{\mu_{a b s}(E)}{\rho}\right)_{a}}
$$

$\mathrm{Na}$ equação (29), $f_{g}$ representa a fração de peso do tecido glandular (por exemplo, $f_{g}=0,5$ para mama com $50 \%$ de tecido glandular $)$. $\left(\mu_{\mathrm{abs}}(\mathrm{E}) / \rho\right)_{\mathrm{g}}$ e $\left(\mu_{\mathrm{abs}}(\mathrm{E}) / \rho\right)_{\mathrm{a}}$ representam os coeficientes mássicos de absorção de energia para o tecido glandular e adiposo, respectivamente ${ }^{86}$. Considerando a função $G(E)$, a dose glandular média pode ser estimada como mostrado na equação (30): 


$$
\bar{D}_{g}=\frac{c}{\rho L f_{g}} \cdot \sum_{E=E_{\min }}^{E_{\max }} \phi_{\text {int }}(E) E\left(\frac{\mu_{a b s}(E)}{\mu(E)}\right) G(E) \Delta E[G y]
$$

Para um valor de kerma no ar incidente conhecido, $K_{0}$ [Gy], a dose glandular média normalizada considerando espectros polienergéticos, $\bar{D} g N_{p}$, pode ser obtida conforme a equação (31):

$$
\bar{D} g N_{p}=\frac{c}{\rho L f_{g} K_{0}} \sum_{E=E_{\min }}^{E_{\max }} \phi_{\text {int }}(E) E\left(\frac{\mu_{a b s}(E)}{\mu(E)}\right) G(E) \Delta E\left[\frac{\mathrm{Gy}}{\mathrm{Gy}}\right]
$$

Neste trabalho, estimativas de dose glandular normalizada foram realizadas para phantoms de mama com diferentes proporções de materiais equivalentes ao tecido glandular e tecido adiposo (CIRS30/70 e CIRS50/50) A distribuição de fótons que interagiram no material, equação (25), foi determinada a partir dos espectros incidentes e transmitidos medidos experimentalmente (subseção 3.1). A dose absorvida, equações (26) e (27), no volume do phantom atravessado pelo espectro transmitido detectado foi determinado utilizando valores de densidades desses materiais estimados por Poletti ${ }^{87}$. Para calcular a função $G(E)$, foram utilizados valores de coeficientes mássicos de absorção de energia determinados utilizando a composição deste material determinada por Hammerstein ${ }^{54}$ e a base de dados do NIST ${ }^{81}$.

\section{Avaliação das Incertezas associadas ao cálculo de $\operatorname{Dg} N_{p}$ pelo Método II}

Com base na equação (31) pode-se considerar a incerteza de $\bar{D} g N_{p}$ como uma composição de incertezas das variáveis $\rho, L, K_{0} E$ e $\phi_{\text {int }}$. Os valores de densidade, $\rho$, dos materiais simuladores de tecido mamário utilizado (CIRS3070 e CIRS5050) e suas respectivas incertezas foram apresentados por Poletti ${ }^{87}$.

Devido à inclinação característica dos tubos de raios $\mathrm{X}$ de mamografia, dependendo da posição onde se queira medir o espectro, o espectrômetro precisa de uma pequena inclinação para estar alinhado ao feixe. Para os equipamentos de mamografia utilizados, esta inclinação variou, aproximadamente, entre $1,8^{\circ}$ e 5, $0^{\circ}$. Desse modo, a espessura $L$, conforme indicado na Figura 20, é a razão da espessura nominal do material utilizado pelo cosseno do ângulo de inclinação do espectrômetro. No entanto, a consideração dessa inclinação produz variações muito pequenas (no máximo $0,4 \%$ para uma inclinação de $5^{\circ}$ ) nas espessuras 
nominais dos materiais utilizados e por isto neste trabalho foram utilizadas as espessuras nominais dos materiais simuladores de tecido mamário no cálculo de dose. Neste caso, foi considerada uma incerteza de $0,4 \%$ nos valores de espessura.

Os valores de kerma no ar incidente, $K_{0}$, foram estimados a partir de medições com câmara de ionização dedicada a aplicações em mamografia. A principal incerteza associada estes valores está relacionada à calibração deste instrumento. Para o instrumento utilizado, foi considerada uma incerteza de $2 \%$ associada ao coeficiente de calibração, conforme apresentado no certificado de calibração.

A calibração de energia do espectrômetro foi feita a partir da medição, com o mesmo detector e mesmo ganho de amplificação, de espectros de raios $\mathrm{X}$ e gama emitidos por fontes radioativas de calibração (Am-241, Ba-133 e Eu-152). Nesse processo, os centroides dos picos observados são determinados a partir do ajuste de uma gaussiana. Então, um ajuste linear aos dados de energia em função dos canais é realizado. Portanto, a incerteza na energia foi determinada a partir da propagação de incerteza na posição (canal) do centroide e nos parâmetros de ajuste da reta de calibração.

Por fim, as incertezas relacionadas aos espectros experimentais no termo $\phi_{\text {int }}(E)$ foram propagadas a partir das incertezas estatística dos espectros, considerando uma distribuição de Poisson, com a incerteza do número de contagens, $N$, registradas em cada canal igual a $\sqrt{N}$.

Sendo $\psi(E)=\phi_{\text {int }}(E) E\left(\frac{\mu_{a b s}(E)}{\mu(E)}\right)$, a fluência de energia absorvida, e considerando as incertezas nas variáveis supracitadas, a variância no valor $D g N_{p}$ pode ser estimada utilizando as derivadas parciais da equação (31) como:

$$
\begin{aligned}
{\sigma_{D g N_{p}}}^{2} & =\left(\frac{\partial D g N_{p}}{\partial \rho}\right)^{2} \sigma_{\rho}^{2}+\left(\frac{\partial D g N_{p}}{\partial L}\right)^{2} \sigma_{L}^{2}+\left(\frac{\partial D g N_{p}}{\partial K_{0,}}\right)^{2} \sigma_{\rho}^{2} \\
+ & \left(\frac{\partial D g N_{p}}{\partial \psi}\right)^{2} \sigma_{\psi}^{2}+\left(\frac{\partial D g N_{p}}{\partial E}\right)^{2} \sigma_{E}^{2}
\end{aligned}
$$

Analisando separadamente cada um dos três primeiros termos da equação (32) temos:

i)

$$
\left(\frac{\partial D g N_{p}}{\partial \rho}\right)^{2} \sigma_{\rho}^{2}=\left(\frac{-1}{\rho^{2}}\right)^{2} \sigma_{\rho}{ }^{2}\left(\frac{c}{L f_{g} K_{0}}\right)^{2} \sum_{E=E_{\min }}^{E_{\max }}(\psi(E) G(E) \Delta E)^{2}
$$


ii)

$$
\left(\frac{\partial D g N_{p}}{\partial L}\right)^{2} \sigma_{L}^{2}=\left(\frac{-1}{L^{2}}\right)^{2} \sigma_{L}^{2}\left(\frac{c}{\rho f_{g} K_{0}}\right)^{2} \sum_{E=E_{\min }}^{E_{\max }}(\psi(E) G(E) \Delta E)^{2}
$$

iii)

$$
\left(\frac{\partial D g N_{p}}{K_{0}}\right)^{2}{\sigma_{K_{0}}}^{2}=\left(\frac{-1}{{K_{0}}^{2}}\right)^{2}{\sigma_{K_{0}}}^{2}\left(\frac{c}{\rho L f_{g}}\right)^{2} \sum_{E=E_{\min }}^{E_{\max }}(\psi(E) G(E) \Delta E)^{2}
$$

Para calcular a derivada parcial do termo que depende do espectro, a equação (31) foi reescrita como:

$$
\bar{D} g N_{p}=C \sum_{E=E_{\min }}^{E_{\max }} \psi(E) G(E) \quad \text { com, } \quad C=\frac{c \Delta E}{\rho L f_{g} K_{0}}
$$

$\bar{D} g N_{p}=C\left[\psi\left(E_{1}\right) G\left(E_{1}\right)+\psi\left(E_{2}\right) G\left(E_{2}\right)+\cdots+\psi\left(E_{\max }\right)\left(E_{\max }\right)\right]$

Portanto, o quarto termo da equação (32) fica:

iv)

$$
\left(\frac{\partial \mathrm{DgN}_{\mathrm{p}}}{\partial \psi(\mathrm{E})}\right)^{2} \sigma_{\psi(\mathrm{E})}^{2}=\mathrm{C}^{2} \sum_{\mathrm{E}=\mathrm{E}_{\min }}^{\mathrm{E}_{\max }}\left[\mathrm{G}(\mathrm{E}) \sigma_{\psi(\mathrm{E})}\right]^{2}
$$

Com:

$$
\begin{gathered}
\psi(E)=\left[\phi_{0}(E)-\phi_{1}(E)\right] E\left(\frac{\mu_{a b s}(E)}{\mu(E)}\right) \\
\sigma_{\psi(\mathrm{E})}{ }^{2}=\left(\frac{\mu_{\mathrm{abs}}(\mathrm{E})}{\mu(\mathrm{E})}\right)^{2} \mathrm{E}^{2}\left({\sigma_{\phi_{0}(\mathrm{E})}}^{2}+{\sigma_{\phi_{1}(\mathrm{E})}}^{2}\right)
\end{gathered}
$$

Então, a contribuição do último termo é:

v)

$$
\left(\frac{\partial \mathrm{DgN}_{\mathrm{p}}}{\partial \mathrm{E}}\right)^{2}{\sigma_{\mathrm{E}}}^{2}=\mathrm{C}^{2} \sum_{\mathrm{E}=\mathrm{E}_{\min }}^{\mathrm{E}_{\max }}\left[\psi(\mathrm{E}) \mathrm{G}(\mathrm{E}) \sigma_{\mathrm{E}}\right]^{2}
$$


3.3.3 Método III: Cálculo da distribuição de dose glandular normalizada com a profundidade

$\mathrm{Na}$ seção 3.3.2 foi apresentado um método para a estimativa da dose glandular normalizada utilizando espectros incidentes e transmitidos por materiais simuladores de tecido mamário tal como os esquematizados na Figura 21 (a). Os valores de doses obtidos por esse método representam a dose média absorvida pela fração de massa do material equivalente ao tecido glandular contido em todo o volume do phantom usado.

Uma abordagem alternativa e mais completa de explorar esse problema é obter a distribuição da dose no conteúdo glandular em diferentes profundidades do material simulador de tecido mamário. É importante conhecer essa distribuição porque o tecido glandular mamário é radiologicamente mais sensível e o risco de indução de câncer por radiação está diretamente associado aos valores de dose recebida por este tipo de tecido. $\mathrm{Na}$ mamografia, a dose não se distribui uniformemente com a profundidade da mama. A medida que o feixe penetra a mama o espectro de raios $\mathrm{X}$ do feixe incidente se modifica ao atravessar cada camada da mama, tornando-se mais penetrante (com aumento da CSR e da energia efetiva). Isso ocorre devido aos processos de interação dos fótons com os tecidos mamários.

Para estimar a distribuição de dose glandular em diferentes profundidades do material simulador de tecido mamário foi considerada a geometria apresentada na Figura 21 (b). Nessa figura, o objeto simulador esquematizado em (a) foi subdividido em $n$ camadas com diferentes espessuras, de $L_{1}$ a $L_{n}$. Essas camadas possuem, respectivamente, diferentes massas de tecido glandular, de $m_{1} a m_{n}$. Conhecendo os espectros incidentes e transmitidos em cada camada, como esquematizado na Figura 21 (c), e utilizando a equação (31) é possível estimar a dose glandular normalizada pelo kerma no ar incidente (na superfície da primeira camada) em cada camada do phantom. 


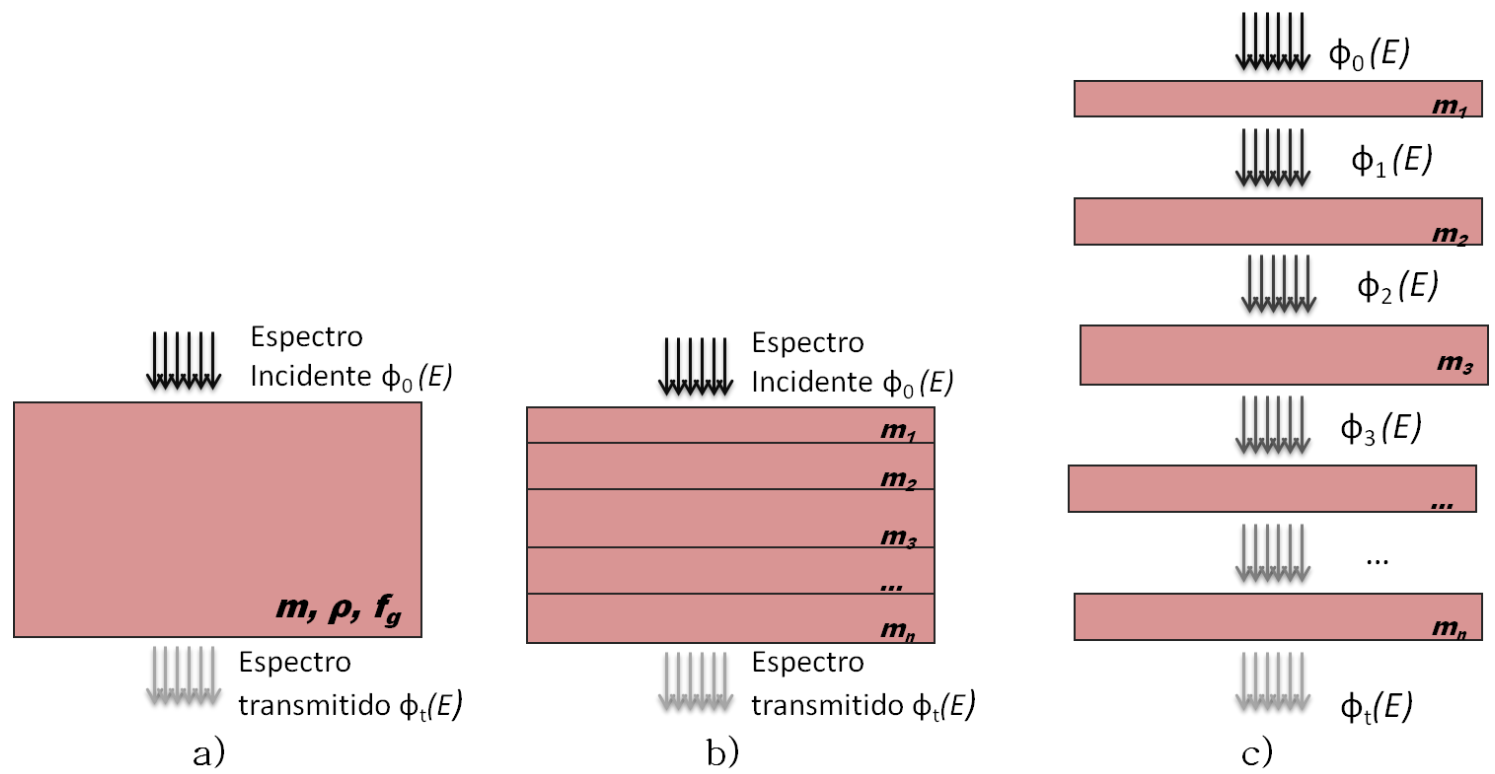

Figura 21: Esquema dos espectros incidentes e transmitidos ao atravessar um material simulador de tecido mamário (a), das diversas camadas consideradas no material simulador (b) e dos espectros incidentes e transmitidos em cada camada deste material.

A dose glandular média para feixes polienergéticos, $D g$, estimada para o phantom inteiro (Figura 21 (a)) é:

$$
\bar{D} g=\frac{\left(\bar{E}_{a b s}\right)}{m} K_{0}
$$

Onde $\left(\bar{E}_{a b s}\right)$ é a energia média absorvida no conteúdo glandular, $m$ é a massa total do conteúdo glandular do material e $K_{0}$ é o kerma no ar incidente. Analogamente, a dose em cada camada, como esquematizado na Figura 21 (c), é:

$$
\bar{D} g_{1}=\frac{\left(\bar{E}_{a b s}\right)_{1}}{m_{1}} ; \bar{D} g_{2}=\frac{\left(\bar{E}_{a b s}\right)_{2}}{m_{2}} ; \ldots ; \bar{D} g_{n}=\frac{\left(\bar{E}_{a b s}\right)_{n}}{m_{n}}
$$

Onde:

$$
\begin{gathered}
\bar{E}_{a b s}=\left(\bar{E}_{a b s}\right)_{1}+\left(\bar{E}_{a b s}\right)_{2}+\cdots+\left(\bar{E}_{a b s}\right)_{n} \\
m=m_{1}+m_{2}+\cdots+m_{n}
\end{gathered}
$$

Pode-se escrever a dose glandular média considerando todo o phantom, $\bar{D} g$, em função da dose glandular nas diferentes camadas desse material: 


$$
\begin{aligned}
\bar{D} g=\frac{\left(\bar{E}_{a b s}\right)}{m} & =\left[\frac{\left(\bar{E}_{a b s}\right)_{1}+\left(\bar{E}_{a b s}\right)_{2}+\cdots+\left(\bar{E}_{a b s}\right)_{n}}{m}\right] \\
& =\left[\frac{m_{1}}{m} \frac{\left(\bar{E}_{a b s}\right)_{1}}{m_{1}}+\frac{m_{2}}{m} \frac{\left(\bar{E}_{a b s}\right)_{2}}{m_{2}}+\cdots+\frac{m_{n}}{m} \frac{\left(\bar{E}_{a b s}\right)_{n}}{m_{n}}\right]
\end{aligned}
$$

Portanto,

$$
\bar{D} g=\frac{m_{1}}{m} \bar{D} g_{1}+\frac{m_{2}}{m} \bar{D} g_{2}+\cdots+\frac{m_{n}}{m} \bar{D} g_{n}
$$

Uma vez sendo a massa $m=\rho . L$ área e $m_{1}=\rho . L_{1}$. área, pode-se reescrever a (44) como:

$$
\bar{D} g=\frac{L_{1}}{L} \bar{D} g_{1}+\frac{L_{2}}{L} \bar{D} g_{2}+\cdots+\frac{L_{n}}{L} \bar{D} g_{n}
$$

Neste trabalho, as distribuições de dose foram calculadas utilizado o Método III, para espectros transmitidos por espessuras que variam de 0,5 a $4,5 \mathrm{~cm}$ dos materiais simuladores de tecido mamário com frações de conteúdo glandular de $30 \%$ e $50 \%$. O Método III é uma aplicação modificada do Método II em camadas do material simulador de tecido mamário de uma determinada espessura, em vez de considerar espessura inteira do material tal como considerado pelo Método II. Desse modo, vale a mesma estimativa de incerteza descrita na subseção anterior.

\subsection{ESTIMATIVAS DE DOSES UTILIZANDO TLDs}

Dosímetros termoluminescentes (TLD-100, Harshaw Chemical Company, OH, USA) foram utilizados para estimar dose absorvida em diferentes profundidades de phantoms modelo 012A (CIRS inc., Norfolk, USA) construídos com materiais equivalentes ao tecido mamário. Os dosímetros termoluminescentes (TLDs) utilizados são compostos de fluoreto de lítio dopado com $\mathrm{Mg}$ e $\mathrm{Ti}$ ( $\mathrm{LiF}: \mathrm{Mg}, \mathrm{Ti}$ ) e tem forma de pastilhas com dimensões de $3 \times 3 \times 1 \mathrm{~mm}^{3}$.

A utilização desses dosimetros TL envolveu três etapas ou procedimentos básicos: tratamento térmico, irradiação e leitura. Para fins de estimativa incerteza na resposta dos dosímetros e cálculo de dose, esses dosimetros passaram também por procedimentos de seleção e calibração, respectivamente. Esses procedimentos são detalhados nas seções subsequentes. 


\subsubsection{Tratamento térmico}

O tratamento térmico refere-se a um pré-aquecimento no qual devem ser submetidos os dosímetros a uma temperatura suficiente para que os elétrons aprisionados nas armadilhas, remanescentes de irradiações e leituras prévias, adquiram energia necessária para se mover no material e se recombinar com os buracos. Essa prática é adotada para "zerar" o sinal do material. Os dosímetros utilizados nesse trabalho foram tratados termicamente com aquecimento durante 1 hora a $400{ }^{\circ} \mathrm{C}$ em um forno modelo LW 200 (Ind. Forlabo LTDA, São Paulo) em seguida foram mantidos por 10 minutos fora do forno resfriando à temperatura ambiente e finalmente aquecidos novamente durante 2 horas a $100{ }^{\circ} \mathrm{C}$ em um forno (Fabbe LTDA, São Paulo).

\subsubsection{Leitura do sinal TL}

A leitura do sinal TL dos dosímetros utilizados neste trabalho foi realizada em um sistema de leitura TL/OSL Ris $\phi$, modelo DA-20 (DTU Nutech. Inc., Rolkilde, Dinamarca), apresentado na Figura 22. Este equipamento é capaz de ler até 48 amostras de dosímetros.

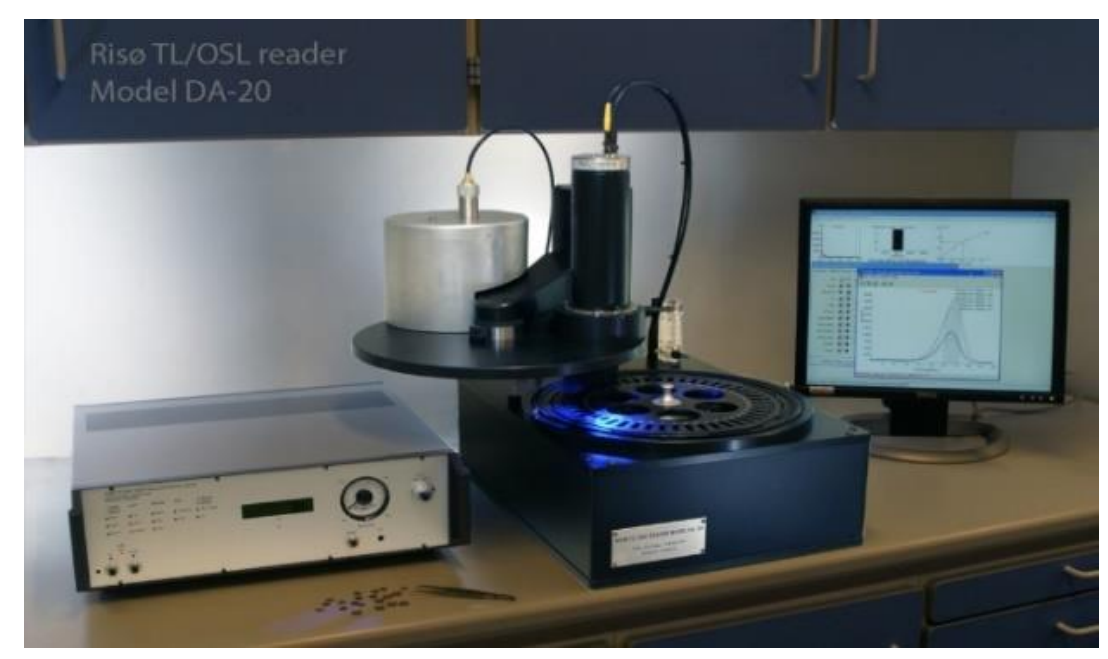

Figura 22: Leitora TL/OSL Ris $\phi$, modelo DA-20. Fonte: nutech.dtu.dk

O processo de leitura consiste basicamente no aquecimento de cada dosímetro individualmente com uma taxa de aquecimento definida pelo operador, e a coleta da luz emitida durante a estimulação do cristal pelo aquecimento por uma fotomultiplicadora. Neste trabalho, o processo de leitura foi realizado por meio de um aquecimento da temperatura ambiente a $350{ }^{\circ} \mathrm{C}$ a uma taxa de aquecimento constante de $10^{\circ} \mathrm{C} / \mathrm{s}$. 
O sinal obtido durante a leitura é processado e apresentado na forma de um gráfico (Curva TL) em função da temperatura, cuja área pode ser relacionada com o kerma no ar por meio de calibração. Neste trabalho, as respostas dos dosimetros TL foram obtidas por meio da integração completa da curva de TL. O sinal proveniente da radiação de fundo foi calculado usando um conjunto de dosímetros não irradiados e subtraído do sinal TL total.

\subsubsection{Seleção dos dosímetros TL}

Para conhecer a precisão de medição ${ }^{88}$ na determinação dose quando se utiliza dosimetros termoluminescentes (TLDs) é necessário conhecer a variação da resposta desses dosimetros quando irradiados com a mesma dose. Os dosimetros TLDs utilizados neste trabalho foram selecionados de acordo com a variação da resposta quando irradiados com uma dose de 2,19 mGy utilizando uma fonte de $\mathrm{Co}^{60}$.

Um porta-dosímetros feito de PMMA (Figura 23 à esquerda) foi utilizado para posicionar as pastilhas de material TL para irradiação após o tratamento térmico. Esse dispositivo é composto por uma base com 900 cavidades cilíndricas (diâmetro de 4,60 mm e profundidade de $1,35 \mathrm{~mm}$ ), dispostas na forma de uma matriz de 30 x 30 posições, nas quais os dosímetros são alocados para a etapa de irradiação. Possui também uma tampa de $5 \mathrm{~mm}$ de espessura que se fixa a base por meio de parafusos. Foram analisadas as respostas de 680 dosímetros. Depois de preenchida a matriz com TLDs, o conjunto inteiro foi posicionado à frente da fonte de cobalto num suporte feito com linhas de nylon (Figura 23 à direita) de modo a deixar o conjunto o mais afastado possível de potenciais materiais espalhadores.

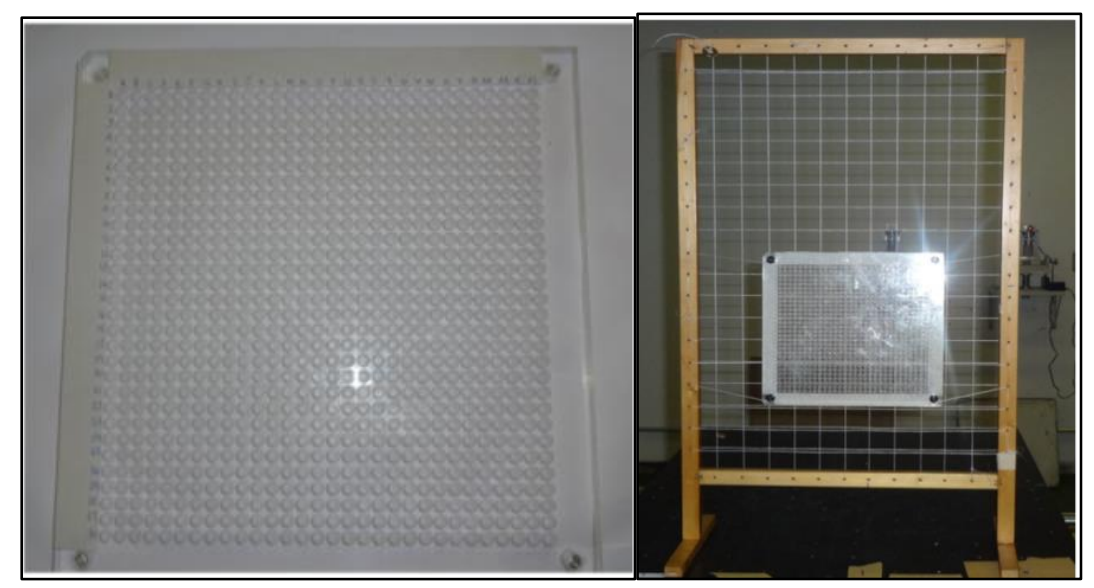

Figura 23: Posicionamento dos TLDs para irradiação no processo de seleção. Matiz de dosimetros posicionada frente à fonte de $\mathrm{Co}^{60}$ (à direita) e porta-dosimetros de PMMA com capacidade de posicionamento de 900 TLDs (à esquerda). 
As respostas dos dosímetros são apresentadas no histograma da Figura 24. Foi calculada a média e o desvio padrão das respostas. Considerando um fator de abrangência $k=1$, um desvio padrão representa $6,5 \%$ do valor da média. Para fins desta pesquisa, foram selecionados os dosímetros cuja resposta está no intervalo compreendido pela média mais ou menos um desvio padrão. Nesse conjunto foram selecionados 449 dosímetros.

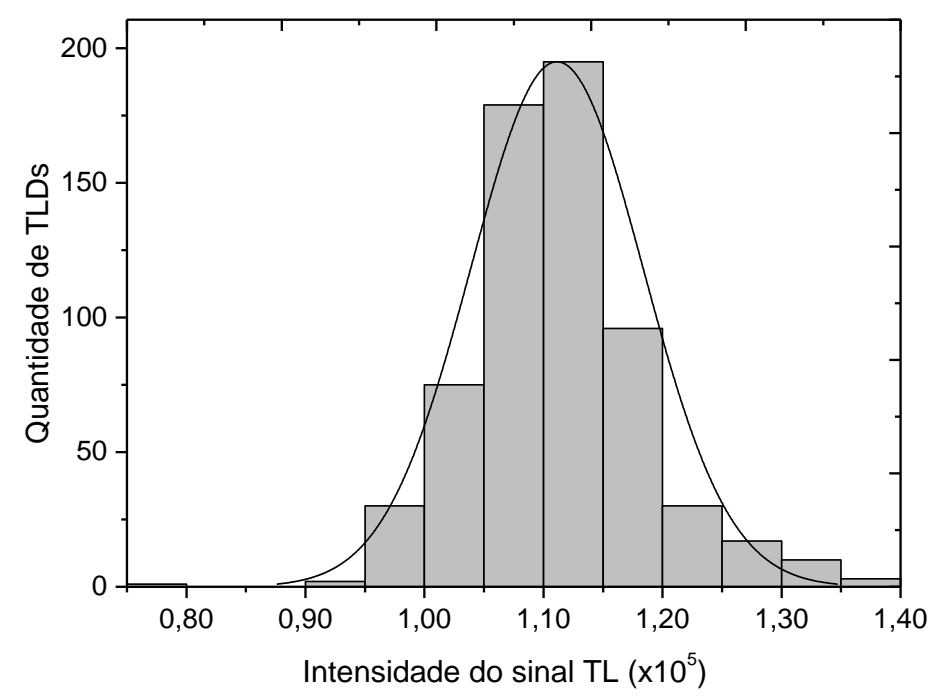

Figura 24: Intensidade do sinal de termoluminescência nos dosímetros TL. A intensidade do sinal representa a integral da curva inteira subtraída do sinal de fundo (background)

3.4.4 Calibração dos TLDs

O processo de calibração consiste na irradiação dos dosímetros com doses conhecidas e a determinação da relação da resposta dos TLDs com a dose. Os dosímetros TLDs utilizados neste trabalho foram calibrados nos feixes de radiação com CSR aproximadas aos feixes padrão RQR-M2 e RQR-M4, utilizados para calibrar câmaras de ionização usadas em mamografia $^{39}$. O procedimento foi realizado no laboratório de calibração de instrumentos (LCI) do Instituto de Pesquisas Energéticas e Nucleares (IPEN/CNEN). A Tabela 9 apresenta informações das qualidades de feixes de raios $\mathrm{X}$ de mamografia implantadas num sistema de radiação modelo Isovolt 160 HS (Pantak/Seifert) do LCI, com anodo de tungstênio.

Tabela 9: Características das qualidades padrão de feixes de radiação de mamografia utilizadas para a calibração dos dosimetros TLDs num sistema Pantak/Seifert.

\begin{tabular}{cccccc}
\hline Qualidade & $\begin{array}{c}\text { Tensão } \\
(\mathbf{k V})\end{array}$ & $\begin{array}{c}\text { Corrente } \\
(\mathbf{m A})\end{array}$ & $\begin{array}{c}\text { CSR } \\
(\mathbf{m m ~ A l})\end{array}$ & $\begin{array}{c}\text { Filtração } \\
(\mathbf{m m} \mathbf{M o})\end{array}$ & $\begin{array}{c}\text { Taxa de Kerma no ar } \\
(\mathbf{m G y} / \mathbf{m i n})^{\mathbf{a}}\end{array}$ \\
\hline RQR-2M & 28 & 10 & 0,37 & 0,07 & 13,0 \\
RQR-4M & 35 & 10 & 0,41 & 0,07 & 19,2 \\
\hline (IPEN/CNEN).
\end{tabular}


Os dosimetros foram empacotados em grupos de quatro TLDs (Figura 25). Foram posicionados a 1 metro do ponto focal do tubo e irradiados nos feixes de radiação equivalentes às qualidades RQR-2M e RQR-4M para 9 valores de dose diferentes. Para cada valor de dose esperado, um grupo de quatro TLDs foi irradiado. Um conjunto de dosímetros foi reservado para medir a radiação de fundo.

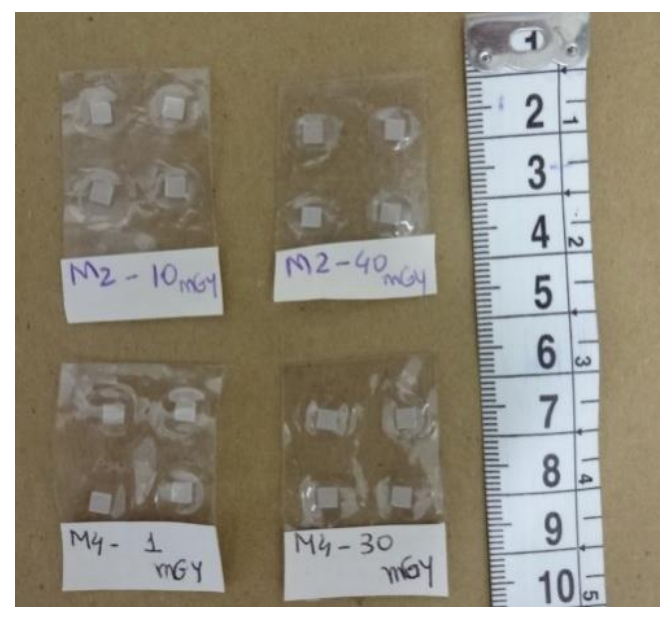

Figura 25: Grupo de dosímetros TLirradiados com diferentes valores de dose para calibração.

A Tabela 10 apresenta os valores de dose esperados com a irradiação dos dosímetros, os valores de corrente (mA), o tempo irradiação estimado a partir dos dados de taxa de kerma no ar apresentados na Tabela 9, e o tempo de irradiação medido com um cronômetro. Foi considerada a incerteza do tipo B na medição do tempo, que incluiu somente a incerteza instrumental do cronômetro (resolução) e o tempo de resposta desse instrumento (relacionado ao manuseio do operador).

Tabela 10: Valores de doses (mGy) esperados com a irradiação dos dosímetros para calibração nas qualidades RQR-2M e RQR-4M. Valores nominais de correntes (mA) utilizados, tempo estimado de irradiação (s) e tempo medido (s). A incerteza no tempo medido foi estimada como 0,23 s (para $\mathrm{k}=1$ ).

\begin{tabular}{cccc|ccc} 
& \multicolumn{3}{c}{ RQR-2M } & \multicolumn{3}{c}{ RQR-4M } \\
\hline $\begin{array}{c}\text { Dose } \\
\text { esperada } \\
\text { (mGy) }\end{array}$ & $\begin{array}{c}\text { Corrente } \\
(\mathrm{mA})\end{array}$ & $\begin{array}{c}\text { Tempo } \\
\text { estimado }(\mathrm{s})\end{array}$ & $\begin{array}{c}\text { Tempo } \\
\text { medido }(\mathrm{s})\end{array}$ & $\begin{array}{c}\text { Corrente } \\
(\mathrm{mA})\end{array}$ & $\begin{array}{c}\text { Tempo } \\
\text { estimado }(\mathrm{s})\end{array}$ & $\begin{array}{c}\text { Tempo } \\
\text { medido }(\mathrm{s})\end{array}$ \\
\hline $\mathbf{1}$ & 2 & 23,08 & 23,38 & 2 & 15,63 & 15,31 \\
$\mathbf{5}$ & 10 & 23,08 & 23,37 & 10 & 15,63 & 15,53 \\
$\mathbf{1 0}$ & 10 & 46,15 & 46,44 & 10 & 31,25 & 31,38 \\
$\mathbf{2 0}$ & 20 & 46,15 & 46,41 & 20 & 31,25 & 31,34 \\
$\mathbf{3 0}$ & 30 & 46,15 & 46,35 & 30 & 31,25 & 31,21 \\
$\mathbf{4 0}$ & 30 & 61,54 & 61,18 & 30 & 41,67 & 41,50 \\
$\mathbf{5 0}$ & 30 & 76,92 & 76,50 & 30 & 52,08 & 52,34 \\
$\mathbf{6 0}$ & 30 & 92,31 & 92,32 & 30 & 62,50 & 62,41 \\
$\mathbf{7 0}$ & 30 & 107,69 & 107,35 & 30 & 72,92 & 72,50 \\
\hline
\end{tabular}




\subsubsection{Irradiação dos dosímetros TLs}

Para avaliar as distribuições de dose em várias profundidades de phantoms de tecidos equivalentes ao tecido mamário, dosímetros TLs foram irradiados conforme o esquema mostrado na Figura 26. Foram utilizados conjuntos de placas dos phantoms, semelhantes aos utilizados nas medições dos espectros transmitidos, para compor o equivalente a 4,5 cm de mama comprimida.

Os phantoms do modelo 012A (CIRS) são compostos por um conjunto de placas com área de $10 \times 12,5 \mathrm{~cm}^{2}$ e espessuras de $0,5,1$ e $2 \mathrm{~cm}$ permitindo agrupamentos que representam mamas de 0,5 a $7 \mathrm{~cm}$ de espessuras comprimidas. São compostos de materiais com coeficientes de atenuação semelhantes aos do tecido mamário e representando mamas com composições de $30 \%$ de tecido glandular e $70 \%$ de tecido adiposo (30/70), $50 \%$ de tecido glandular e 50\% de tecido adiposo (50/50) e 70\% de tecido glandular e 30\% de tecido adiposo (70/30). Neste trabalho nos referiremos a estes phantoms como CIRS30/70, CIRS50/50 e CIRS70/30, respectivamente.

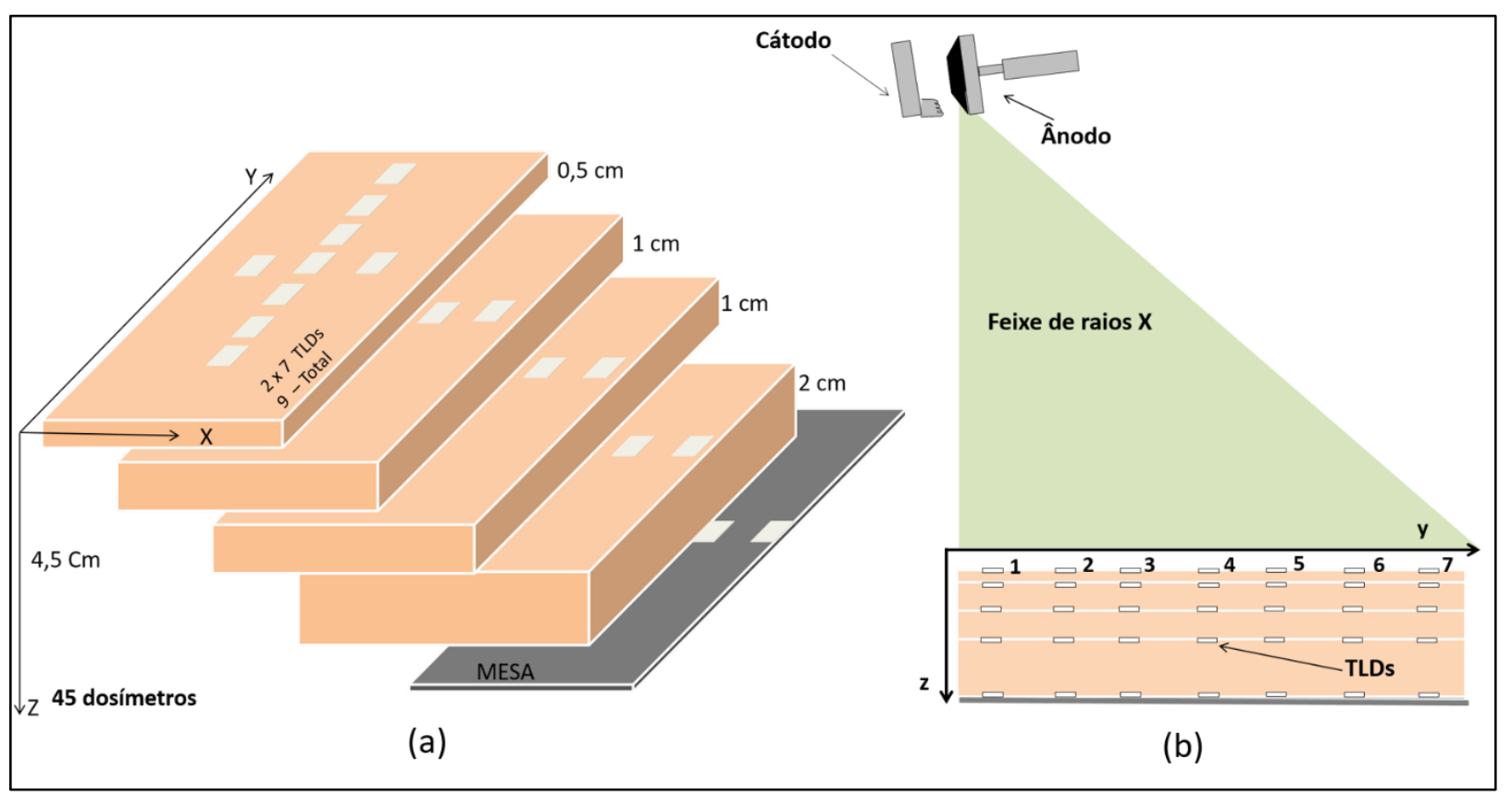

Figura 26: Esquema de posicionamento dos dosímetros TL para irradiação em feixes de raios $\mathrm{X}$ produzidos pelo mamógrafo (a). Neste esquema, o eixo y representa sentido catodo-anodo, como apresentado no corte vertical que representa o plano $x z$ (b).

Os phantoms foram posicionados sobre o suporte de mama e sobre os phantoms foram dispostos sete dosímetros no eixo y (eixo catodo-anodo conforme a Figura 26) e dois dosímetros no eixo $x$. A maior quantidade de dosímetros foi posicionada no eixo $y$ porque nessa direção há maior variação na intensidade do feixe, devido ao efeito anódico ${ }^{89}$. 
Os dosímetros foram, então, irradiados por feixes de radiação produzidos por um equipamento de mamografia (Siemens, modelo Mammomat 3000 Nova) utilizando a técnica de $28 \mathrm{kV}$ e $100 \mathrm{mAs}$, tamanho de campo de 17 x $23 \mathrm{~cm}^{2}$ e com bandeja de compressão acoplada durante as irradiações, conforme apresentado na Figura 27. Para facilitar o posicionamento dos dosímetros e evitar absorção do feixe pelos dosímetros das camadas superiores do phantom, cada conjunto de 9 dosímetros foi irradiado separadamente em diferentes profundidades do phantom. A Figura 27 apresenta o setup de irradiação de um conjunto de dosímetros na superfície phantom 50/50.

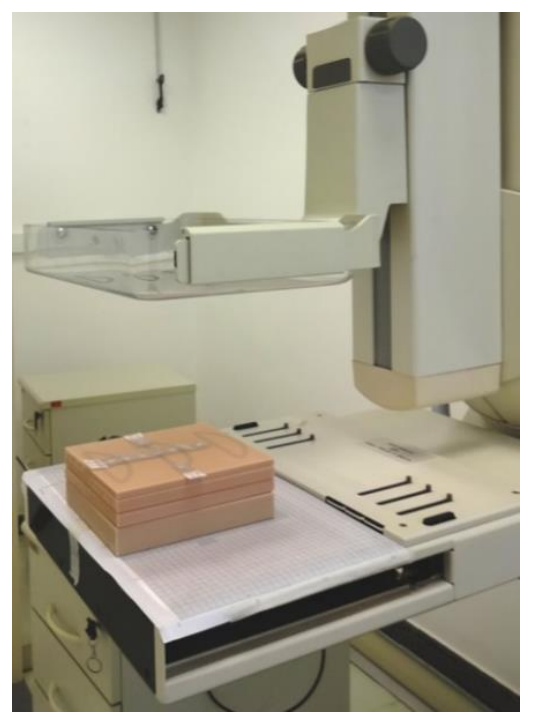

Figura 27: Setup de irradiação dos dosímetros sobre a superfície do phantom 50/50 no equipamento Mammomat 3000 Nova. O posicionamento dos dosímetro foi guiado pelas marcações opacas da bandeja de compressão.

As medições de dose absorvida foram realizadas utilizando três phantoms compostos por diferentes combinações de tecidos glandular/adiposo e as três combinações de anodo/filtro disponíveis no equipamento Mammomat 3000 Nova, conforme apresentado na Tabela 11.

Tabela 11: Combinações de tipo de phantom e anodo/filtro utilizados para irradiações dos TLDs. Todas as irradiações foram realizadas utilizando feixes produzidos com $28 \mathrm{kV}$ e $100 \mathrm{mAs}$ no equipamento Mammomat 3000 Nova.

\begin{tabular}{cc}
\hline Phantom & Combinação anodo/filtro \\
\hline \multirow{2}{*}{$50 / 50$} & $\mathrm{Mo} / \mathrm{Mo}$ \\
& $\mathrm{Mo} / \mathrm{Rh}$ \\
$\mathrm{W} / \mathrm{Rh}$ \\
\hline \multirow{2}{*}{$\mathbf{3 0} / \mathbf{7 0}$} & $\mathrm{Mo} / \mathrm{Mo}$ \\
& $\mathrm{Mo} / \mathrm{Rh}$ \\
\hline \multirow{2}{*}{$\mathbf{7 0 / 3 0}$} & $\mathrm{Mo} / \mathrm{Mo}$ \\
& $\mathrm{Mo} / \mathrm{Rh}$ \\
& $\mathrm{W} / \mathrm{Rh}$ \\
\hline
\end{tabular}


As posições dos dosímetros sobre o plano irradiado $\left(23,2 \times 17,4 \mathrm{~cm}^{2}\right)$ foram determinadas utilizando as imagens radiográficas. Os dosimetros foram enumerados como indicado na Figura 28. Os valores das coordenadas $x$ e $y$ do centro de cada TLD apresentado na imagem, em relação à origem do plano apresentado na Figura 29, foram determinadas individualmente utilizando o software ImageJ (NIH Image, Bethesda,USA).

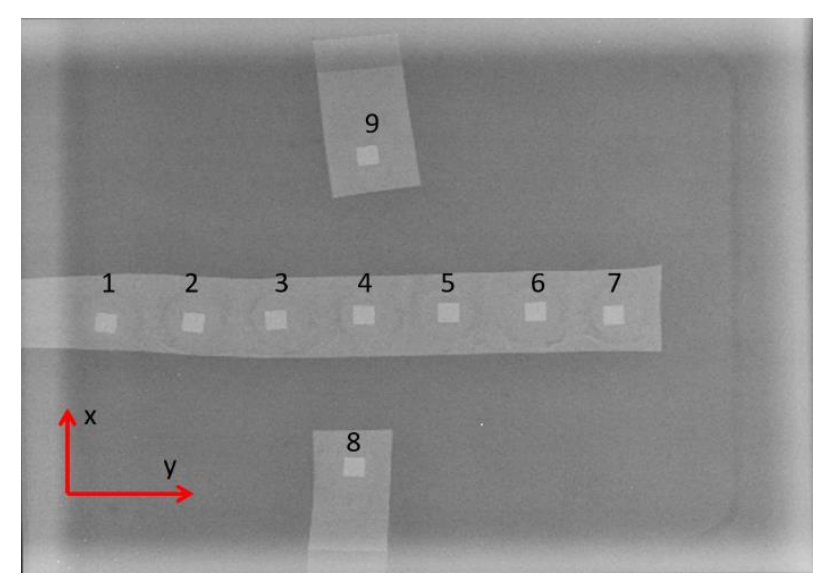

Figura 28: Imagem radiográfica de um conjunto de dosímetros sobre um phantom de tecido equivalente irradiados no mamógrafo. O eixo $y$ representa o sentido cátodo-anodo.

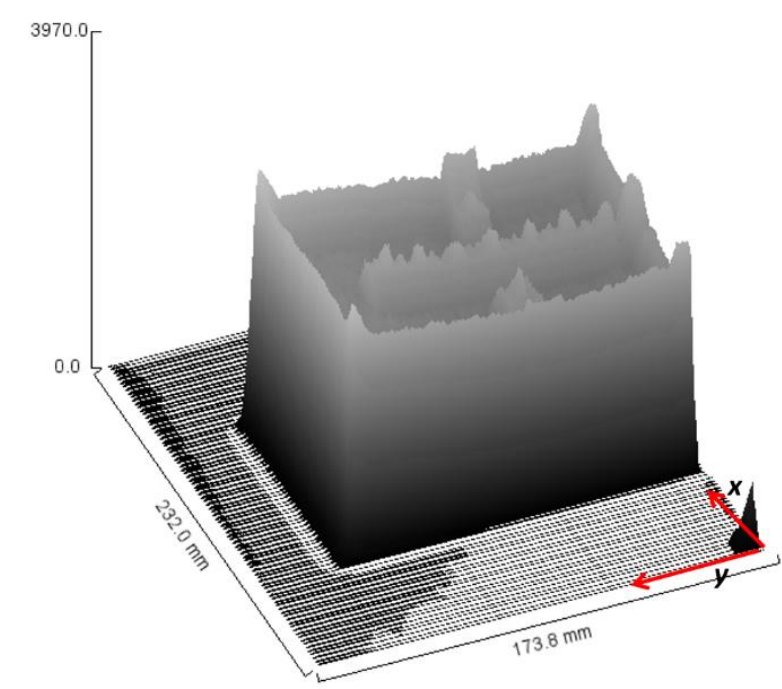

Figura 29: Plot 3D da Figura 7 apresentando a posição no plano $x y$ em função do valor do pixel. $\mathrm{O}$ eixo $y$ representa o sentido cátodo-anodo.

No experimento, buscou-se posicionar cada conjunto de dosímetros aproximadamente na mesma posição, em relação ao phantom, em cada setup de irradiação. Sendo assim, foram determinadas as posições de cada dosímetro em 15 imagens adquiridas durante o experimento. A partir desses dados, a posição média (x, y) foi então determinada conforme apresentado na Tabela 12.

Tabela 12: Posição média de cada dosímetro, (x, y), no plano de irradiação conforme apresentado na Figura 29

\begin{tabular}{cll}
\hline Dosímetro TL & $\begin{array}{c}\text { Posição média no } \\
\text { eixo } \boldsymbol{y}(\mathbf{c m})\end{array}$ & $\begin{array}{l}\text { Posição média } \\
\text { no eixo } \boldsymbol{x}(\mathbf{c m})\end{array}$ \\
\hline $\mathbf{1}$ & $6,72 \pm 0,16$ & $11,21 \pm 0,18$ \\
$\mathbf{2}$ & $8,06 \pm 0,15$ & $11,23 \pm 0,17$ \\
$\mathbf{3}$ & $9,43 \pm 0,13$ & $11,20 \pm 0,16$ \\
$\mathbf{4}$ & $10,76 \pm 0,10$ & $11,18 \pm 0,15$ \\
$\mathbf{5}$ & $12,11 \pm 0,15$ & $11,15 \pm 0,17$ \\
$\mathbf{6}$ & $13,46 \pm 0,16$ & $11,13 \pm 0,20$ \\
$\mathbf{7}$ & $14,85 \pm 0,17$ & $11,14 \pm 0,22$ \\
$\mathbf{8}$ & $10,77 \pm 0,12$ & $18,08 \pm 0,19$ \\
$\mathbf{9}$ & $10,74 \pm 0,11$ & $14,18 \pm 0,18$ \\
\hline
\end{tabular}


As leituras do sinal TL foram realizadas na leitora TL/OSL (Ris申). O cálculo de dose absorvida é descrito na subseção 3.4.6.

\subsubsection{Estimativa de dose absorvida}

Para transformar os dados obtidos a partir das leituras dos TLDs em dose absorvida nos phantoms de tecido equivalente, calculou-se inicialmente o valor de dose absorvida no ar associado aos valores de leituras TL, utilizando o fator de calibração, $f_{c}$, obtido conforme descrito na subseção 3.4.4. A dose absorvida no ar é então estimada conforme a equação (46).

$$
D_{a r}=M f_{c}
$$

Na equação (46), $M$ é o valor da integral de toda a curva TL, subtraído do valor médio de Background. A dose absorvida no phantom ${ }^{31}$ é então calculada de acordo à equação (47).

$$
\begin{gathered}
D_{\text {phantom }}(E)=D_{a r}(E) \times f(E) \\
f(E)=\frac{\left[\frac{\mu_{a b}}{\rho}(E)\right]_{\text {phantom }}}{\left[\frac{\mu_{a b}}{\rho}(E)\right]_{a r}}
\end{gathered}
$$

Onde $\left[\frac{\mu_{a b}}{\rho}(E)\right]_{\text {phantom }}$ são os coeficientes mássicos de absorção de energia para o meio de interesse, nesse caso os phantoms, em função da energia e $\left[\frac{\mu_{a b}}{\rho}(E)\right]_{a r}$ são os coeficientes mássicos de absorção de energia do ar em função da energia $E$ do feixe incidente sobre os dosímetros. Para feixes polienergéticos utilizados nesse trabalho, os coeficientes mássicos de absorção de energia foram calculados em função da energia efetiva do espectro.

Os coeficientes mássicos de absorção de energia para o ar e para os elementos químicos que compõem os phantoms CIRS30/70, CIRS50/50 e CIRS70/30 foram obtidos por meio da base de dados XCOM do The National Institute of Standards and Technology $(\mathrm{NIST})^{81}$. Foram utilizadas as composições químicas dos phantoms de tecido equivalente determinadas por Poletti e colaboradores ${ }^{87}$. Os valores de $\left[\frac{\mu_{a b}}{\rho}(E)\right]_{\text {phantom }}$ foram então determinados utilizando a regra das misturas ${ }^{86}$, equação (49). 


$$
\left[\frac{\mu_{a b}}{\rho}(E)\right]_{\text {mistura }}=\sum_{i} w_{i}\left[\frac{\mu_{a b}}{\rho}(E)\right]_{i}
$$

onde $w_{i}$ é a fração de peso do $i$-ésimo elemento químico que compõe a mistura.

Para o cálculo de dose, utilizou-se os valores de $\frac{\mu_{a b}}{\rho}$ correspondentes à energia efetiva do feixe incidente, $E_{\text {ef. }}$ A relação entre energia efetiva e camada semirredutora do feixe, CSR, foi apresentada previamente na equação (12). Portanto, conhecendo a camada semirredutora do feixe e considerando a densidade do alumínio igual $2,699 \mathrm{~g} / \mathrm{cm}^{3}$ (NIST) ${ }^{29}$, a energia efetiva do feixe foi determinada por meio da distribuição de valores de $\left(\frac{\mu}{\rho}\right)_{A l}$ obtida por meio da base de dados do NIST ${ }^{81}$.

\subsubsection{Estimativa de dose glandular normalizada utilizando os TLDs}

A equação (47) calcula a dose absorvida no material simulador de tecido mamário considerando ambas componentes, glandular e adiposa, desse material. A dose glandular é, no entanto, definida como a dose absorvida somente no conteúdo glandular da mama. Pode-se estimar a dose glandular normalizada pelo kerma no ar incidente $\left(K_{0}\right)$ pela aplicação da função $G(E)$, apresentada anteriormente na equação (29), que determina a fração da dose total absorvida pela mama que é especificamente absorvida pelo componente glandular. Portanto, a dose glandular foi estimada usando a equação (50)

$$
D g N=\frac{D_{\text {phantom }}\left(E_{e f}\right) \cdot G\left(E_{e f}\right)}{K_{0}}
$$

Onde $E_{e f}$ é a energia efetiva do feixe apresentada na seção 3.2 .5 e $D_{\text {phantom }}\left(E_{e f}\right)$ é a dose absorvida determinada a partir das medições com TLDs. 


\section{RESULTADOS E DISCUSSÕES}

\subsection{ESPECTROS DE RAIOS X}

\subsubsection{Calibração em energia}

A calibração do espectrômetro em energia foi realizada conforme descrito na subseção 3.2.3. A Figura 30 apresenta um exemplo de reta de calibração utilizada, obtida com espectros de fontes padrão de ${ }^{133} \mathrm{Ba},{ }^{241} \mathrm{Am}$ e os picos característicos do molibdênio que surgem nos espectros de raios X medidos no mamógrafo usando o anodo de Mo. A calibração em energia foi checada para cada conjunto de medições realizadas utilizando como referência as energias correspondentes aos picos característicos dos espectros de Molibdênio.

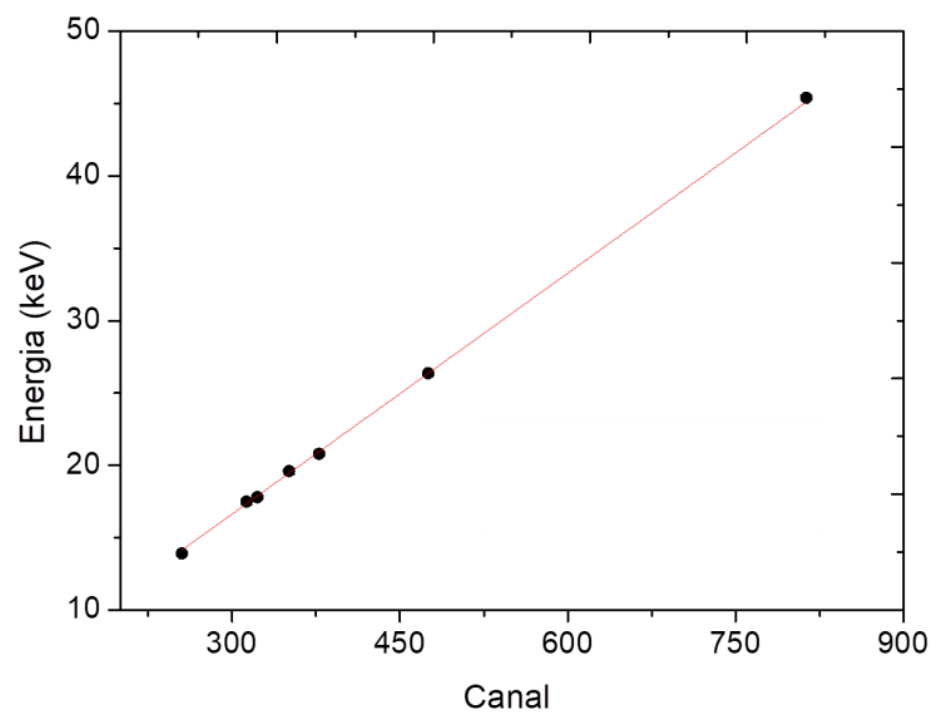

Figura 30: Curva de calibração em energia utilizando dados de fontes de ${ }^{241} \mathrm{Am},{ }^{133} \mathrm{Be}$ raios $\mathrm{X}$ de fluorescência do molibdênio. A incerteza nos pontos experimentais é inferior a 1,1\%.

A posição dos picos (em canal) foi determinada por ajuste de uma função gaussiana em cada pico, conforme descrito na subseção 3.2.3. Foram consideradas as incertezas na posição dos picos resultantes do ajuste da gaussiano utilizando o software Origin (OriginLab Corp., Northampton, USA).

\subsubsection{Validação}

\section{A. Espectros de raios $X$ medidos no equipamento de mamografia Selenia}

A Figura 31 apresenta os resultados comparativos entre os espectros de raios $\mathrm{X}$ experimentais gerados pelo equipamento Selenia, descrito no item 3.2.1, utilizando a 
combinação de anodo filtro Mo/Mo, e espectros equivalentes calculados usando o modelo de Boone e colaboradores (1997) para tensões de 25, 26, 27 e 28 kV. A Figura 32 apresenta um resultado comparativo similar para espectros de raios $\mathrm{X}$ gerados pelo mesmo equipamento de mamografia considerando a combinação anodo/filtro de $\mathrm{Mo} / \mathrm{Rh}$. Os espectros experimentais são representados por linhas pretas e enquanto os calculados são apresentados por linhas vermelhas. Todos os espectros de raios $\mathrm{X}$ experimentais apresentados neste trabalho foram estimados em unidades de fluência normalizado pela carga $\left(\mathrm{N} / \mathrm{mm}^{2} . \mathrm{mA} . \mathrm{s} . \mathrm{keV}\right)$ a 1 metro, após passar pelo processo de correção descrito no item 3.2.3. As Figuras mostram uma boa concordância entre esses espectros para as duas combinações de anodo/filtro utilizadas. Algumas dessas comparações foram também apresentadas por Santos et. al (2017) $)^{72}$.
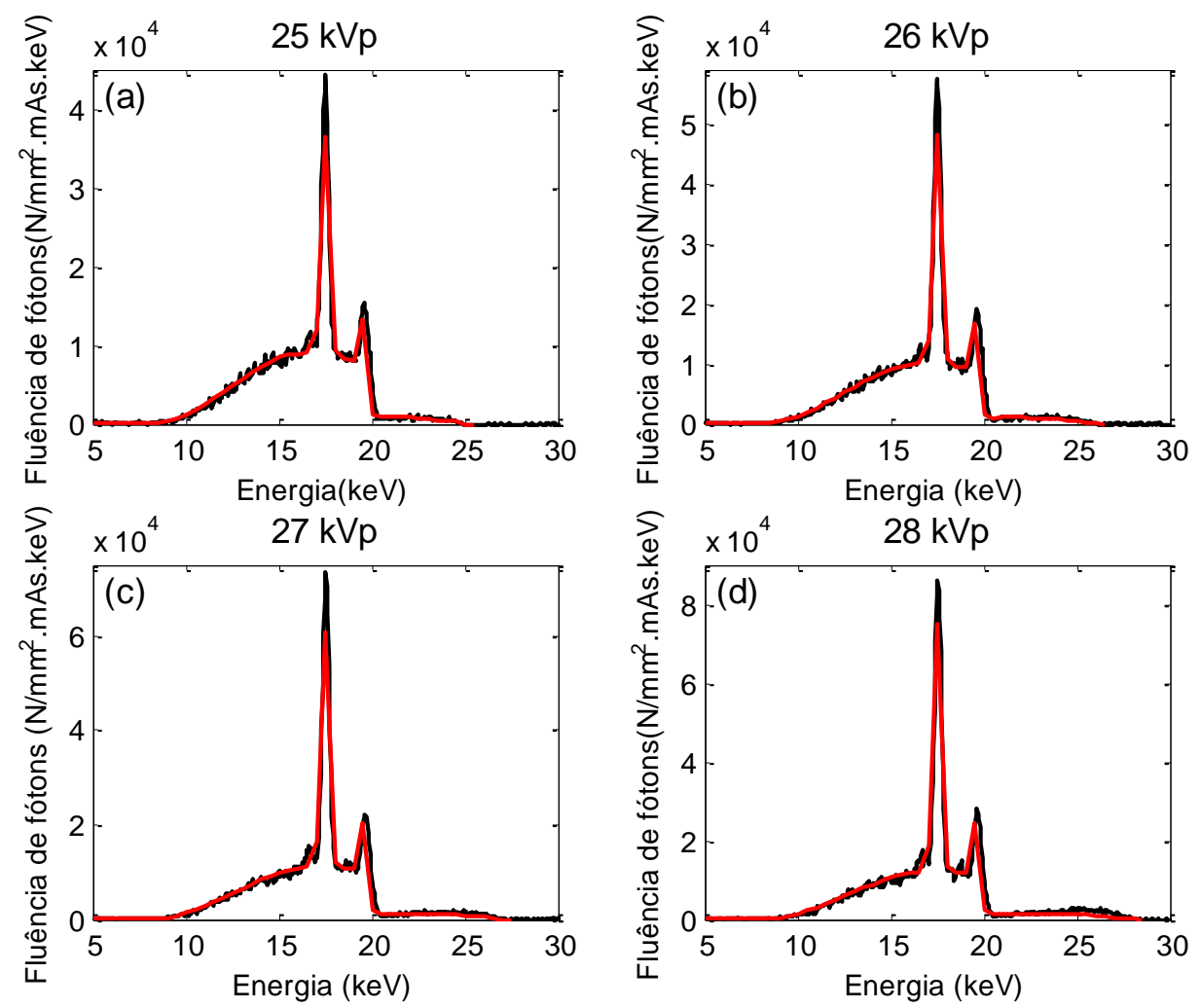

Figura 31: Espectros de raios $X$ experimentais de Mo/Mo medidos no equipamento Selenia (linha preta) e espectros gerados pelo modelo de Boone e colaboradores (1997) (linha vermelha) para valores típicos de tensão utilizados em mamografia. 

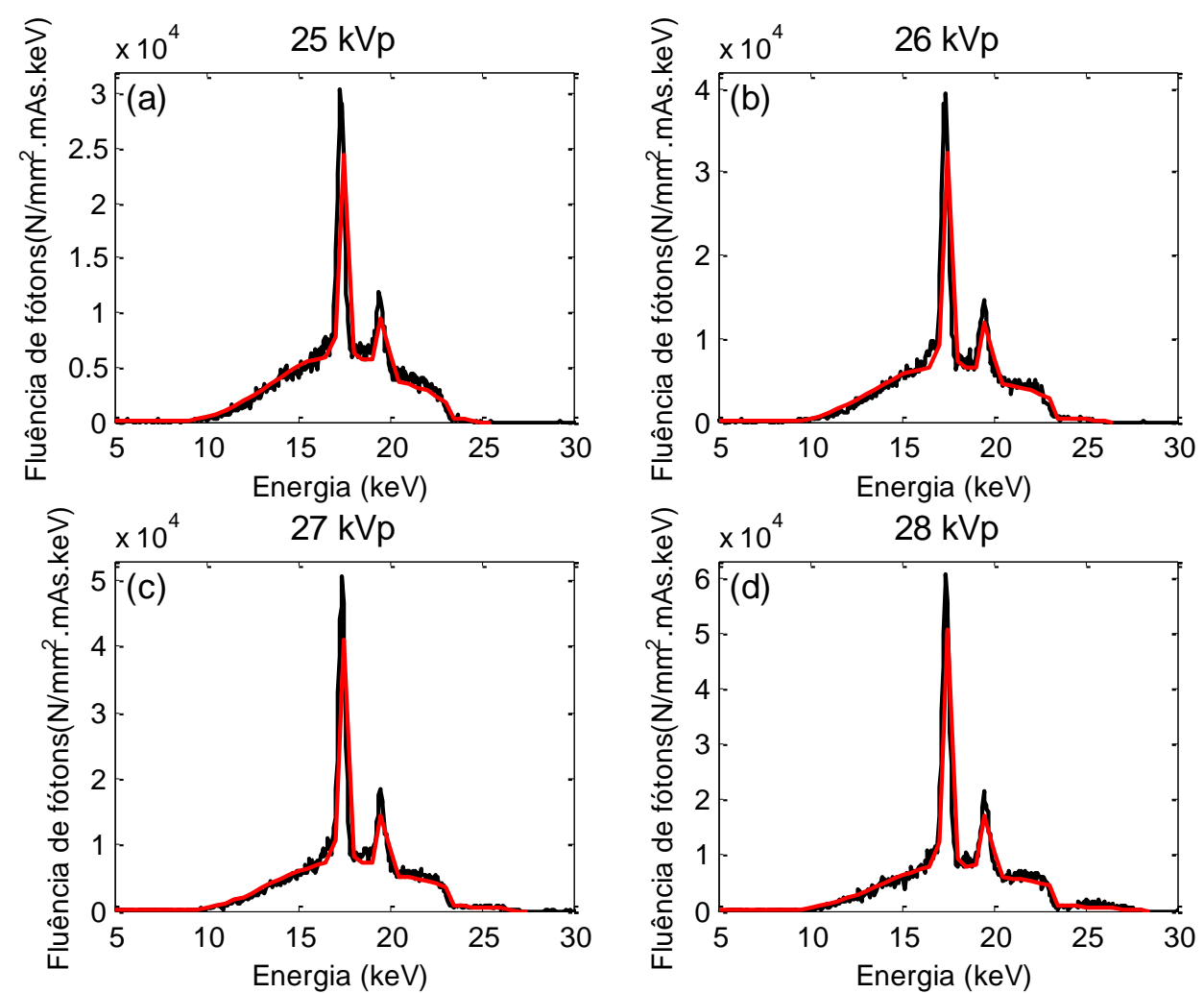

Figura 32: Espectros de raios $X$ experimentais de $\mathrm{Mo} / \mathrm{Rh}$ medidos no equipamento Selenia (linha preta) e espectros gerados pelo modelo de Boone e colaboradores (1997) (linha vermelha) para valores típicos de tensão no utilizados em mamografia.

A Tabela 13 apresenta os valores de camada semirredutora, CSR, calculados a partir dos espectros experimentais e os espectros calculados. As incertezas nos valores de CSR obtidas para os espectros experimentais foram menores que $0,3 \%$ e para os espectros calculados foram menores que $0,6 \%$. O procedimento utilizado para o cálculo de CSR e estimativa de incertezas é apresentado no Apêndice I. A máxima diferença observada entre os valores de CRS foi de $-1,3 \%$ para o espectro $\mathrm{Mo} / \mathrm{Rh}$ de $25 \mathrm{kV}$.

Tabela 13: Valores de CSR calculados a partir dos espectros experimentais (Selenia) e espectros calculados pelo modelo de Boone e colaboradores (1997). As incertezas nos valores de CSR obtidas para os espectros experimentais foram menores que $0,3 \%$ e para os espectros calculados foram menores que $0,6 \%$ (para $k=1$ ).

\begin{tabular}{cccc}
\hline Anodo/filtro & $\begin{array}{c}\text { Tensão no } \\
\text { tubo }(\mathbf{k V})\end{array}$ & \multicolumn{2}{c}{ CSR calculada (mmAl) } \\
\cline { 3 - 4 } & & $\begin{array}{c}\text { Espectro } \\
\text { experimental }\end{array}$ & $\begin{array}{c}\text { Espectro } \\
\text { calculado }\end{array}$ \\
\hline \multirow{3}{*}{ Mo/Mo } & 25 & 0,313 & 0,314 \\
& 26 & 0,327 & 0,326 \\
& 27 & 0,335 & 0,337 \\
& 28 & 0,346 & 0,348 \\
\hline \multirow{3}{*}{ Mo/Rh } & 25 & 0,381 & 0,376 \\
& 26 & 0,395 & 0,391 \\
& 27 & 0,404 & 0,404 \\
& 28 & 0,415 & 0,415 \\
\hline
\end{tabular}


B. Espectros de raios $X$ medidos no equipamento de mamografia Mammomat 3000 Nova

A Figura 33 apresenta os resultados comparativos entre os espectros experimentais gerados pelo equipamento Mammomat 3000 Nova utilizando a combinação de anodo/filtro Mo/Mo e espectros equivalentes gerados pelo modelo de Boone e colaboradores (1997) para tensões de 25, 26, 27 e $28 \mathrm{kV}$.
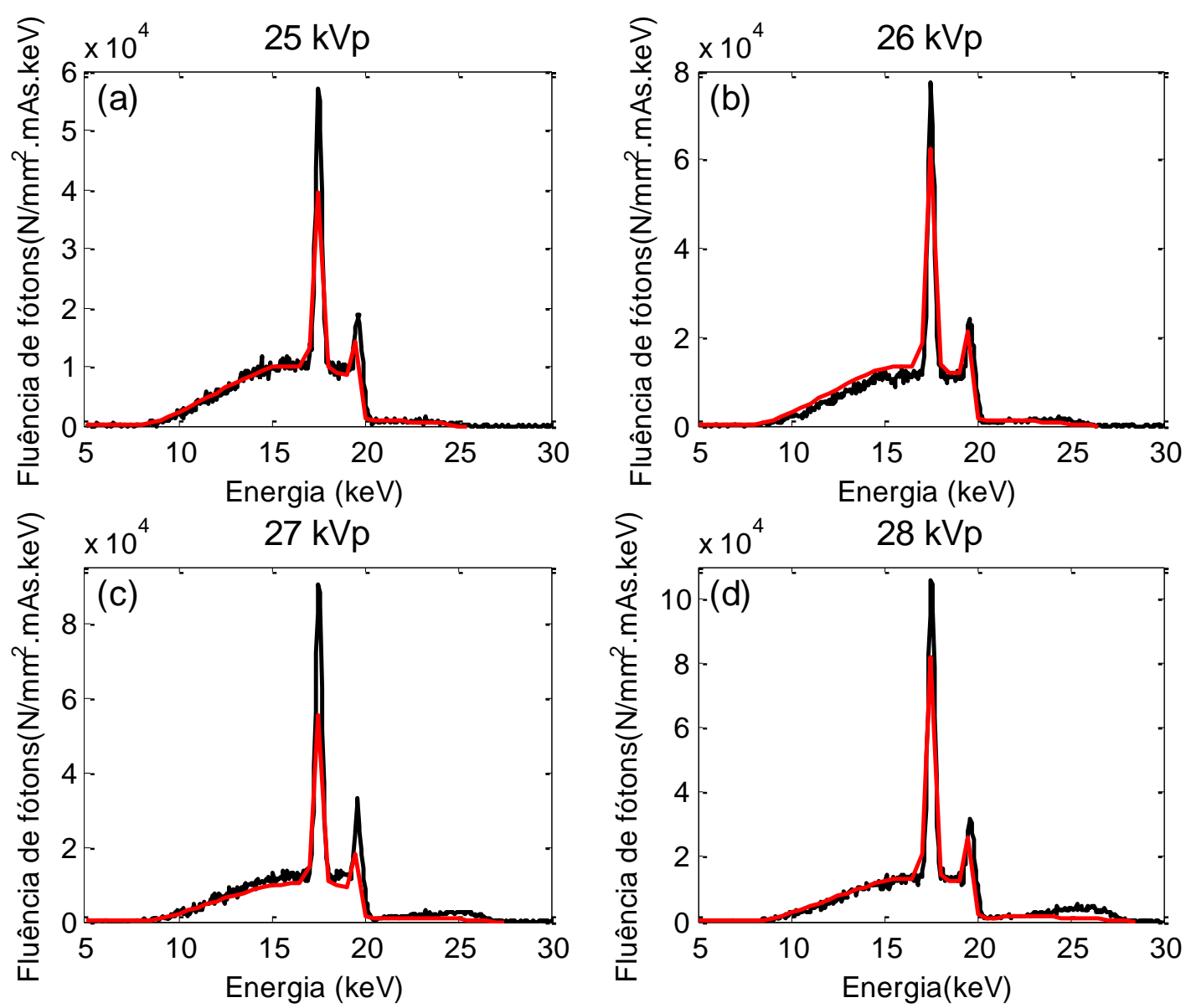

Figura 33: Espectros de raios $X$ experimentais de Mo/Mo médios no equipamento Mammomat 3000 Nova (linha preta) e espectros gerados pelo modelo de Boone e colaboradores (1997) (linha vermelha) para valores típicos de tensão utilizados em mamografia.

A Figura 34 e a Figura 35 apresentam resultados comparativos similares para espectros medidos no mesmo equipamento considerando as combinações de anodo/filtro $\mathrm{Mo} / \mathrm{Mo} \mathrm{e} \mathrm{W/Rh}$. 

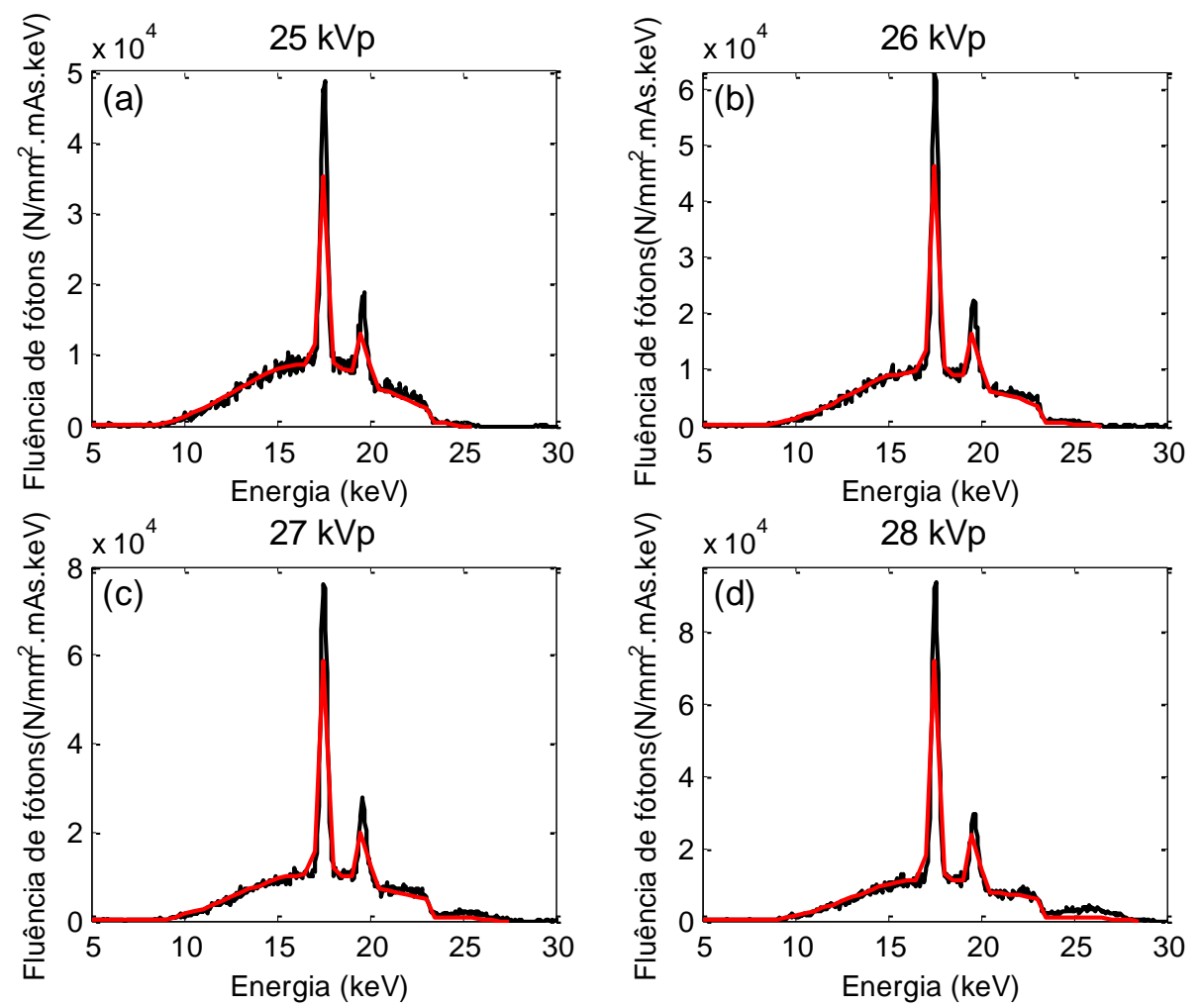

Figura 34 : Espectros de raios $\mathrm{X}$ experimentais de Mo/Rh médios no equipamento Mammomat 3000 Nova (linha preta) e espectros gerados pelo modelo de Boone e colaboradores (1997) (linha vermelha) para valores típicos de tensão utilizados em mamografia.
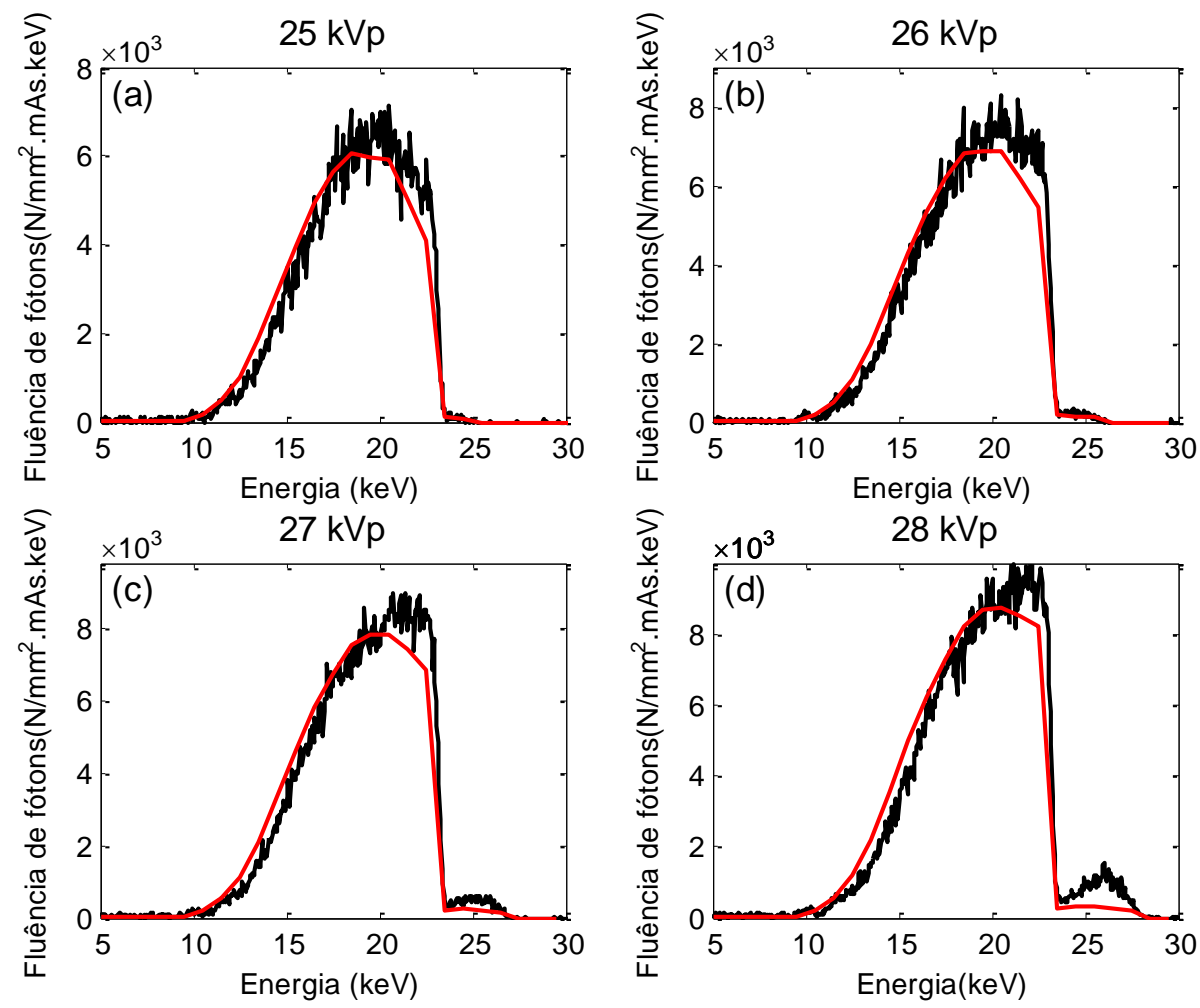

Figura 35: Espectros de raios $X$ experimentais de W/Rh médios no equipamento Mammomat 3000 Nova (linha preta) e espectros gerados pelo modelo de Hernandez and Boone (2014) (linha vermelha) para valores típicos de tensão utilizados em mamografia. 
O conjunto de espectros de raios $\mathrm{X}$ medidos apresentou, em geral, boa concordância com os espectros obtidos por modelos computacionais descritos na subseção 2.6.2 para todas as combinações de anodo/filtro utilizadas. No entanto, pequenas diferenças entre estes espectros podem ser notadas no final dos espectros de $28 \mathrm{kV}$ (Mo/Mo e $\mathrm{Mo} / \mathrm{Rh}$ ) medido no equipamento Mammomat 3000 Nova. Isso ocorre devido à alta corrente utilizada para geração desses feixes nesse equipamento (cerca de $100 \mathrm{~mA}$ ), em relação aos mesmos espectros de $28 \mathrm{kV}(\mathrm{Mo} / \mathrm{Mo}$ e $\mathrm{Mo} / \mathrm{Rh})$ gerados pelo equipamento Selenia (cerca de $30 \mathrm{~mA}$ ). A alta corrente é responsável pelo aumento na taxa de contagens e, portanto, resulta em tempo morto no processamento da detecção dos fótons. Desse modo, a metodologia proposta nesse trabalho se limita a medir espectros diretos utilizando tensões de, no máximo, $28 \mathrm{kV}$. Para medir espectros gerados com tensões maiores, sem modificar as configurações originais do equipamento clínico, é necessário reduzir o diâmetro do colimador, o que prejudica significativamente a qualidade do alinhamento do espectrômetro. Além disso, estes espectros experimentais contêm, nas energias próximas à energia máxima, alguns fótons resultantes de espalhamento no arranjo experimental conforme descrito na subseção 3.1.3.

A Tabela 14 apresenta os valores de CSR para os espectros de raios X experimentais e espectros calculados por métodos computacionais considerando as exposições realizadas no equipamento Mammomat 3000 Nova. As incertezas nos valores de CSR obtidas para os espectros experimentais foram menores que $1 \%$ e para os espectros calculados foram menores que $0,7 \%$. A diferença máxima observada entre estes valores foi de $4,7 \%$.

Tabela 14: Valores de CSR calculados a partir dos espectros experimentais de (Mammomat 3000 Nova) espectros calculados por modelos computacionais. As incertezas nos valores de CSR obtidas para os espectros experimentais foram menores que $1 \%$ e para os espectros calculados foram menores que $0,7 \%$.

\begin{tabular}{cccc}
\hline Anodo/filtro & Tensão no & \multicolumn{2}{c}{ CSR calculada (mmAl) } \\
\cline { 3 - 4 } & & $\begin{array}{c}\text { Espectro } \\
\text { experimental }\end{array}$ & $\begin{array}{c}\text { Espectro } \\
\text { calculado }\end{array}$ \\
\hline \multirow{3}{*}{ Mo/Mo } & 25 & 0,296 & 0,295 \\
& 26 & 0,311 & 0,310 \\
& 27 & 0,323 & 0,321 \\
& 28 & 0,333 & 0,330 \\
\hline \multirow{3}{*}{ Mo/Rh } & 25 & 0,346 & 0,335 \\
& 26 & 0,360 & 0,350 \\
& 27 & 0,370 & 0,363 \\
W/Rh & 28 & 0,378 & 0,374 \\
\hline & 25 & 0,473 & 0,452 \\
& 26 & 0,487 & 0,465 \\
& 27 & 0,493 & 0,476 \\
& 28 & 0,503 & 0,486 \\
\hline
\end{tabular}




\section{Diferença percentual entre espectros de raios X experimentais e espectros modelados.}

A diferença percentual entre a quantidade de fótons dos espectros experimentais e dos espectros simulados para cada intervalo de energia do espectro $(0,056 \mathrm{keV})$, foi calculada seguindo a metodologia usada por Boone e colaboradores ${ }^{61}$. Esta metodologia permite comparar espectros experimentais e espectros gerados por modelos computacionais. Para essa análise, foram considerados os intervalos de energia (canais) cujos valores de fluência eram maiores que $5 \%$ do valor de fluência do pico de maior intensidade. Para cada equipamento de mamografia utilizado, os resultados foram agrupados em conjuntos de espectros de $25-28 \mathrm{kV}$ de mesma combinação anodo/filtro. Os resultados foram dispostos em histogramas e a diferença média dos valores de fluência de cada conjunto de espectros foi estimada como o valor médio de uma distribuição normal ajustada aos dados.

A Figura 36 apresenta a diferença percentual entre os espectros experimentais e espectros calculados correspondentes ao equipamento Selenia para ambas combinações de anodo/filtro analisadas, Mo/Mo (a) e Mo/Rh (b). Para os espectros de Mo/Mo, a distribuição apresentou média e desvio padrão iguais a $-3,53 \%$ e $9,6 \%$, respectivamente. Para os espectros de $\mathrm{Mo} / \mathrm{Rh}$, a média e o desvio padrão obtidos foram 2,2\% e 18,8\%. Estes resultados foram obtidos através do ajuste da função gaussiana para $\mathrm{Mo} / \mathrm{Mo}$ e $\mathrm{Mo} / \mathrm{Rh}$, respectivamente.
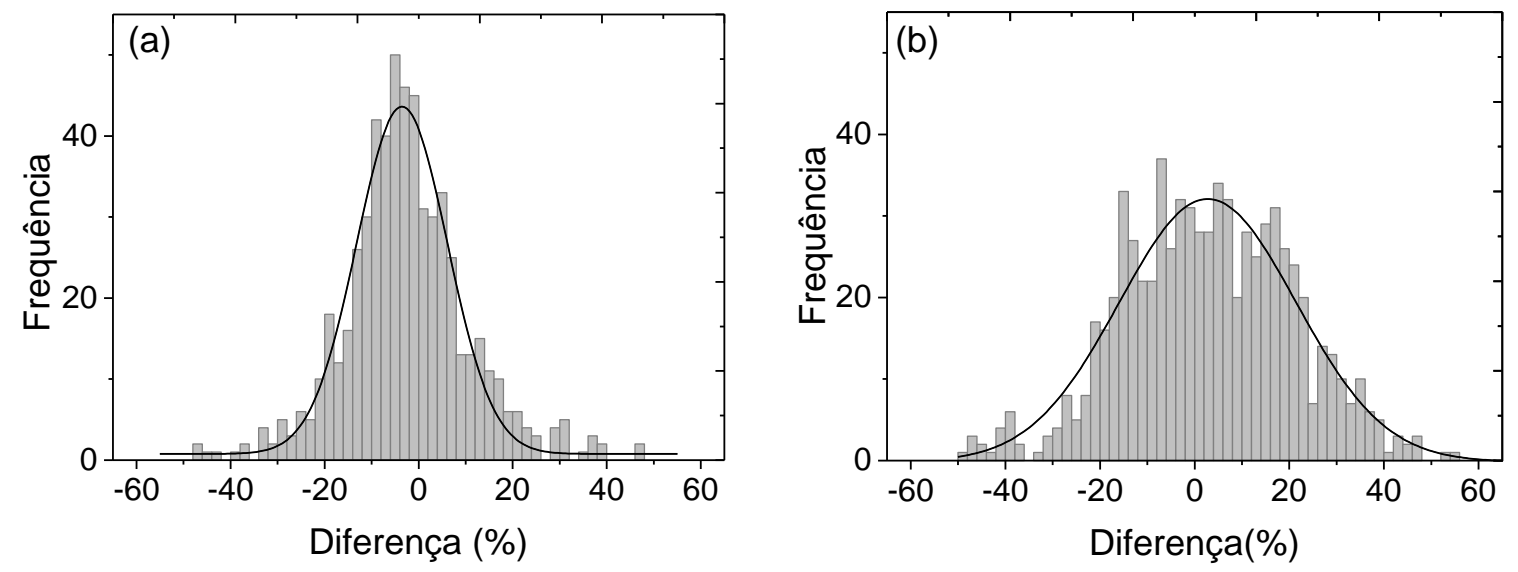

Figura 36: Diferença percentual entre a fluência de fótons dos espectros experimentais e espectros calculados, para cada intervalo de energia $(0,056 \mathrm{keV})$. (a) apresenta os resultados para os espectros de Mo/Mo de 25 a $28 \mathrm{kV}$ correspondentes ao equipamento Selenia. (b) apresenta os resultados para os espectros de $\mathrm{Mo} / \mathrm{Rh}$ deste mesmo equipamento. A diferença média e desvio padrão estimados a partir dos histogramas foram $-3,53 \%$ e 9,6\%, respectivamente, para os espectros de Mo/Mo. Para os espectros de $\mathrm{Mo} / \mathrm{Rh}$, a média e o desvio padrão obtidos foram $2,2 \%$ e $18,8 \%$. Estes valores foram estimados a partir do ajuste de uma gaussiana (curva em preto) para os dados correspondentes a Mo/Mo e Mo/Rh, respectivamente. 
A Figura 37 apresenta a diferença percentual entre os espectros experimentais e espectros calculados correspondentes ao equipamento Mammomat 3000 Nova para as combinações de anodo/filtro, Mo/Mo (a), Mo/Rh (b) e W/Rh (c). As distribuições apresentaram valores médios e desvios padrão, respectivamente iguais a: $-2,92 \%$ e $10,5 \%$, para $\mathrm{Mo} / \mathrm{Mo} ;-1,26 \%$ e 13,0\%, para Mo/Rh; e, $-5,37 \%$ e 18,2\%, para W/Rh. Estes valores foram estimados a partir do ajuste de uma função gaussiana para os dados correspondente a $\mathrm{Mo} / \mathrm{Mo}, \mathrm{Mo} / \mathrm{Rh}$ e $\mathrm{W} / \mathrm{Rh}$, respectivamente.
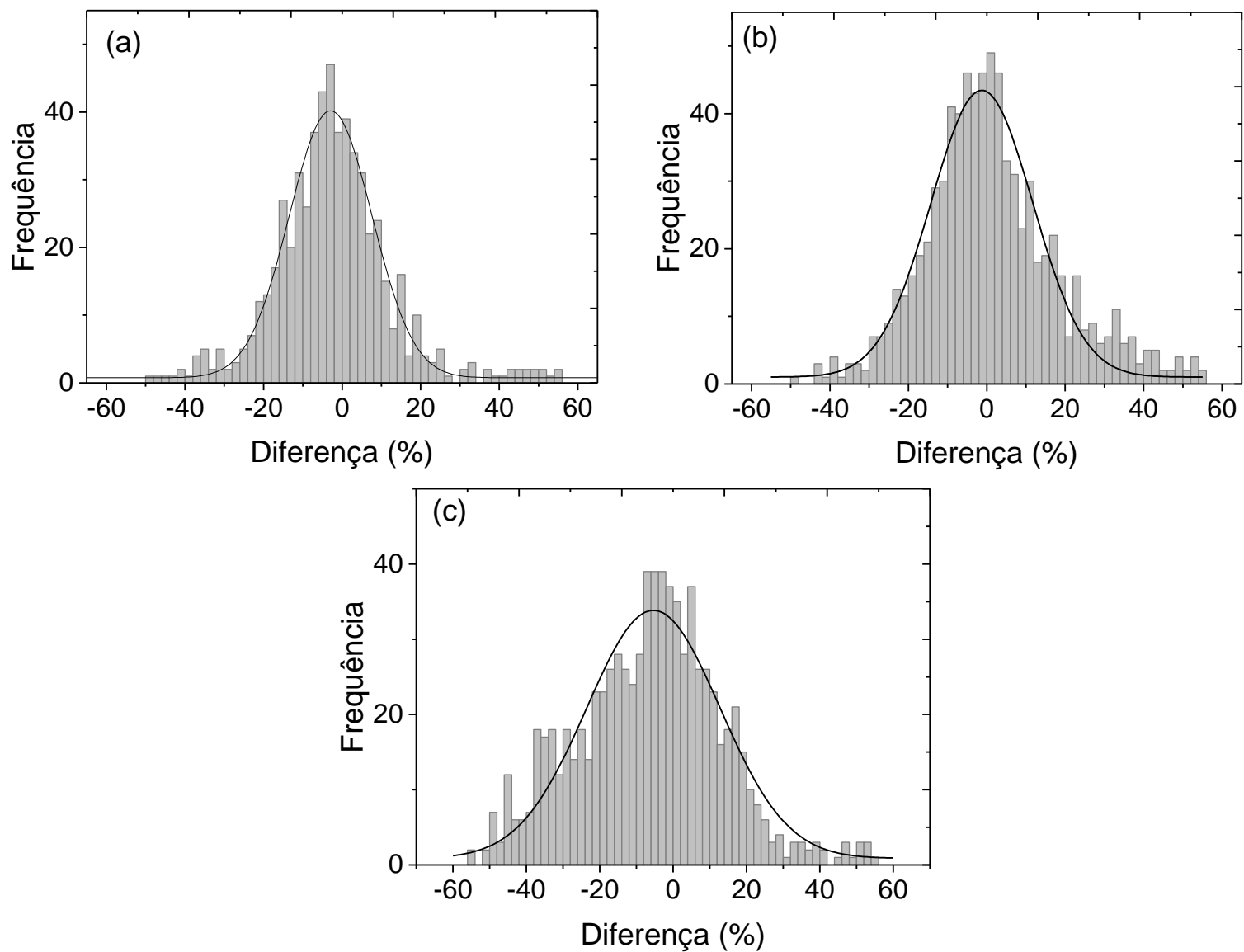

Figura 37: Diferença percentual entre a fluência de fótons dos espectros experimentais e espectros calculados, para cada intervalo de energia $(0,055 \mathrm{keV}$ ) para: (a) $\mathrm{Mo} / \mathrm{Mo}$, (b) $\mathrm{Mo} / \mathrm{Rh}$ e (c) $\mathrm{W} / \mathrm{Rh}$ correspondentes ao equipamento Mammomat 3000 Nova. A diferença média e desvio padrão estimados a partir dos histogramas foram $-2,92 \% \pm 10,5 \%$ para Mo/Mo, $-1,26 \% \pm 13,0 \%$ para Mo/Rh e $-5,37 \% \pm 18,2 \%$ para W/Rh. Estes valores foram estimados a partir do ajuste de uma função gaussiana (curva em preto) para os dados correspondente a Mo/Mo, Mo/Rh e W/Rh, respectivamente.

Os espectros experimentais correspondentes à combinação Mo/Mo mostraram melhor concordância com os respectivos espectros calculados por modelos computacionais para ambos os equipamentos Selenia e Mammomat. A grande dispersão do valor médio se deve às flutuações estatísticas dos espectros experimentais. O fato de não haver coincidência entre os dois picos de fluorescência do Mo é refletido no deslocamento do valor médio da distribuição em relação ao zero do eixo das abcissas. 


\subsubsection{Efeitos do desalinhamento do detector}

A imprecisão no alinhamento do espectrômetro pode afetar o espectro medido em dois diferentes e importantes aspectos: A quantidade (intensidade) e qualidade do espectro (forma). Quando o espectrômetro está desalinhado, as bordas da pequena abertura do colimador provocam uma atenuação indesejada dos fótons de baixa energia que deveriam chegar ao detector. Isso provoca uma redução do número de fótons que deveriam ser registrados e uma modificação na forma deste espectro. Em outros termos, isto resulta no endurecimento do feixe detectado e no aumento da estimativa da camada semirredutora calculada a partir desses espectros.

A intensidade dos espectros é um parâmetro prático para avaliar a qualidade do alinhamento. A diferença entre a quantidade de eventos registrados pelo espectrômetro quando este dispositivo está corretamente alinhado e quando está desalinhado é um indicador para a escolha de um posicionamento adequado do espectrômetro. Este efeito é apresentado nos espectros de fluência $(\mathrm{W} / \mathrm{Rh}, 28 \mathrm{kV})$ da Figura 38. Essa figura mostra os espectros medidos quando o espectrômetro foi posicionado em ângulos maiores (Figura 38 (a)) e menores (Figura 38 (b)) que 4,3․ Essa posição (a 4,3 $3^{\circ}$ corresponde a posição de melhor alinhamento do espectrômetro conforme apresentado na Figura 10 .

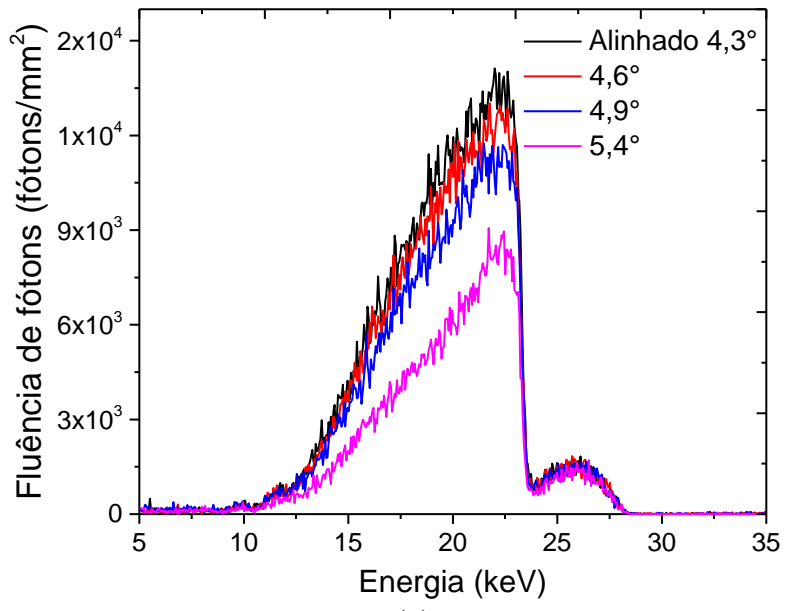

(a)

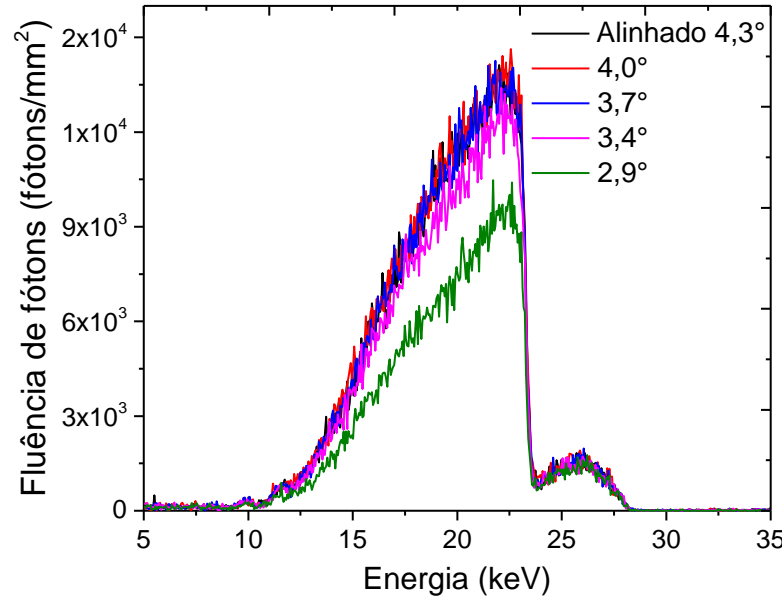

(b)

Figura 38: Comparação dos espectros de fluência gerados usando $28 \mathrm{kV}$ e combinação ando/filtro de W/Rh. Espectros medidos com espectrômetro posicionado em diferentes inclinações, para ângulos maiores (Figura 38 (a)) e menores que $4,3^{\circ}$ (Figura 38 (b) ).

A fluência total de fótons corresponde à integral do espectro sobre todos os intervalos de energia. Para os espectros obtidos no caso em que o espectrômetro teve a posição desviada da posição inicial de alinhamento, a máxima variação do número total de fótons foi de $44 \%$, 
obtida para o espectro medido a 5,4 . A variação mínima foi de $3 \%$, obtida para o espectro medido a $4,0^{\circ}$. A incerteza dos valores de fluência total dos espectros foi propagada considerando a distribuição de Poisson para cada canal do espectro. A incerteza média obtida foi de $0,5 \%$.

A deformação dos espectros medidos e, consequentemente, a variação dos valores de CSR obtidos a partir desses espectros, devido ao desalinhamento do espectrômetro, é uma questão importante a ser considerada nas análises de espectros experimentais. $\mathrm{O}$ efeito do desalinhamento do espectrômetro nos valores estimados de CSR é apresentado na Figura 39. São apresentados valores de CSR derivados a partir dos espectros em função do ângulo de posicionamento do espectrômetro.

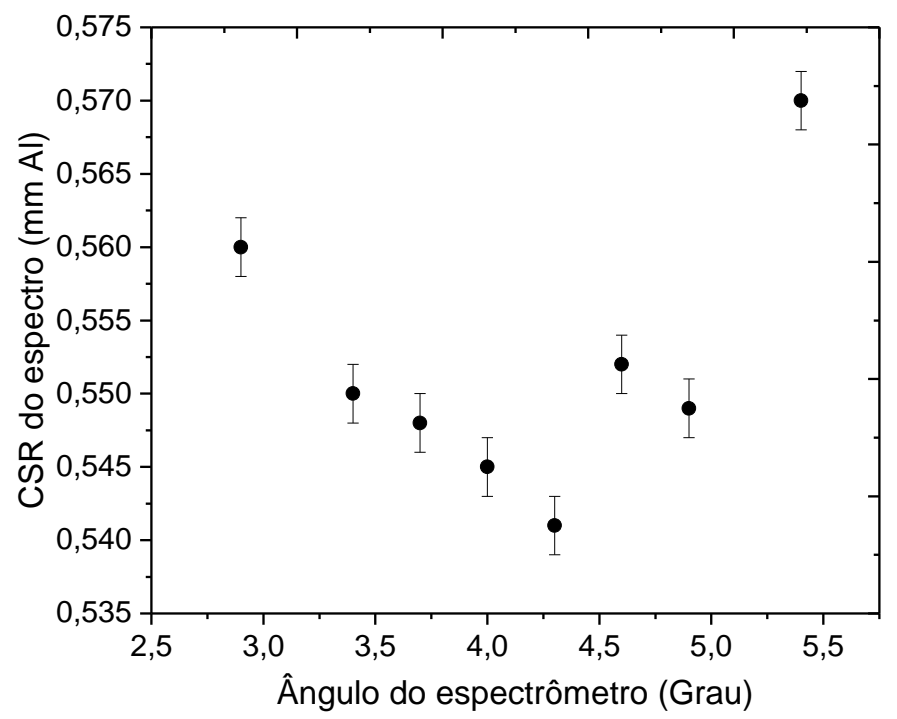

Figura 39: Valores de camada semirredutora derivados a partir dos espectros medidos como função do ângulo de posicionamento do espectrômetro

O menor valor de CSR obtido está relacionado ao menor grau de endurecimento do feixe e, consequentemente, ao melhor alinhamento. Nesse caso, a distorção no espectro devido à filtração de fótons de baixa energia pelas bordas do furo do colimador por causa do desalinhamento é mínima. A Figura 39 mostra que o valor mínimo de CSR foi obtido por meio do espectro medido com o espectrômetro alinhado a $4,3^{\circ}$, tal como esperado. Este mesmo espectro é também um dos que possui maior intensidade entre o conjunto medido. A variação máxima do valor de CSR foi de $5 \%$. 


\subsubsection{Espectros de raios $\mathrm{X}$ transmitidos}

Os espectros de raios $\mathrm{X}$ transmitidos por phantoms de tecido equivalente foram medidos conforme metodologia descrita na seção a seção 3.2.2. A Figura 40 apresenta os espectros fluência de fótons transmitidos por algumas espessuras, entre $5 \mathrm{~mm}$ e $45 \mathrm{~mm}$, dos phantoms 30/70 e 50/50. Os espectros foram medidos utilizando a tensão de $28 \mathrm{kV}$ e estão normalizados pela carga (mAs). A Figura 41 e a Figura 42 apresentam resultados similares para feixes de $\mathrm{Mo} / \mathrm{Rh}$ e $\mathrm{W} / \mathrm{Rh}$. Todos os espectros transmitidos medidos encontram-se no Apêndice II.

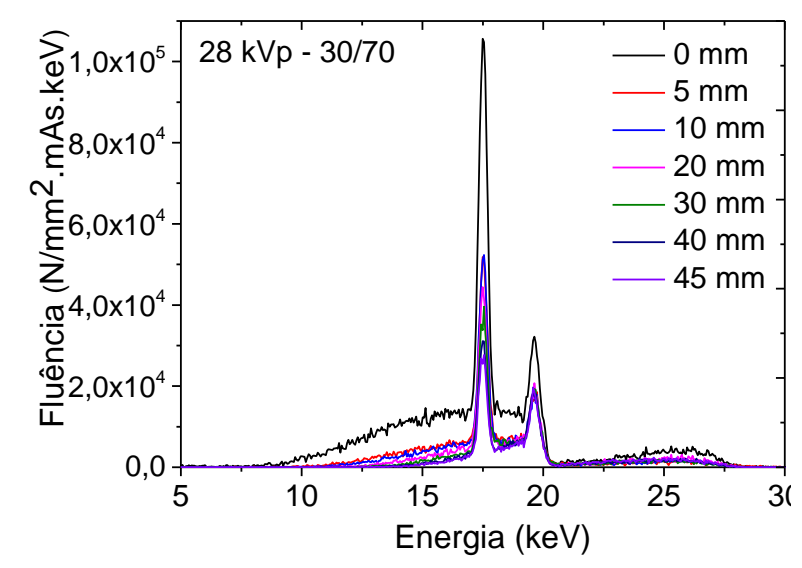

(a)

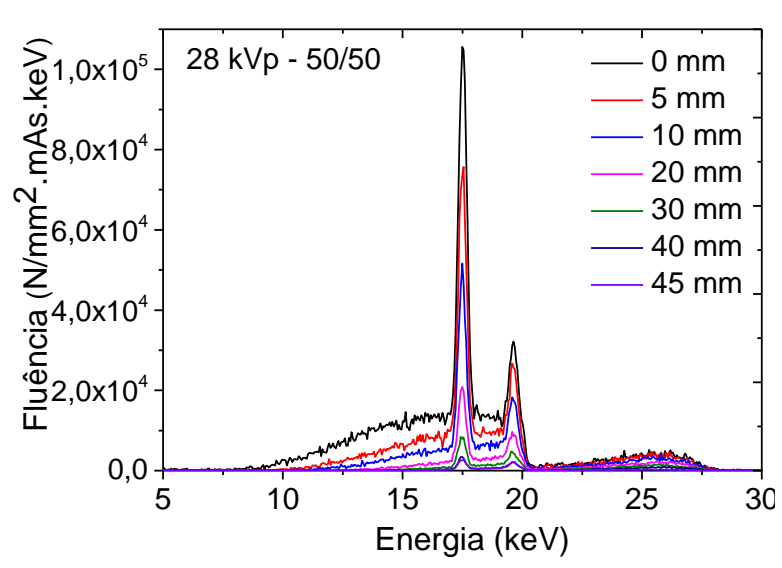

(b)

Figura 40: Espectros de fluência de fótons de feixes de raios $\mathrm{X}$ transmitidos por várias espessuras dos phantoms de tecido equivalente 30/70 (a) e 50/50 (b). Os feixes de radiação foram gerados com $28 \mathrm{kV}$ utilizando a combinação Mo/Mo. Todos os espectros foram normalizados pela carga total (mAs).

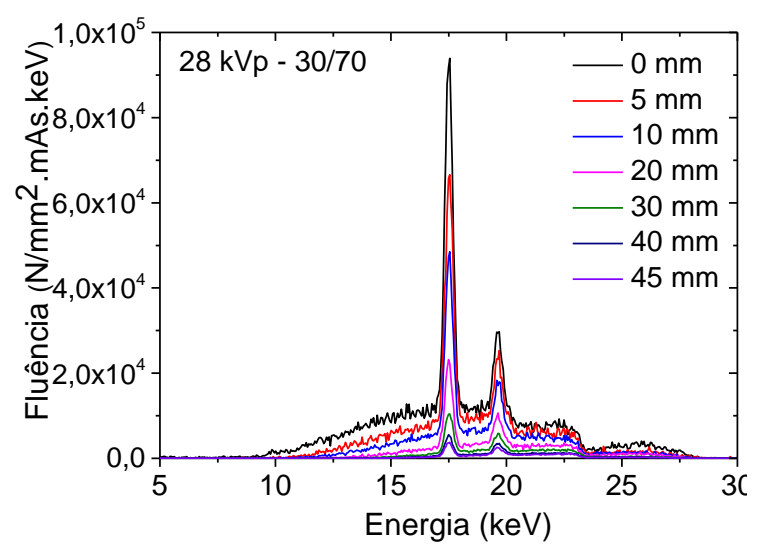

(a)

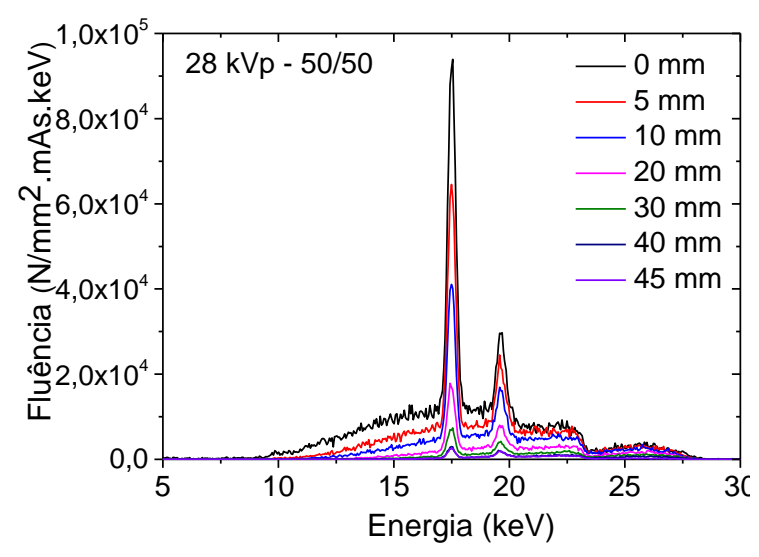

(b)

Figura 41: Espectros de fluência de fótons de feixes de raios $\mathrm{X}$ transmitidos por várias espessuras dos phantoms de tecido equivalente 30/70 (a) e 50/50 (b). Os feixes de radiação foram gerados com $28 \mathrm{kV}$ utilizando a combinação $\mathrm{Mo} / \mathrm{Rh}$. Todos os espectros foram normalizados pela carga total (mAs). 


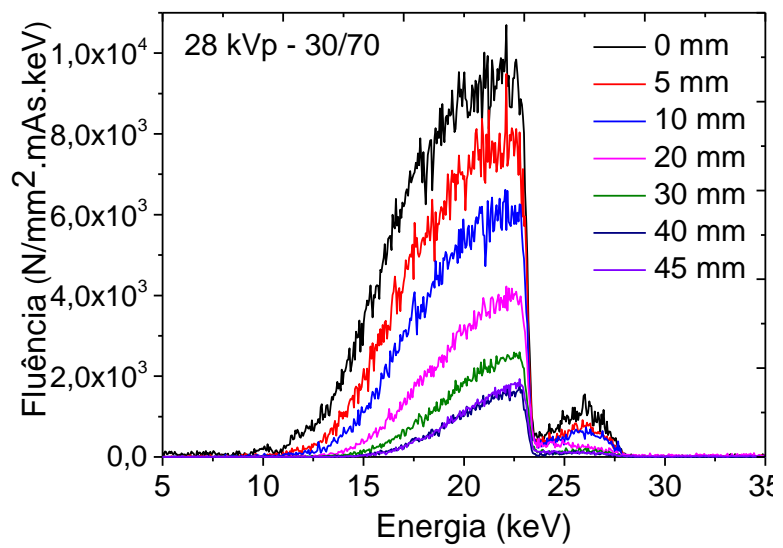

(a)

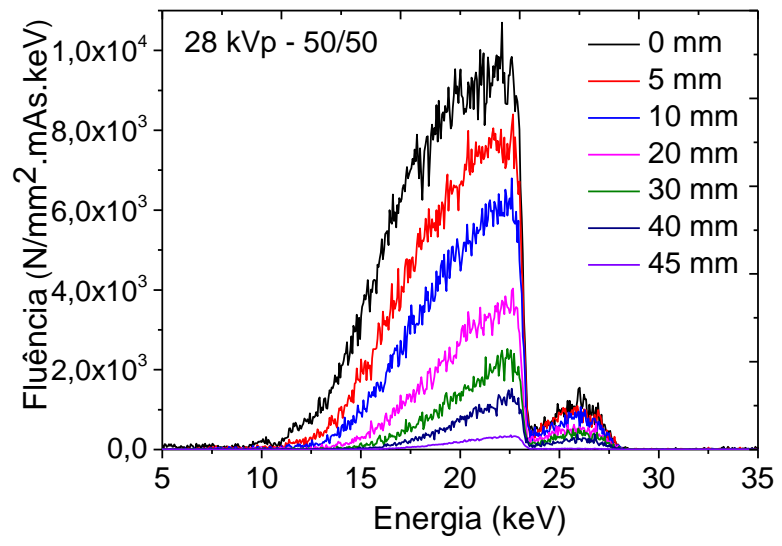

(b)

Figura 42: Espectros de fluência de fótons de feixes de raios $\mathrm{X}$ transmitidos por várias espessuras dos phantoms de tecido equivalente 30/70 (a) e 50/50 (b). Os feixes de radiação foram gerados com $28 \mathrm{kV}$ utilizando a combinação W/Rh. Todos os espectros foram normalizados pela carga total (mAs).

A Figura 43 apresenta as curvas de transmissão de feixes de mamografia por phantoms de tecido equivalente 30/70 e 50/50. As figuras com índices (a), (b) e (c) apresentam as curvas de transmissão para feixes de 26,28 e $30 \mathrm{kV}$, respectivamente.

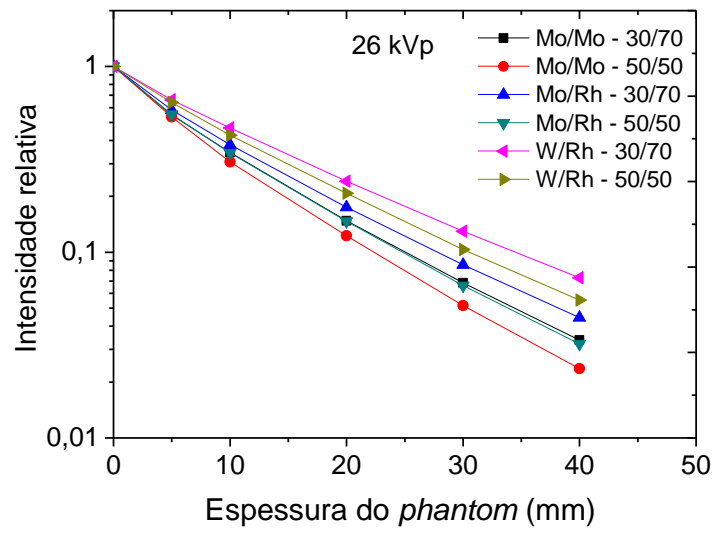

(a)

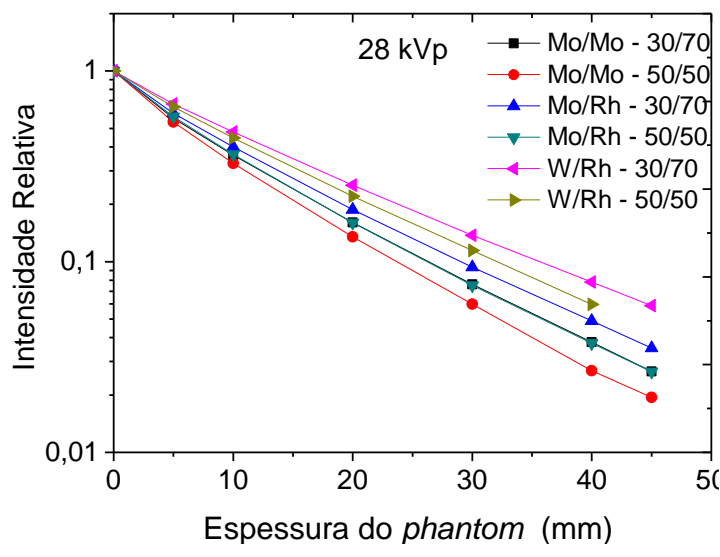

(b)

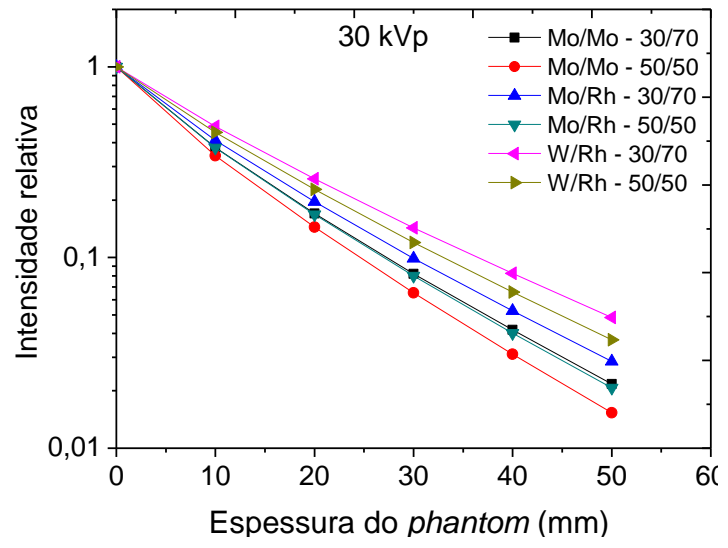

(c)

Figura 43: Curvas de transmissão de feixes utilizados em mamografia por phantoms de composições 30/70 e 50/50. Os feixes foram produzidos utilizando as combinações anodo/filtro $\mathrm{Mo} / \mathrm{Mo}, \mathrm{Mo} / \mathrm{Rh}$ e W/Rh com valores de tensão aplicada ao tubo iguais a: $26 \mathrm{kV}$ (a), $28 \mathrm{kV}$ (b) e $30 \mathrm{kV}$ (c). 
Os feixes de raios $\mathrm{X}$ utilizados para a obtenção das curvas de transmissão apresentadas na Figura 43 foram produzidos utilizando as diferentes combinações de anodo/filtro, Mo/Mo, $\mathrm{Mo} / \mathrm{Rh}$ e W/Rh. A Figura 43 (b) apresenta as curvas de transmissão correspondentes aos espectros transmitidos apresentados nas Figuras 39-41.

Os conjuntos de espectros apresentados para $28 \mathrm{kV}$ (Figuras 39-41) mostram como a distribuição de fótons por energia é modificada quando o feixe atravessa diferentes espessuras do material equivalente ao tecido mamário. Como esperado, os espectros transmitidos medidos para todas as combinações anodo/filtro usadas (Mo/Mo, Mo/Rh e W/Rh) apresentam redução de intensidade, principalmente nas regiões de baixas energias, com o aumento da espessura do material atenuador. Além disso, para uma mesma combinação de anodo/filtro, os espectros transmitidos pelo phantom 30/70 tem intensidades ligeiramente maiores que os espectros transmitidos pelo phantom 50/50. Isso ocorre porque a fração de material que representa o tecido glandular no phantom 50/50 é maior que no phantom 30/70. O tecido glandular apresenta maior coeficiente de atenuação linear que o tecido adiposo nessa faixa de energia $^{89}$. Esse efeito pode ser observado também nas curvas de transmissão apresentadas na Figura 43 (b). Para uma mesma combinação anodo/filtro, as curvas de transmissão do feixe pelo phantom 50/50 possui valores de intensidade relativa menores que os das curvas de transmissão do feixe pelo phantom 30/70.

\subsection{AVALIAÇÃO DA DOSE GLANDULAR NORMALIZADA UTILIZANDO ESPECTROS EXPERIMENTAIS}

A dose glandular média normalizada, $\mathrm{DgN}_{\mathrm{p}}$, foi estimada por meio de 3 diferentes métodos conforme descrito na subseção 3.3. Os resultados foram avaliados com relação aos seguintes parâmetros: tensão no tubo, camada semirredutora, combinação alvo/filtro, espessura de mama comprimida e glandularidade. As seções subsequentes apresentam os principais resultados obtidos.

\subsubsection{Método I: Dose glandular normalizada $\left(\mathrm{DgN}_{\mathrm{p}}\right)$ usando espectros primários}

A dose glandular normalizada pelo kerma no ar incidente, $\operatorname{DgN} \mathrm{N}_{\mathrm{p}}$, foi estimada utilizando espectros experimentais primários, conforme descrito na subseção 3.3.1, por meio da equação (15). As incertezas nos valores obtidos consideram somente a flutuação estatística no número de fótons em cada intervalo de energia dos espectros medidos. Desse modo, as 
incertezas obtidas variaram em torno de $4,5 \%$ dos valores de $\mathrm{DgN}_{\mathrm{p}}$ calculados com este método

\section{A - DgN $N_{p}$ em função da CSR para diferentes espessuras de mama comprimida}

Os valores de $\mathrm{DgN}_{\mathrm{p}}$ obtidos utilizando espectros de raios $\mathrm{X}$ primários experimentais foram comparados com aqueles obtidos com espectros simulados ${ }^{90}$. Estes valores são apresentados na Figura 44 para a combinação alvo/filtro Mo/Mo e, na Figura 45, para a combinação $\mathrm{Mo} / \mathrm{Rh}$. Ambas figuras apresentam resultados para a glandularidade de $50 \%$ e espessuras de $2-8 \mathrm{~cm}$. As linhas cheias e pontilhadas representam ajustes lineares aplicados aos dados. Os parâmetros de ajuste encontram-se no Apêndice III - A.

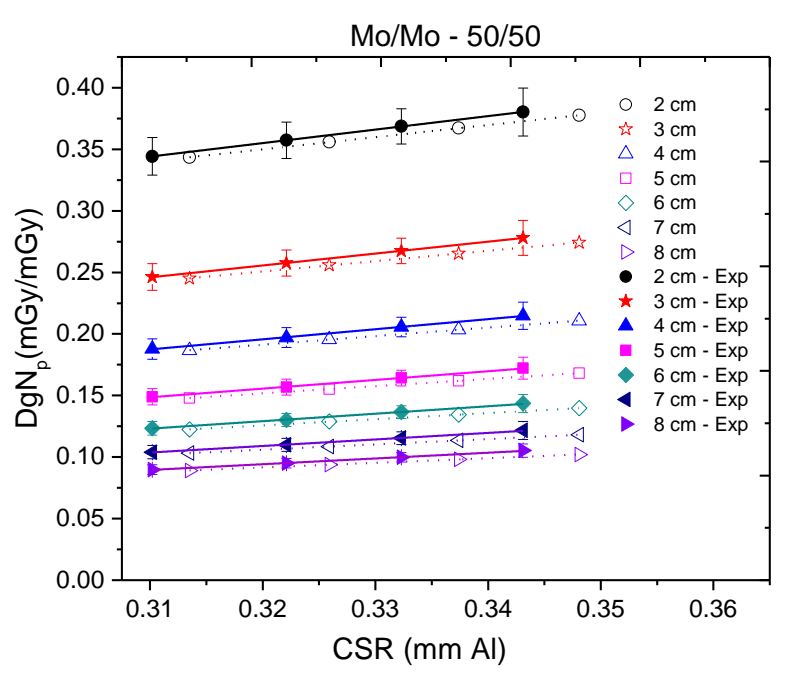

Figura 44: Valores de $\operatorname{DgN}_{\mathrm{p}}$ como função da camada semirredutora (CSR) obtidos utilizando espectros experimentais (símbolos cheios) e espectros simulados (símbolos vazios) para espectros de Mo/Mo e mama com composição de tecido glandular equivalente a $50 \%$. As linhas cheias e pontilhadas representam um ajuste linear aos dados.

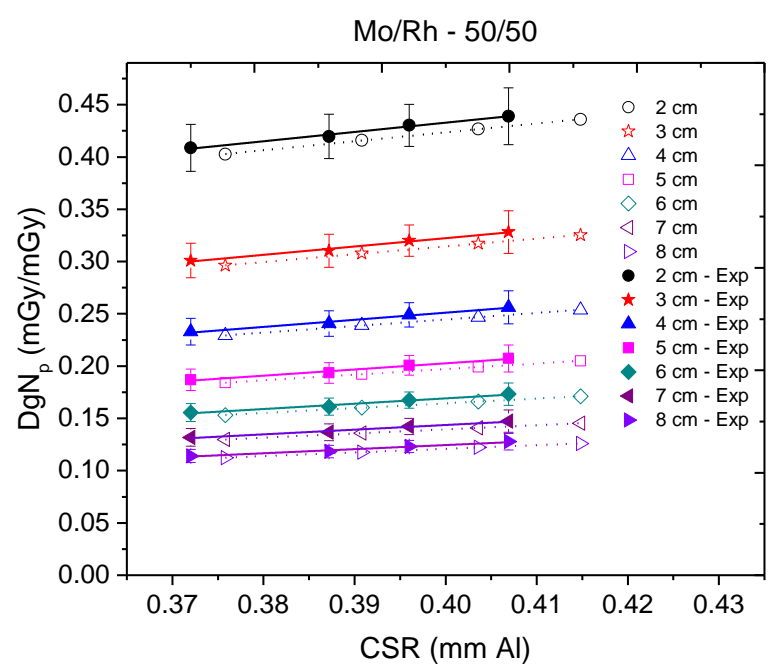

Figura 45: Valores de $\operatorname{DgN}_{\mathrm{p}}$ como função da camada semirredutora (CSR) obtidos utilizando espectros experimentais (símbolos cheios) e espectros simulados (símbolos vazios) para espectros de $\mathrm{Mo} / \mathrm{Rh}$ e mama com composição de tecido glandular equivalente a $50 \%$. As linhas cheias e pontilhadas representam um ajuste linear aos dados.

Os valores de $\mathrm{DgN}_{\mathrm{p}}$ obtidos com espectros experimentais são ligeiramente maiores que aqueles obtidos com espectros simulados. Apesar disso, esses valores são equivalentes considerando as respectivas incertezas. De acordo com as figuras apresentadas, a $\operatorname{DgN}_{\mathrm{p}}$ cresce linearmente com a CSR, diretamente relacionada à energia efetiva do feixe (equação(12)).

Como a dose glandular é inversamente proporcional à massa de tecido glandular (equação (28)), para um mesmo espectro incidente (ou mesmo kerma no ar incidente usado para normalização) era esperado que esses valores fossem maiores para espessuras menores de mama. Associado a este fato, deve-se considerar que a probabilidade de interação dos 
fótons do feixe com o tecido glandular, e a consequente deposição da energia nesse tecido, é uma função decrescente da energia (Figura 2). Como os fótons de baixa energia do feixe são absorvidos logo nas primeiras camadas do material, este processo resulta em uma maior proporção da dose média absorvida nas camadas iniciais do material.

\section{$B$ - DgN em função da espessura de mama comprimida para diferentes glandularidades}

A $\operatorname{DgN}_{\mathrm{p}}$ foi também avaliada para situações que representam mamas com diferentes proporções de tecido glandular $(0 \%, 30 \%, 50 \%, 70 \%$ e $100 \%)$. A $\mathrm{DgN}_{\mathrm{p}}$ obtida conforme o método apresentado na seção 3.3.1 depende de uma função DGN(E), que representa a dose glandular normalizada para fótons monoenergéticos, apresentada previamente na literatura ${ }^{82}$ somente para as glandularidades de $0 \%, 50 \%$ e $100 \%$. Portanto, foi necessário obter a função DGN(E) para valores de glandularidades complementares aos encontrados na literatura, tais como 30\% (Figura 46) e 70\% (Figura 47), por meio de interpolação linear. Os resultados são apresentados nas figuras citadas para espessuras de mama comprimidas no intervalo de 2 a $8 \mathrm{~cm}$.

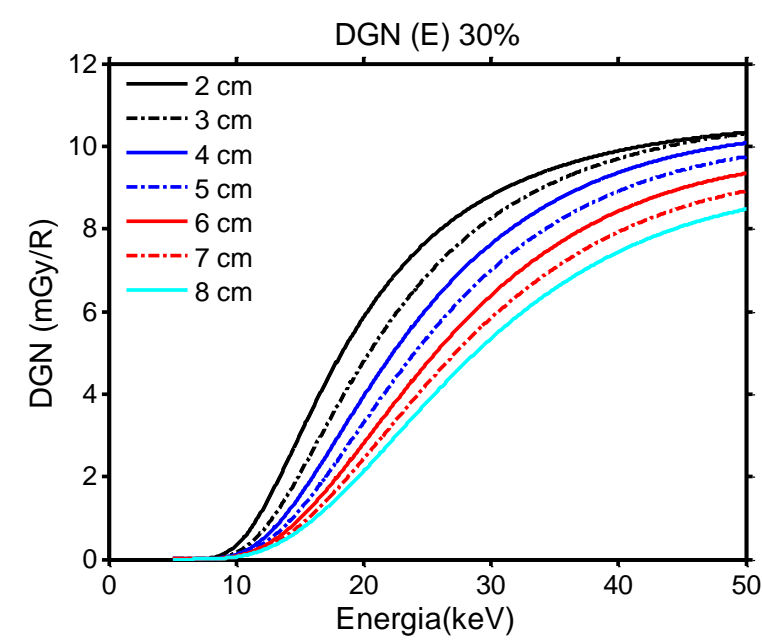

Figura 46: Valores da função $\operatorname{DGN}(\mathrm{E})$ para glandularidade de $30 \%$ e espessuras de mama entre 2 e $8 \mathrm{~cm}$. Valores obtidos por meio de interpolação linear da relação $D G N(E) x$ glandularidade $(0,50$ e $100 \%$.) fornecida na literatura ${ }^{82}$.

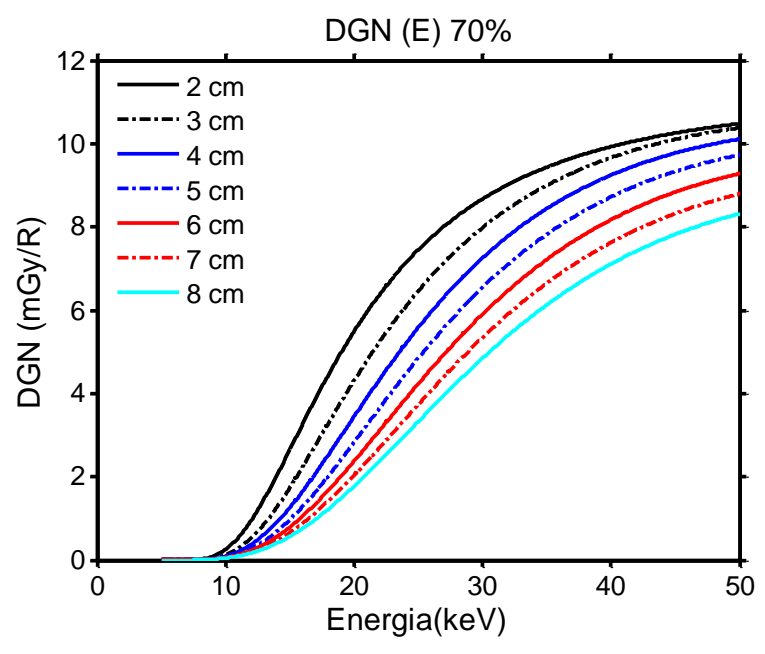

Figura 47: Valores da função $\operatorname{DGN}(\mathrm{E})$ para glandularidade de $70 \%$ e espessuras de mama entre 2 e $8 \mathrm{~cm}$. Valores obtidos por meio de interpolação linear da relação $D G N(E) x$ glandularidade $(0,50$ e $100 \%$.) fornecida na literatura ${ }^{82}$.

A Figura 48 e a Figura 49 apresentam valores de $\mathrm{DgN}_{\mathrm{p}}(\mathrm{mGy} / \mathrm{mGy})$ em função da espessura $(\mathrm{cm})$ para diferentes glandularidades, entre $0 \%$ e $100 \%$, ambas para espectro de $28 \mathrm{kV}$ medido no equipamento Selenia (Hologic). A Figura 48 apresenta os resultados para a combinação alvo/filtro Mo/Mo e a Figura 49 para a combinação Mo/Rh. As linhas nos 
gráficos representam o ajuste de uma função exponencial. Os parâmetros ajustados encontram-se o Apêndice III-B.

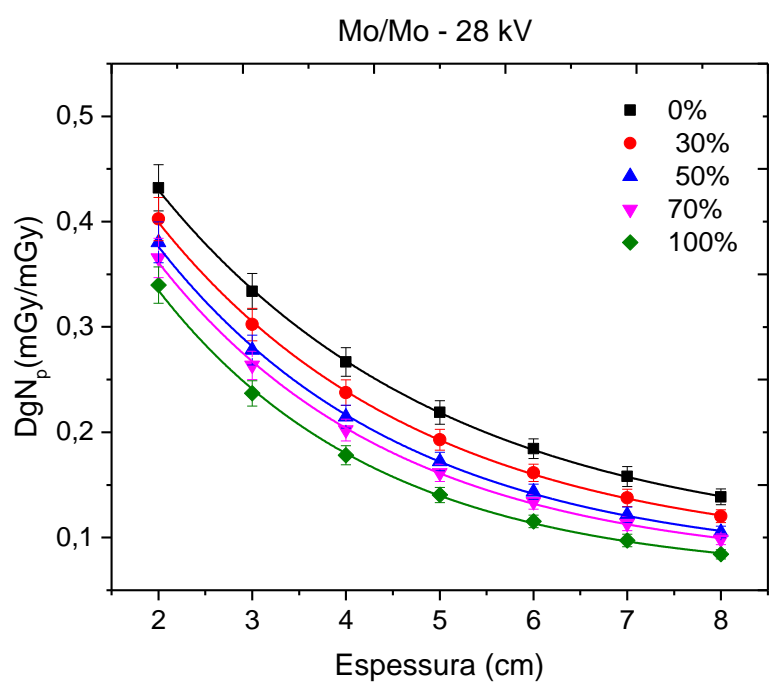

Figura 48: Variação da $D g N_{p}$ com a espessura de mamas com valores de glandularidade entre de $0 \%$ e $100 \%$ para o espectro de Mo/Mo, $28 \mathrm{kV}$.

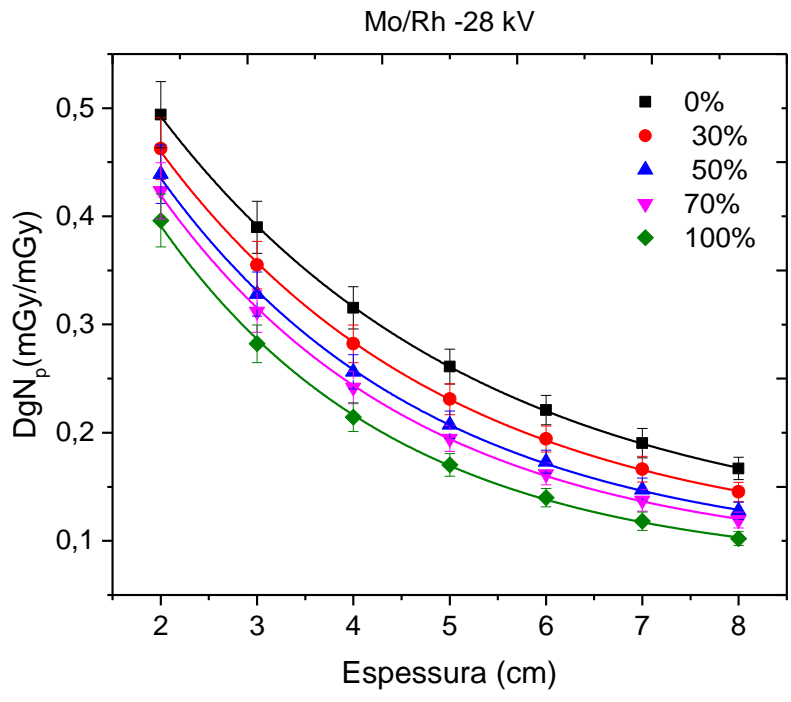

Figura 49: Variação da $D g N_{p}$ com a espessura de mamas com valores de glandularidade entre de $0 \%$ e $100 \%$ para o espectro de Mo/Rh, $28 \mathrm{kV}$.

De acordo com as figuras (Figura 48 e Figura 49) os valores de $\mathrm{DgN}_{\mathrm{p}}$ tendem a diminuir com o aumento da glandularidade. Isso se dá por conta da relação de proporcionalidade inversa da dose absorvida e da massa de tecido glandular. Esse comportamento era esperado, uma vez que todos os parâmetros foram mantidos fixos e houve somente variação na proporção de tecido glandular e, consequentemente, de massa deste tipo de tecido.

A Figura 50 apresenta alguns dos resultados mostrados na Figura 48 e na Figura 49 porém, desta vez, em função da glandularidade. São valores de $\mathrm{DgN}_{\mathrm{p}}$ para quatro diferentes espessuras (entre 2 e $8 \mathrm{~cm}$ ) e espectro representando um feixe gerado com $28 \mathrm{kV}$ utilizando alvo de Mo e filtros de Mo (símbolos cheios) e Rh (símbolos vazios). As linhas cheias representam ajuste linear aos resultados provenientes do uso do espectro de Mo/Mo e as linhas vazias representam o mesmo ajuste aos resultados obtidos com o espectro de Mo/Rh. Os resultados mostram que os valores de $\mathrm{DgNp}$ decrescem linearmente com o aumento da glandularidade e que são maiores para o feixe de maior energia média, Mo/Rh nesse caso específico. 


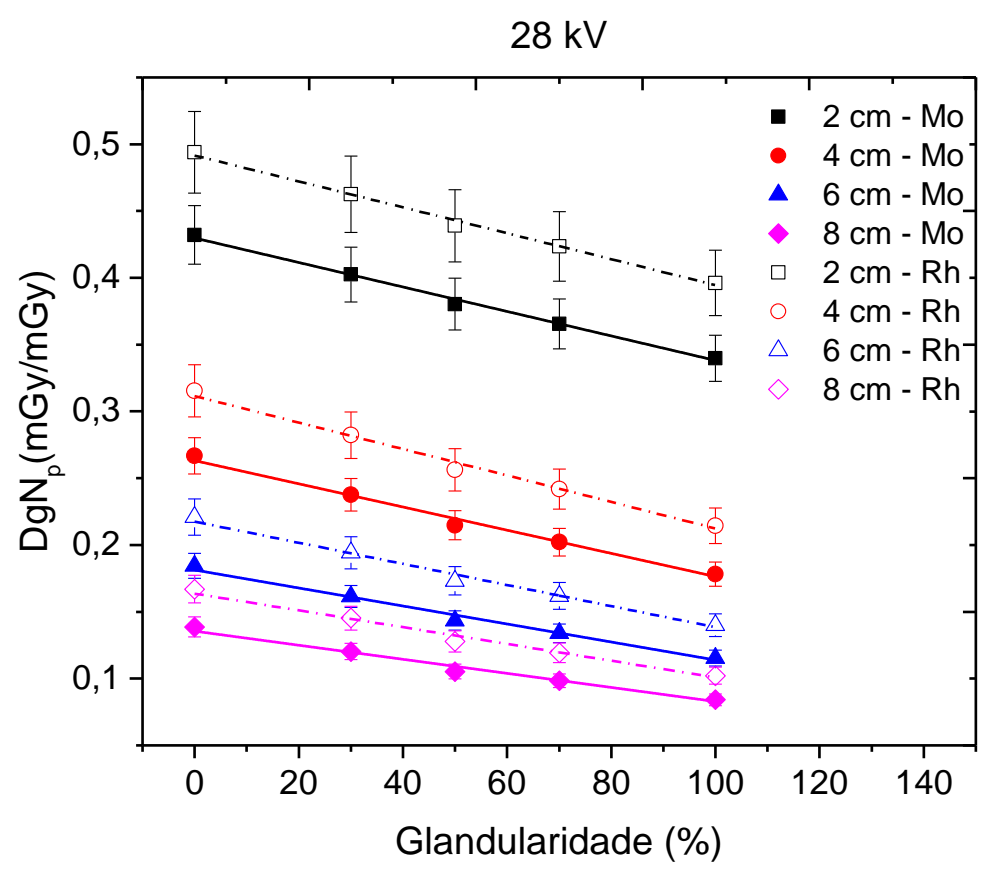

Figura 50: $\operatorname{DgN}_{\mathrm{p}}$ em função da glandularidade para quatro diferentes espessuras (entre 2 e $8 \mathrm{~cm}$ ) e espectro de $28 \mathrm{kV}$ gerado com alvo de Mo e filtros de Mo (símbolos cheios) e Rh (símbolos vazios). As linhas cheias representam ajuste linear aos resultantes provenientes do uso do espectro de Mo/Mo e as linhas vazias representam o mesmo ajuste aos resultados obtidos com o espectro de $\mathrm{Mo} / \mathrm{Rh}$.

$C$ - DgN $N_{p}$ em função da espessura de mama comprimida para diferentes combinações alvo/filtro

Para avaliar a $\operatorname{DgN}_{\mathrm{p}}$ com relação à combinação alvo/filtro, foram usados espectros experimentais primários gerados com a combinação convencional Mo/Mo e Mo/Rh (Selenia Hologic $)^{72}$ e combinações que produzem feixes mais energéticos comumente utilizados em procedimentos com mamas mais espessas e densas W/Rh e W/Ag (Selenia Dimensions Hologic). A Figura 51 apresenta uma caracterização desses espectros de fluência incidentes com relação à sua morfologia para as quatro diferentes combinações alvo/filtro avaliadas. Os espectros estão normalizados pela carga total (mAs). 


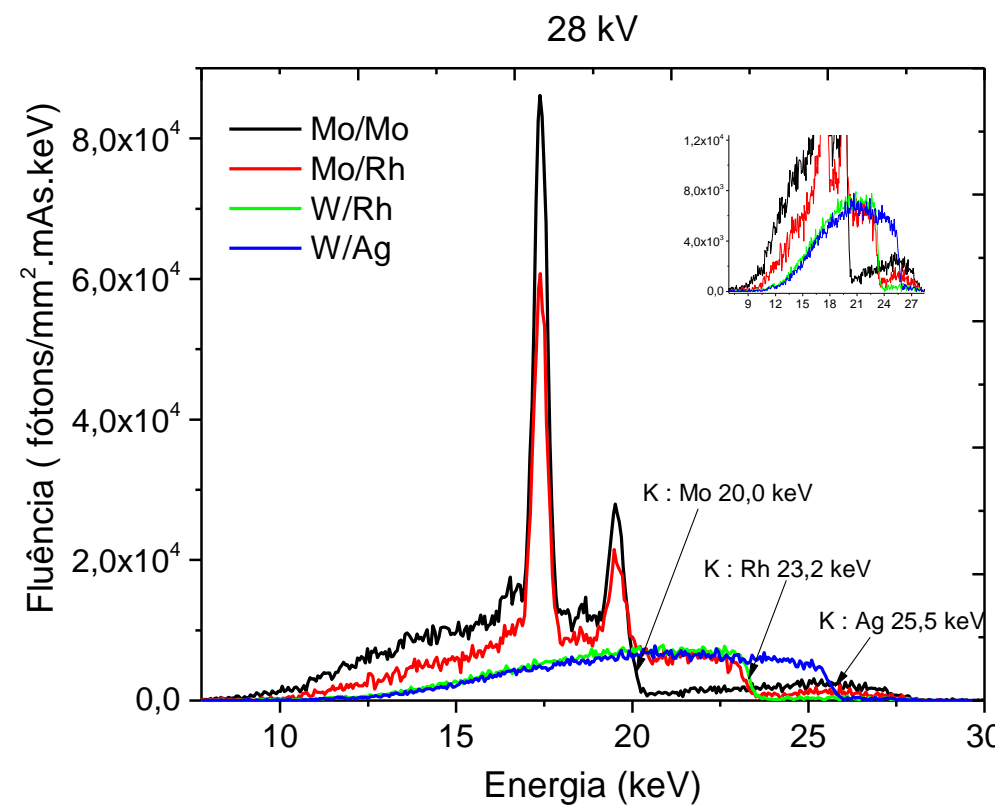

Figura 51: Espectros de fluência normalizados pela carga total (mAs) gerados com $28 \mathrm{kV}$ e com combinações alvo/filtro de: Mo/Mo (linha preta), Mo/Rh (linha vermelha), W/Rh (linha azul) e W/Ag (linha magenta). O subplot à direita destaca os espectros de bremsstrahlung de cada feixe.

A análise da $\operatorname{DgN}_{\mathrm{p}}$ em função da espessura de mama comprimida, com relação às diferentes combinações alvo/filtro, considera espectros gerados com $28 \mathrm{kV}$ e mamas com composição 50/50 (Figura 52) e 30/70 (Figura 53). Nessas figuras, os pontos representam os resultados obtidos através dos espectros experimentais e as linhas representam um ajuste exponencial cujos parâmetros encontram-se no Apêndice III-C.

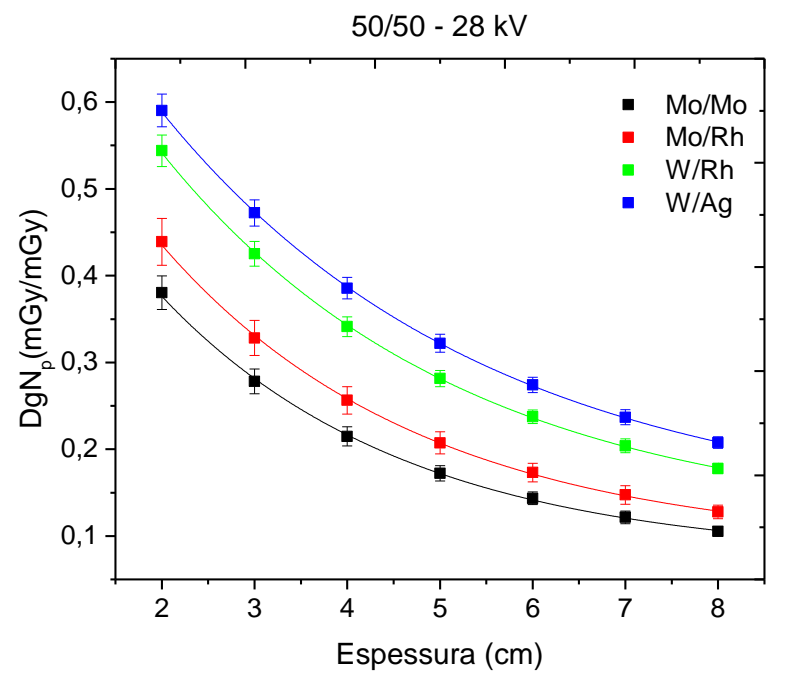

Figura 52: $\operatorname{DgN} \mathrm{N}_{\mathrm{p}}$ como função da espessura da mama comprimida para 4 diferentes combinações alvo/filtro. Estes resultados consideram uma mama 50/50 e um feixe gerado com $28 \mathrm{kV}$.

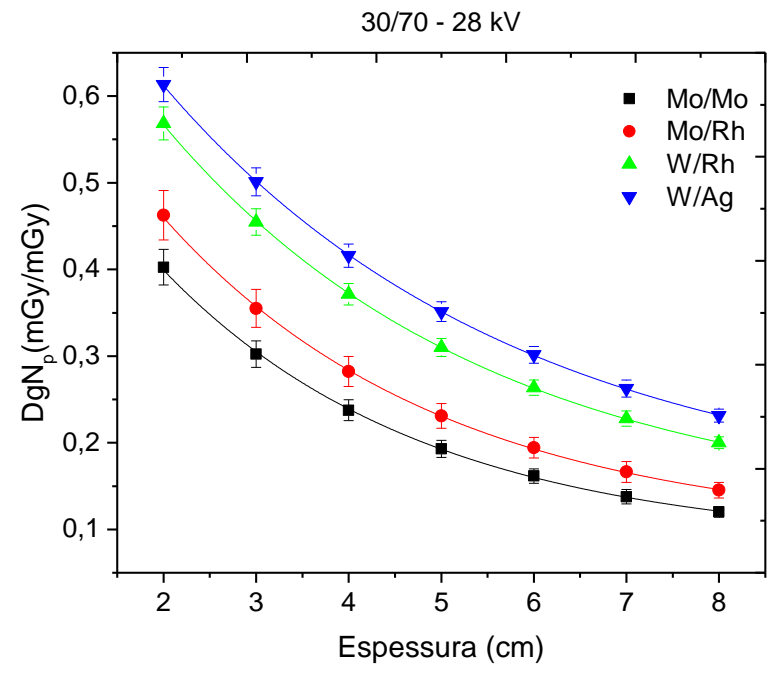

Figura 53: $\operatorname{DgN} \mathrm{N}_{\mathrm{p}}$ como função da espessura da mama comprimida para 4 diferentes combinações alvo/filtro. Estes resultados consideram uma mama 30/70 e um feixe gerado com $28 \mathrm{kV}$. 
A tendência aproximadamente exponencial dos valores de $\mathrm{DgN}_{\mathrm{p}}$ com relação à espessura de mama comprimida é novamente observada. Uma análise qualitativa da morfologia dos espectros apresentados na Figura 51 nos permite inferir que os espectros com menor e maior energia média são Mo/Mo e W/Ag, respectivamente. Os espectros com maior energia média são os que fornecem maiores proporções da dose absorvida com relação aos espectros menos energéticos. Na prática esses feixes são utilizados para irradiar mamas mais espessas e/ou mais densas.

D - $\quad D g N_{p}$ em função da espessura de mama comprimida para diferentes valores de tensão

A Figura 54 apresenta os valores de $\operatorname{DgN}_{\mathrm{p}}$ obtidos em função da espessura de mama comprimida para valores de tensão entre 25 e $31 \mathrm{kV}$ em um gráfico monologarítimico. Estes resultados consideram composição mamária de 50/50. As linhas representam um ajuste exponencial aos dados (Apêndice III-D). A Figura 55 apresenta resultados similares para espectros do $\mathrm{Mo} / \mathrm{Rh}$.

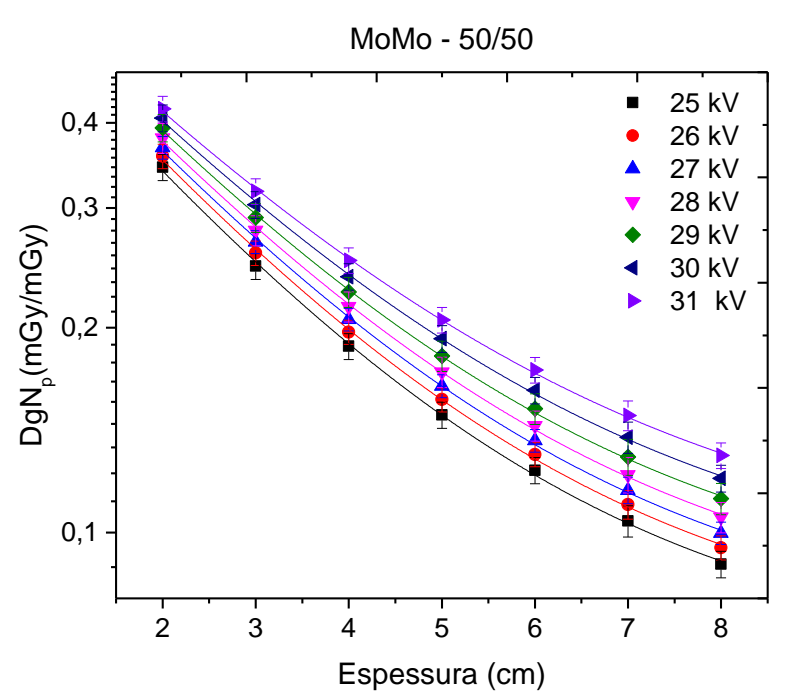

Figura 54: $\operatorname{DgN} N_{p}$ em função da espessura de mama comprimida para valores de tensão entre 25 e $31 \mathrm{kV}$. Estes resultados consideram um espectro de $\mathrm{Mo} / \mathrm{Mo}$ e composição mamária de 50/50. As linhas representam um ajuste exponencial aos dados.

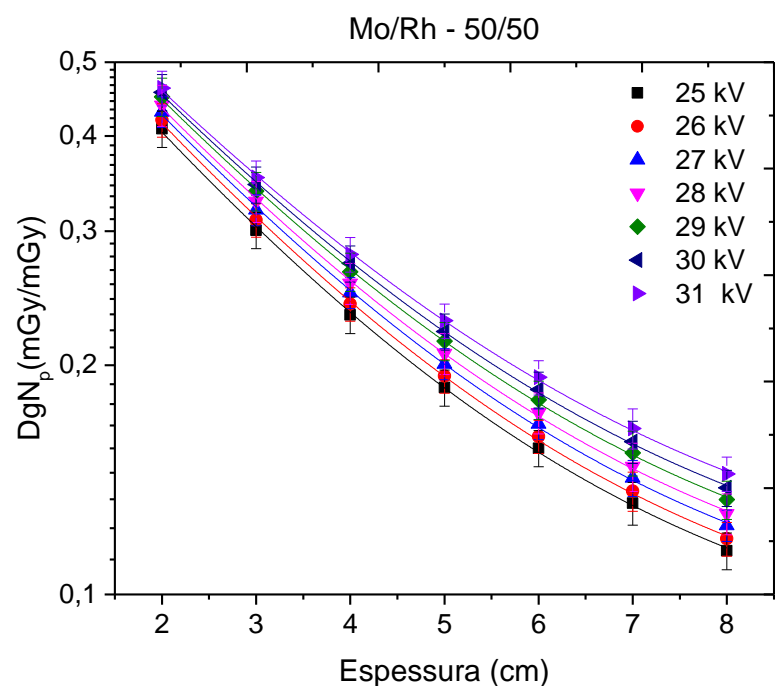

Figura 55: $\operatorname{DgN}_{\mathrm{p}}$ em função da espessura de mama comprimida para valores de tensão entre 25 e $31 \mathrm{kV}$. Estes resultados consideram um espectro de $\mathrm{Mo} / \mathrm{Rh}$ e composição mamária de 50/50. As linhas representam um ajuste exponencial aos dados.

E - Um exemplo de comparação dos resultados e aplicação

Alguns resultados obtidos nesse trabalho foram comparados com valores de dose glandular normalizada, $\mathrm{DgN}$, obtidos por meio dos valores de dose glandular informados no cabeçalho DICOM de imagens da mama de pacientes do Instituto do Câncer do Estado de São 
Paulo (ICESP), feitas com um equipamento Selenia (Hologic), e com valores calculados pelo software Volpara, descrito subseção 2.4.5. Para essa comparação, foi utilizado um banco de dados com mais de 9 mil imagens da mama de pacientes do ICESP. O acesso a essas informações foi obtido por conta de uma parceria previamente estabelecida com essa instituição (ver seção 1.3). As imagens foram previamente anonimizadas e, dessas imagens, foram extraídas todas as informações técnicas fornecidas no cabeçalho DICOM, tais como tensão, combinação alvo/filtro, espessura de mama comprimida etc. Além dessas informações, foram acrescentados aos dados, referente a cada imagem, os respectivos valores de glandularidade e dose glandular calculados pelo software Volpara ${ }^{39}$. Os dados extraídos das imagens e resultados de cálculos utilizando o Volpara foram fornecidos por Tomal (2016) ${ }^{\mathrm{ii}}$.

Para esta comparação, foram utilizados os resultados de $\operatorname{DgN}_{\mathrm{p}}$, obtidos neste trabalho por meio do Método I, para mamas de espessuras entre 2 e $8 \mathrm{~cm}$ com composição de aproximadamente 50/50 e para um espectro produzido por um tubo com combinação alvo/filtro de Mo/Mo e tensão 28 kV. Para obter dados equivalentes para esta comparação, foram filtradas do banco de dados informações registradas referente às imagens produzidas com a mesma combinação alvo/filtro $(\mathrm{Mo} / \mathrm{Mo})$ e tensão $(28 \mathrm{kV})$ e cuja a glandularidade da mama estimada pelo software Volpara ${ }^{48 ;} 91$ apresentou valor entre $50 \% \pm 3 \%$. Os valores de kerma no ar incidente registrados no cabeçalho DICOM foram usados para fazer a normalização dos valores de dose glandular do próprio cabeçalho DICOM e dos valores obtidos pelo software Volpara.

A Figura 56 apresenta a comparação dos valores de DgNp obtidos neste trabalho (em preto) com os valores do cabeçalho DICOM de imagens de mama (em vermelho) e valores obtidos pelo Volpara (em azul) para o caso específico onde foi usado a combinação Mo/Mo, tensão de $28 \mathrm{kV}$ e glandularidade aproximada de 50/50, em função da espessura de mama comprimida. Vale ressaltar que a letra "p" na sigla $\mathrm{DgN}_{\mathrm{p}}$ é usado apenas para indicar que os resultados foram obtidos a partir de espectros polienergéticos (Método I) e que os coeficientes $\mathrm{DgN}$ e $\operatorname{DgN}_{\mathrm{p}}$ na Figura 56 são grandezas equivalentes.

\footnotetext{
ii TOMAL, A. (Instituto de Física Gleb Wataghin (IFGW). Universidade Estadual de Campinas (UNICAMP). Campinas, SP, Brasil) Comunicação Pessoal, 2017.
} 


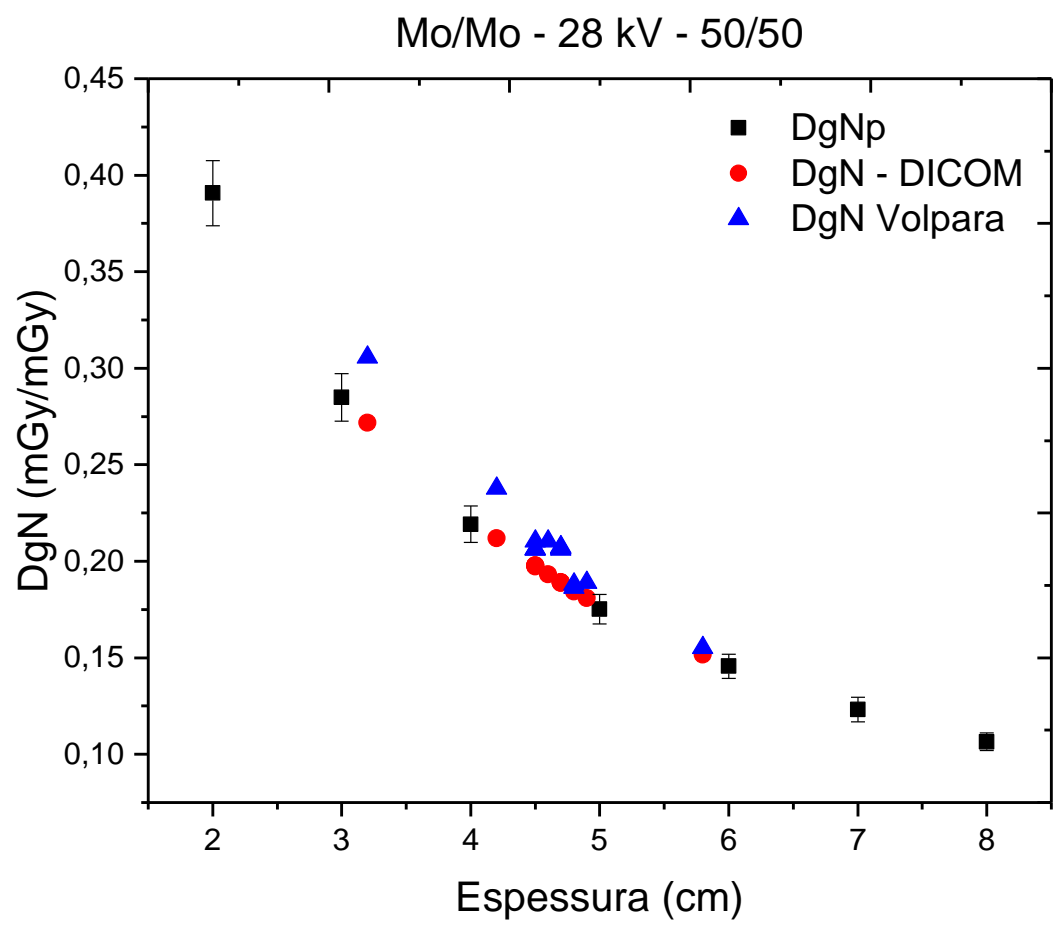

Figura 56 : Dados de DGNp obtidos neste trabalho para mamas 50/50 (em preto) em comparação com dados de dose glandular normalizada obtidos por meio de imagens de pacientes, utilizando dados extraídos do cabeçalho DICOM (em vermelho) e estimativa de dose feita pelo software Volpara (em azul).

Os resultados apresentados na Figura 56 mostram que os valores de dose glandular normalizada obtidos pelos três diferentes métodos possuem comportamento similar. Os valores obtidos neste trabalho são bem próximos daqueles obtidos por meio do cabeçalho DICOM e sistematicamente menores que os valores obtidos pelo software Volpara. O fato da dose glandular obtida pelo software Volpara ser maior que os valores informados pelo cabeçalho DICOM já tinha sido observado na literatura ${ }^{48 ; 49}$.

Considere agora alguns casos específicos onde as informações técnicas de imagens de mamografia de pacientes, provenientes do conjunto imagens utilizadas para extrair os dados da Figura 56, são apresentados Tabela 15. Em todos os casos, a imagem foi adquirida com tensão de 28 kV e combinação alvo/filtro de Mo/Mo. Do cabeçalho DICOM são apresentadas somente as informações a respeito da projeção de irradiação, espessura de mama comprimida, kerma no ar incidente $\left(K_{0}\right)$ e dose glandular média (DGM - DICOM). Esta tabela também exibe as respectivas glandularidades (Gland.) dessas mamas e a dose glandular média estimadas pelo software Volpara (DGM-Volpara). Note que os valores de glandularidade estão entre $50 \% \pm 3 \%$. Os valores da DGM apresentados na última coluna (DGM-Met. I) foram obtidos por meio do produto do kerma no ar incidente e os correspondentes valores de $\mathrm{DgN}_{\mathrm{p}}$, obtidos pelo Método I, apresentados na Figura 56 (em preto) para uma mama 50/50. 
Tabela 15: Dados extraídos do cabeçalho DICOM de imagens de mamografia de pacientes do ICESP* e os respectivos valores de DGM obtidos do cabeçalho DICOM, calculados pelo software Volpara e estimados pelo Método I proposto neste trabalho, com incerteza média de $4,4 \%$

\begin{tabular}{ccccccccc}
\hline Paciente & Projeção & $\begin{array}{c}\text { Espessura } \\
(\mathbf{c m})\end{array}$ & $\begin{array}{c}\mathbf{K}_{\mathbf{0}} \\
(\mathbf{m G y})\end{array}$ & $\begin{array}{c}\text { Gland. } \\
(\mathbf{\%})\end{array}$ & $\begin{array}{c}\text { DGM - } \\
\text { DICOM } \\
(\mathbf{m G y})\end{array}$ & $\begin{array}{c}\text { DGM - } \\
\text { Volpara } \\
(\mathbf{m G y})\end{array}$ & DGN $_{\mathbf{p}}$ & $\begin{array}{c}\text { DGM- Met. I } \\
(\mathbf{m G y})\end{array}$ \\
\hline 1 & CC & 4,2 & 11,7 & 47,31 & 2,48 & 2,78 & 0,210 & $2,46(10)$ \\
2 & MLO & 4,5 & 14,5 & 52,29 & 2,86 & 2,99 & 0,195 & $2,83(12)$ \\
3 & CC & 4,7 & 10,9 & 51,32 & 2,06 & 2,25 & 0,187 & $2,04(9)$ \\
4 & MLO & 4,8 & 13,4 & 50,78 & 2,47 & 2,50 & 0,183 & $2,45(11)$ \\
5 & CC & 4,8 & 18,3 & 48,87 & 3,39 & 3,44 & 0,183 & $3,35(12)$ \\
\hline
\end{tabular}

*Pesquisa autorizada pela instituição e aprovada pelo comitê de ética (protocolo de pesquisa 389/14)

A dose glandular média obtida pelo Método I apresentado neste trabalho (DGM-Met. I), nos casos exibidos na Tabela 15, pode ser considerada estatisticamente compatível com os valores de dose fornecidos na imagem DICOM e calculados pelo software Volpara. No entanto, pode se notar que os valores estimados pelo Método I são, de forma sistemática, ligeiramente menores que os valores obtidos pelos outros métodos comparados.

Como aplicação, os valores DGM apresentados na Tabela 15 podem ser usados, por exemplo, para avaliar a adequabilidade das doses produzidas por este equipamento (Selenia Hologic) conforme as normas americanas, já que no Brasil não há a exigência do uso da DGM no controle de qualidade de equipamentos em mamografia ${ }^{12}$. Nos Estados Unidos, o FDA (Food and Drug Administration) determina que para uma única irradiação na projeção craniocaudal, utilizando phantoms específicos e técnicas e condições usadas clinicamente em mamografia, a dose glandular média não deve ultrapassar $3 \mathrm{mGy}^{92}$. Nessas condições, a dose na mama da paciente 5 foi maior que o limite estabelecido. A união europeia, por exemplo, recomenda que os níveis de dose glandular aceitáveis ${ }^{10}$ para espessuras de mamas comprimidas de 4,5 $\mathrm{cm}$ e 5,3 $\mathrm{cm}$ devem ser menores que $2 \mathrm{mGy}$ e 2,5 $\mathrm{mGy}$, respectivamente, para pacientes entre 50 e 59 anos. De acordo à estas recomendações, somente o paciente 3 recebeu dose abaixo do limite recomendado.

$\mathrm{Na}$ prática, um serviço de mamografia pode adotar esse método para estimar dose glandular média em pacientes, ou para fazer controle de qualidade, a partir dos espectros de raios $\mathrm{X}$ específicos de seus equipamentos. Uma vez tendo os espectros medidos, a $\mathrm{DgN}_{\mathrm{p}}$ pode ser calculada para valores de glandularidade, que podem ser estimados, por exemplo, pela relação espessura da mama X glandularidade apresentada por Dance $(2000)^{40}$ ou usando software como o Volpara. A vantagem de usar os espectros experimentais específicos de cada equipamento para essa estimativa está no fato de que as medições experimentais são sensíveis às modificações dos feixes produzidos por equipamentos devido, por exemplo, ao tempo de uso, à alta carga de trabalho etc. Os métodos tradicionais para estimativa de dose glandular 
consideram feixes genéricos, não claramente descritos em alguns casos, e modelos simples da mama.

\subsubsection{Método II: Dose glandular normalizada $\left(\mathrm{DgN}_{\mathrm{p}}\right)$ usando espectros transmitidos}

A dose glandular normalizada pelo kerma no ar incidente, $\operatorname{Dg} \mathrm{N}_{\mathrm{p}}$, foi estimada utilizando espectros experimentais primários e transmitidos por materiais equivalentes a tecido mamário, conforme o método descrito na subseção 3.3.2. A $\operatorname{DgN}_{\mathrm{p}}$ foi avaliada para diversas espessuras de mama comprimida e diferentes glandularidades. Essas espessuras de mama comprimida foram consideradas iguais às espessuras dos phantoms disponíveis e as glandularidades consideradas, representam as proporções dos tecidos glandular/adiposo que caracterizam estes materiais (30/70 e 50/50). A Tabela 16 apresenta os valores de $\operatorname{DgN}_{\mathrm{p}}$ obtidos para algumas espessuras de mama comprimida (entre $0,5 \mathrm{~cm} \mathrm{a} 4,5 \mathrm{~cm}$ ) considerando os materiais simuladores de tecidos mamários com glandularidade de $30 \%$ e $50 \%$. Estes valores foram estimados para espectros de $\mathrm{Mo} / \mathrm{Mo}, \mathrm{Mo} / \mathrm{Rh}$ e $\mathrm{W} / \mathrm{Rh}$ gerados com tensões de $26 \mathrm{kV}$ e $28 \mathrm{kV}$.

As incertezas relativas expandidas $(\mathrm{k}=2)$ representam, em média, 2,6 \% dos valores de $\mathrm{DgN}_{\mathrm{p}}$. De acordo ao código de prática para dosimetria em radiologia diagnóstica ${ }^{39}$, TRS 457, as incertezas relativas expandidas dos valores de dose glandular estimadas utilizando TLDs e câmaras de ionização podem variar entre $8 \%$ a $14 \%(\mathrm{k}=2)$ quando se consideram todas as fontes de incerteza listadas por este documento. Isso possivelmente pode indicar que as incertezas determinadas neste trabalho podem ter sido sobrestimadas. 
Tabela 16: Valores de $\operatorname{DgN}_{\mathrm{p}}$ obtidos usando espectros incidentes e transmitidos por diversas espessuras de materiais simuladores de tecido mamário com composições de 30/70 e 50/50. Estes valores foram obtidos por meio da equação (31) para espectros de $\mathrm{Mo} / \mathrm{Mo}$, /Mo/Rh e $\mathrm{W} / \mathrm{Rh}$ gerados com tensões aplicadas ao tubo de $26 \mathrm{kV}$ e $28 \mathrm{kV}$. As incertezas relativas expandidas ( $\mathrm{k}=1$ ) representam, em média, 1,3\% dos valores de $\mathrm{DgN}_{\mathrm{p}}$.

\begin{tabular}{|c|c|c|c|c|c|}
\hline & & $\begin{array}{c}\mathrm{DgN}_{\mathrm{p}} \\
(\mathrm{mGy} / \mathrm{mGy})\end{array}$ & $\begin{array}{c}\sigma_{\text {DgNp }} \\
(\mathbf{m G y} / \mathbf{m G y})\end{array}$ & $\begin{array}{c}\operatorname{DgN}_{\mathrm{p}} \\
(\mathrm{mGy} / \mathrm{mGy})\end{array}$ & $\begin{array}{c}\sigma_{\text {DgNp }} \\
(\mathbf{m G y} / \mathbf{m G y})\end{array}$ \\
\hline Tensão (kV) & Espessura (cm) & \multicolumn{2}{|c|}{ Mo/Mo $-30 / 70$} & \multicolumn{2}{|c|}{ Mo/Mo $-\mathbf{5 0 / 5 0}$} \\
\hline \multirow{5}{*}{26} & 0,5 & 0,675 & 0,003 & 0,619 & 0,016 \\
\hline & 1,0 & 0,525 & 0,002 & 0,518 & 0,008 \\
\hline & 2,0 & $\mathrm{NC}$ & $\mathrm{NC}$ & 0,352 & 0,004 \\
\hline & 3,0 & 0,259 & 0,001 & 0,261 & 0,003 \\
\hline & 4,0 & 0,205 & 0,001 & 0,204 & 0,002 \\
\hline \multirow{6}{*}{28} & 0,5 & 0,678 & 0,028 & 0,655 & 0,031 \\
\hline & 1,0 & 0,549 & 0,012 & 0,537 & 0,014 \\
\hline & 2,0 & 0,388 & 0,006 & 0,373 & 0,007 \\
\hline & 3,0 & 0,294 & 0,004 & 0,279 & 0,005 \\
\hline & 4,0 & 0,232 & 0,003 & 0,220 & 0,003 \\
\hline & 4,5 & 0,209 & 0,003 & 0,198 & 0,003 \\
\hline \multirow{6}{*}{26} & & \multicolumn{2}{|c|}{$\mathrm{Mo} / \mathrm{Rh}-\mathbf{3 0} / 70$} & \multicolumn{2}{|c|}{ Mo/Rh $-50 / 50$} \\
\hline & 0,5 & 0,674 & 0,020 & 0,674 & 0,016 \\
\hline & 1,0 & 0,550 & 0,008 & 0,545 & 0,007 \\
\hline & 2,0 & 0,394 & 0,004 & 0,380 & 0,003 \\
\hline & 3,0 & 0,300 & 0,002 & 0,286 & 0,002 \\
\hline & 4,0 & 0,239 & 0,002 & 0,225 & 0,002 \\
\hline \multirow{6}{*}{28} & 0,5 & 0,694 & 0,036 & 0,666 & 0,029 \\
\hline & 1,0 & 0,573 & 0,015 & 0,553 & 0,013 \\
\hline & 2,0 & 0,414 & 0,007 & 0,396 & 0,007 \\
\hline & 3,0 & 0,317 & 0,005 & 0,300 & 0,004 \\
\hline & 4,0 & 0,253 & 0,004 & 0,238 & 0,003 \\
\hline & 4,5 & 0,229 & 0,003 & 0,215 & 0,003 \\
\hline \multirow{6}{*}{26} & & \multicolumn{2}{|c|}{ W/Rh $-30 / 70$} & \multicolumn{2}{|c|}{$\mathrm{W} / \mathrm{Rh}-\mathbf{5 0 / 5 0}$} \\
\hline & 0,5 & 0,690 & 0,006 & 0,711 & 0,005 \\
\hline & 1,0 & 0,591 & 0,003 & 0,594 & 0,002 \\
\hline & 2,0 & 0,446 & 0,001 & 0,435 & 0,001 \\
\hline & 3,0 & 0,349 & 0,001 & 0,335 & 0,001 \\
\hline & 4,0 & 0,282 & 0,001 & 0,268 & 0,001 \\
\hline \multirow{6}{*}{28} & 0,5 & 0,696 & 0,004 & 0,688 & 0,004 \\
\hline & 1,0 & 0,605 & 0,002 & 0,594 & 0,002 \\
\hline & 2,0 & 0,458 & 0,001 & 0,447 & 0,001 \\
\hline & 3,0 & 0,363 & 0,001 & 0,347 & 0,001 \\
\hline & 4,0 & 0,294 & 0,001 & 0,280 & 0,001 \\
\hline & 4,5 & 0,260 & 0,001 & 0,263 & 0,001 \\
\hline
\end{tabular}

NC = Não calculado

Os valores de $\operatorname{DgN}_{\mathrm{p}}$ obtidos por meio do Método II, foram comparados, em alguns casos possíveis, com valores obtidos pelo Método I. Essa comparação é conveniente uma vez que o Método I resulta da aplicação adaptada de um método já existente na literatura ${ }^{82}$ considerando casos onde o espectro incidente é conhecido enquanto, para o Método II, não foram encontrados trabalhos semelhantes disponíveis na literatura. A Figura 57 apresenta a comparação de valores de $\operatorname{DgN}_{\mathrm{p}}$ obtidos pelo Método I (símbolos vazios) e Método II (símbolos preenchidos) para o espectro Mo/Mo gerado com $28 \mathrm{kV}$ e considerando materiais 
com composição 30/70 (em preto) e 50/50 (em azul). A Figura 58 apresenta resultados similares para o espectro de $\mathrm{Mo} / \mathrm{Rh}$.

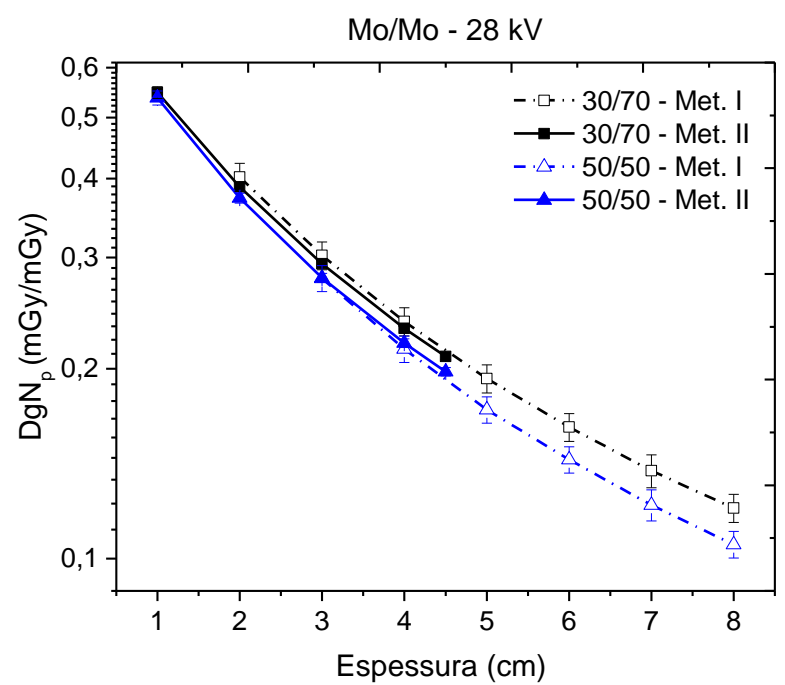

Figura 57: Comparação dos valores de $\mathrm{DgN}_{\mathrm{p}}$ obtidos por meio dos Métodos I (símbolos vazios) e Método II (símbolos cheios) para materiais que representam mama com composição 30/70 (em preto) e 50/50 (em azul). Estes resultados consideram um espectro de Mo/Mo gerado com $28 \mathrm{kV}$.

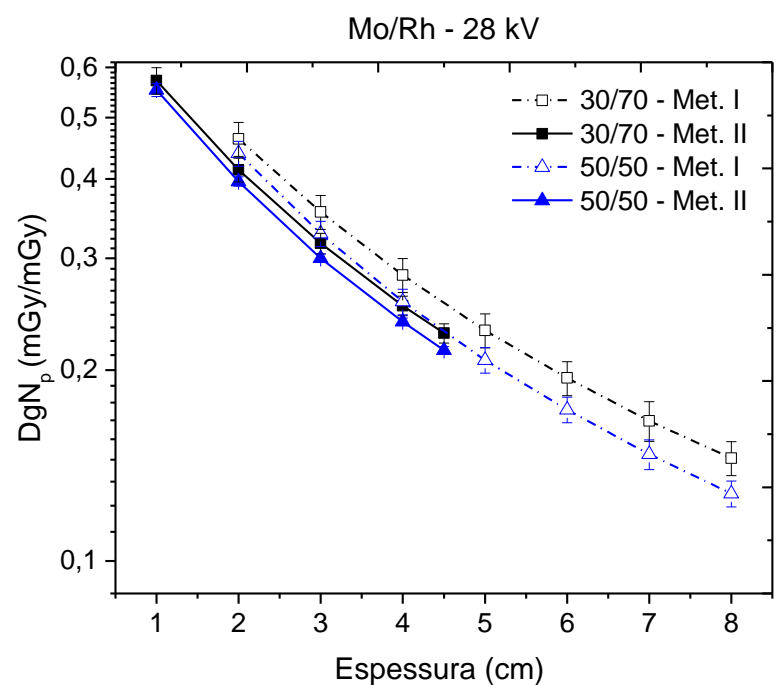

Figura 58: Comparação dos valores de $\operatorname{DgN}_{\mathrm{p}}$ obtidos por meio dos Métodos I (símbolos vazios) e Método II (símbolos cheios) para materiais que representam mama com composição 30/70 (em preto) e 50/50 (em azul). Estes resultados consideram um espectro de $\mathrm{Mo} / \mathrm{Rh}$ gerado com $28 \mathrm{kV}$.

De modo geral, os valores obtidos pelos dois métodos apresentam tendência semelhante com relação à espessura da mama comprimida e possuem a mesma ordem de grandeza. Uma análise qualitativa dos exemplos mostrados nas figuras acima permite concluir que, nesses casos, os valores obtidos são equivalentes, considerando as respectivas incertezas. No entanto, os resultados obtidos pelo Método I e Método II são mais próximos para os espectros de Mo/Mo que para os espectros de Mo/Rh.

Devido às limitações do procedimento experimental os espectros transmitidos foram medidos apenas para espessuras até 4 ou 4,5 cm. Desse modo esses valores só podem ser comparados diretamente para 3 espessuras, a saber: 2, 3 e $4 \mathrm{~cm}$. A Tabela 17 apresenta a diferença percentual entre valores de $\mathrm{DgN}_{\mathrm{p}}$ obtidos por meio dos Métodos I e II, relativa aos valores obtidos com o Método I para as espessuras supracitadas.

Tabela 17: Diferença percentual entre valores de $\mathrm{DgN}_{\mathrm{p}}$ obtidos por meio dos Métodos I e II, relativa aos valores obtidos com o Método I [100x(DgNp(II) - $\operatorname{DgNp}(\mathrm{I})) / \mathrm{DgNp}(\mathrm{I})]$.

\begin{tabular}{cccccc} 
& & \multicolumn{2}{c}{$\mathbf{2 6} \mathbf{k V}$} & \multicolumn{2}{c}{$\mathbf{2 8} \mathbf{k V}$} \\
\cline { 3 - 6 } Glandularidade & Espessura (cm) & Mo/Mo & Mo/Rh & Mo/Mo & Mo/Rh \\
\hline \multirow{2}{*}{$\mathbf{3 0 / 7 0}$} & 2 & NC & $-11 \%$ & $-4 \%$ & $-10 \%$ \\
& 3 & $-8 \%$ & $-11 \%$ & $-3 \%$ & $-11 \%$ \\
& 4 & $-6 \%$ & $-10 \%$ & $-2 \%$ & $-10 \%$ \\
\hline \multirow{2}{*}{$\mathbf{5 0 / 5 0}$} & 2 & $-2 \%$ & $-9 \%$ & $-2 \%$ & $-10 \%$ \\
& 3 & $1 \%$ & $-8 \%$ & $0 \%$ & $-9 \%$ \\
\hline NC = Não calculado & 4 & $3 \%$ & $-7 \%$ & $2 \%$ & $-7 \%$ \\
\hline
\end{tabular}


Os resultados apresentados na Tabela 17 revelam que os valores de $\mathrm{DgN}_{\mathrm{p}}$ obtidos utilizando o Método II são sistematicamente menores que aqueles obtidos pelo Método I. Essa diferença é mais significativa para os espectros de $\mathrm{Mo} / \mathrm{Rh}$ com relação aos espectros de Mo/Mo.

A Figura 59 apresenta os valores de $\operatorname{DgN}_{\mathrm{p}}$ obtidos para os espectros gerados com as combinações alvo/filtro Mo/Mo (em preto), Mo/Rh (em vermelho) e W/Rh (em azul) e tensão de $28 \mathrm{kV}$. Os símbolos vazios representam os resultados para a composição 30/70 enquanto que os símbolos cheios representam resultados para a composição 50/50. As linhas representam um ajuste exponencial aos dados. Foi possível observar que, de modo geral, a $\mathrm{DgN}_{\mathrm{p}}$ sempre aumenta com a energia média do feixe, tal como foi também observado com os resultados obtidos com o Método I. Desse modo, com relação à combinação alvo/filtro era esperado que a proporção da dose glandular fosse maior para a combinação W/Rh, com relação as demais combinações avaliadas. Quanto à glandularidade, para todas as combinações alvo/filtro testadas, a consideração da composição 30/70 resultou em valores $\mathrm{DgN}_{\mathrm{p}}$ superiores aos obtidos para a composição 50/50.

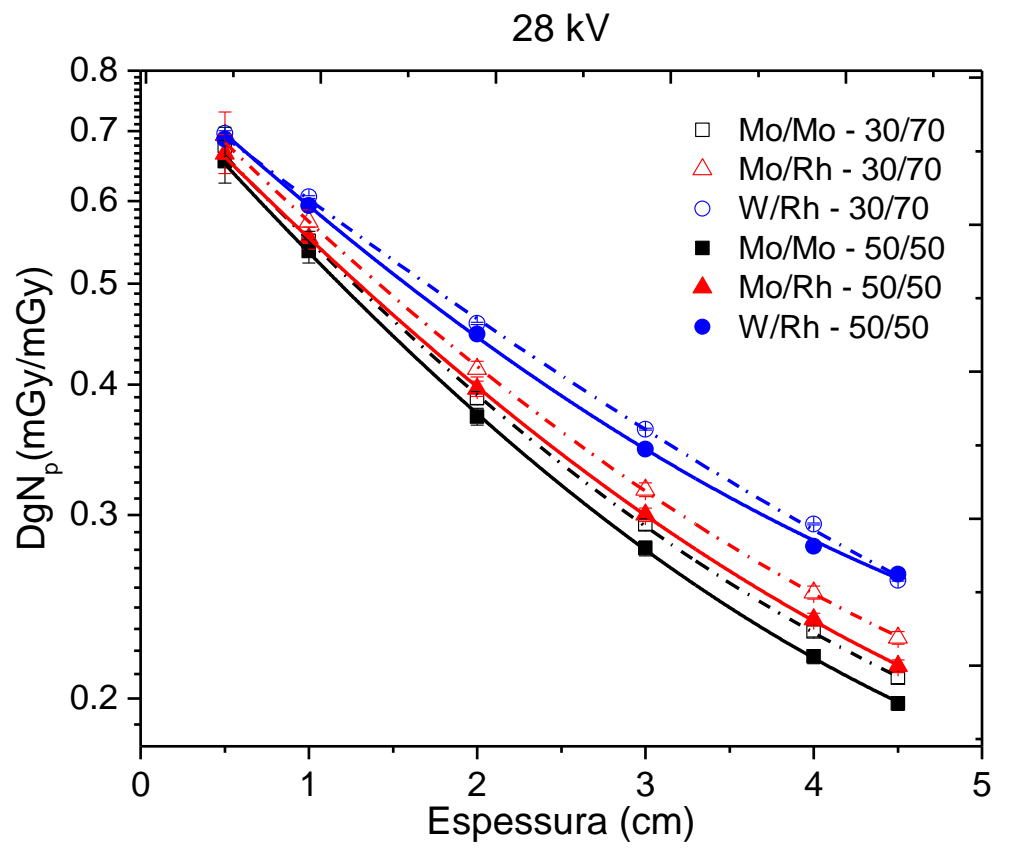

Figura 59: $\mathrm{DgN}_{\mathrm{p}}$ em função da espessura para os espectros gerados com as combinações alvo/filtro $\mathrm{Mo} / \mathrm{Mo}$ (em preto), Mo/Rh (em vermelho) e W/Rh (em azul) e tensão de $28 \mathrm{kV}$. Os símbolos vazios representam os resultados para a composição 30/70 enquanto que os símbolos cheios representam resultados para a composição 50/50. As linhas representam um ajuste exponencial aos dados.

Vale destacar que os valores de $\mathrm{DgN}_{\mathrm{p}}$ são coeficientes de dose e que a dose glandular média é calculada por meio da multiplicação do kerma no ar incidente por esses coeficientes. Os coeficientes determinados para uma mesma técnica de exposição, por exemplo, Mo/Mo 
com $28 \mathrm{kV}$, resultam da normalização da dose glandular pelo valor de kerma incidente produzido por esse feixe independente da glandularidade considerada. Desse modo, os valores de dose glandular obtidos para materiais equivalentes às mamas 30/70 e 50/50, para mesma técnica de exposição, foram normalizados pelo mesmo valor de kerma no ar. Na mamografia, mamas mais densas geralmente são irradiadas com técnicas que fornecem maior kerma no ar incidente que para mamas menos densas. Apesar dos coeficientes $\mathrm{DgN}_{\mathrm{p}}$ obtidos neste trabalho apresentarem valores maiores para glandularidade menores, na prática, quando considerado os diferentes valores de kerma no ar incidente para mamas com diferentes glandularidades e mesma espessura, o valor da dose glandular média deve ser maior para mamas mais densas.

\subsubsection{Método III: Distribuições de dose glandular}

A distribuição dose glandular normalizada foi estimada em camadas de diferentes profundidades do material simulador de tecido mamário utilizando espectros de raios $\mathrm{X}$ experimentais, conforme o método descrito na subseção 3.3.3. A Tabela 18 apresenta os valores obtidos para os materiais de composição de 30/70 e 50/50. Estes valores foram estimados para espectros de Mo/Mo, Mo/Rh e W/Rh gerados com tensões de $26 \mathrm{kV}$ e $28 \mathrm{kV}$. Vale ressaltar que esse método utiliza espectros transmitidos por materiais tecido-equivalentes que representam a mama como uma mistura homogênea de tecido glandular e adiposo, o que é diferente das mamas reais. 
Tabela 18: $\operatorname{DgN}_{\mathrm{p}}$ para camadas em diferentes profundidades do material simulador de tecido mamário de composições 30/70 e 50/50. Valores obtidos para espectros de $\mathrm{Mo} / \mathrm{Mo}$, Mo/Rh e W/Rh gerados com tensões de 26 e $28 \mathrm{kV}$. As incertezas relativas expandidas $(\mathrm{k}=1)$ representam em média $1,8 \%$ dos valores de $\mathrm{DgN}_{\mathrm{p}}$.

\begin{tabular}{|c|c|c|c|c|c|}
\hline & & $\begin{array}{c}\mathrm{DgN}_{\mathrm{p}} \\
(\mathrm{mGy} / \mathrm{mGy})\end{array}$ & $\begin{array}{c}\text { бDgNp } \\
(\mathrm{mGy} / \mathrm{mGy})\end{array}$ & $\begin{array}{c}\operatorname{DgN}_{p} \\
(\mathrm{mGy} / \mathrm{mGy})\end{array}$ & $\begin{array}{c}\sigma_{\text {DgNp }} \\
(\mathrm{mGy} / \mathrm{mGy})\end{array}$ \\
\hline Tensão (kV) & Camada $(\mathbf{c m})$ & \multicolumn{2}{|c|}{ Mo/Mo $-30 / 70$} & \multicolumn{2}{|c|}{ Mo/Mo $-\mathbf{5 0 / 5 0}$} \\
\hline \multirow{5}{*}{26} & $0,0-0,5$ & 0,675 & 0,003 & 0,619 & 0,016 \\
\hline & $0,5-1,0$ & 0,395 & 0,002 & 0,429 & 0,006 \\
\hline & $1,0-2,0$ & $\mathrm{NC}$ & $\mathrm{NC}$ & 0,193 & 0,001 \\
\hline & $1,0-3,0$ & 0,132 & 0,001 & 0,084 & 0,000 \\
\hline & $3,0-4,0$ & 0,048 & 0,001 & 0,036 & 0,000 \\
\hline \multirow{6}{*}{28} & $0,0-0,5$ & 0,678 & 0,028 & 0,655 & 0,031 \\
\hline & $0,5-1,0$ & 0,447 & 0,020 & 0,441 & 0,017 \\
\hline & $1,0-2,0$ & 0,237 & 0,004 & 0,216 & 0,004 \\
\hline & $2,0-3,0$ & 0,112 & 0,001 & 0,097 & 0,001 \\
\hline & $3,0-4,0$ & 0,052 & 0,001 & 0,047 & 0,001 \\
\hline & $4,0-4,5$ & 0,033 & 0,001 & 0,030 & 0,001 \\
\hline \multirow{6}{*}{26} & & \multicolumn{2}{|c|}{ Mo/Rh - 30/70 } & \multicolumn{2}{|c|}{ Mo/Rh $-\mathbf{5 0 / 5 0}$} \\
\hline & $0,0-0,5$ & 0,674 & 0,020 & 0,674 & 0,016 \\
\hline & $0,5-1,0$ & 0,448 & 0,017 & 0,439 & 0,012 \\
\hline & $1,0-2,0$ & 0,250 & 0,004 & 0,230 & 0,002 \\
\hline & $2,0-3,0$ & 0,124 & 0,001 & 0,107 & 0,001 \\
\hline & $3,0-4,0$ & 0,060 & 0,001 & 0,047 & 0,001 \\
\hline \multirow{6}{*}{28} & $0,0-0,5$ & 0,694 & 0,036 & $\mathrm{NC}$ & $\mathbf{N C}$ \\
\hline & $0,5-1,0$ & 0,477 & 0,026 & 0,462 & 0,013 \\
\hline & $1,0-2,0$ & 0,266 & 0,006 & 0,250 & 0,003 \\
\hline & $2,0-3,0$ & 0,133 & 0,002 & 0,116 & 0,001 \\
\hline & $3,0-4,0$ & 0,067 & 0,001 & 0,058 & 0,001 \\
\hline & $4,0-4,5$ & 0,043 & 0,001 & 0,033 & 0,001 \\
\hline \multirow{6}{*}{26} & & \multicolumn{2}{|c|}{ W/Rh - 30/70 } & \multicolumn{2}{|c|}{ W/Rh $-\mathbf{5 0 / 5 0}$} \\
\hline & $0,0-0,5$ & 0,690 & 0,006 & 0,711 & 0,005 \\
\hline & $0,5-1,0$ & 0,511 & 0,005 & 0,498 & 0,003 \\
\hline & $1,0-2,0$ & 0,314 & 0,001 & 0,296 & 0,001 \\
\hline & $2,0-3,0$ & 0,169 & 0,001 & 0,147 & 0,000 \\
\hline & $3,0-4,0$ & 0,092 & 0,001 & 0,079 & 0,000 \\
\hline \multirow{6}{*}{28} & $0,0-0,5$ & 0,696 & 0,004 & $\mathrm{NC}$ & $\mathrm{NC}$ \\
\hline & $0,5-1,0$ & 0,531 & 0,003 & 0,519 & 0,003 \\
\hline & $1,0-2,0$ & 0,325 & 0,001 & 0,312 & 0,001 \\
\hline & $2,0-3,0$ & 0,189 & 0,004 & 0,158 & 0,001 \\
\hline & $3,0-4,0$ & 0,099 & 0,002 & 0,088 & 0,001 \\
\hline & $4,0-4,5$ & 0,012 & 0,001 & $\mathrm{NC}$ & $\mathrm{NC}$ \\
\hline
\end{tabular}

A Figura 60 apresenta a distribuição de dose glandular normalizada em algumas camadas de um phantom de $4 \mathrm{~cm}$ de espessura. Como ilustrado no diagrama de cores (Figura 60 - a), é possível notar que a proporção da dose glandular é maior nas camadas iniciais e decresce para as camadas mais profundas desse material. A Figura 60-b representa os mesmos dados da Figura 60-a porém, dispostos na forma de pontos num gráfico $D g \mathrm{~N}_{\mathrm{p}} \mathrm{x}$ Espessura. Nessa figura, os pontos foram dispostos para os valores máximos de profundidade de cada camada analisada. Assim, por exemplo, o valor de $\mathrm{DgN}_{\mathrm{p}}$ correspondente a $0,5 \mathrm{~cm}$ de profundidade no gráfico, refere-se à $\mathrm{DgN}_{\mathrm{p}}$ calculada entre 0 e $0,5 \mathrm{~cm}$ no material. A 
representação gráfica mostrada na Figura 60-b foi adotada para avaliar as distribuições de $\mathrm{DgN}_{\mathrm{p}}$ obtidas neste trabalho.

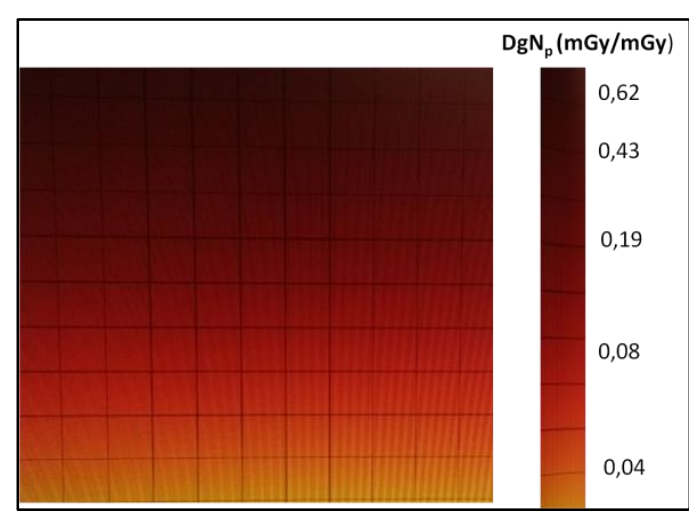

(a)

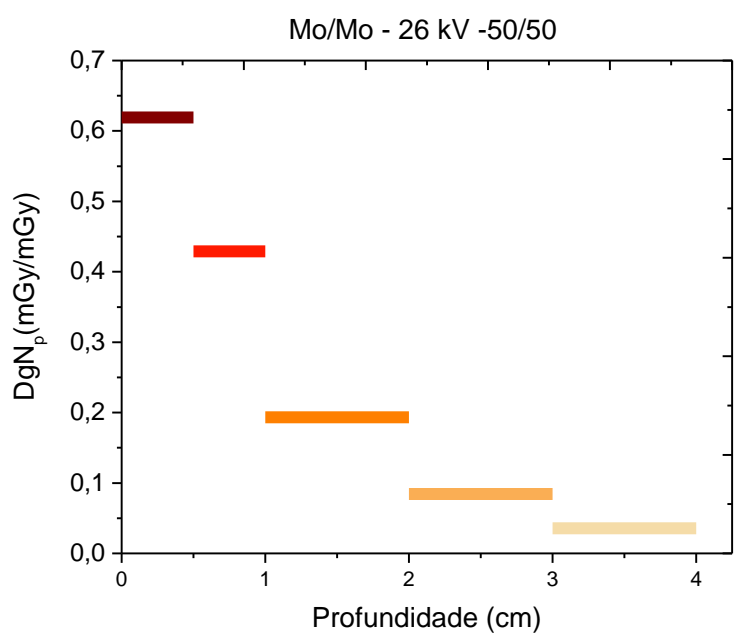

(b)

Figura 60: Distribuição de dose glandular normalizada com a espessura do material simulador de tecido mamário. O diagrama de cores (a) ilustra a os valores de $\mathrm{DgN}_{\mathrm{p}}$ para várias camadas de um phantom de $4 \mathrm{~cm}$ de espessura. Os resultados apresentados em (b) correspondem aos resultados apresentados em (a). Os pontos em (b) foram dispostos para os valores máximos de profundidade de cada camada analisada.

Os resultados de distribuição de dose glandular normalizada obtidos por meio do Método III serão apresentados graficamente e discutidos com mais detalhes na subseção 4.3.4 juntamente com resultados similares obtidos utilizando TLDs.

Enquanto o Método II estima a dose glandular normalizada na mama inteira de espessura $L$, que é aqui representada por um phantom, o Método III estima a dose glandular normalizadas em várias camadas desse material. No entanto, é possível obter a dose glandular normalizada num material de espessura $L$, como no Método II através dos resultados de doses em camadas, tal como obtido com o Método III. Esse procedimento foi descrito na subseção 3.3.3 e o cálculo foi realizado conforme apresentado na equação (45). Os resultados obtidos foram comparados com aqueles avaliados diretamente a partir da aplicação do Método II. A Tabela 19 apresenta essa comparação para espessuras de 2, 3, 4 e 4,5 cm de material simuladores de tecido mamário de composições 30/70 e 50/50. Foram utilizados espectros de $\mathrm{Mo} / \mathrm{Mo}, \mathrm{Mo} / \mathrm{Rh}$ e W/Rh com tensões de 26 e $28 \mathrm{kV}$. Além disso, a tabela também apresenta a diferença percentual desses valores. 
Tabela 19: Comparação entre valores dos DgNp obtidos pelo Método II para espessuras de 2, 3 e 4 cm e valores obtidos utilizando a equação (45) e Método III..

\begin{tabular}{|c|c|c|c|c|c|c|c|}
\hline & & Met II & $\begin{array}{c}\text { Equação (45) } \\
\text { e Met III }\end{array}$ & $\begin{array}{c}\text { Diferença } \\
\% \\
\end{array}$ & Met II & $\begin{array}{c}\text { Equação (45) } \\
\text { e Met III } \\
\end{array}$ & Dif \% \\
\hline $\begin{array}{c}\text { Tensão } \\
(\mathrm{kV})\end{array}$ & $\begin{array}{l}\text { Espessura } \\
\text { (cm) }\end{array}$ & \multicolumn{3}{|c|}{ Mo/Mo - 30/70 } & \multicolumn{3}{|c|}{ Mo/Mo - 50/50 } \\
\hline \multirow{3}{*}{$26 \mathrm{kV}$} & 2,0 & $\mathrm{NC}$ & $\mathrm{NC}$ & $\mathrm{NC}$ & 0,352 & 0,359 & $1,9 \%$ \\
\hline & 3,0 & 0,259 & 0,266 & $2,6 \%$ & 0,261 & 0,267 & $2,5 \%$ \\
\hline & 4,0 & 0,205 & 0,211 & $3,2 \%$ & 0,204 & 0,209 & $2,8 \%$ \\
\hline \multirow{3}{*}{$28 \mathrm{kV}$} & 3,0 & 0,294 & 0,304 & $3,5 \%$ & 0,279 & 0,287 & $3,1 \%$ \\
\hline & 4,0 & 0,232 & 0,241 & $3,9 \%$ & 0,220 & 0,227 & $3,5 \%$ \\
\hline & 4,5 & 0,209 & 0,218 & $4,1 \%$ & 0,198 & 0,205 & $3,7 \%$ \\
\hline \multirow{4}{*}{$26 \mathrm{kV}$} & & \multicolumn{3}{|c|}{ Mo/Rh - 30/70 } & \multicolumn{3}{|c|}{ Mo/Rh $-\mathbf{5 0} / \mathbf{5 0}$} \\
\hline & 2,0 & 0,394 & 0,405 & $2,8 \%$ & 0,380 & 0,393 & $3,6 \%$ \\
\hline & 3,0 & 0,300 & 0,311 & $3,7 \%$ & 0,286 & 0,298 & $4,2 \%$ \\
\hline & 4,0 & 0,239 & 0,249 & $4,1 \%$ & 0,225 & 0,235 & $4,6 \%$ \\
\hline \multirow{3}{*}{$28 \mathrm{kV}$} & 3,0 & 0,317 & 0,328 & $3,4 \%$ & 0,300 & 0,260 & $2,0 \%$ \\
\hline & 4,0 & 0,253 & 0,263 & $3,9 \%$ & 0,238 & 0,247 & $2,5 \%$ \\
\hline & 4,5 & 0,229 & 0,238 & $4,2 \%$ & 0,215 & 0,223 & $2,7 \%$ \\
\hline \multirow{4}{*}{$26 \mathrm{kV}$} & & \multicolumn{3}{|c|}{ W/Rh $-30 / 70$} & \multicolumn{3}{|c|}{ W/Rh $-\mathbf{5 0 / 5 0}$} \\
\hline & 2,0 & 0,446 & 0,457 & $2,5 \%$ & 0,435 & 0,451 & $3,6 \%$ \\
\hline & 3,0 & 0,349 & 0,361 & $3,6 \%$ & 0,335 & 0,349 & $4,4 \%$ \\
\hline & 4,0 & 0,282 & 0,294 & $4,2 \%$ & 0,268 & 0,282 & $4,9 \%$ \\
\hline \multirow{3}{*}{$28 \mathrm{kV}$} & 3,0 & 0,363 & 0,376 & $3,6 \%$ & 0,347 & 0,358 & $3,1 \%$ \\
\hline & 4,0 & 0,294 & 0,306 & $4,2 \%$ & 0,280 & 0,290 & $3,7 \%$ \\
\hline & 4,5 & 0,260 & 0,274 & $5,4 \%$ & 0,263 & 0,274 & $4,3 \%$ \\
\hline
\end{tabular}

De acordo a Tabela 19 é possível notar que diferença percentual aumenta com a espessura e que a máxima diferença obtida foi de 5,4\%. Além disso as diferenças são, em geral, maiores para os espectros de $\mathrm{Mo} / \mathrm{Rh}$ com relação aos espectros de $\mathrm{Mo} / \mathrm{Mo}$ e maiores para a tensão de $28 \mathrm{kV}$ com relação a $26 \mathrm{kVp}$, o que indica uma dependência energética entre os resultados fornecidos por cada método.

\subsection{ESTIMATIVAS DE DOSE USANDO TLDS}

\subsubsection{Calibração dos dosímetros termoluminescentes}

A Tabela 20 apresenta os valores de doses absorvida no ar para os quais os dosímetros TLDs foram irradiados para calibração nos feixes RQR-2M e RQR-4M ${ }^{39}$. Os valores de dose absorvida foram estimados a partir da taxa de kerma no ar apresentada na Tabela 9 para cada qualidade padrão de feixe, e valores de corrente e tempo utilizados durante as irradiações (Tabela 10). As incertezas nos valores de dose levam em consideração a incerteza na taxa de kerma no ar apresentada na Tabela 9 e a incerteza do tempo medido com o cronômetro. 
Tabela 20: Valores de doses absorvidas devido à exposição dos dosímetros aos feixes de raios $\mathrm{X}$ equivalentes aos feixes padrões para mamografia de qualidades RQR-M2 e RQR-M4 ${ }^{39}$.

\begin{tabular}{cc}
\hline $\begin{array}{c}\text { RQR-2M } \\
\text { Dose absorvida } \\
(\mathbf{m G y})\end{array}$ & $\begin{array}{c}\text { RQR-4M } \\
\text { Dose absorvida } \\
(\mathbf{m G y})\end{array}$ \\
\hline $1,00 \pm 0,07$ & $0,98 \pm 0,09$ \\
$5,06 \pm 0,07$ & $4,97 \pm 0,09$ \\
$10,10 \pm 0,09$ & $10,00 \pm 0,09$ \\
$20,10 \pm 0,09$ & $20,00 \pm 0,09$ \\
$30,10 \pm 0,09$ & $29,90 \pm 0,09$ \\
$39,70 \pm 0,09$ & $39,89 \pm 0,09$ \\
$49,70 \pm 0,20$ & $50,30 \pm 0,20$ \\
$60,00 \pm 0,20$ & $59,90 \pm 0,20$ \\
$69,90 \pm 0,20$ & $69,60 \pm 0,20$ \\
\hline
\end{tabular}

A Figura 61 apresenta a resposta dos TLDs em função da dose (mGy) com as quais foram irradiados nas qualidades de feixes RQR-M2 e RQR-M4. As retas indicam ajuste linear aplicado aos dois conjuntos de dados com interceptação na origem. As barras apresentadas na figura representam a incerteza nos valores de dose (Tabela 13) combinados com valores de incerteza na resposta dos dosímetros (considerados 6,5\% do valor da leitura) transferidos para o eixo das ordenadas ${ }^{93}$.

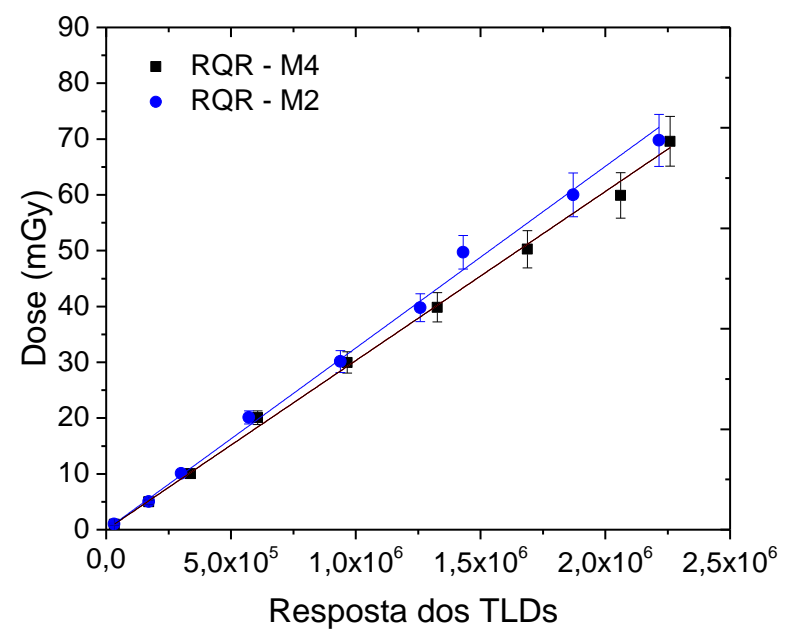

Figura 61: Resposta dos dosimetros TL em função da dose absorvida no ar nas quais foram irradiados nas qualidades RQR-M2 (preto) e RQR-M4 (azul). As retas indicam ajuste linear aplicado para cada conjunto de dados.

A Tabela 21 apresenta os coeficientes angular e valores de $\mathrm{R}^{2}$ ajustados, para os dois ajustes apresentados na Figura 61. Os fatores de calibração dos dosímetros, que devem ser utilizados para converter a leitura do sinal TL em dose (mGy), representam o coeficiente angular das retas ajustadas (Figura 61). Como os dosímetros foram irradiados com feixes 
gerados com tensão de $28 \mathrm{kV}$, neste trabalho utilizou-se a calibração obtida com o feixe de qualidade RQR-M2.

Tabela 21: Fator de calibração dos TLDs (coeficientes angulares do ajuste linear) e coeficientes de correlação, $\mathrm{R}^{2}$, para as duas retas ajustadas na Figura 61. Os valores de incerteza na resposta (considerados 6,5\% do valor da leitura) foram transferidos para o eixo das ordenadas e os ajustes interceptaram a origem $(0,0)$.

\begin{tabular}{c|c}
\hline RQR - M2 & RQR - M4 \\
\hline $\begin{array}{c}\text { Fator de calibração } \\
(\mathrm{mGy})\end{array}$ & $\begin{array}{c}\text { Fator de calibração } \\
(\mathrm{mGy})\end{array}$ \\
$(3,25 \pm 0,06) \times 10^{-5}$ & $(3,03 \pm 0,04) \times 10^{-5}$ \\
\hline
\end{tabular}

\subsubsection{Coeficientes mássicos de absorção de energia dos phantoms}

A Figura 62 apresenta os coeficientes mássicos de absorção para os phantoms CIRS30/70, CIRS50/50 e CIRS70/30 usados para o cálculo de dose absorvida conforme descrito na seção 3.4.6. Estes valores foram calculados a partir da composição química desses materiais estimada por Poletti e colaboradores ${ }^{87}$ e coeficientes mássicos para a absorção de energia dos elementos químicos fornecidas pela base de dados XCOM (NIST) ${ }^{81}$. Essa base de dados fornece os coeficientes para uma grade de energia ampla, porém com poucos valores dentro do intervalo de energia de interesse deste trabalho. Os pontos apresentados no gráfico são resultados para as energias fornecidas pelo NIST. As curvas representam uma interpolação dos resultados do tipo spline cúbica (Matlab, Mathworks Inc.).

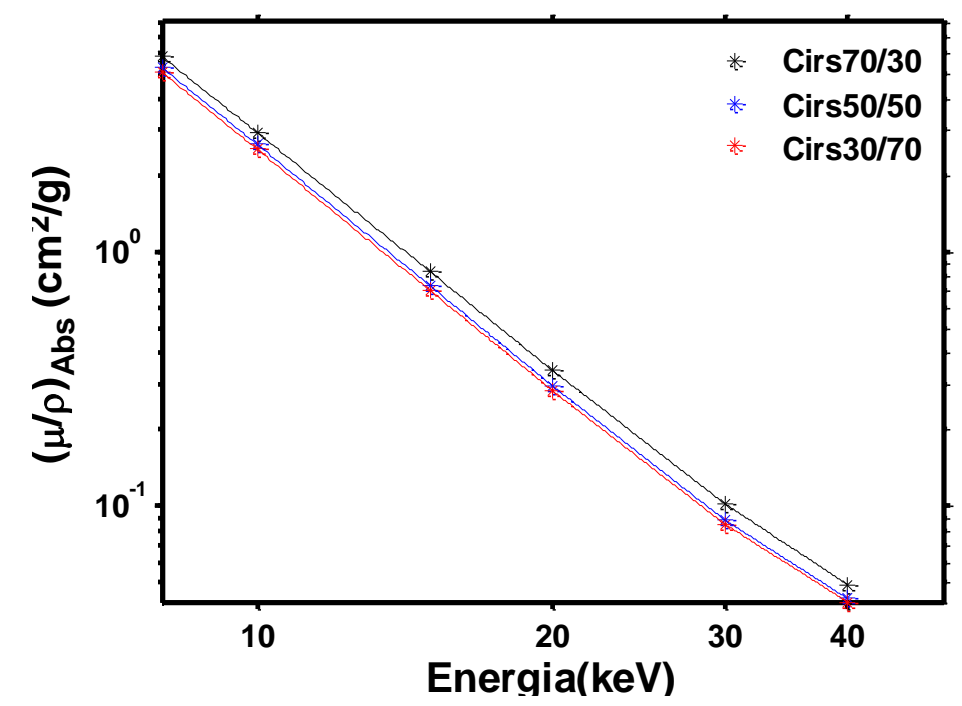

Figura 62: Coeficientes mássicos para absorção de energia, $(\mu / \rho)_{A b s}$, dos phantoms CIRS30/70, CIRS50/50 e CIRS70/30. Valores calculados a partir da composição química estimada por Poletti e colaboradores $^{87}$ Coeficientes mássicos para a absorção de energia dos elementos químicos fornecidas pelo NIST. 


\subsubsection{Dose absorvida nos phantoms}

Os dosímetros TL foram irradiados em diferentes profundidades dos phantoms de tecido equivalentes à mama com feixes gerados com 28 kV e 100 mAs para as 3 combinações anodo/filtro possíveis, como descrito na seção 3.4.5. O cálculo de dose absorvida nos phantoms em diferentes profundidades foi realizado conforme a equação (47) utilizando valores de coeficientes mássicos de absorção de energia para os phantoms e para o ar correspondentes à energia efetiva dos diferentes feixes incidentes nos dosimetros. Valores de energia efetiva e camada semirredutora dos feixes (CSR) foram estimados por meio dos espectros de raios $\mathrm{X}$ primários e transmitidos medidos nas condições correspondentes.

A Tabela 22 apresenta os valores de camada semirredutora ( $\mathrm{mm} \mathrm{Al})$ e energia efetiva para os espectros gerados com $28 \mathrm{kV}$ e medidos após atravessarem diferentes profundidades dos phantoms CIRS30/70 e CIRS50/50. São também apresentados os valores de coeficientes mássicos para a absorção de energia para o ar, $\left(\mu_{\mathrm{ab}} / \rho\right)_{\text {ar }}$, e para os phantoms CIRS30/70, $\left(\mu_{\mathrm{ab}} / \rho\right)_{30 / 70}$, e CIRS50/50, $\left(\mu_{\mathrm{ab}} / \rho\right)_{50 / 50}$, equivalentes às energias efetivas estimadas conforme equação (12). O procedimento para estimação da camada semirredutora e energia efetiva e considerações de incertezas são descritos no Apêndice I. 
Tabela 22: Camada semirredutora (CSR) e energia efetiva (Eef) para os espectros de raios $\mathrm{X}$ medidos com $28 \mathrm{kV}$ e utilizando diferentes combinações alvo/filtro. Esses espectros foram usados para irradiar os dosímetros TLs em diferentes profundidades dos phantoms Cirs30/70, Cirs50/50. Coeficientes mássicos para a absorção de energia para o ar, $\left(\mu_{a b} / \rho\right)_{\text {ar, }}$ e para os phantoms CIRS30/70, $\left(\mu_{a b} / \rho\right)_{30 / 70}$ e CIRS50/50, $\left(\mu_{a b} / \rho\right)_{50 / 50}$.

\begin{tabular}{|c|c|c|c|c|c|c|c|c|}
\hline \multirow[b]{2}{*}{$\underset{(\mathbf{m m})}{\boldsymbol{x}}$} & \multicolumn{4}{|c|}{ CIRS 30/70 } & \multicolumn{4}{|c|}{ CIRS 50/50 } \\
\hline & $\begin{array}{c}\mathrm{CSR} \\
(\mathrm{mm} \mathrm{Al})\end{array}$ & $\begin{array}{c}\text { Eef } \\
(\mathrm{keV})\end{array}$ & $\begin{array}{c}\left(\mu_{\mathrm{ab}} / \rho\right)_{a r} \\
\left(\mathrm{~cm}^{2} / \mathrm{g}\right)\end{array}$ & $\begin{array}{c}\left(\mu_{\mathrm{ab}} / \rho\right)_{30 / 70} \\
\left(\mathrm{~cm}^{2} / \mathrm{g}\right)\end{array}$ & $\begin{array}{c}\mathrm{CSR} \\
(\mathrm{mm} \mathrm{Al})\end{array}$ & Eef (keV) & $\begin{array}{c}\left(\mu_{\mathrm{ab}} / \rho\right)_{a r} \\
\left(\mathrm{~cm}^{2} / \mathrm{g}\right)\end{array}$ & $\begin{array}{c}\left(\mu_{\mathrm{ab}} / \rho\right)_{50 / 50} \\
\left(\mathrm{~cm}^{2} / \mathrm{g}\right)\end{array}$ \\
\hline \multicolumn{9}{|c|}{ Mo/Mo } \\
\hline $\mathbf{0}$ & 0,33 & 15,12 & 1,30 & 0,68 & 0,33 & 15,12 & 1,30 & 0,72 \\
\hline 5 & 0,42 & 16,42 & 1,00 & 0,53 & 0,43 & 16,52 & 0,98 & 0,54 \\
\hline 10 & 0,45 & 16,84 & 0,93 & 0,49 & 0,46 & 17,00 & 0,90 & 0,50 \\
\hline 20 & 0,50 & 17,49 & 0,82 & 0,43 & 0,53 & 17,80 & 0,78 & 0,43 \\
\hline 30 & 0,54 & 17,85 & 0,77 & 0,41 & 0,58 & 18,31 & 0,71 & 0,39 \\
\hline 40 & 0,56 & 18,17 & 0,73 & 0,38 & 0,61 & 18,67 & 0,67 & 0,37 \\
\hline 45 & 0,58 & 18,39 & 0,70 & 0,37 & - & - & - & - \\
\hline \multicolumn{9}{|c|}{ Mo/Rh } \\
\hline $\mathbf{0}$ & 0,38 & 15,81 & 1,13 & 0,60 & 0,38 & 15,81 & 1,13 & 0,62 \\
\hline 5 & 0,46 & 16,97 & 0,90 & 0,48 & 0,47 & 17,08 & 0,89 & 0,49 \\
\hline 10 & 0,50 & 17,40 & 0,84 & 0,44 & 0,52 & 17,61 & 0,80 & 0,44 \\
\hline 20 & 0,55 & 18,06 & 0,74 & 0,39 & 0,58 & 18,31 & 0,71 & 0,39 \\
\hline 30 & 0,60 & 18,54 & 0,68 & 0,36 & 0,65 & 19,11 & 0,62 & 0,34 \\
\hline 40 & 0,63 & 18,89 & 0,64 & 0,34 & 0,67 & 19,27 & 0,61 & 0,33 \\
\hline 45 & 0,64 & 19,06 & 0,63 & 0,33 & - & - & - & - \\
\hline \multicolumn{9}{|c|}{ W/Rh } \\
\hline $\mathbf{0}$ & 0,50 & 17,47 & 0,83 & 0,43 & 0,50 & 17,47 & 0,83 & 0,45 \\
\hline 5 & 0,58 & 18,33 & 0,71 & 0,37 & 0,58 & 18,36 & 0,71 & 0,39 \\
\hline 10 & 0,61 & 18,66 & 0,67 & 0,35 & 0,62 & 18,78 & 0,66 & 0,35 \\
\hline 20 & 0,68 & 19,42 & 0,59 & 0,31 & 0,68 & 19,34 & 0,60 & 0,32 \\
\hline 30 & 0,71 & 19,66 & 0,57 & 0,30 & 0,76 & 20,09 & 0,53 & 0,28 \\
\hline 40 & 0,75 & 20,02 & 0,57 & 0,28 & 0,78 & 20,32 & 0,51 & 0,27 \\
\hline 45 & 0,78 & 20,32 & 0,51 & 0,27 & - & - & - & - \\
\hline
\end{tabular}

É importante notar que os dosímetros foram irradiados em algumas profundidades para as quais não foram medidos espectros de transmissão (15 mm e $25 \mathrm{~mm}$ ). Para cada uma dessas profundidades específicas, a energia efetiva dos respectivos feixes transmitidos que incidiram sobre os TLDs foi determinada por meio de interpolação relacionando espessura do phantom $(x)$ e energia efetiva $\left(E_{e f}\right)$, estimada por ajuste (utilizando o software Origin) da função:

$$
E_{e f}=a * x^{b}
$$

Na equação (51), $a$ e $b$, são parâmetros de ajuste. A Tabela 23 apresenta os valores dos parâmetros de ajuste da equação (51) obtidos para todos os conjuntos de dados de espessura do phantom e energia efetiva apresentados na Tabela 22. 
Tabela 23: Parâmetros de ajuste da equação (51) e valores dos correspondentes coeficientes de determinação $\left(\mathrm{R}^{2}\right)$

\begin{tabular}{ccccccc}
\hline & \multicolumn{2}{c}{ Mo/Mo } & \multicolumn{2}{c}{ Mo/Rh } & \multicolumn{2}{c}{ W/Rh } \\
\hline $\begin{array}{c}\text { Parâmetros de } \\
\text { ajuste }\end{array}$ & CIRS30/70 & CIRS50/50 & CIRS30/70 & CIRS0/50 & CIRS30/70 & CIRS50/50 \\
$a$ & & & & & & \\
$b$ & $15,03(12)$ & $14,9(2)$ & $15,5(1)$ & $15,4(2)$ & $16,9(2)$ & $16,8(3)$ \\
$R^{2}$ & $0,051(3)$ & $0,060(3)$ & $0,054(4)$ & $0,061(5)$ & $0,046(4)$ & $0,050(5)$ \\
\hline
\end{tabular}

Os valores de energia efetiva correspondentes às espessuras 15 e $25 \mathrm{~mm}$ foram então derivados do ajuste da equação (51). Os valores dos coeficientes mássicos de absorção de energia para o ar e para o material dos phantoms utilizados foram então obtidos para cada valor de energia efetiva e são apresentados na Tabela 24.

Tabela 24: Valores de energia efetiva dos feixes transmitidos por espessuras de 15 e $25 \mathrm{~mm}$ dos phantoms CIRS30/70 e CIRS50/50 e correspondentes valores de coeficientes mássicos de absorção de energia para o ar e para os phantoms.

\begin{tabular}{|c|c|c|c|c|c|c|}
\hline \multirow[b]{3}{*}{ Espessura } & \multicolumn{3}{|c|}{ CIRS30/70 } & \multicolumn{3}{|c|}{ CIRS50/50 } \\
\hline & $\begin{array}{c}\text { Eef } \\
(\mathrm{keV})\end{array}$ & $\begin{array}{c}\left(\mu_{\mathrm{ab}} / \rho\right)_{a r} \\
\left(\mathrm{~cm}^{2} / \mathrm{g}\right)\end{array}$ & $\begin{array}{c}\left(\mu_{\mathrm{ab}} / \rho\right)_{30 / 70} \\
\left(\mathrm{~cm}^{2} / \mathrm{g}\right)\end{array}$ & $\begin{array}{c}\text { Eef } \\
(\mathrm{keV})\end{array}$ & $\begin{array}{c}\left(\mu_{\mathrm{ab}} / \rho\right)_{a r} \\
\left(\mathrm{~cm}^{2} / \mathrm{g}\right)\end{array}$ & $\begin{array}{c}\left(\mu_{\mathrm{ab}} / \rho\right)_{50 / 50} \\
\left(\mathrm{~cm}^{2} / \mathrm{g}\right)\end{array}$ \\
\hline & \multicolumn{6}{|c|}{ Mo/Mo } \\
\hline 15 & $17,28(4)$ & 0,85 & 0,45 & $17,54(5)$ & 0,81 & 0,45 \\
\hline \multirow[t]{2}{*}{25} & $17,74(4)$ & 0,78 & 0,41 & $18,09(5)$ & 0,74 & 0,41 \\
\hline & \multicolumn{6}{|c|}{ Mo/Rh } \\
\hline 15 & $17,88(4)$ & 0,77 & 0,40 & $18,15(7)$ & 0,73 & 0,40 \\
\hline \multirow[t]{2}{*}{25} & $18,38(4)$ & 0,70 & 0,37 & $18,73(8)$ & 0,66 & 0,36 \\
\hline & \multicolumn{6}{|c|}{ W/Rh } \\
\hline 15 & $19,16(6)$ & 0,62 & 0,32 & $19,27(8)$ & 0,61 & 0,33 \\
\hline 25 & $19,62(6)$ & 0,57 & 0,30 & $19,78(9)$ & 0,56 & 0,31 \\
\hline
\end{tabular}

A partir dos resultados de coeficientes mássicos de absorção de energia para o ar e para os phantoms CIRS, apresentados na Tabela 22 e na Tabela 24, foram calculados os valores de fator $f$ (equação (48)). A Figura 63 apresenta os fatores $f$ calculados para cada combinação possível de tipo de phantom (CIRS30/70 ou CIRS50/50) e tipo de espectro (Mo/Mo, Mo/Rh e W/Rh) em função da energia efetiva dos espectros transmitidos. 


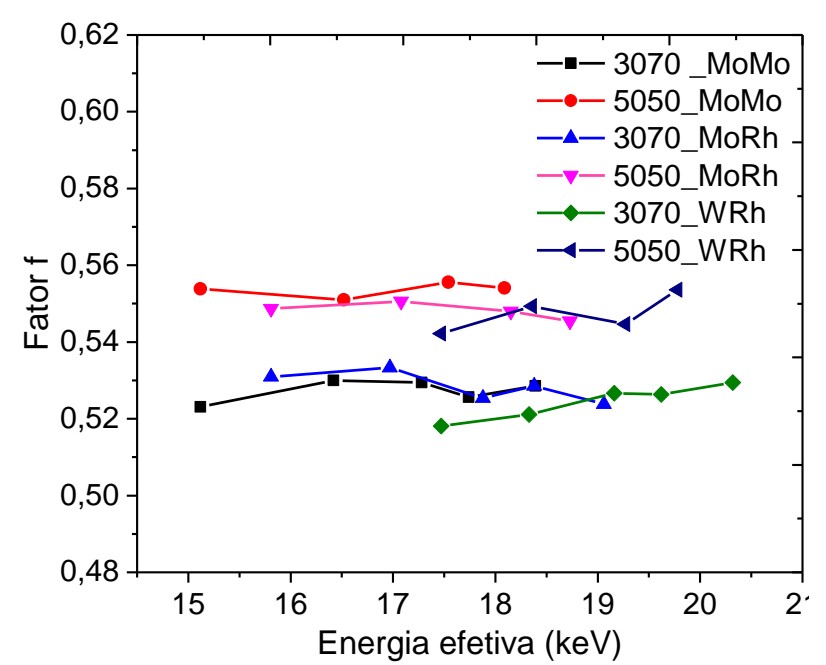

Figura 63: Fatores $f$ calculados para as combinações de tipo de phantom (CIRS30/70 ou CIRS50/50) e tipo de espectro (Mo/Mo, Mo/Rh e W/Rh) em função da energia efetiva dos espectros transmitidos.

$\mathrm{Na}$ Figura 63 pode se notar que os valores de fator $f$ se distribuíram em dois grupos de valores aproximadamente constantes. Os fatores $f$ correspondentes ao phantom CIRS50/50 apresentaram valores ligeiramente maiores que aqueles correspondentes ao phantom CIRS3070. Este comportamento era esperado uma vez que os valores de coeficientes mássicos de absorção de energia para o tecido glandular são maiores que para o tecido adiposo e o phantom CIRS50/50 possui maior proporção de material equivalente ao tecido glandular (Figura 62). Os cálculos de dose absorvida, conforme a equação (47), foram realizados utilizando os valores médios dos conjuntos de valores do fator $f$ apresentados na Tabela 25.

Tabela 25: Valores médios e desvios padrão dos fatores $\mathrm{f}$ apresentados na Figura 63

\begin{tabular}{ccccccc}
\hline \multicolumn{4}{c}{ Mo/Mo } & \multicolumn{2}{c}{ Mo/Rh } & \multicolumn{2}{c}{ W/Rh } \\
\hline \multirow{2}{*}{ Fator $f$} & CIRS30/70 & CIRS50/50 & CIRS30/70 & CIRS50/50 & CIRS30/70 & CIRS50/50 \\
& $0,527(3)$ & $0,554(2)$ & $0,528(4)$ & $0,548(2)$ & $0,524(4)$ & $0,547(5)$ \\
\hline
\end{tabular}

Para o phantom CIRS70/30, considerou-se o fator $f$ obtido por meio do espectro incidente. Esta aproximação foi adotada uma vez que os fatores $f$ para os espectros transmitidos por um mesmo phantom e derivados de um mesmo espectro incidente apresentaram valores de fator $f$ aproximadamente constantes.

A Figura 64 apresenta a distribuição de dose absorvida em diferentes posições, definidas na Tabela 12, do eixo anodo-catodo (eixo das ordenadas, conforme a Figura 28 e a Figura 29) em profundidades entre 0 a 45 mm dos phantoms CIRS30/70 (a), CIRS50/50 (b) e 
Cirs70/30 (c). Os phantoms foram irradiados no equipamento Mammomat 3000 Nova com feixes produzidos com $28 \mathrm{kV}$ e 100 mAs para a combinação Mo/Mo.

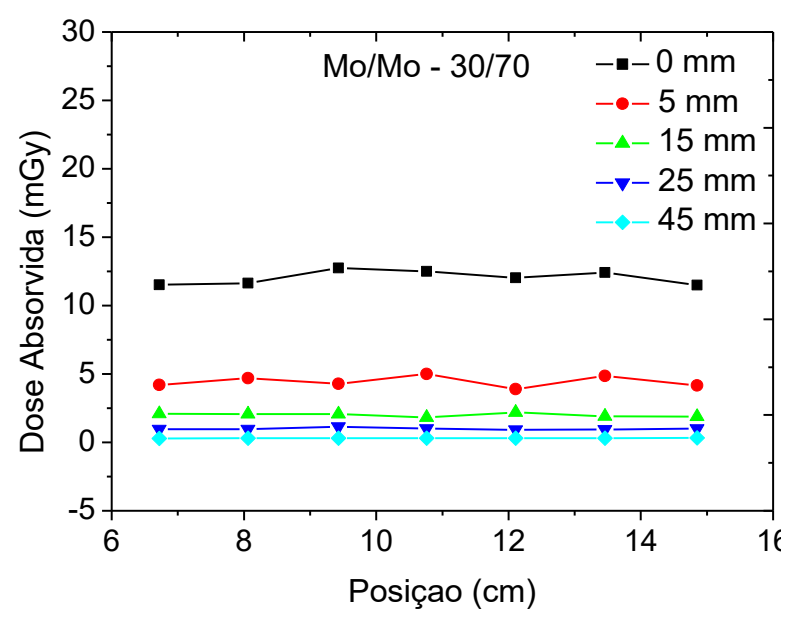

(a)

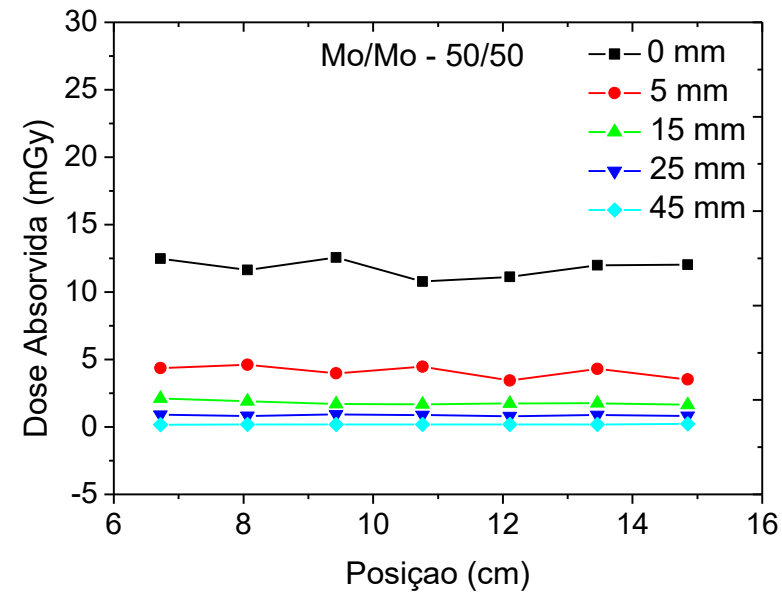

(b)

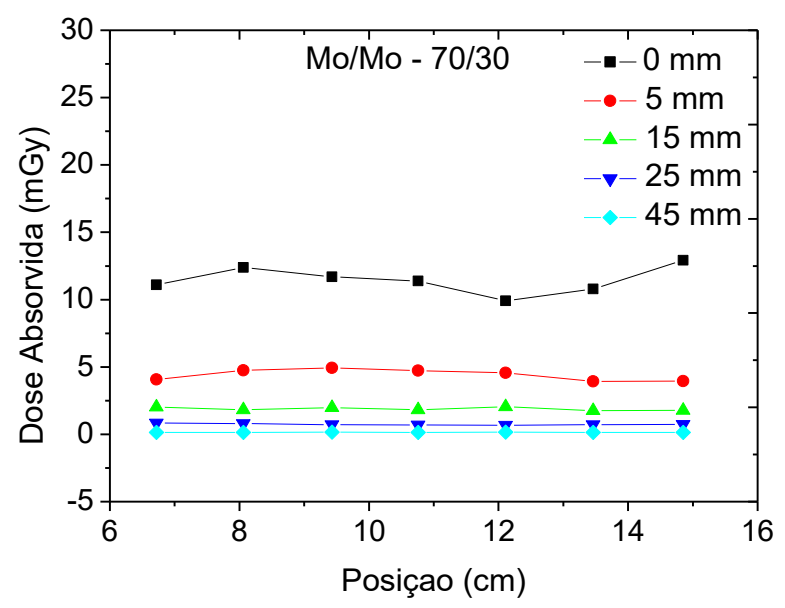

(c)

Figura 64: Distribuição de dose absorvida sobre o eixo catodo-anodo em diferentes profundidades dos Phantoms Cirs30/70 (a), Cirs50/50 (b) e Cirs70/30 (c). O feixe utilizado para irradiação foi produzido com 28 $\mathrm{kV}, 100 \mathrm{mAs}$ e a combinação de anodo/filtro Mo/Mo. A máxima incerteza no valor de dose absorvida, considerando as incertezas propagadas do fator de calibração e fator $f$, foi de $2,3 \%$ do valor da dose.

A Figura 65 e a Figura 66 apresentam resultados similares para feixes produzidos com as combinações $\mathrm{Mo} / \mathrm{Rh}$ e $\mathrm{W} / \mathrm{Rh}$ respectivamente. Os valores de dose absorvida apresentados para $0 \mathrm{~mm}$ equivalem à dose absorvida no ar na entrada da pele, incluindo o retroespalhamento. Os valores de dose absorvida apresentados para as demais profundidades são doses absorvidas nos phantoms calculadas conforme a equação (47). 


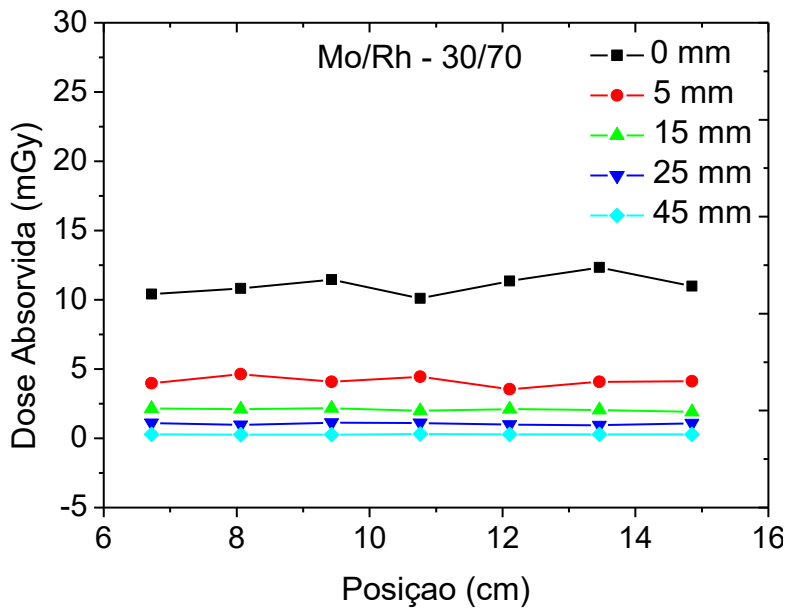

(a)

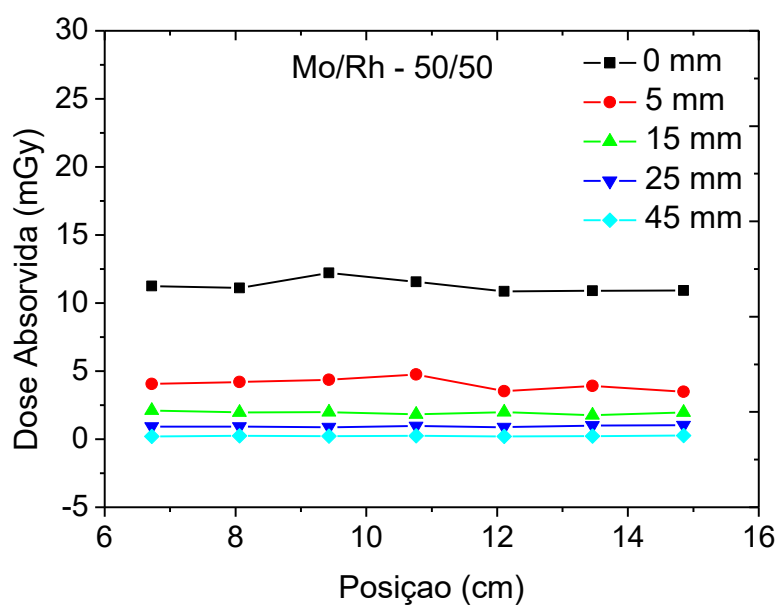

(b)

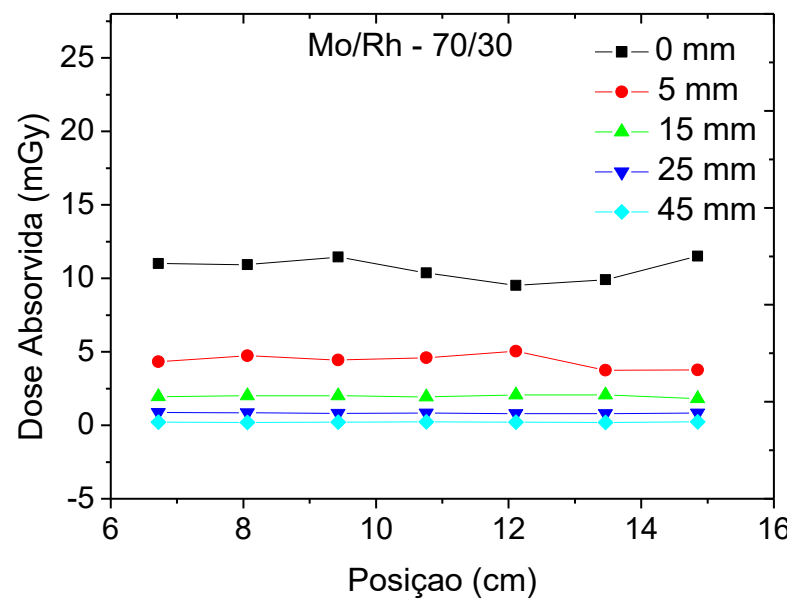

(c)

Figura 65: Distribuição de dose absorvida sobre o eixo catodo-anodo em diferentes profundidades dos Phantoms Cirs30/70 (a), Cirs50/50 (b) e Cirs70/30 (c). O feixe utilizado para irradiação foi produzido com 28 $\mathrm{kV}, 100 \mathrm{mAs}$ e a combinação de anodo/filtro Mo/Rh. A máxima incerteza no valor de dose absorvida, considerando as incertezas propagadas do fator de calibração e fator $f$, foi de $2,3 \%$ do valor da dose.

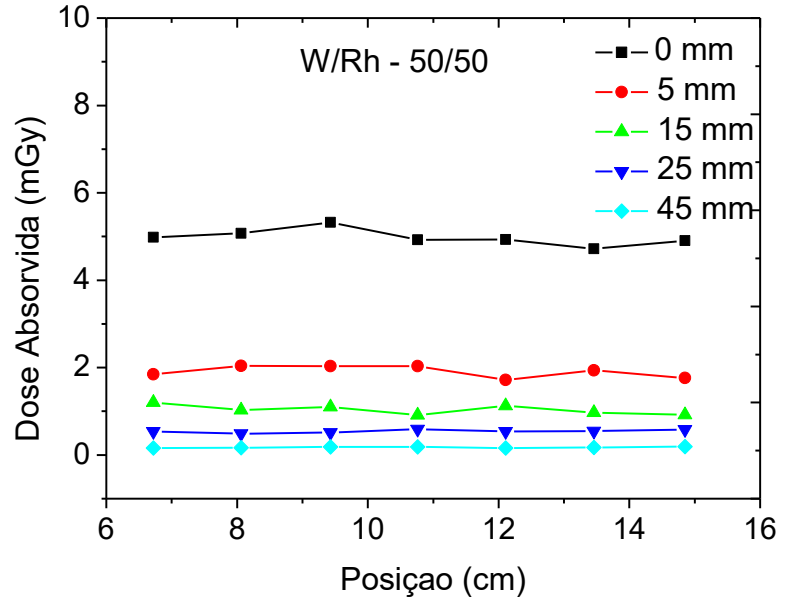

(a)

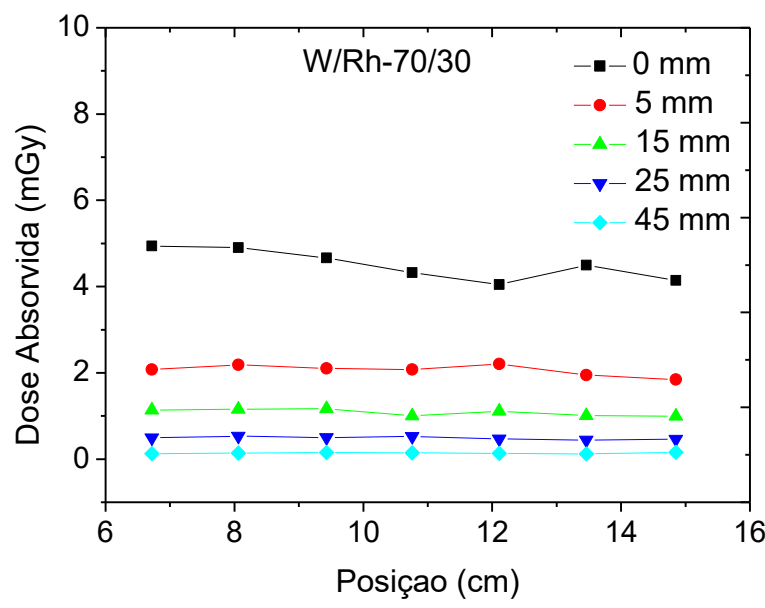

(b)

Figura 66: Distribuição de dose absorvida sobre o eixo catodo-anodo em diferentes profundidades dos Phantoms Cirs50/50 (a) e Cirs70/30 (b). O feixe utilizado para irradiação foi produzido com $28 \mathrm{kV}, 100 \mathrm{mAs}$ e a combinação de anodo/filtro W/Rh. A máxima incerteza no valor de dose absorvida, considerando as incertezas propagadas do fator de calibração e fator $f$, foi de $2,3 \%$ do valor da dose. 
O posicionamento de vários dosímetros no eixo catodo-anodo foi realizado buscando encontrar possíveis variações nos valores de dose, características do efeito anódico. No entanto, esse efeito não pôde ser observado nos resultados devido, provavelmente, à pequena quantidade de dosímetros utilizados e a distância entre cada dosímetro no experimento (aproximadamente $1 \mathrm{~cm}$ ). A máxima incerteza no valor de dose absorvida, considerando as incertezas propagadas do fator de calibração e fator $f$, foi de $2,3 \%$ do valor da dose.

A variação de dose absorvida, normalizada pela carga (mAs), em função da espessura dos phantoms utilizados é apresentada na Figura 67. Essa relação foi determinada os feixes incidentes produzidos com as combinações de anodo/filtro Mo/Mo (a), Mo/Rh (b) e $\mathrm{W} / \mathrm{Rh}(\mathrm{c})$.

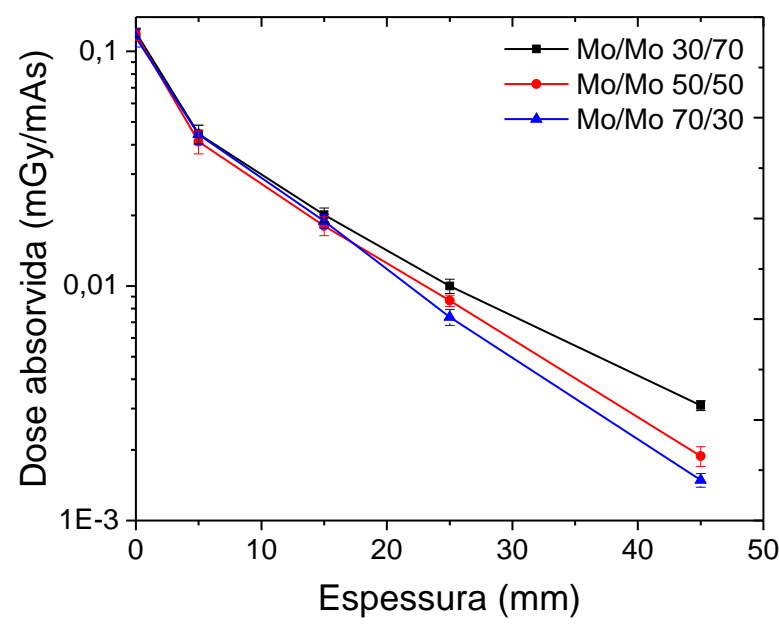

(a)

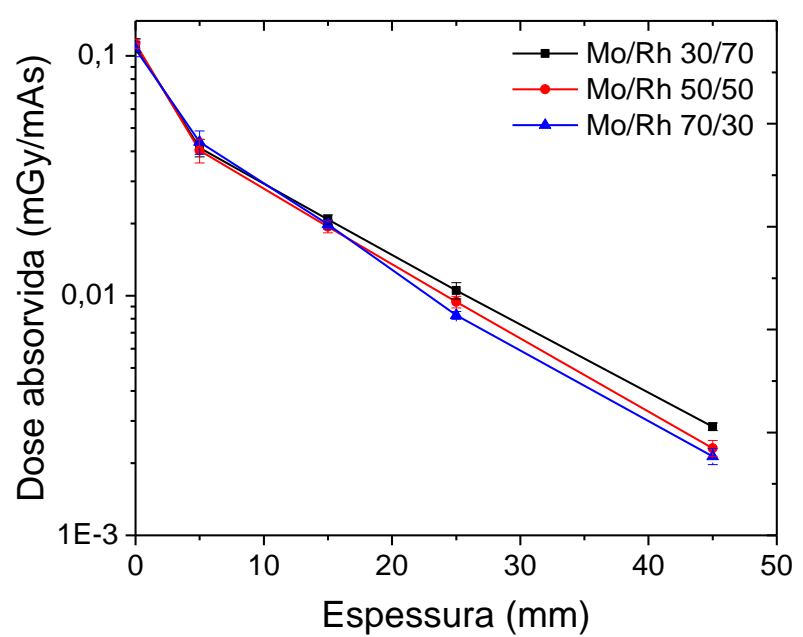

(b)

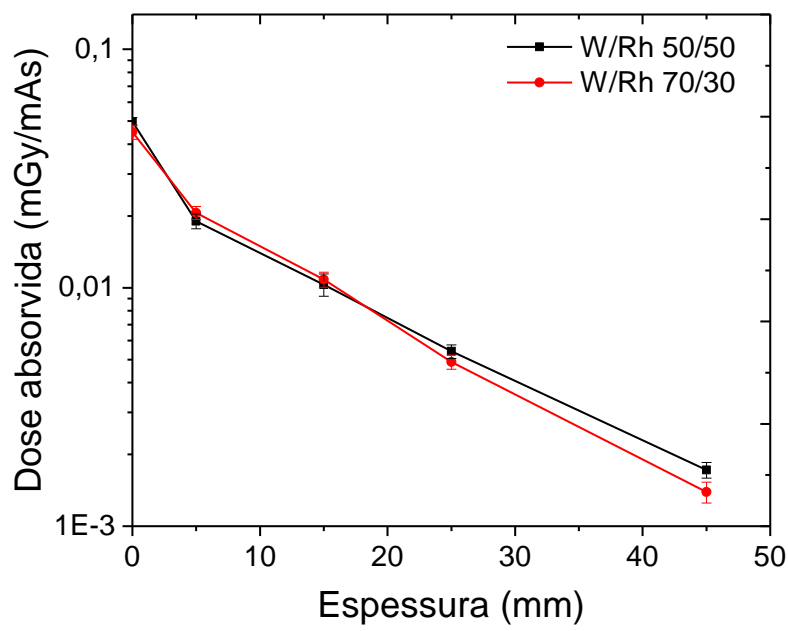

(c)

Figura 67: Variação de dose absorvida normalizada pela carga (mAs) em diferentes profundidades dos phantoms CIRS30/70, CIRS50/50 e CIRS70/30 para feixes incidentes produzidos com a combinação Mo/Mo (a), $\mathrm{Mo} / \mathrm{Rh}$ (b) e W/Rh (c). Os valores de dose apresentados para cada espessura representam a média dos valores de dose absorvida obtidos com dosimetros alocados em sete diferentes posições do eixo catodo anodo, conforme apresentado nas Figuras 63-65. 
Os resultados apresentados na Figura 67 mostram como a dose decresce rapidamente com a espessura de material equivalente ao tecido mamário para as diferentes composições de tecido glandular e tecido adiposo. Desse modo, em média, 61,4\% do valor da dose fornecida pelos feixes utilizados é absorvida nos primeiros $5 \mathrm{~mm}$ dos materiais simuladores de tecido mamário, enquanto somente $2,3 \%$ da dose é absorvido nos últimos $20 \mathrm{~mm}$ dos $45 \mathrm{~mm}$ de espessura total desses materiais. Da Figura 67 pode-se também notar que para cada combinação de anodo/filtro utilizada, a dose decresce mais rapidamente quando o feixe incide no material com maior percentual em tecido glandular.

\subsubsection{Distribuições da dose glandular normalizada}

A Figura 66 compara as distribuições de $\mathrm{DgN}_{\mathrm{p}}$ em profundidade obtidas utilizando dosímetros TLs (em pontos) e utilizando espectros de raios X pela aplicação do Método III (em barras coloridas). As linhas pontilhadas representam ajuste exponencial aos dados obtidos utilizando os TLDs. São comparados os resultados obtidos para o material equivalente a tecido mamário de composição 30/70 para as combinações alvo/filtro Mo/Mo (a) e Mo/Rh (b) e para o material de composição 50/50 (Mo/Mo (c) e Mo/Rh (d)). Vale esclarecer que os resultados obtidos por TLDs representam a dose normalizada em um pequeno volume de área $3 \times 3 \mathrm{~mm}^{2}$ e espessura de apenas $1 \mathrm{~mm}$ localizado numa profundidade conhecida do material equivalente a tecido mamário, enquanto que os resultados obtidos pelo Método III representam a dose média normalizada em camadas (de $0,5 \mathrm{~cm}$ ou $1 \mathrm{~cm}$ ) com espessuras de até 10 vezes maior que a espessura dos TLDs. As distribuições de $\mathrm{DgN}_{\mathrm{p}}$ comparadas na Figura 67 apresentam comportamento bastante similar.

Considere por exemplo, na Figura 66 (a), o resultado obtido por TLD na profundidade de $2,5 \mathrm{~cm}$ e o resultado obtido pelo Método III na camada de profundidade de 2 a $3 \mathrm{~cm}$. Sabese que a dose é decrescente com a profundidade e se fosse possível medir a dose ponto a ponto entre 2 e $3 \mathrm{~cm}$ ela teria valor máximo em $2 \mathrm{~cm}$, valor mínimo em $3 \mathrm{~cm}$, e um valor intermediário em 2,5 cm. Dos 3 pontos citados, a dose média estaria mais próxima daquele valor obtido para $2,5 \mathrm{~cm}$. Isso torna coerente o fato de que, em todos os casos mostrados, a linha de ajuste aos dados obtidos com TLDs cortam aproximadamente os centros das barras. 


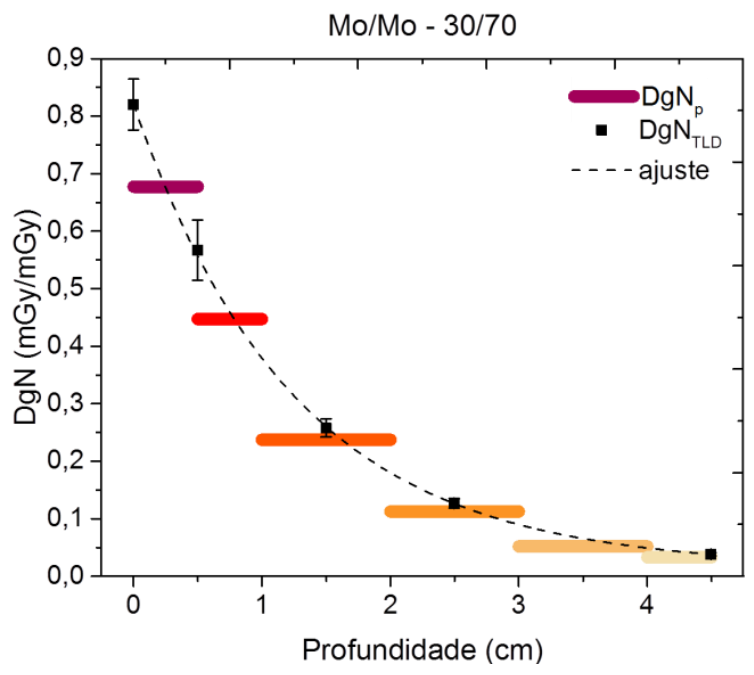

(a)

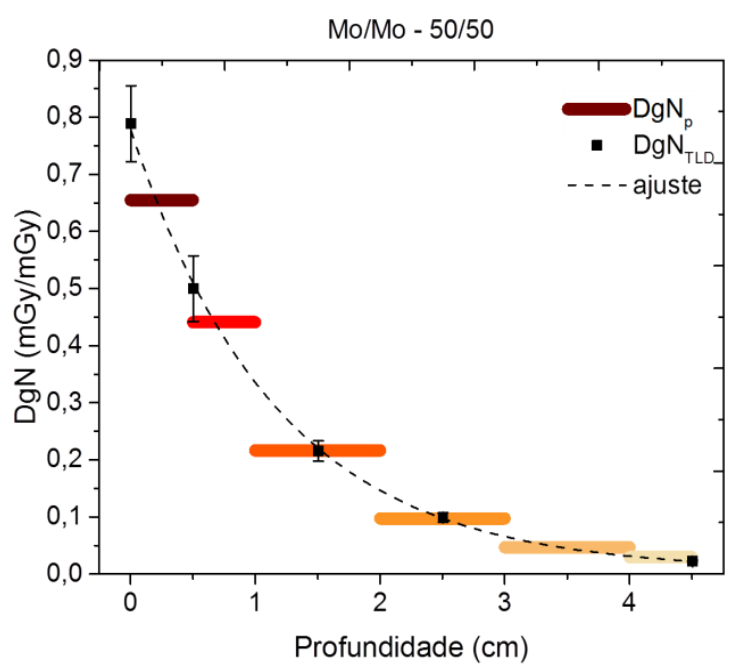

(c)

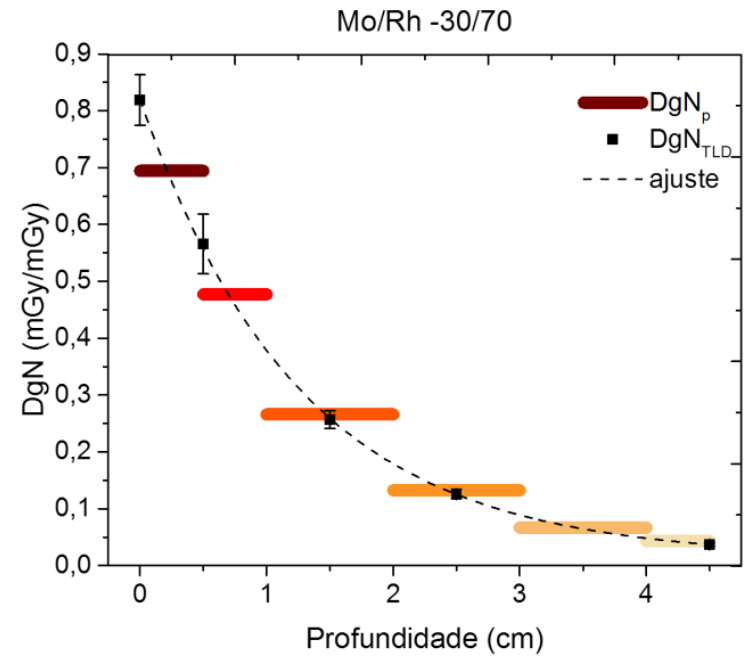

(b)

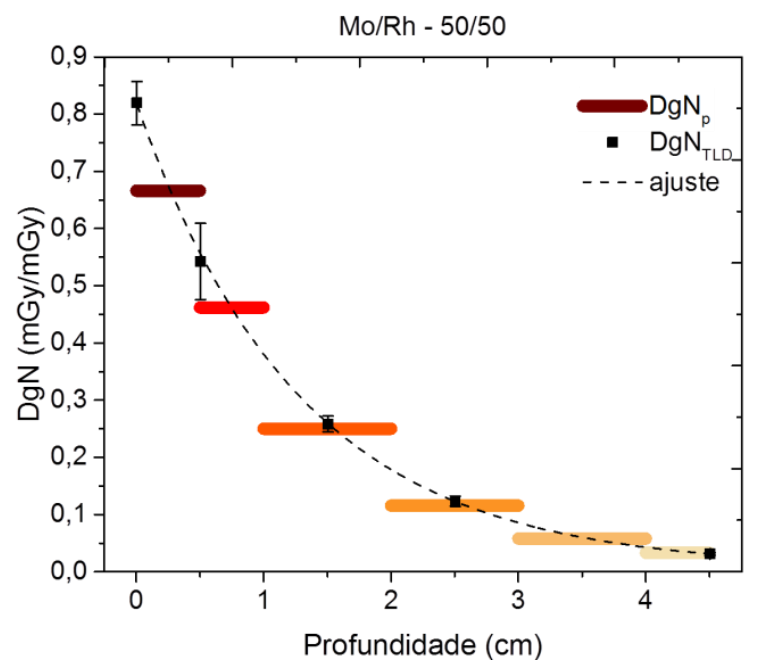

(d)

Figura 65: Comparações entre as distribuições de $\mathrm{DgN}_{\mathrm{p}}$ em profundidade obtidas utilizando dosímetros TLs (em pontos) e utilizando espectros de raios X pela aplicação do Método III (em barras coloridas). As linhas pontilhadas representam ajuste exponencial aos dados obtidos utilizando os TLDs. Resultados obtidos para o material equivalente a tecido mamário de composição 30/70 para as combinações alvo/filtro Mo/Mo (A) e $\mathrm{Mo} / \mathrm{Rh}$ (B) e para o material de composição 50/50 (Mo/Mo (C) e Mo/Rh (D)). 


\section{CONCLUSÕES}

Neste trabalho foi desenvolvida uma metodologia para medições de espectros de raios $\mathrm{X}$ primários e transmitidos por materiais equivalentes a tecidos mamários utilizando equipamentos de mamografia. Com os resultados obtidos pela aplicação dessa metodologia, foram realizadas estimativas de dose glandular normalizada na mama para diferentes espectros de raios $\mathrm{X}$ e considerando diferentes espessuras e composições mamárias.

O alinhamento do espectrômetro é um procedimento muito complexo e inviável de ser realizado rapidamente e precisamente somente por ajuste visual. No entanto, a metodologia desenvolvida $^{72}$ permitiu o adequado posicionamento e alinhamento do detector no feixe e, consequentemente, a medição de espectros diretos, mantendo as configurações originais do equipamento de mamografia. Os resultados da avaliação do efeito do desalinhamento nos espectros medidos mostraram que a precisão dos resultados é sensível ao correto alinhamento do espectrômetro. Além disso, o método apresentado para o alinhamento do espectrômetro em feixes de mamografia permite a medição de espectros com distorção mínima quanto a forma e máxima taxa de contagens. O sistema utilizado para esse procedimento é compacto, possível de ser reproduzido com baixo custo e pode ser utilizado para alinhar o espectrômetro em outros equipamentos. Por fim, o método descrito neste trabalho é promissor para a caracterização completa de feixes de raios $\mathrm{X}$ mamográficos que podem ser adotados para avaliação avançada de sistemas de mamografia.

Os espectros primários medidos em dois equipamentos de mamografia diferentes foram comparados com espectros gerados pelos modelos computacionais MASMIP (anodo de Mo) ${ }^{61}$ e TASMICS (anodo de $\left.\mathrm{W}\right)^{94}$. Os espectros experimentais apresentaram boa concordância com os espectros simulados tanto na morfologia quanto nos valores de CSR estimados. A diferença máxima dos valores de CSR para os espectros calculados e espectros experimentais medidos nos equipamentos Selenia e Mammomat 3000 foram de 1,3\% e 4,7\% respectivamente.

A metodologia usada mostrou-se adequada para medições tanto dos espectros primários ${ }^{72}$ quanto dos transmitidos ${ }^{95}$. No entanto, devido à alta taxa de fluência de fótons e a impossibilidade de posicionar o detector mais afastado da fonte, só foi possível medir espectros primários até $32 \mathrm{kV}$ e a faixa de tensões utilizadas em mamografia pode se estender a até $35 \mathrm{kV}$. Essa limitação pode ser resolvida com o uso de colimadores menores do que os que foram usados $(25 \mu \mathrm{m})$, desde que seja feito um alinhamento adequado. Outra opção é 
atenuar o feixe com materiais de alta pureza para reduzir a taxa de fluência para as medições e fazer a reconstrução do espectro original matematicamente.

Neste trabalho também foi realizado o cálculo de dose glandular normalizada, $\operatorname{DgN}_{\mathrm{p}}$ por meio da aplicação de três diferentes métodos (Método I, Método II e Método III) que utilizam espectros de raios $\mathrm{X}$ obtidos experimentalmente para o cálculo. Além disso, para efeito de comparação, a $\mathrm{DgN}_{\mathrm{p}}$ também foi avaliada utilizando dosímetros termoluminescentes (TLDs).

Os resultados de $\operatorname{DgN}_{\mathrm{p}}$ obtidos pelo Método I utilizando espectros experimentais apresentaram boa concordância com os resultados obtidos com o mesmo método, porém utilizando espectros simulados. Para um dado espectro, os valores de $\mathrm{DgN}_{\mathrm{p}}$ apresentaram a tendência de decrescimento exponencial com a espessura do material simulador de tecido mamário e decrescimento linear com a glandularidade. Os resultados mostraram também que, para os espectros analisados, esses coeficientes crescem linearmente com o aumento da camada semirredutora, e, portanto, com a energia efetiva. Esse resultado se confirma com a análise da $\mathrm{DgN}_{\mathrm{p}}$ com relação aos parâmetros combinação alvo/filtro e tensão. A combinação que produz feixes com maior energia efetiva (W/Ag) é a que resulta em maiores valores de $\mathrm{DgN}_{\mathrm{p}}$, quando comparados com outras combinações que produzem feixes menos energéticos. Por sua vez, os valores de $\mathrm{DgN}_{\mathrm{p}}$ também aumentam com a tensão. A distribuição bemcomportada desses coeficientes, com tendência linear ou exponencial, com relação aos parâmetros analisados, é de grande utilidade uma vez que isso possibilita estimar a $\operatorname{DgN} N_{p}$ para situações diferentes das testadas experimentalmente por meio de interpolações.

O Método II, que considera ambos os espectros incidentes e transmitidos, produz valores de $\operatorname{DgN}_{\mathrm{p}}$ sistematicamente menores que aqueles obtidos pelo Método I, para os casos analisados, atingindo uma diferença máxima de $-11 \%$. Essa diferença é mais significativa para os espectros de $\mathrm{Mo} / \mathrm{Rh}$ com relação aos espectros de $\mathrm{Mo} / \mathrm{Mo}$. Apesar disso, os resultados obtidos com este método apresentam as mesmas tendências, com relação os parâmetros analisados, observadas com os resultados obtidos pelo Método I.

O Método III, que também considera espectros incidentes e transmitidos, fornece resultados para distribuição da $\mathrm{DgN}_{\mathrm{p}}$ em camadas de diferentes profundidades dos materiais simuladores de tecido mamário utilizados. Por meio dessa distribuição da dose em camadas é possível calcular a dose média considerando o phantom inteiro (como no Método II). A utilização desse procedimento resultou em valores de $\operatorname{DgN}_{\mathrm{p}}$ que diferem no máximo de 5,2\% dos valores obtidos com o Método II. Tal como esperado, a $\operatorname{DgN}_{\mathrm{p}}$ decresce exponencialmente com a profundidade das camadas analisadas. 
A distribuição da dose absorvida (nos tecidos glandular e adiposo) e da dose glandular normalizada em função da profundidade também foi avaliada utilizando dosímetros termoluminescentes (TLDs). Os resultados mostram que deposição de dose nas diversas camadas dos phantoms depende do espectro de raios $\mathrm{X}$ usados e também da composição do phantom. A variação da $\operatorname{DgN}_{\mathrm{p}}$ com a profundidade obtidas com TLDs mostrou-se bastante coerente com os resultados observados pela utilização do Método III.

Conclui-se que é possível avaliar a dose glandular na mamografia utilizando espectros de raios $\mathrm{X}$ experimentais. No entanto, mesmo utilizando os métodos propostos neste trabalho, essas medições ainda são complexas quando comparadas com medições realizadas com câmaras de ionização para testes de controle de qualidade. Apesar disso, deve-se considerar a maior riqueza de informações sobre os feixes produzidos pelos mamógrafos, e até mesmo sobre os materiais atenuadores, que as avaliações espectrométricas trazem. A recomendação do uso de espectrometria de raios $\mathrm{X}$ para testes de rotina em mamografia, mesmo para testes a serem realizados com menor frequência, não teria sustentação considerando-se as condições atuais de desenvolvimento de detectores desta natureza. No entanto, tanto a instrumentação adotada em testes de controle de qualidade ou dosimetria quanto os sistemas de mamografia têm evoluído muito desde a sua criação. Isso permite projetar um futuro onde o próprio detector do mamógrafo consiga registrar os espectros transmitidos pela mama da paciente ${ }^{96 ; 97 ;}$ ${ }^{98}$. Essa possibilidade viabilizaria o uso dos espectros e do método de cálculo de dose para práticas rotineiras de controle de qualidade e avaliação de dose de pacientes.

Finalmente, vale ressaltar que não se havia medido espectros de raios $\mathrm{X}$ em ambientes clínicos de mamografia, sem modificar as configurações originais do equipamento ${ }^{72}$, antes deste trabalho. O método proposto é o primeiro passo para se pensar no uso dessa ferramenta em aplicações clinicas. Desse modo, enquanto não se têm condições favoráveis para o uso dessa ferramenta na prática clínica, pode-se explorar o leque de possibilidades de pesquisa com espectrometria em mamografia que surge com o método de medição proposto nesse trabalho. 


\section{REFERÊNCIAS}

1 WCRFI. World Cancer Reseacher Fund International 2017. Disponível em: < http://www.wcrf.org/int/cancer-facts-figures/worldwide-data $>$. Acesso em: $11 / 10 / 2017$.

INCA. Instituto Nacional do Câncer. Estimativa 2016 : Incidência de Câncer no Brasil Ministério da Saude: Rio de Janeiro, 2015.

URBAN, L. A. B. D. et al. Breast cancer screening: Updated recommendations of the Brazilian college of radiology and diagnostic imaging, Brazilian breast disease society, and Brazilian federation of gynecological and obstetrical associations. Radiologia Brasileira, v. 50, n. 4, p. 244-249, 2017.

URBAN, L. A. B. D. et al. Recomendações do Colégio Brasileiro de Radiologia e Diagnóstico por Imagem, da Sociedade Brasileira de Mastologia e da Federação Brasileira das Associações de Ginecologia e Obstetrícia para rastreamento do câncer de mama por métodos de imagem. Radiologia Brasileira, v. 45, p. 334-339, 2012.

INCA. Instituto Nacional do Câncer Disponível em: http://www.inca.gov.br/outubro-rosa/outubro-rosa.asp >. Acesso em: 27/10/2017.

DANCE, D. R.; SKINNER, C. L.; ALM CARLSSON, G. Breast dosimetry. Appl Radiat Isotopes, v. 50, n. 1, p. 185-203, 1999. ISSN 0969-8043.

PRESTON, D. L. et al. Radiation effects on breast cancer risk: A pooled analysis of eight cohorts. Radiation Research, v. 158, n. 2, p. 220-235, 2002.

PAUWELS, E. K. J.; FORAY, N.; BOURGUIGNON, M. H. Breast Cancer Induced by X-Ray Mammography Screening? A Review Based on Recent Understanding of Low-Dose Radiobiology. Medical Principles and Practice, v. 25, n. 2, p. 101-109, 2016.

IAEA. Quality assurance programme for digital mammography. International Atomic Energy Agency. Viena. 2011

EUROPEAN COMMISSION (EC). European Guidelines for Quality Assurance in Breast Cancer Screening and Diagnosis. (Luxembourg: Office for Official Publications of the European Communities). 4th edn 2013.

ACR. Mammography Quality Control Manual. American College of Radiology. Reston, Va. 1999

BRASIL. Radiodiagnóstico Médico: Desempenho de Equipamentos e Segurança. Brasília: Editora Anvisa, 2005. 104 p. ISBN 85-334-1040-9

DANCE, D. R.; YOUNG, K. C.; VAN ENGEN, R. E. Further factors for the estimation of mean glandular dose using the United Kingdom, European and IAEA breast dosimetry protocols. PHYS MED BIOL, v. 54, n. 14, p. 4361-4372, 2009. filter and rhodium target-rhodium filter mammography. Radiology, 1994. 83-89 
DANCE, D. R. Monte-Carlo calculation of conversion factors for the estimation of mean glandular breast dose. Physics in Medicine and Biology, v. 35, n. 9, p. 12111219, 1990.

SOBOL, W. T.; WU, X. Parametrization of mammography normalized average glandular dose tables. Medical Physics, v. 24, n. 4, p. 547-554, 1997.

JAMAL, N. et al. Mammographic Breast Glandularity in Malaysian Women: Data Derived from Radiography. American Journal of Roentgenology, v. 182, n. 3, p. 713-717, 2004.

BUSHBERG, J. T. et al. The Essential Physics of Medical Imaging. third edition. USA: Lippincott williams and wilkins, 2011.

HIPPERSON, V. L. Magnification and Compression Views. Digital Mammography: A Holistic Approach. HOGG, P.;KELLY, J., et al. Switzerland Springer 2015.

URBAN, L. A. B. D. et al. Recommendations of colégio brasileiro de radiologia e diagnóstico por imagem, sociedade brasileira de mastologia, and federação brasileira das associações de ginecologia e obstetrícia for imaging screening for breast cancer. Radiologia Brasileira, v. 45, n. 6, p. 334-339, 2012.

MINISTÉRIO DA SAÚDE; INSTITUTO NACIONAL DO CÂNCER. Mamografia: da prática ao controle (Recomendações para profissionais de saúde) INCA. Rio de Janeiro. 2007

Physics in Medicine and Biology, v. 61, n. 19, p. R271-R304, 2016.

KELARANTA, A. et al. Conformance of mean glandular dose from phantom and patient data in mammography. Radiation Protection Dosimetry, v. 164, n. 3, p. 342$353,2015$.

DARLINGTON, A. J. Anatomy of the Breast. In: HOGG, P. e KELLY, J. (Ed.). Digital Mammography: A Holistic Approach. Switzerland: Springer, 2015.

TOMAL, A. Estudo semianalítico da qualidade da imagem e dose em mamografia. 2010. (Doutorado). Faculdade de Filosofia, Ciências e Letras de Ribeirão Preto, Universidade de São Paulo. , Ribeirão Preto.

BOONE, J. M. Glandular breast dose for monoenergetic and high-energy x-ray beams: Monte Carlo assessment. Radiology, v. 213, n. 1, p. 23-37, 1999.

TOMAL, A. Mammography applications. In: DEWERD, L. e KISSICK, M. (Ed.). The Phantoms of Medical and Health Physics New York: springer, v.1, 2014. cap. 8 ,

YAFFE, M. J. et al. The myth of the 50-50 breast. Medical Physics, v. 36, n. 12, p. 5437-5443, 2009.

NIST. [online]. Tabela de composição de materiais. < http://physics.nist.gov/cgi$\underline{\text { bin/Star/compos.pl?matno }=013}>$ [12/11/ 2015]. 
ICRU. Fundamental quantities and units for ionizing radiation Oxford - ICRU Report 85. 2011

OKUNO, E.; YOSHIMURA, E. M. FÍsica das Radiações. $1^{\text {a }}$ Edição. São Pulo: Oficina de Textos, 2010. ISBN 9788579750052.

KARLSSON, M. et al. Absorbed dose in mammary radiography. Acta Radiologica Series Therapy, Physics and Biology, v. 15, n. 3, p. 252-258, 1976.

ICRP. Statement from the 1987 Como meeting of the ICRP. International Commission on Radiological Protection Annals of the ICRP 17(4). 1987

BERNS, E. A. et al. Digital Mammography Quality Control Manual. American College of Radiology. Reston, Va. 2016

(1)

ICRU. Patient Dosimetry for X Rays Used in Medical Imaging. Oxford - ICRU Report 74. 2005

SANTOS, J. C.; COSTA, P. R. Evaluation of the effective energy of primary and transmmitted workload weighted X-ray spectra. Radiat Phys Chem, 2013.

IPEM. The commissioning and routine testing of mammographic $\mathrm{x}$-ray systems Intitute of Physics and Engineering in Medicine. York. 2005. (Report 89)

EUROPE COMMISION. European Guidelines for Quality Assurance in Breast Cancer Screening and Diagnosis fourth edition. 2006.

IAEA. Dosimetry in Diagnostic Radiology: An international Code of Practice. Viena. 2007. (Technical Report Series $n^{\circ}$ 457)

DANCE, D. R. et al. Additional factors for the estimation of mean glandular breast dose using the UK mammography dosimetry protocol. Physics in Medicine and Biology, v. 45, n. 11, p. 3225-3240, 2000.

DANCE, D. R.; YOUNG, K. C.; VAN ENGEN, R. E. Estimation of mean glandular dose for breast tomosynthesis: Factors for use with the UK, European and IAEA breast dosimetry protocols. Physics in Medicine and Biology, v. 56, n. 2, p. 453-471, 2011.

DANCE, D. R. Monte-Carlo calculation of conversion factors for the estimation of mean glandular breast dose. Physics in Medicine \& Biology, v. 35, n. 9, p. 1211, 1990. ISSN 0031-9155.

WU, X.; BARNES, G. T.; TUCKER, D. M. Spectral dependence of glandular tissue dose in screen-film mammography. Radiology, v. 179, n. 1, p. 143-148, 1991.

SARNO, A. et al. A Monte Carlo study of monoenergetic and polyenergetic normalized glandular dose $(\mathrm{DgN})$ coefficients in mammography. Physics in Medicine and Biology, v. 62, n. 1, p. 306-325, 2017.

BOONE, J. M.; HERNANDEZ, A. M.; SEIBERT, J. A. Two-dimensional breast dosimetry improved using three-dimensional breast image data. Radiological Physics and Technology, v. 10, n. 2, p. 129-141, 2017. 
HERNANDEZ, A. M.; SEIBERT, J. A.; BOONE, J. M. Breast dose in mammography is about $30 \%$ lower when realistic heterogeneous glandular distributions are considered. Medical Physics, v. 42, n. 11, p. 6337-6348, 2015.

SECHOPOULOS, I.; TRIANNI, A.; PECK, D. The DICOM radiation dose structured report: What it is and what it is not. Journal of the American College of Radiology, v. 12, n. 7, p. 712-713, 2015.

HIGHNAM, R. VolparaSolutions - Patient-Specific Radiation Dose Estimation in Breast Cancer Screening. 2017. Disponível em: < https://volparasolutions.com/assets/Uploads/VolparaDose-White-Paper.pdf >. Acesso em: 09/10/2017.

C. TROMANS; A. CHAN; R. HIGHNAM. Comparing personalized mean glandular dose estimates between $x$-ray systems over time in mammography European Congress of Radiology 2014.

PRADHAN, A. S. Thermoluminescence dosimetry and its applications. Radiation Protection dosimetry, v. 1, n. 3, p. 153-167, 1981.

MCKEEVER, S. W. S. Thermoluminescence of Solids USA: Cambridge Solid State Science Series, 2001.

REIS, C. et al. Quality assurance and quality control in mammography: a review of available guidance worldwide. Insights into Imaging, Berlin/Heidelberg, v. 4, n. 5, p. 539-553, 2013. ISSN 1869-4101.

STANTON, L. et al. Dosage evaluation in mammography. Radiology, v. 150, n. 2, p. 577-584, 1984/02/01 1984. ISSN 0033-8419.

HAMMERSTEIN, R. G. et al. Absorbed Radiation Dose in Mammography. Radiology, v. 130, n. 2, p. 485-491, 1979/02/01 1979. ISSN 0033-8419.

JOHNS, H. E.; CUNNINGHAM, J. R. The Physics of Radiology. fouth edition USA: Springfield U.S.A, : Thomas Book, 1983.

SANTOS, J. C. et al. Determinação da camada semirredutora e da tensão aplicada a partir de espectros emitidos por um tubo de raios X. Revista Brasileira de Física Médica (Online), v. 10, n. 3, p. 28-33, 2016.

DUSI, W. et al. Evaluation of the possible use of a CdTe detector for the characterization of diagnostic X-ray beams. Nucl. Instrum. Methods. Phys. Res A, v. 374, n. 3, p. 390-394, 1996. ISSN 0168-9002.

MATSUMOTO, M. et al. Direct measurement of mammographic x-ray spectra using a CdZnTe detector. Med. Phys., v. 27, n. 7, p. 1490-1502, 2000.

MIYAJIMA, S.; IMAGAWA, K.; MATSUMOTO, M. An alignment method for mammographic X-ray spectroscopy under clinical conditions. Brit. J. Radiol., v. 75, n. 897, p. $763-766,2002$. ISSN 00071285

WILKINSON, L. E.; JOHNSTON, P. N.; HEGGIE, J. C. P. A comparison of mammography spectral measurements with spectra produced using several different 
mathematical models. Physics in Medicine and Biology, v. 46, n. 5, p. 1575-1589, 2001.

BOONE, J. M.; FEWELL, T. R.; JENNINGS, R. J. Molybdenum, rhodium, and tungsten anode spectral models using interpolating polynomials with application to mammography. Med. Phys., v. 24, n. 12, p. 1863-1874, 1997.

TUCKER, D. M.; BARNES, G. T.; WU, X. Molybdenum target X-ray spectra: A semiempirical model. Med. Phys., v. 18, n. 3, p. 402-407, 1991.

BLOUGH, M. M. et al. Calculated mammographic spectra confirmed with attenuation curves for molybdenum, rhodium, and tungsten targets. Med. Phys., v. 25, n. 9 , p. $1605-1612,1998$.

KAWAGUCHI, S. et al. Reconstruction of mammography x-ray spectrum by using Rayleigh and Compton scattering corrections. IFMBE Proceedings, 2009. 231-233 p.

ALMEIDA JR., J. N. et al. Dosimetria de raios X em mamografia para combinação Mo/Mo utilizando espectrometria Compton. Revista da Imagem, v. 32, p. 13-19, 2010.

ALMEIDA JR., J. N. et al. Espectrometria Compton aplicada à medição de doses em mamografia para combinações W/Mo e Mo/Mo. Revista Brasileira de Física Médica (Online), v. 4, p. 39-43, 2010.

VIEIRA, A. A. et al. A portable Compton spectrometer for clinical X-ray beams in the energy range 20 to 150keV. . Applied Radiation and Isotopes, p. 350-357, 2010.

KÜNZEL, R. et al. X-ray spectroscopy in mammography with a silicon PIN photodiode with application to the measurement of tube voltage. Med. Phys., v. 31, n. 11, p. 2996-3003, 2004.

STUMBO, S. et al. Direct analysis of molybdenum target generated x-ray spectra with a portable device. Med. Phys., v. 31, n. 10, p. 2763-2770, 2004.

ABBENE, L. et al. Direct measurement of mammographic X-Ray spectra with a digital CdTe detection system. Sensors (Switzerland), v. 12, n. 6, p. 8390-8404, 2012.

ZHANG, D.; LI, X.; LIU, B. X-ray spectral measurements for tungsten-anode from 20 to $49 \mathrm{kVp}$ on a digital breast tomosynthesis system. Med. Phys., v. 39, n. 6, p. 3493$3500,2012$.

SANTOS, J. C. et al. Direct measurement of clinical mammographic x-ray spectra using a CdTe spectrometer. Medical Physics, v. 44, n. 7, p. 3504-3511, 2017.

HERNANDEZ, A. M.; BOONE, J. M. Tungsten anode spectral model using interpolating cubic splines: Unfiltered x-ray spectra from $20 \mathrm{kV}$ to $640 \mathrm{kV}$. Medical Physics, v. 41, n. 4, 2014.

CHU, S. Y. F.; EKSTRÖM, L. P.; FIRESTONE, R. B. The Lund/LBNL Nuclear Data Search (Version 2.0). 1999. Disponível em: < http://nucleardata.nuclear.lu.se/toi/ $>$. Acesso em: 28/10/2017. 
DI CASTRO, E. et al. The use of cadmium telluride detectors for the qualitative analysis of diagnostic x-ray spectra. Phys Med Biol, v. 29, n. 9, p. 1117-1131, 1984.

SEELENTAG, W. W.; PANZER, W. Stripping of X ray bremsstrahlung spectra up to $300 \mathrm{kV}$ (p) on a desk type computer. Physics in Medicine and Biology, v. 24, n. 4, p. 767-780, // 1979. of electron and photon transport. Paris: 2003.

TOMAL, A. et al. Response functions of $\mathrm{Si}(\mathrm{Li}), \mathrm{SDD}$ and CdTe detectors for mammographic X-ray spectroscopy. Appl Radiat Isot, v. 70, n. 7, p. 1355-1359, 2012.

TERINI, R. A. et al. Measurements of discrete and continuous X-ray spectra with a photodiode at room temperature. Appl Radiat Isot, v. 50, n. 2, p. 343-353, 1999.

SANTOS, J. C. Estudo experimental das relações entre Kerma no ar e equivalente de dose ambiente para o cálculo de barreiras primárias em salas radiológicas. 2013. Dissertação (Mestrado). IFUSP, Universidade de São Paulo, São Paulo.

BERGER, M. J. et al. XCOM: Photon Cross Sections Database (version 1.5) Gaithersburg, MD, 2010. Disponível em: < http://physics.nist.gov/xcom >. Acesso em: 25/09/2017.

BOONE, J. M. Normalized glandular dose (DgN) coefficients for arbitrary x-ray spectra in mammography: Computer-fit values of Monte Carlo derived data. Medical Physics, v. 29, n. 5, p. 869-875, 2002.

NOSRATIEH, A. et al. Mean glandular dose coefficients (DgN) for x-ray spectra used in contemporary breast imaging systems. Physics in Medicine and Biology, v. 60, n. 18, p. 7179-7190, 2015.

FENG, S. S. J.; SECHOPOULOS, I. Clinical Digital Breast Tomosynthesis System: Dosimetric Characterization. Radiology, v. 263, n. 1, p. 35-42, 04/ 2012.

CUNHA, D. M.; TOMAL, A.; POLETTI, M. E. Evaluation of scatter-to-primary ratio, grid performance and normalized average glandular dose in mammography by Monte Carlo simulation including interference and energy broadening effects. Physics in Medicine and Biology, v. 55, n. 15, p. 4335-4359, 2010.

NIST. [online].Tables of X-Ray Mass Attenuation Coefficients and Mass EnergyAbsorption Coefficients from $1 \mathrm{keV}$ to $20 \mathrm{MeV}$ for Elements $\mathrm{Z}=1$ to 92 and 48 Additional Substances of Dosimetric Interest <http://www.nist.gov/pml/data/xraycoef/> [viewed on december 2015].

POLETTI, M. E.; GONÇALVES, O. D.; MAZZARO, I. X-ray scattering from human breast tissues and breast-equivalent materials. Physics in Medicine and Biology, v. 47, n. 1, p. 47-63, 2002.

INMETRO. Vocabulário Internacional de Metrologia: Conceitos Fundamentais e Gerais e Termos Associados. Primeira edição brasilleira do VIM 2008. Rio de Janeiro 2009. 
BUSHBERG, J. T. et al. The essential Physics of medical imaging. second USA: Lippincott Williams and Wilkins, 2001.

BOONE, J. M.; SEIBERT, J. A. An accurate method for computer-generating tungsten anode x-ray spectra from 30 to $140 \mathrm{kV}$. Medical Physics, v. 24, n. 11, p. 1661-1670, 1997.

TOMAL, A. Densidade mamária de mulheres brasileiras._. SANTOS, J. C. XXI Congresso Brasileiro de Física Médica - Florianópolis 2016.

DEPARTMENT OF HEALTH AND HUMAN SERVICES FOOD AND DRUG ADMINISTRATION. Mammography Quality Standards Act Regulations. 21. 2013. Disponível em: < http://www.accessdata.fda.gov/scripts/cdrh/cfdocs/cfcfr/CFRSearch. cfm?fr=900.12 >. Acesso em: 28/10/2017.

HELENE, O. A. M.; VANIN, V. R. Tratamento estatistico de dados física experimental. São Paulo: Edgard Blücher, 1981.

HERNANDEZ, A. M.; BOONE, J. M. Tungsten anode spectral model using interpolating cubic splines: Unfiltered $\mathrm{x}$-ray spectra from $20 \mathrm{kV}$ to $640 \mathrm{kV}$. Med. Phys., v. 41, n. 4, p. 042101, 2014.

SANTOS, J. C.; TOMAL, A.; COSTA, P. R. Application of a CdTe Detector for Measurements of Mammographic X-ray Spectra. Journal of Nuclear Physics, Material Sciences, Radiation and Applications, v. 5, n. 1, p. 91-102, 2017.

KARELLAS, A. Photon-Counting Digital Mammography. Evaluation of Performance under Clinically Relevant Conditions. Academic Radiology, v. 19, n. 8, p. 913-915, 2012.

$\mathrm{CHO}, \mathrm{H}$. M. et al. Microcalcification detectability using a bench-top prototype photon-counting breast CT based on a Si strip detector. Medical Physics, v. 42, n. 7, p. 4401-4410, 2015.

OKAMOTO, C. et al. Discrimination between normal breast tissue and tumor tissue using CdTe series detector developed for photon-counting mammography. Progress in Biomedical Optics and Imaging - Proceedings of SPIE, 2016. p. 


\section{Apêndice I}

\section{Estimativa de CSR e incerteza a partir do espectro}

Método: Cálculo de variâncias e covariâncias usando o formalismo matricial $^{1}$.

\section{Caso Geral:}

Sejam as funções $Z_{1}$ e $Z_{2}$ de variáveis aleatórias $y_{1}, y_{2}, \ldots, y_{\mu}$

$$
\begin{aligned}
& z_{1}=Z_{1}\left(y_{1}, y_{2}, \ldots, y_{\mu}\right) \\
& Z_{2}=Z_{2}\left(y_{1}, y_{2}, \ldots, y_{\mu}\right)
\end{aligned}
$$

Para $\rho$ funções $Z_{1}, Z_{2}, \ldots, Z \rho$ de $\mu$ variáveis aleatórias $y_{1}, y_{2}, \ldots, y_{\mu}$ de $\vec{y}$, a matriz de covariância de $\vec{Z}$ é dada por

$$
V_{z} \cong C \cdot V_{y} \cdot C^{t}
$$

Onde $\boldsymbol{C}$ é a matriz das derivadas parciais de $\vec{Z}$ com relação a $\vec{y}$,

$$
\begin{gathered}
C_{\nu \lambda}=\frac{\partial z_{v}}{\partial y_{\lambda}} \\
v=1,2, \ldots, \rho \quad \lambda=1,2, \ldots, \mu
\end{gathered}
$$

$\boldsymbol{V}_{y}$ é a matriz de covariância das variáveis y.

$$
\boldsymbol{V}_{y}=\left(\begin{array}{cccc}
\sigma y_{1}{ }^{2} & \operatorname{cov}\left(y_{1}, y_{2}\right) & \ldots & \operatorname{cov}\left(y_{1}, y_{\mu}\right) \\
\operatorname{cov}\left(y_{2}, y_{1}\right) & \sigma y_{2}{ }^{2} & \ldots & \operatorname{cov}\left(y_{2}, y_{\mu}\right) \\
\vdots & \vdots & \ddots & \vdots \\
\operatorname{cov}\left(y_{\mu}, y_{1}\right) & \operatorname{cov}\left(y_{\mu}, y_{2}\right) & \ldots & \sigma y_{\mu}{ }^{2}
\end{array}\right)
$$




\section{Caso dos Espectros:}

\section{Considerações iniciais:}

Considere o espectro de fluência, $n(E)$, corrigido pelo programa Corresp ${ }^{2}$. A distribuição de kerma no ar, $k(E)$, pode ser calculada a partir do espectro de fluência como:

$$
k(E)=n(E) \cdot E \cdot\left(\frac{\mu_{a r}(E)}{\rho_{a r}}\right)_{t}
$$

Onde $\left(\frac{\mu_{a r}(E)}{\rho_{a r}}\right)_{t}$ é o coeficiente mássico de transferência de energia para o ar.

Considerando somente a incerteza estatística de $n(E)$, como incerteza de Poisson, e desconsiderando incertezas nos demais termos da equação (5), a incerteza propagada em k, seria:

$$
\sigma k^{2}=\left(E \cdot\left(\frac{\mu_{a r}(E)}{\rho_{a r}}\right)_{t}\right)^{2} \cdot n
$$

Desconsiderando as covariâncias dos termos da equação (5), a matriz de covariância de $k$ é então:

$$
\boldsymbol{V}_{k}=\left(\begin{array}{ccc}
\sigma k_{1}{ }^{2} & 0 & \ldots \\
0 & \sigma k_{2}{ }^{2} & \ldots \\
\vdots & \vdots & \ddots
\end{array}\right)
$$

$\operatorname{Com} k_{1}=k\left(E_{1}\right), k_{2}=k\left(E_{2}\right), \ldots$

\section{Cálculo de CSR e Incerteza:}

Seja $K$, o somatório das distribuições de kerma no ar $k(E)$ transmitido por uma espessura $x$ de alumínio. Esse somatório representa o kerma no ar total referente ao espectro transmitido por alumínio.

$$
K_{1}=\sum_{i} k_{i} e^{-\frac{\mu_{A l}}{\rho} \cdot \rho \cdot x_{1}}
$$




$$
K_{2}=\sum_{i} k_{i} e^{-\frac{\mu_{A l} l}{\rho} \cdot \rho \cdot x_{2}}
$$

A matriz de covariância das funções $K_{i}$ é:

$$
\boldsymbol{V}_{K} \cong \mathbf{C} \cdot \mathbf{V}_{\mathrm{k}} \cdot \mathbf{C}^{\mathbf{t}}
$$

Com $\mathbf{V}_{\mathrm{k}}$ determinado nas equações (6) e (7).

Os elementos da matriz $\mathbf{C}$ das derivadas parciais são:

$$
C_{v \lambda}=\frac{\partial K_{v}}{\partial k_{\lambda}}
$$

Assim:

$$
\begin{aligned}
& C_{11}=\frac{\partial K_{1}}{\partial k_{1}}=e^{-\frac{\mu_{A l}}{\rho} \cdot \rho \cdot x_{1}} \\
& C_{12}=\frac{\partial K_{1}}{\partial k_{2}}=e^{-\frac{\mu_{A l}}{\rho} \cdot \rho \cdot x_{1}} \\
& C_{21}=\frac{\partial K_{2}}{\partial k_{1}}=e^{-\frac{\mu_{A l}}{\rho} \cdot \rho \cdot x_{1}}
\end{aligned}
$$

Desse modo a matriz $\mathbf{C}$, das derivadas parciais, pode ser então determinada e relação apresentada em (9) pode ser obtida.

Agora, considere $I=I\left(K_{1}, K_{2}, \ldots\right)$, as intensidades relativas do kerma no ar no ar:

$$
\begin{gathered}
\mathrm{I}_{\mathrm{i}}=\frac{\mathrm{K}_{\mathrm{j}}}{\mathrm{K}_{1}} \quad i=1,2,3 \ldots . \quad j=2,3, . . \\
\mathrm{I}_{1}=\frac{\mathrm{K}_{2}}{\mathrm{~K}_{1}}
\end{gathered}
$$




$$
\begin{aligned}
& \mathrm{I}_{2}=\frac{\mathrm{K}_{3}}{\mathrm{~K}_{1}} \\
& \mathrm{I}_{3}=\frac{\mathrm{K}_{4}}{\mathrm{~K}_{1}}
\end{aligned}
$$

A matriz de covariância de I é:

$$
V_{I} \cong \mathrm{D} \cdot \mathrm{V}_{\mathrm{K}} \cdot \mathrm{D}^{\mathrm{t}}
$$

Com $\mathbf{V}_{\mathrm{K}}$ determinado anteriormente pela equação (9) e $\mathbf{D}$, a matriz das derivadas parciais, tal como $\mathbf{C}$ na equação (4). Para resolver a equação (14), basta determinar D:

$$
\begin{aligned}
& C_{v \lambda}=\frac{\partial I_{v}}{\partial K_{\lambda}} \\
& D_{11}=\frac{\partial I_{1}}{\partial K_{1}}=-\frac{K_{2}}{\left(K_{1}\right)^{2}} ; \quad D_{12}=\frac{\partial I_{1}}{\partial K_{2}}=\frac{1}{K_{1}} ; \quad D_{13}=\frac{\partial I_{1}}{\partial K_{3}}=0 \\
& D_{21}=\frac{\partial I_{2}}{\partial K_{1}}=-\frac{K_{3}}{\left(K_{1}\right)^{2}} ; \quad D_{22}=\frac{\partial I_{2}}{\partial K_{2}}=0 ; \quad D_{23}=\frac{\partial I_{2}}{\partial K_{3}}=\frac{1}{K_{1}} \\
& D_{31}=\frac{\partial I_{3}}{\partial K_{1}}=-\frac{K_{4}}{\left(K_{1}\right)^{2}} ; \quad D_{32}=\frac{\partial I_{3}}{\partial K_{2}}=0 ; \quad D_{33}=\frac{\partial I_{3}}{\partial K_{3}}=0
\end{aligned}
$$

Determinados os valores de I e $\mathbf{V}_{\mathbf{I}}$, uma interpolação linear do valor de x é feita usando o Matlab (The MathWorks Inc.) conforme apresentado na Figura 1.

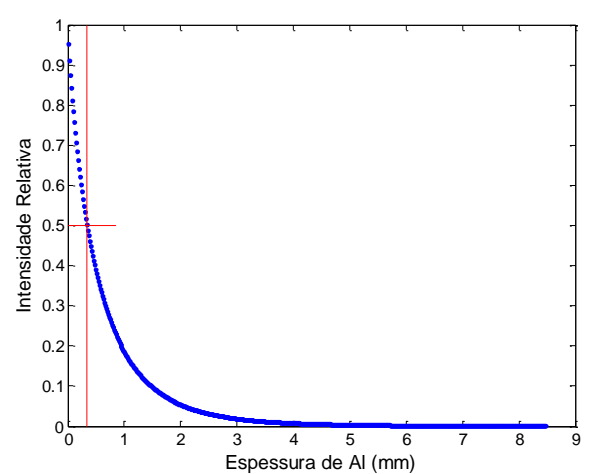

(a)

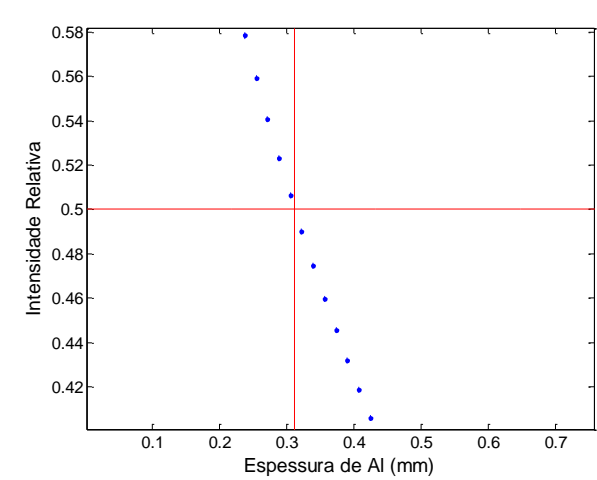

(b) 
Figura 1: Interpolação do valor de $x$, para o qual $I=0,5$, o que representa a primeira camada semirredutora (a). Ampliação do gráfico na região onde $I=0,5$.

Uma vez encontrado o valor de camada semirredutora, um ajuste linear é feito entre os pontos imediatamente maior e menor que a CSR.

$$
y=a x+b
$$

Onde $x=\frac{0,5-b}{a}$ expressa que a camada semirredutora em função dos parâmetros de ajuste da reta.

A matriz de covariância de $x$ é dada por:

$$
V_{x} \cong \mathbf{E} \cdot \mathbf{V}_{\mathrm{y}} \cdot \mathbf{E}^{\mathrm{t}}
$$

$\mathbf{V}_{\mathrm{y}}$, é calculado pelo matlab quando se usa o m.m.q. A matriz de derivadas parciais $\boldsymbol{E}$ de $x$ em é:

$$
\begin{gathered}
E_{11}=\frac{\partial x}{\partial b}=-\frac{1}{a} \quad ; \quad E_{12}=\frac{\partial x}{\partial a}=-\frac{b-0,5}{a^{2}} \\
\mathbf{E}=\left(\begin{array}{ll}
\left.-\frac{1}{a} \quad-\frac{b-0,5}{a^{2}}\right)
\end{array}\right.
\end{gathered}
$$

Portanto, uma vez conhecidos $\mathbf{E}$ e $\mathbf{V}_{\mathbf{y}}$, a matriz de covariância $\mathbf{V}_{\mathbf{x}}$ pode ser determinada. $\mathbf{A}$ matriz de covariância $\mathbf{V}_{\mathbf{x}}$ possui um único elemento que é $\sigma x^{2}$. A raiz quadrada desse valor representa a incerteza do valor de camada semirredutora. Para espectros experimentais de mamografia, foram calculados valores de incerteza ente $0,4 \%$ e $0,5 \%$ do valor de CSR.

\section{Cálculo de Energia Efetiva e Incerteza:}

Uma vez conhecida a CSR, pode se determinar a energia efetiva, $E_{e f}$, do feixe pela seguinte relação:

$$
\frac{\mu_{A l}}{\rho}\left(E_{e f}\right)=\frac{\log (2)}{\rho_{A l} \cdot C S R}
$$


O valor de energia efetiva é determinado por meio de interpolação por spline cúbica do valor de $\frac{\mu_{A l}}{\rho}\left(E_{e f}\right)$ no conjunto de dados de $\frac{\mu_{A l}}{\rho}$ em função da energia. Esse é procedimento é o recomendado pelo NIST $^{3}$ para interpolação de dados de coeficientes mássicos de atenuação linear da energia fornecidos por sua base de dados:

A incerteza de $\frac{\mu_{A l}}{\rho}\left(E_{e f}\right)$ é calculada pela seguinte expressão:

$$
\sigma_{\frac{\mu_{A l}\left(E_{e f}\right)}{2}}^{2}=\left(\frac{\partial \frac{\mu_{A l}}{\rho}(E e f)}{\partial C S R}\right)^{2} \sigma_{C S R}^{2}
$$

A incerteza da energia efetiva pode então ser determinada pela equação (22):

$$
\sigma_{E_{e f}}=\frac{\frac{\sigma \mu_{A l}(\text { Eef })}{\rho}}{\left|\frac{d \frac{\mu_{A l}}{\rho}(E)}{d E}\right|_{E_{e f}}}
$$

\section{REFERÊNCIAS}

VANIN, V. R.; GOUFFON, P. Topicos avancados em tratamento estatistico de dados em fisica experimental. Edicao preliminar. São Paulo: Laboratorio do Acelerador Linear, 1996.

2 SANTOS, J. C. Estudo experimental das relações entre Kerma no ar e equivalente de dose ambiente para o cálculo de barreiras primárias em salas radiológicas. 2013. Dissertação (Mestrado). IFUSP, Universidade de São Paulo, São Paulo.

3 NIST. [online]. XCOM: Photon Cross Sections Database. < http://physics.nist.gov/PhysRefData/Xcom/html/xcom1.html > [viewed on december 2015]. 


\section{Apêndice II}

\section{Espectros Transmitidos}

$\mathrm{A}$ - Espectros de raios X de Mo/Mo transmitidos pelo phantom CIRS30/70
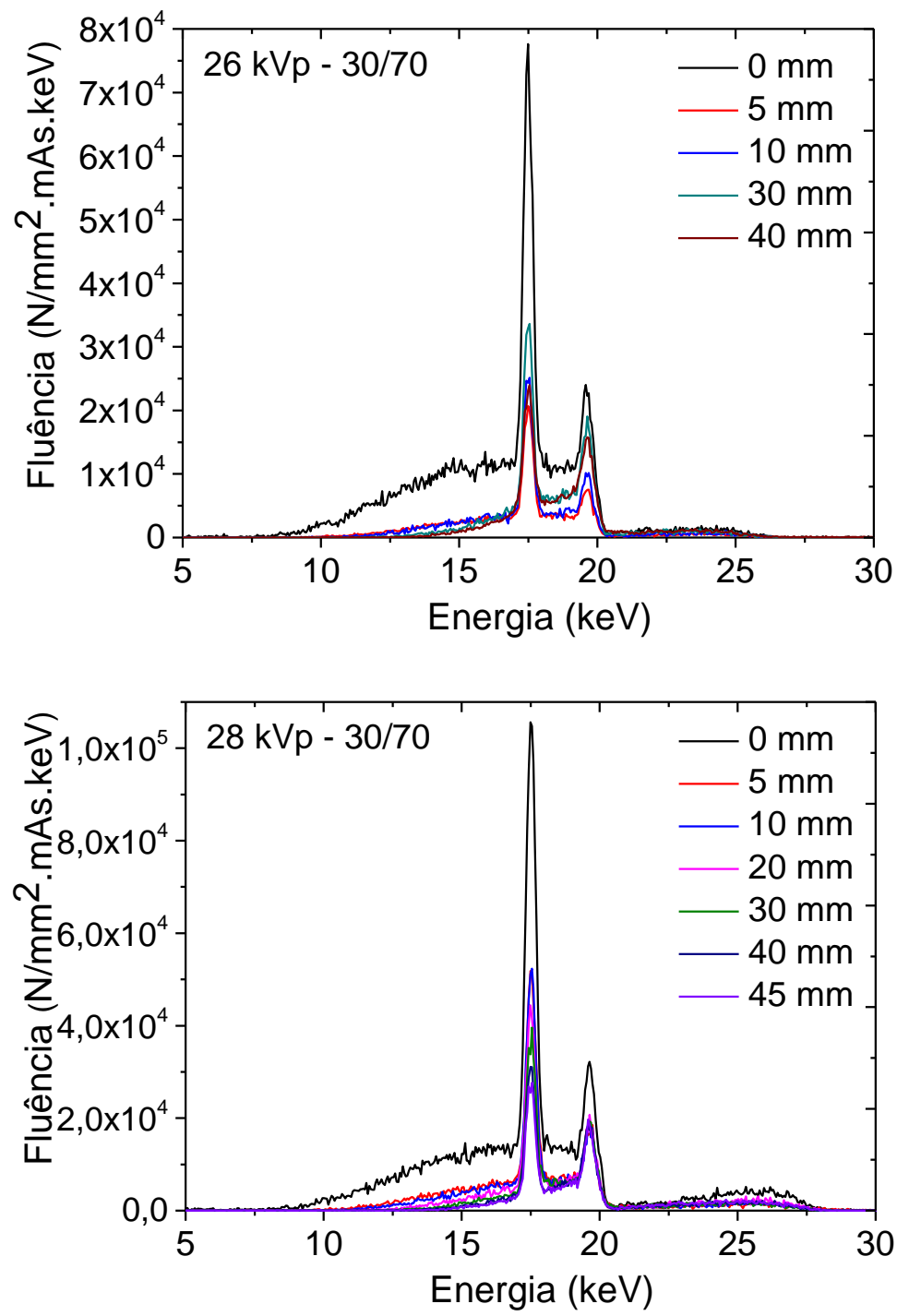


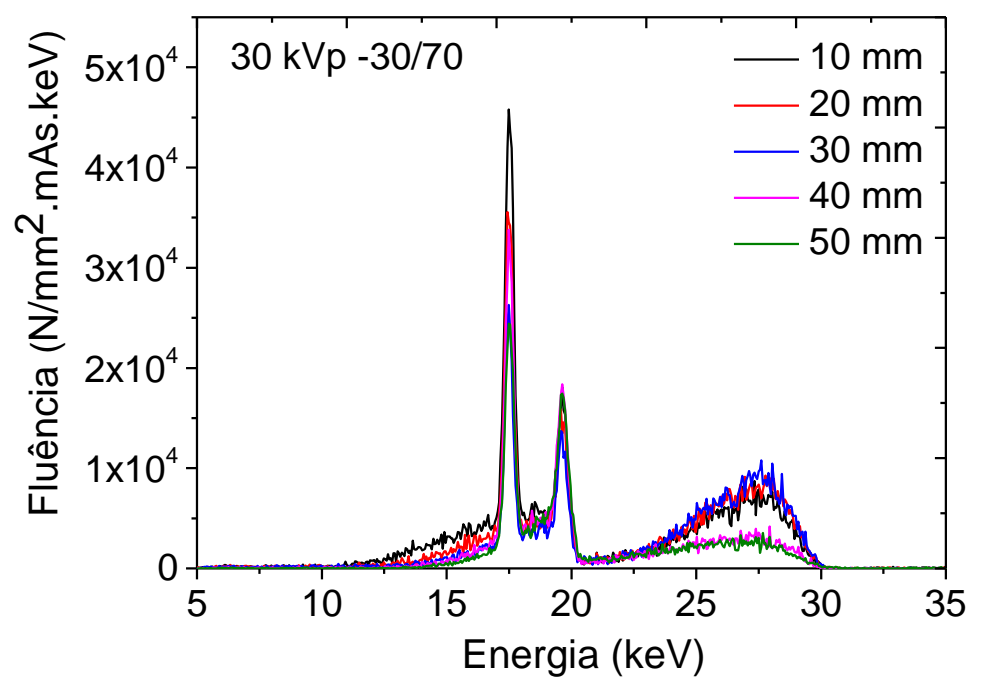

B - Espectros de raios X de Mo/Mo transmitidos pelo phantom CIRS50/50
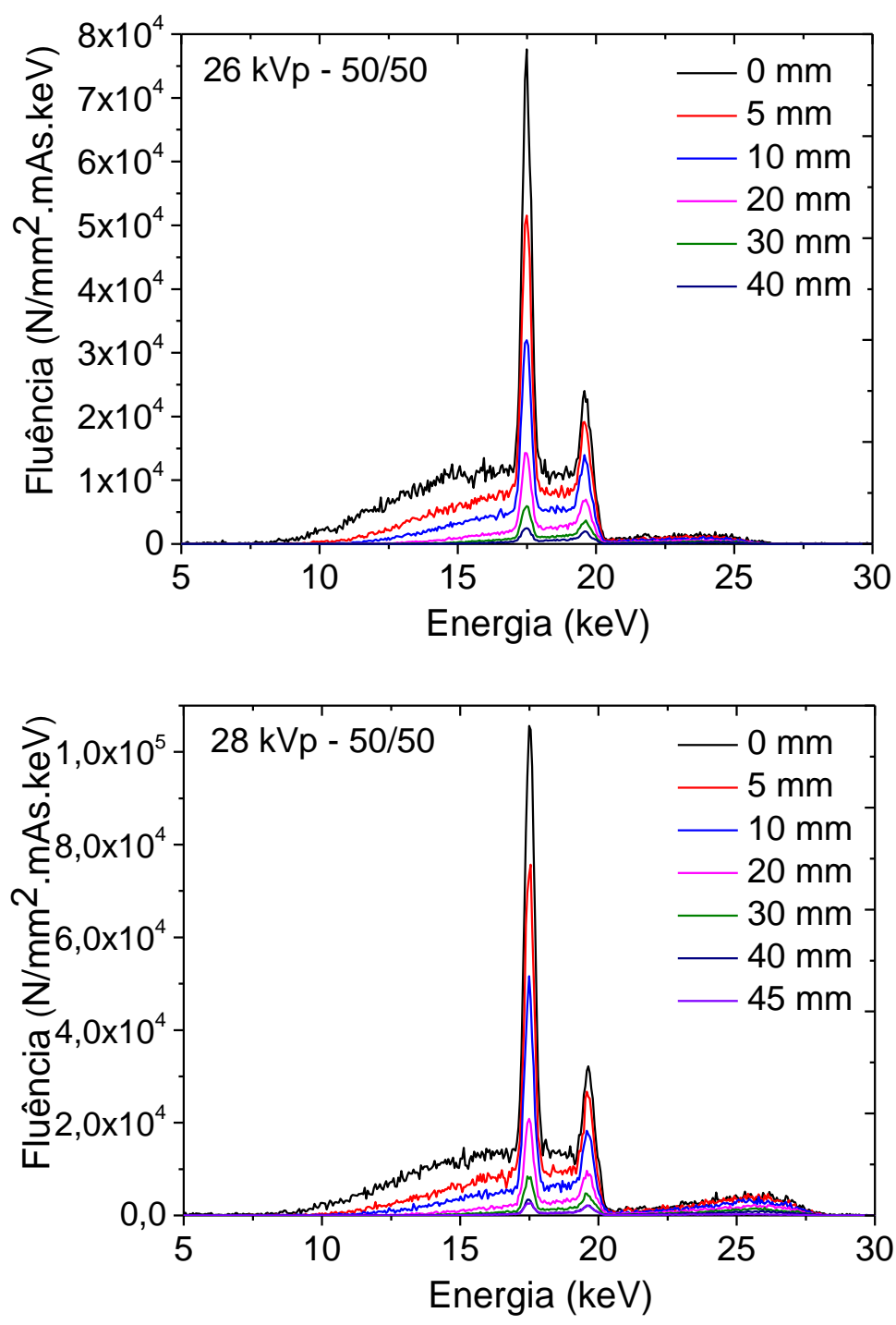


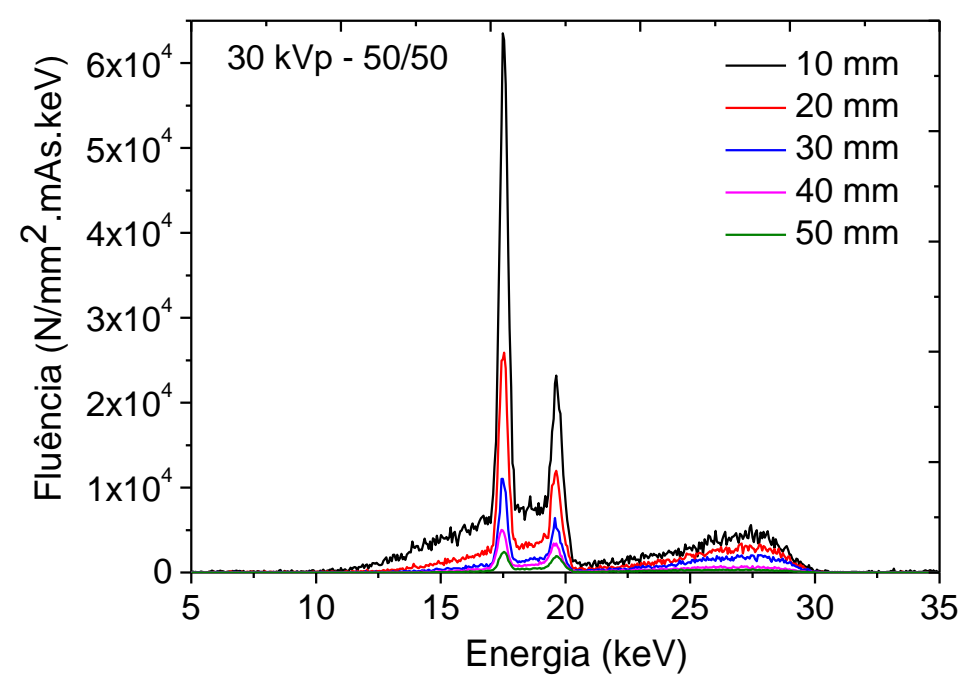

$\mathrm{C}$ - Espectros de raios X de Mo/Rh transmitidos pelo phantom CIRS30/70

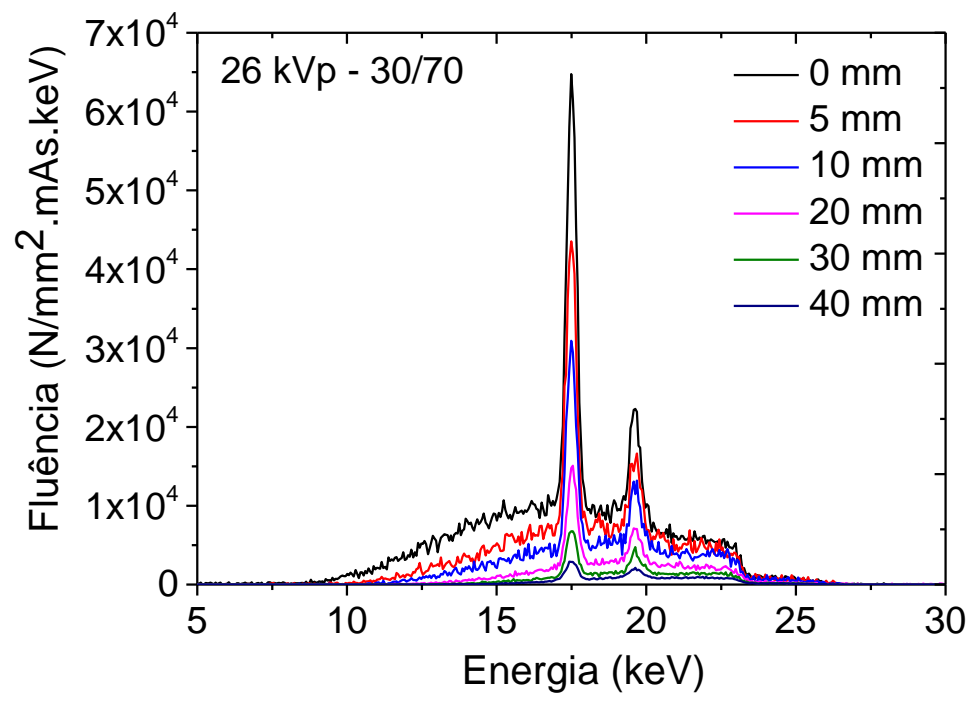



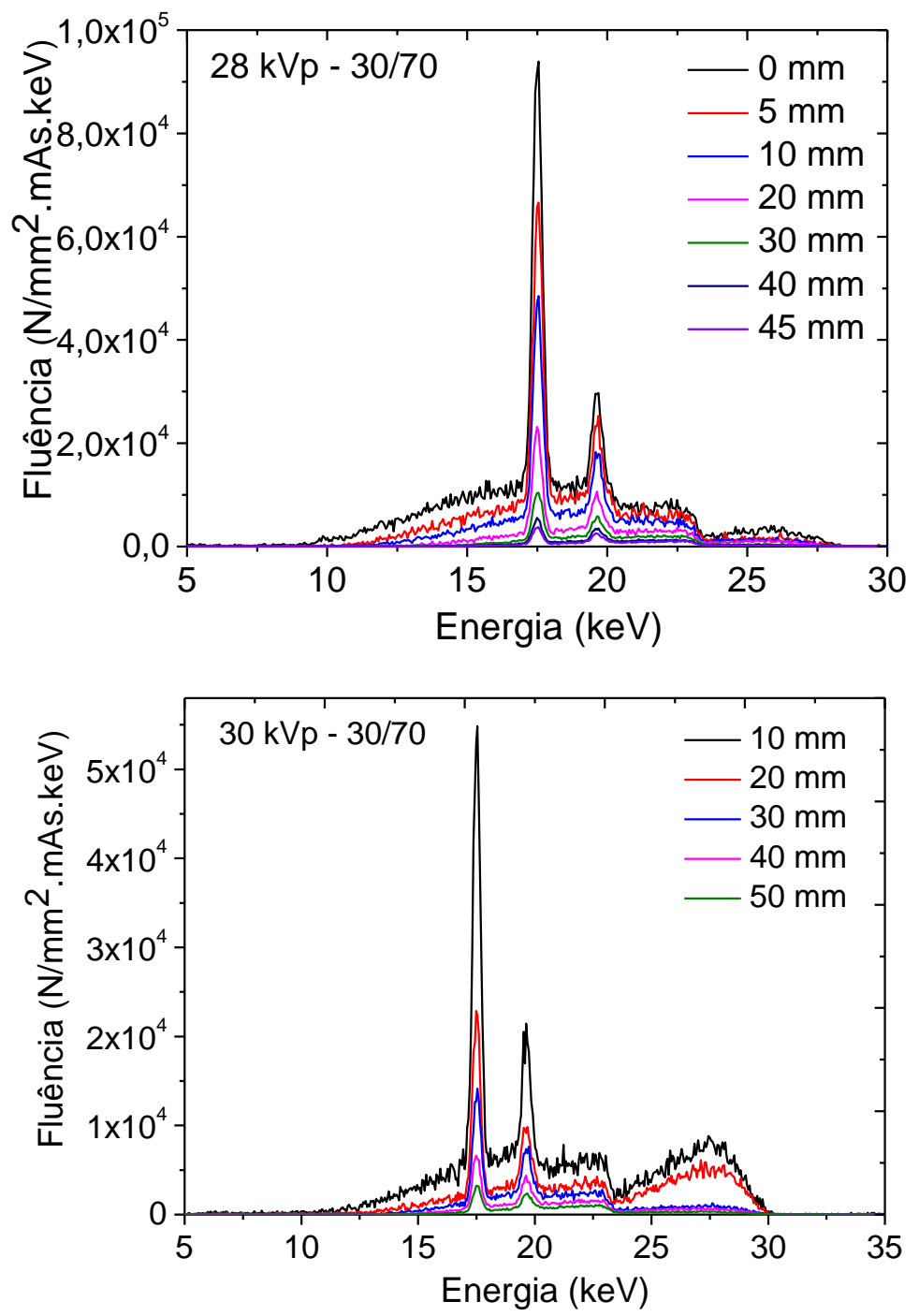

$\mathrm{D}$ - Espectros de raios $\mathrm{X}$ de $\mathrm{Mo} / \mathrm{Rh}$ transmitidos pelo phantom CIRS50/50

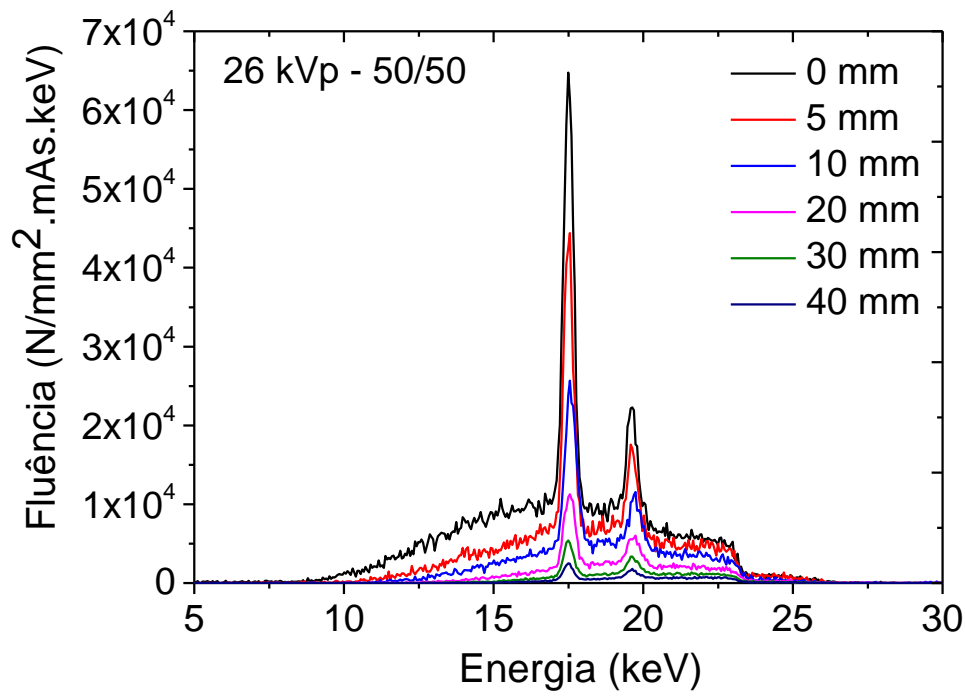



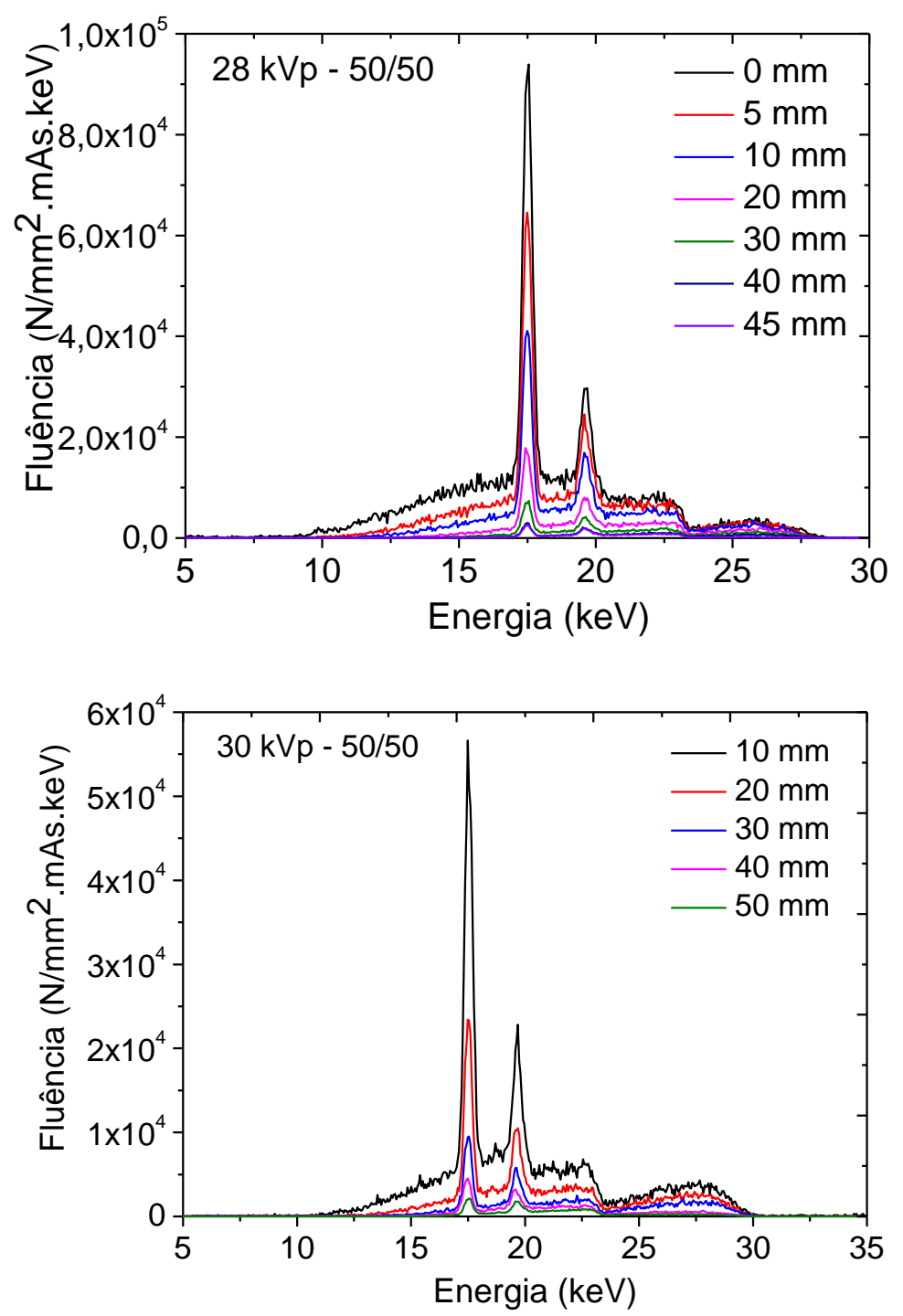

$\mathrm{E}$ - Espectros de raios $\mathrm{X}$ de W/Rh transmitidos pelo phantom CIRS30/70 

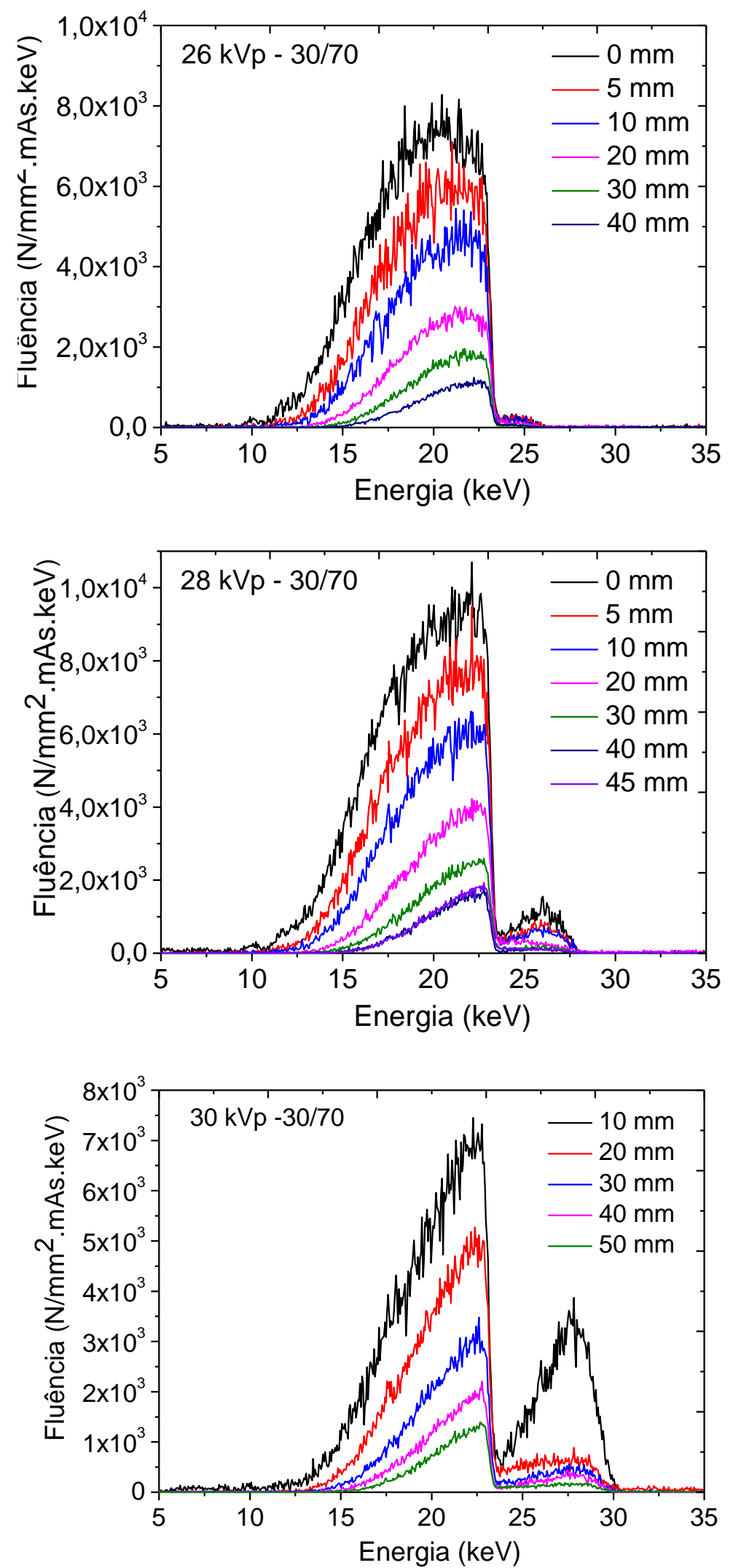

$\mathrm{F}$ - Espectros de raios $\mathrm{X}$ de $\mathrm{W} / \mathrm{Rh}$ transmitidos pelo phantom CIRS50/50 

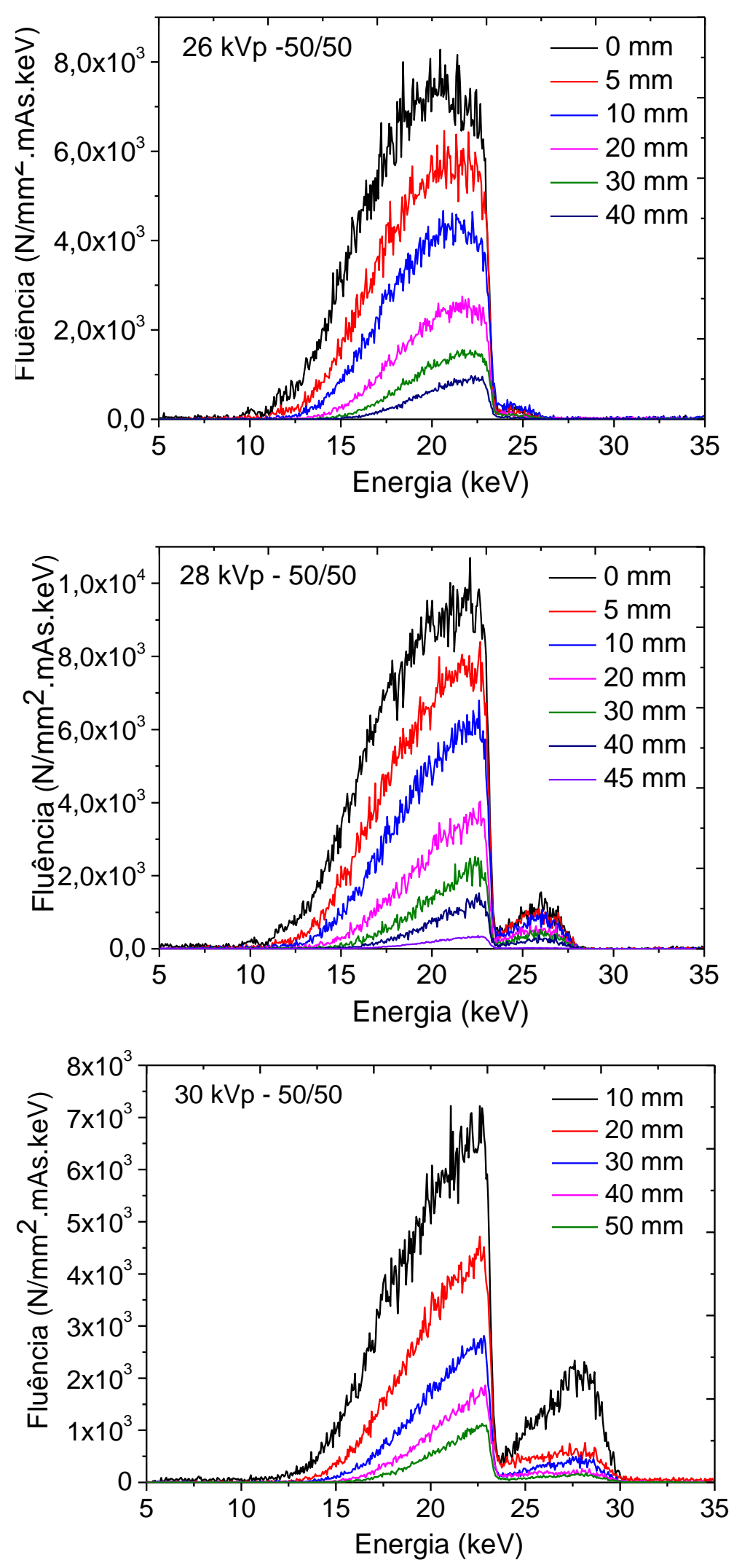


\section{Apêndice III :Parâmetros de Ajuste}

A- $\quad$ Parâmetros do ajuste linear aos dados apresentados nas figuras 43 e 44: CSR $x$ $D g N_{p}$

Função: $D g N_{p}(C S R)=a \times C S R+b$

\begin{tabular}{|c|c|c|c|c|c|c|c|c|c|c|}
\hline \multicolumn{11}{|c|}{ Мo/Mo 50\% } \\
\hline \multirow[b]{2}{*}{$\begin{array}{c}\text { Espessura } \\
\quad(\mathbf{c m})\end{array}$} & \multicolumn{5}{|c|}{ Experimental } & \multicolumn{5}{|c|}{ Boone (1997) } \\
\hline & b & $\sigma_{b}$ & $\mathbf{a}$ & $\sigma_{\mathrm{a}}$ & $\mathbf{R}^{2}$ & b & $\sigma_{\mathrm{b}}$ & $\mathbf{a}$ & $\sigma_{\mathrm{a}}$ & $\mathbf{R}^{2}$ \\
\hline 2 & 0,004 & 0,001 & 1,096 & 0,003 & 1,0000 & 0,035 & 0,003 & 0,986 & 0,010 & 0,9997 \\
\hline 3 & $-0,053$ & 0,003 & 0,966 & 0,008 & 0,9998 & $-0,018$ & 0,002 & 0,841 & 0,007 & 0,9998 \\
\hline 4 & $-0,067$ & 0,004 & 0,820 & 0,012 & 0,9994 & $-0,031$ & 0,002 & 0,693 & 0,005 & 0,9999 \\
\hline 5 & $-0,070$ & 0,005 & 0,706 & 0,014 & 0,9988 & $-0,036$ & 0,000 & 0,586 & 0,001 & 1,0000 \\
\hline 6 & $-0,065$ & 0,004 & 0,607 & 0,013 & 0,9985 & $-0,034$ & 0,001 & 0,499 & 0,003 & 0,9999 \\
\hline 7 & $-0,061$ & 0,004 & 0,531 & 0,014 & 0,9981 & $-0,032$ & 0,000 & 0,431 & 0,001 & 1,0000 \\
\hline 8 & $-0,055$ & 0,004 & 0,467 & 0,012 & 0,9979 & $-0,029$ & 0,000 & 0,376 & 0,001 & 1,0000 \\
\hline \multicolumn{11}{|c|}{ Mo/Rh 50\% } \\
\hline & \multicolumn{5}{|c|}{ Experimental } & \multicolumn{5}{|c|}{ Boone (1997) } \\
\hline $\begin{array}{l}\text { Espessura } \\
(\mathbf{c m})\end{array}$ & b & $\sigma_{\mathrm{b}}$ & $\mathbf{a}$ & $\sigma_{\mathrm{a}}$ & $\mathbf{R}^{2}$ & b & $\sigma_{\mathrm{b}}$ & $\mathbf{a}$ & $\sigma_{\mathrm{a}}$ & $\mathbf{R}^{2}$ \\
\hline 2 & 0,077 & 0,028 & 0,889 & 0,071 & 0,9813 & 0,083 & 0,004 & 0,852 & 0,010 & 0,9996 \\
\hline 3 & 0,003 & 0,027 & 0,797 & 0,070 & 0,9775 & 0,016 & 0,003 & 0,746 & 0,007 & 0,9997 \\
\hline 4 & $-0,021$ & 0,026 & 0,681 & 0,066 & 0,9724 & $-0,007$ & 0,002 & 0,628 & 0,006 & 0,9997 \\
\hline 5 & $-0,034$ & 0,023 & 0,591 & 0,059 & 0,9706 & $-0,017$ & 0,002 & 0,536 & 0,006 & 0,9997 \\
\hline 6 & $-0,035$ & 0,021 & 0,509 & 0,053 & 0,9681 & $-0,019$ & 0,002 & 0,459 & 0,005 & 0,9997 \\
\hline 7 & $-0,035$ & 0,018 & 0,448 & 0,047 & 0,9676 & $-0,020$ & 0,001 & 0,398 & 0,004 & 0,9998 \\
\hline 8 & $-0,033$ & 0,017 & 0,393 & 0,044 & 0,9638 & $-0,019$ & 0,009 & 0,349 & 0,002 & 0,9999 \\
\hline
\end{tabular}

B- $\quad$ Ajuste exponencial da relação $D g N_{p} x$ Espessura apresentadas para diversas glandularidades nas figuras 47 e 48

Função: $D g N_{p}(x)=A_{1} * \exp \left(-x / t_{1}\right)+y_{0}$

\begin{tabular}{cccccccc}
\hline \multicolumn{10}{c}{$\mathbf{M o} / \mathbf{M o}-\mathbf{2 8 k V}$} \\
\hline $\begin{array}{c}\text { Glandularidade } \\
(\mathbf{\%})\end{array}$ & $\mathbf{y}_{\mathbf{0}}$ & $\boldsymbol{\sigma}_{\mathbf{y} \mathbf{0}}$ & $\mathbf{A}_{\mathbf{1}}$ & $\boldsymbol{\sigma}_{\mathbf{A} \mathbf{1}}$ & $\mathbf{t}_{\mathbf{1}}$ & $\boldsymbol{\sigma}_{\mathbf{t} \mathbf{1}}$ & $\mathbf{R}^{2}$ \\
$\mathbf{0}$ & 0,091 & 0,003 & 0,650 & 0,008 & 3,06 & 0,07 & 0,999 \\
$\mathbf{3 0}$ & 0,083 & 0,003 & 0,641 & 0,014 & 2,83 & 0,09 & 0,999 \\
$\mathbf{5 0}$ & 0,075 & 0,004 & 0,641 & 0,019 & 2,65 & 0,10 & 0,999 \\
$\mathbf{7 0}$ & 0,072 & 0,003 & 0,634 & 0,021 & 2,55 & 0,10 & 0,999 \\
$\mathbf{1 0 0}$ & 0,064 & 0,003 & 0,632 & 0,026 & 2,36 & 0,10 & 0,998 \\
\multicolumn{7}{c}{$\mathbf{M o R h}-\mathbf{2 8} \mathbf{~ k V}$} \\
$\mathbf{0}$ & 0,104 & 0,003 & 0,711 & 0,006 & 3,31 & 0,05 & 1,000 \\
$\mathbf{3 0}$ & 0,096 & 0,003 & 0,705 & 0,011 & 3,02 & 0,08 & 1,000 \\
$\mathbf{5 0}$ & 0,088 & 0,004 & 0,708 & 0,017 & 2,81 & 0,09 & 0,999 \\
$\mathbf{7 0}$ & 0,084 & 0,004 & 0,704 & 0,019 & 2,70 & 0,09 & 0,999 \\
\hline
\end{tabular}




\begin{tabular}{llllllll}
\hline $\mathbf{1 0 0}$ & 0,075 & 0,004 & 0,708 & 0,024 & 2,48 & 0,09 & 1,000 \\
\hline
\end{tabular}

C- $\quad$ Ajuste exponencial da relação $D g N_{p} x$ Espessura apresentadas para quatro combinações alvo/filtro nas figuras 51 e 52

Função: $\operatorname{Dg} N_{p}(x)=A_{1} * \exp \left(-x / t_{1}\right)+y_{0}$

\begin{tabular}{cccccccc}
\hline \multicolumn{10}{c}{$\mathbf{5 0 / 5 0}-\mathbf{2 8 k V}$} \\
\hline Alvo/filtro & $\mathbf{y}_{\mathbf{0}}$ & $\boldsymbol{\sigma}_{\mathbf{y 0}}$ & $\mathbf{A}_{\mathbf{1}}$ & $\boldsymbol{\sigma}_{\mathbf{A} \mathbf{1}}$ & $\mathbf{t}_{\mathbf{1}}$ & $\boldsymbol{\sigma}_{\mathbf{t} 1}$ & $\mathbf{R}^{2}$ \\
$\mathbf{M o} / \mathbf{M o}$ & 0,083 & 0,003 & 0,64 & 0,01 & 2,83 & 0,09 & 0,999 \\
$\mathbf{M o} / \mathbf{R h}$ & 0,096 & 0,003 & 0,71 & 0,01 & 3,02 & 0,08 & 1,000 \\
W/Rh & 0,120 & 0,003 & 0,79 & 0,01 & 3,51 & 0,06 & 1,000 \\
W/Ag & 0,131 & 0,003 & 0,81 & 0,00 & 3,84 & 0,05 & 1,000 \\
Mo/Mo & 0,075 & 0,004 & 0,64 & 0,02 & 2,65 & 0,10 & 0,999 \\
Mo/Rh & 0,088 & 0,004 & 0,71 & 0,02 & 2,81 & 0,10 & 0,999 \\
W/Rh & 0,112 & 0,004 & 0,80 & 0,01 & 3,23 & 0,08 & 1,000 \\
W/Ag & 0,124 & 0,004 & 0,82 & 0,01 & 3,52 & 0,07 & 1,000 \\
\hline
\end{tabular}

D- $\quad$ Ajuste exponencial da relação $D g N_{p} x$ Espessura apresentadas para diferentes valores de tensão nas figuras 53 e 54

Função: $\operatorname{Dg} N_{p}(x)=A_{1} * \exp \left(-x / t_{1}\right)+y_{0}$

\begin{tabular}{|c|c|c|c|c|c|c|c|}
\hline \multicolumn{8}{|c|}{ 50/50 - Мo/Mo } \\
\hline Tensão $(k V)$ & $\mathbf{y}_{0}$ & $\overline{\sigma_{y 0}}$ & $\overline{\mathbf{A}_{1}}$ & $\overline{\sigma_{\mathrm{A} 1}}$ & $\overline{\mathbf{t}_{1}}$ & $\sigma_{t 1}$ & $\overline{\mathbf{R}^{2}}$ \\
\hline 25 & 0,080 & 0,004 & 0,68 & 0,02 & 2,70 & 0,10 & 0,9991 \\
\hline 26 & 0,082 & 0,004 & 0,69 & 0,02 & 2,73 & 0,10 & 0,9992 \\
\hline 27 & 0,085 & 0,004 & 0,70 & 0,02 & 2,77 & 0,09 & 0,9992 \\
\hline 28 & 0,088 & 0,004 & 0,71 & 0,02 & 2,81 & 0,10 & 0,9993 \\
\hline 29 & 0,091 & 0,004 & 0,72 & 0,02 & 2,85 & 0,09 & 0,9993 \\
\hline 30 & 0,094 & 0,004 & 0,72 & 0,02 & 2,90 & 0,09 & 0,9994 \\
\hline 31 & 0,097 & 0,004 & 0,71 & 0,01 & 2,96 & 0,10 & 0,9994 \\
\hline \multicolumn{8}{|c|}{ 50/50 - Mo/Rh } \\
\hline 25 & 0,066 & 0,003 & 0,61 & 0,02 & 2,51 & 0,10 & 0,9987 \\
\hline 26 & 0,069 & 0,003 & 0,62 & 0,02 & 2,56 & 0,10 & 0,9988 \\
\hline 27 & 0,071 & 0,003 & 0,63 & 0,02 & 2,61 & 0,10 & 0,9989 \\
\hline 28 & 0,075 & 0,004 & 0,64 & 0,02 & 2,65 & 0,10 & 0,9990 \\
\hline 29 & 0,080 & 0,004 & 0,65 & 0,02 & 2,69 & 0,10 & 0,9991 \\
\hline 30 & 0,084 & 0,004 & 0,65 & 0,02 & 2,78 & 0,10 & 0,9991 \\
\hline 31 & 0,090 & 0,004 & 0,65 & 0,02 & 2,88 & 0,10 & 0,9992 \\
\hline
\end{tabular}


Anexo A 


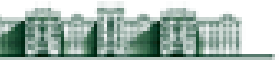 \\ MEDICINA \\ TSP \\ COMITÊ DE ÉTICA EM PESQUISA}

\section{APROVAÇÃO}

o Comitê de Ética em Pesquisa da Faculdade de Medicina da Universidade de São Paulo, em sessão de 18/03/2015, APROVOU o Protocolo de Pesquisa no ${ }^{389} / \mathbf{1 4}$ intitulado: "DETERMINAÇÃo EXPERIMENTAL DA DISTRIBUIÇÃO DA DOSE GLANDULAR MÉDIA EM DIFERENTES QUALIDADES DE FEIXES MAMOGRÁFICOS"”, apresentado pelo Departamento de RADIOLOGLA E ONCOLOGIA

Cabe ao pesquisador elaborar e apresentar ao CEPFMUSP, os relatórios parciais e final sobre a pesquisa (Resolução do Conselho Nacional de Saúde ${ }^{\circ}{ }_{466 / 12}$, inciso IX.2, letra "c").

Pesquisador (a) Responsável: NESTOR DE BARROS

Pesquisador (a) Executante: PAULO ROBERTO COSTA

CEP-FMUSP, 18 de Março de 2015.

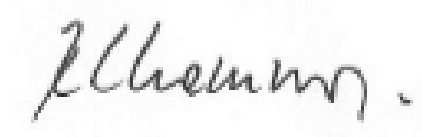

Prof. Dr. Roger Chammas Coordenador

Comitê de Ética em Pesquisa 
Anexo B 


\title{
Direct measurement of clinical mammographic x-ray spectra using a CdTe spectrometer
}

\author{
Josilene C. Santos \\ Instituto de Física, Universidade de São Paulo, São Paulo, SP 05508-090, Brazil \\ Alessandra Tomal \\ Instituto de Física Gleb Wataghin, Universidade Estadual de Campinas, Campinas, SP 13083-859, Brazil
}

Tânia A. Furquim

Instituto de Física, Universidade de São Paulo, São Paulo, SP 05508-090, Brazil

Agnes M. F. Fausto

Departamento de Ciências Exatas e Tecnológicas, Universidade Estadual de Santa Cruz, Ilhéus, BA 45662-900, Brazil

Maria S. Nogueira

Centro de Desenvolvimento de Tecnologia Nuclear, Comissão Nacional de Energia Nuclear, Belo Horizonte, MG 31270-901, Brazil

Paulo R. Costa ${ }^{\text {a) }}$

Instituto de Física, Universidade de São Paulo, São Paulo, SP 05508-090, Brazil

(Received 15 August 2016; revised 29 March 2017; accepted for publication 11 April 2017; published 26 May 2017)

\begin{abstract}
Purpose: To introduce and evaluate a method developed for the direct measurement of mammographic x-ray spectra using a CdTe spectrometer. The assembly of a positioning system and the design of a simple and customized alignment device for this application is described.

Methods: A positioning system was developed to easily and accurately locate the CdTe detector in the x-ray beam. Additionally, an alignment device to line up the detector with the central axis of the radiation beam was designed. Direct $\mathrm{x}$-ray spectra measurements were performed in two different clinical mammography units and the measured x-ray spectra were compared with computer-generated spectra. In addition, the spectrometer misalignment effect was evaluated by comparing the measured spectra when this device is aligned relatively to when it is misaligned.

Results: The positioning and alignment of the spectrometer have allowed the measurements of direct mammographic x-ray spectra in agreement with computer-generated spectra. The most accurate $\mathrm{x}$-ray spectral shape, related with the minimal HVL value, and high photon fluence for measured spectra was found with the spectrometer aligned according to the proposed method. The HVL values derived from both simulated and measured x-ray spectra differ at most 1.3 and $4.5 \%$ for two mammography devices evaluated in this study.

Conclusion: The experimental method developed in this work allows simple positioning and alignment of a spectrometer for x-ray spectra measurements given the geometrical constraints and maintenance of the original configurations of mammography machines. () 2017 American Association of Physicists in Medicine [https://doi.org/10.1002/mp.12287]
\end{abstract}

Key words: CdTe detector, detector alignment, mammography, spectrometry

\section{INTRODUCTION}

Mammography x-ray spectra measurement is a complex task due to the high photon fluence rates produced by clinical systems. ${ }^{1-4}$ The design of the equipment constitutes a constraint owing to the short distance between the focal spot and breast support. Additionally, an important factor to consider in x-ray spectra measurements is the alignment between the radiation source and the detector. ${ }^{5,6}$ The high photon fluence rates associated with the short distance between the x-ray tube and a detector positioned over the breast support require the use of pinhole collimators to limit the exposed detector area. However, it makes the alignment a delicate and laborious process.
Due to the aforementioned limitations, the most common method for obtaining mammography $\mathrm{x}$-ray spectra is by means of mathematical models. ${ }^{7-11}$ However, in some cases, not all parameters that characterize the $\mathrm{x}$-ray spectra are available in these models. ${ }^{4}$ Indirect methods to obtain a representation of x-ray spectra can also be found in the literature, for example, the reconstruction of measured scattered $\mathrm{x}$-ray spectra ${ }^{12,13}$ and nonclinical spectra. ${ }^{14}$ However, the measurement of X-ray spectra can provide an accurate representation of a mammography radiation beam, and it is the best procedure to improve image quality and dose optimization in mammography. ${ }^{15}$

Portable and room temperature detectors are the most suitable devices for mammographic $\mathrm{x}$-ray spectroscopy 


\title{
Application of a CdTe Detector for Measurements of Mammographic X-ray Spectra
}

\author{
$\mathrm{J} \mathrm{C} \mathrm{SANTOS}^{{ }^{1 *}, \mathrm{~A} \mathrm{TOMAL}^{2} \text { AND P R COSTA }}{ }^{1}$. \\ ${ }^{1}$ Instituto de Física, Universidade de São Paulo, SP, Brazil \\ ${ }^{2}$ Instituto de Física Gleb Wataghin, Universidade Estadual de Campinas, SP, Brazil \\ *Email: josilene@usp.br
}

Published online: August 07, 2017

The Author(s) 2017. This article is published with open access at www.chitkara.edu. in/publications

\begin{abstract}
This work aims to characterize mammographic x-ray beams incident and transmitted by breast phantoms (from 0 to $45 \mathrm{~mm}$ ) composed from known proportion of glandular and adipose tissue-equivalent materials. This study was performed for mammographic $\mathrm{x}$-ray beams generated by a mammography equipment using different target/filter combinations ( $\mathrm{Mo} / \mathrm{Mo}, \mathrm{Mo} / \mathrm{Rh}$ and $\mathrm{W} / \mathrm{Rh}$ ). It was studied the modification of spectra shape of the beams transmitted through different thicknesses of these materials. It was also evaluated the penetrability of these transmitted beams by its correlations to the HVL, which were experimentally estimated and derived from the $\mathrm{x}$-ray spectra measured using a spectrometry system with a CdTe detector. The x-ray spectra transmitted by the phantom with higher density presented lower intensity than those transmitted by those with lower density, as expected. The differences between the HVL values derived from the spectra and those estimated using air kerma measurements are lesser than $6 \%$ for about $88 \%$ of the spectra measured in this work. The expected spectra variations with phantom thickness, revealed by the measured transmitted x-ray spectra, were also confirmed by HVL measurements and agree with the estimated attenuation curves. The motivation of the study was related to the robustness of the spectra as a descriptor of radiation beams and the possibility of using these transmitted spectra for dose assessment related to mammographic procedures. We can conclude that developed method is able to characterize mammographic x-ray beams making it possible the use of this kind of data for dose assessment in mammography.
\end{abstract}

Keywords: CdTe detector; Mammography; x-ray spectra measurements

\section{INTRODUCTION}

The x-ray spectra quantify the amount of photons and its energies in a x-ray beam. It allows the calculation of derived quantities, generally applied for

Journal of Nuclear

Physics, Material Sciences, Radiation and

Applications

Vol-5 No-1

August 2017 pp. 91-102 


\title{
Determinação da camada semirredutora e da tensão aplicada a partir de espectros emitidos por um tubo de raios $X$ Determination of half value layer and applied voltage from emitted spectra by an $X$ ray tube
}

\author{
Josilene C. Santos ${ }^{1}$; Alejandro H.L. Gonzales ${ }^{1}$; Ricardo A. Terini ${ }^{1}$; Paulo R. Costa ${ }^{1}$ \\ ${ }^{1}$ Instituto de Física, Universidade de São Paulo, São Paulo, Brasil.
}

\begin{abstract}
Resumo
Este trabalho descreve um método para o cálculo de camada semirredutora (CSR) e tensão de pico $(\mathrm{k} V \mathrm{p})$ aplicada ao tubo de raios $\mathrm{X}$ por meio de espectros medidos utilizando um detector de CdTe. São avaliados alguns parâmetros que podem influenciar na determinação dessas grandezas, tais como, tempo morto, taxa de contagens e valor de corrente anódica utilizado. Para isso, foram medidos dois conjuntos de espectros de raios X: Conjunto $A$, utilizando filtração de cobre de diferentes espessuras $(1,8-5,4 \mathrm{~mm})$ e mantendo fixa a corrente anódica aplicada ao tubo; Conjunto $B$, mantendo a filtração de cobre fixa e variando a corrente $(0,5-3 \mathrm{~mA})$. As configurações de medições dos espectros do conjunto $A$ permitiram a avaliação da kVp e CSR para diferentes taxas de contagens e tempo morto do sistema de detecção, enquanto o conjunto B permitiu avaliar a dependência dessas grandezas com a corrente anódica do tubo. Fontes radioativas padrão foram usadas para fazer a calibração em energia do sistema espectrométrico. Os valores de tensão aplicados ao tubo foram determinados por meio de regressão linear a partir dos espectros medidos buscando o end point de cada um. Os valores de CSR foram determinados a partir dos espectros medidos, após sua correção por meio de um método de stripping implementado em ambiente Matlab $^{\circledR}$. Para comparação, a CSR também foi determinada usando uma câmara de ionização de $30 \mathrm{~cm}^{3} \mathrm{e}$ filtros de Al de alta pureza. Os resultados mostram que é possível determinar a $\mathrm{kVp}$ com boa exatidão e reprodutibilidade, utilizando espectros com tempo morto de até $10 \%$. Apesar disso, os valores obtidos apresentaram desvio de até $7 \mathrm{kV}$, para espectros medidos com mesma tensão nominal e diferentes valores de corrente, indicando a dependência entre esses dois parâmetros.
\end{abstract}

Palavras-chave: Espectrometria de raios X; Detector de CdTe; radiodiagnóstico; camada semirredutora; tensão de pico.

\begin{abstract}
This work describes a method for assessment of half value layer (HVL) and peak tube voltage $(k V p)$ applied in an $x$-ray tube by means of experimental $x$-ray spectra measured using a CdTe detector. It was assessed some parameters that can affect the evaluation of these quantities such as dead time, count rate and tube current (mA). For this study, two sets of $x$-ray spectra were measured: Set $A$ ), spectra measurements using $\mathrm{Cu}$ filters with different thicknesses $(1.8-5.4 \mathrm{~mm})$ and fixed tube current; Set B), spectra measurements keeping a fixed $\mathrm{Cu}$ filtration and varying tube current $(0.5-3.0 \mathrm{~mA})$. The experimental setup for the Set $A$ spectra measurements allowed the assessment of the HVL and kVp for different count rates and dead time in the detection system, while the Set $B$ setup allowed to assess the dependence of these quantities with the tube current. The spectrometer was energy calibrated using standard $X / \gamma$ rays radioactive sources. The tube voltage values were estimated by means of experimental measured $x$-ray spectra, using linear regression in order to search the end point of each spectrum. The spectra correction was performed using the stripping procedure developed for the Matlab ${ }^{\circledR}$ software and the HVL values were derived from these corrected spectra. For comparison, HVL was also determined using a $30 \mathrm{~cm}^{3}$ ion chamber and high purity Al filters. The results show that it is possible to determine the $k V p$ with accuracy and reproducibility using spectra with dead time of up to $10 \%$. In spite of this, the values obtained showed a deviation of up to $7 \mathrm{kV}$, for spectra measured using the same nominal tube voltage different tube current values, indicating dependence between these two parameters.
\end{abstract}

Keywords: X-ray spectrometry; CdTe detector; diagnostic radiology; half value layer; peak voltage.

\section{Introdução}

O espectro de radiação é a representação mais completa do feixe gerado por um equipamento de raios $X^{1}$. Porém, complexidades técnicas no processo de medições destes espectros dificultaram por muito tempo a aplicação da espectrometria em condições clínicas para avaliar feixes de radiodiagnostico. No entanto, com o surgimento dos sistemas de espectrometria portáteis, o uso dessa técnica tem sido ampliado, incluindo aplicações para avaliação de espectros de raios $X$ de feixes clínicos para fins de pesquisa ${ }^{2-8}$. 